\title{
Uso de propriedades visuais-interativas na avaliação da qualidade de dados
}

João Marcelo Borovina Josko

TESE APRESENTADA

$\mathrm{AO}$

Instituto de Matemática e Estatística

DA

Universidade DE SÃo PAULO

PARA

OBTENÇÃO DO TÍTULO

$\mathrm{DE}$

DOUTOR EM Cî̂NCIAS

\author{
Programa: Ciência da Computacão \\ Orientador: Prof. Dr. João Eduardo Ferreira
}

Este trabalho recebeu auxílio financeiro do CNPQ (concessão 141647/2011-6) 


\section{Uso de propriedades visuais-interativas na avaliação da qualidade de dados}

Esta versão da dissertação contém as correções e alterações sugeridas pela Comissão Julgadora durante a defesa da versão original do trabalho, realizada em 29/04/2016. Uma cópia da versão original está disponível no Instituto de Matemática e Estatística da Universidade de São Paulo.

Comissão Julgadora:

- Prof. Dr. João Eduardo Ferreira (orientador) - IME-USP

- Profa. Dra. Isabel Cristina Italiano - EACH-USP

- Prof. Dr. Luiz Camolesi Júnior - UNICAMP

- Prof. Dr. Ronaldo dos Santos Mello - UFSC

- Prof. Dr. Roberto Hirata Junior - IME-USP 


\section{Agradecimentos}

Realizações humanas são como uma peça de teatro. Poucos a protagonizam, mas essa jamais seria realizada sem aqueles que estão nos bastidores. Quero aqui agradecer profundamente aqueles que me ajudaram alcançar essa realização.

a minha amada esposa Celia, obrigado por estar sempre presente, especialmente nos momentos difíceis. Jamais esquecerei o que fez por mim. a minha doce filha Sarah, obrigado pelo carinho e enorme sorriso estampado no rosto que alegrou os muitos e muitos dias que passei no meu "bunker". aos meus queridos pais Diva e Roberto, obrigado por preparar-me para vida e pela ajuda operacional.

a minha amiga e irmã Renata, obrigado pelo apoio sempre inconteste. ao meu orientador, Prof. João Eduardo Ferreira, são tantos obrigados que não caberiam aqui. Principalmente, obrigado pela oportunidade proporcionada a mim. JEF, você é um exemplo a seguir, mas com uma carga menor de afazeres. ao Prof. Márcio K. Oikawa (UFABC), obrigado pelas perspectivas oferecidas sobre o meu trabalho.

ao Prof. Mario Lúcio Côrtes (UNICAMP-IC), obrigado por ter apontado minhas deficiências. Muito aprendi e refleti (mais do que imagina) sobre suas orientações ao longo de nossas reuniões.

aos amigos Fábio Monteiro, Fidel Beraldi, Eduardo Cotrin e Pedro Losco, obrigado pela colaboração e companhia ao longo desses anos.

a Deus, por tanto, e por colocar todas essas pessoas no meu caminho. a todos, de coração, muito obrigado. 


\section{Resumo}

\section{BOROVINA JOSKO, J. M. Uso de propriedades visuais-interativas na avaliação}

da qualidade de dados 2016. 188 f. Tese (Doutorado) - Instituto de Matemática e Estatística, Universidade de São Paulo, São Paulo, 2016.

Os efeitos dos dados defeituosos sobre os resultados dos processos analíticos são notórios. Aprimorar a qualidade dos dados exige estabelecer alternativas a partir de vários métodos, técnicas e procedimentos disponíveis. O processo de Avaliação da Qualidade dos Dados pAQD - provê relevantes insumos na definição da alternativa mais adequada por meio do mapeamento dos defeitos nos dados.

Relevantes abordagens computacionais apoiam esse processo. Tais abordagens utilizam métodos quantitativos ou baseados em asserções que usualmente restringem o papel humano a interpretação dos seus resultados. Porém, o pAQD depende do conhecimento do contexto dos dados visto que é impossível confirmar ou refutar a presença de defeitos baseado exclusivamente nos dados. Logo, a supervisão humana é essencial para esse processo.

Sistemas de visualização pertencem a uma classe de abordagens supervisionadas que podem tornar visíveis as estruturas dos defeitos nos dados. Apesar do considerável conhecimento sobre o projeto desses sistemas, pouco existe para o domínio da avaliação visual da qualidade dos dados.

Isto posto, este trabalho apresenta duas contribuições. A primeira reporta uma taxonomia que descreve os defeitos relacionados aos critérios de qualidade da acuracidade, completude e consistência para dados estruturados e atemporais. Essa taxonomia seguiu uma metodologia que proporcionou a cobertura sistemática e a descrição aprimorada dos defeitos em relação ao estado-da-arte das taxonomias. A segunda contribuição reporta relacionamentos entre propriedades-defeitos que estabelecem que certas propriedades visuais-interativas são mais adequadas para a avaliação visual de certos defeitos em dadas resoluções de dados. Revelados por um estudo de caso múltiplo e exploratório, esses relacionamentos oferecem indicações que reduzem a subjetividade durante o projeto de sistemas de visualização de apoio a avaliação visual da qualidade dos dados.

Palavras-chave: Avaliação Visual da Qualidade de Dados, Visualização de Dados, Análise 
Intensiva de Dados, Estudo de Caso Exploratório, Estudo Observacional Qualitativo, Defeitos nos Dados, Taxonomia Formal, Bancos de Dados Relacionais 


\section{Abstract}

BOROVINA JOSKO, J. M. Using visual-interactive properties in the data quality assessment. 2016. 188 p . PhD Thesis - Institute of Mathematics and Statistics, University of São Paulo, São Paulo, 2016

The effects of poor data quality on the reliability of the outcomes of analytical processes are notorious. Improving data quality requires alternatives that combine procedures, methods, techniques and technologies. The Data Quality Assessment process - DQAp provides relevant and practical inputs for choosing the most suitable alternative through a data defects mapping.

Relevant computational approaches support this process. Such approaches apply quantitative or assertions-based methods that usually limit the human interpretation of their outcomes. However, the DQAp process strongly depends on data context knowledge since it is impossible to confirm or refute a defect based only on data. Hence, human supervision is essential throughout this process.

Visualization systems belong to a class of supervised approaches that can make visible data defect structures. Despite their considerable design knowledge encodings, there is little support design to data quality visual assessment.

Therefore, this work reports two contributions. The first reports a taxonomy that organizes a detailed description of defects on structured and timeless data related to the quality criteria of accuracy, completeness and consistency. This taxonomy followed a methodology which enabled a systematic coverage of data defects and an improved description of data defects in regard to state-of-art literature. The second contribution reports a set of property-defect relationships that establishes that certain visual and interactive properties are more suitable for visual assessment of certain data defects in a given data resolution. Revealed by an exploratory and multiple study case, these relationships provides implications that reduce the subjectivity in the visualization systems design for data quality visual assessment.

Keywords: Data Quality Visual Assessment, Data Visualization, Intensive Data Analysis, Exploratory Study Case, Qualitative Observational Study, Data Defects, Formal Taxonomy, Relational Database 


\section{Sumário}

Resumo $\quad$ v

Abstract vii

Lista de Abreviações e Acrônimos $\quad$ xiii

Lista de Figuras $\quad$ Xv

Lista de Tabelas $\quad$ xix

Lista de Quadros $\quad$ xx

1 Introdução 23

1.1 Caracterização do Problema . . . . . . . . . . . . . . . . . . . 23

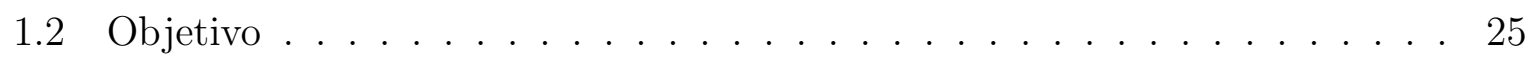

1.2.1 Objetivo Principal _. . . . . . . . . . . . . . . 26

1.3 Hipótese . . . . . . . . . . . . . . . . . . . . . . . . . . 26

1.4 Justificativa da Hipótese . . . . . . . . . . . . . . . . . . . . . . 27

1.5 Resultados Obtidos . . . . . . . . . . . . . . . . . . . . . . 28

1.5.1 Originalidade . . . . . . . . . . . . . . . . . 28

1.6 Organização do Trabalho . . . . . . . . . . . . . . . . . . . . . . 29

2 Fundamentos $\quad 31$

2.1 Introdução . . . . . . . . . . . . . . . . . . . . . . . . . . 31

2.2 Avaliação da Qualidade dos Dados . . . . . . . . . . . . . . . . . 31

2.2 .1 A Qualidade . . . . . . . . . . . . . . . . . . 31

2.2.2 A Qualidade dos Dados . . . . . . . . . . . . . . . . 32

2.2.3 O Processo de Avaliação da Qualidade dos Dados . . . . . . . . . . 32

2.2.3.1 Fatores de Influência . . . . . . . . . . . . . . . . . . . 33

2.2.3.2 Critérios de Qualidade . . . . . . . . . . . . . 35

2.2.3.3 Defeitos de Conteúdo dos Dados . . . . . . . . . . . . 39

2.3 A Visualização de Dados . . . . . . . . . . . . . . . . . . . . . . . . 40

2.3 .1 A Área de Pesquisa . . . . . . . . . . . . . . . . . . . . . 40 
2.3.2 A Visualização e a Qualidade de Dados . . . . . . . . . . . . . . . . 41

2.3.3 O Processo de Visualização de Dados . . . . . . . . . . . . . . . . . 42

2.3.4 Sistema de Visualização de Dados . . . . . . . . . . . . . . . . . . . 44

2.3.4.1 Técnicas de Interação . . . . . . . . . . . . . . . . . . 44

2.3.4.2 Técnicas de Visualização . . . . . . . . . . . . . . . . . 53

2.3.4.2.1 Propriedades Visuais . . . . . . . . . . . . 59

2.4 A Cognição Humana e seus Sistemas . . . . . . . . . . . . . . . . 60

2.4 .1 Processamento Inicial da Visão . . . . . . . . . . . . . . . . . . 61

2.4.2 Processamento de Organização dos Elementos . . . . . . . . . . . . 61

2.4.3 Processamento Atentivo . . . . . . . . . . . . . . . . . . . . 62

2.5 Conclusão . . . . . . . . . . . . . . . . . . . . . 63

3 Trabalhos Relacionados $\quad 65$

3.1 Introdução . . . . . . . . . . . . . . . . . . . . 65

3.2 Avaliação da Qualidade dos Dados por Abordagens Computacionais . . . . 65

3.2.1 Categorização de dados . . . . . . . . . . . . . . . . . . 66

3.2.1.1 Características . . . . . . . . . . . 66

3.2.1.2 Limites . . . . . . . . . . . . . . . . 67

3.2 .2 Mineração de Dados . . . . . . . . . . . . . . . . . . . 67

3.2.2.1 Características . . . . . . . . . . . . 67

$3.2 .2 .2 \quad$ Limites . . . . . . . . . . . . . . . . . . . 68

3.3 Avaliação da Qualidade dos Dados por Abordagens Visuais . . . . . . . . . 69

3.3.1 O Protocolo de Identificação dos Trabalhos . . . . . . . . . . . . . . 69

3.3.2 O Protocolo de Triagem dos Trabalhos . . . . . . . . . . . . . . 70

3.3.3 O Protocolo de Interpretação dos Resultados . . . . . . . . . . . . . 72

3.3.4 Caracterização dos Trabalhos . . . . . . . . . . . . . . 73

3.3.4.1 Manet .................. 73

3.3.4.1.1 Características . . . . . . . . . . 73

3.3.4.1.2 Limites . . . . . . . . . . . . . . 74

3.3.4.2 GGobi ......................... 74

3.3.4.2.1 Características . . . . . . . . . . 74

3.3.4.2.2 Limites . . . . . . . . . . . . 76

3.3.4.3 DaVis ..................... 76

3.3.4.3.1 Características . . . . . . . . 76

3.3.4.3.2 Limites . . . . . . . . . . . . . . . . . . 77

3.3.4.4 XMDVTOOL ${ }^{Q} \ldots \ldots \ldots \ldots \ldots 77$

3.3.4.4.1 Características . . . . . . . . . . . 77

3.3.4.4.2 Limites . . . . . . . . . . . . . . . . . 79

3.3.4.5 D-DUPE . . . . . . . . . . . . . 80 
3.3.4.5.1 Características ............. 80

3.3.4.5.2 Limites . . . . . . . . . . . . . . . . . 81

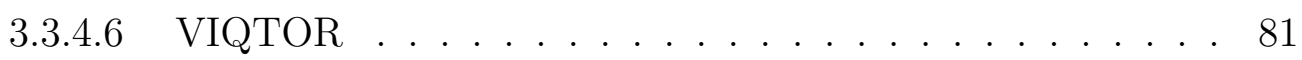

3.3.4.6.1 Características . . . . . . . . . . 81

3.3.4.6.2 Limites . . . . . . . . . . . . . . . . . 81

3.3.4.7 Visual Profiling . . . . . . . . . . . . . . . . . . . 82

3.3.4.7.1 Características . . . . . . . . . . . . . 82

3.3.4.7.2 Limites . . . . . . . . . . . . . 83

3.3.4.8 VIM . . . . . . . . . . . . . . . . . . . . . . . . . . 84

3.3.4.8.1 Características . . . . . . . . . . 84

3.3.4.8.2 Limites . . . . . . . . . . . . . . 85

3.3.4.9 Mondrian . . . . . . . . . . . . . . . . . . 85

3.3.4.9.1 Características . . . . . . . . . . . 85

3.3.4.9.2 Limites . . . . . . . . . . . . 86

3.3.4.10 Profiler . . . . . . . . . . . . . . 86

3.3.4.10.1 Características . . . . . . . . . . 86

3.3.4.10.2 Limites . . . . . . . . . . . . . . . 88

3.3 .4 .11 VDQAM . . . . . . . . . . . . . . . 88

3.3.4.11.1 Características . . . . . . . . . . . 88

3.3.4.11.2 Limites . . . . . . . . . . . . . . . . . . . . 88

3.3.4.12 DQVis . . . . . . . . . . . . . . . . . . 89

3.3.4.12.1 Características . . . . . . . . . . . . 89

3.3.4.12.2 Limites . . . . . . . . . . . . . . . . . . . . . 89

3.3.4.13 Identity Explorer . . . . . . . . . . . . . . . . . 90

3.3.4.13.1 Características .............. . . 90

3.3.4.13.2 Limites . . . . . . . . . . . . . . 91

3.3.4.14 Síntese dos Trabalhos . . . . . . . . . . . . . . . . . . 91

3.4 Limites das Abordagens de Descrição dos Defeitos nos Dados . . . . . . . . 97

3.5 Limites das Abordagens de Projeto de Sistemas de Visualização . . . . . . 100

3.6 Conclusão . . . . . . . . . . . . . . . . . . . . . . . . . . . . . 102

4 Uma Taxonomia Formal de Defeitos nos Dados 105

4.1 Introdução . . . . . . . . . . . . . . . . . . . . . . . . 105

4.2 A Abordagem Metodológica . . . . . . . . . . . . . . . . . . 105

4.3 Os Conceitos Estruturais Base . . . . . . . . . . . . . . . . . . . . 108

4.4 A Descrição dos Defeitos nos Dados . . . . . . . . . . . . . . . . . 112

4.5 Conclusão . . . . . . . . . . . . . . . . . . . . . . . . . 121

4.5 .1 Originalidade . . . . . . . . . . . . . . . . . 122 
5 Propriedades para Avaliação Visual da Qualidade dos Dados

5.1 Introdução . . . . . . . . . . . . . . . . . . . . . . . . . 123

5.2 Avaliação Visual da Qualidade dos Dados . . . . . . . . . . . . . . . 123

5.3 A Configuração do Estudo de Caso . . . . . . . . . . . . . . . . . . . . . . 124

5.3.1 O Escopo do Estudo de Caso . . . . . . . . . . . . . . . . . . . . . 124

5.3.1.1 Critérios de Seleção das Propriedades . . . . . . . . . . . 125

5.3 .2 O Arcabouço de Atividades . . . . . . . . . . . . . . . . 125

5.3.2.1 Definição de Atividade . . . . . . . . . . . . . . . . 126

5.3 .3 O Participante . . . . . . . . . . . . . . . . . . . 128

5.3 .4 As Condições . . . . . . . . . . . . . . . . . . . . . . . 129

5.3.5 A Ferramenta de Apoio Vis4DD . . . . . . . . . . . . . . 129

5.3.6 Os Artefatos de Dados . . . . . . . . . . . . . . . . . . . . . 131

5.3.7 Os Procedimentos . . . . . . . . . . . . . . . . . . . . . . . . . . . 132

5.4 Resultados do Estudo de Caso . . . . . . . . . . . . . . . . . . . 136

5.4.1 Unidade de Estudo - Tupla Atípica . . . . . . . . . . . . . . . 137

5.4 .2 Unidade de Estudo - Tupla Falsa . . . . . . . . . . . . . . . . . . . 144

5.4.3 Unidade de Estudo - Granularidade Heterogênea . . . . . . . . . . . 146

5.4.4 Unidade de Estudo - Unidade de Medida Heterogênea . . . . . . . . 148

5.4.5 Unidade de Estudo - Referência Ausente e Incorreta . . . . . . . . . 151

5.4.6 Unidade de Estudo - Defeitos sem Evidência Visual . . . . . . . . . 153

5.5 Limitações do Estudo de Caso . . . . . . . . . . . . . . . . . . . . 154

5.6 Conclusão . . . . . . . . . . . . . . . . . . . . . . . 155

5.6.1 O Relacionamento Propriedade-Defeito . . . . . . . . . . . . . . . 155

5.6.2 A Aplicação Prática da Relação Propriedade-Defeito . . . . . . . . 158

5.6 .3 Originalidade . . . . . . . . . . . . . . . . . . 161

6 Conclusão 163

6.1 Síntese do Trabalho . . . . . . . . . . . . . . . . . . 163

6.2 Principais Contribuições . . . . . . . . . . . . . . . . . . . . 164

6.3 Limites . . . . . . . . . . . . . . . . . . . . . . 166

6.4 Oportunidades de Pesquisa . . . . . . . . . . . . . . . . . 167

$\begin{array}{ll}\text { A Anexo } & 169\end{array}$

A.1 Registro das Interações . . . . . . . . . . . . . . . . . . . . . . . . . 169

A.2 Resumos Analíticos . . . . . . . . . . . . . . . . 170

$\begin{array}{ll}\text { Referências Bibliográficas } & 171\end{array}$

$\begin{array}{ll}\text { Índice Remissivo } & 188\end{array}$ 


\title{
Lista de Abreviações e Acrônimos
}

\author{
ACM Association for Computing Machinery \\ AIS Association for Information Systems \\ ASA American Statistical Association \\ CFJ Catholic Fu-jen University, Department of Statistics \\ Colet. Coletadas \\ Conc. Concorrente \\ DBLP DBLP Computer Science Bibliography \\ EuroStat European Statistics Commission \\ FCS Foundation of Computer Science \\ GPU Graphics Processing Unit \\ Het. Heterogêneo \\ Hier. Hierarquia \\ IEEE Institute of Electrical and Electronics Engineers \\ IHC Interface Homem-Computador \\ IFIP International Federation for Information Processing \\ MITIQ Massachusetts Institute of Technology Information Quality \\ NYU New York School of Social Worker Building, Department of Statistics \\ OLAP On-line Analytical Processing \\ pAQD processo de Avaliação da Qualidade dos Dados \\ PB Petabytes \\ PNG Portable Network Graphics \\ ref Referência \\ RDM Renmin University of China, Data Mining Center \\ Selec. Selecionadas \\ SGBD Sistema Gerenciador de Banco de Dados \\ SQL Structured Query Language \\ UdD Universo de Discurso \\ Var. Variante \\ Viol. Violação \\ Vis4DD Visualization for Defect Detection \\ WWW World Wide Web
}




\section{Lista de Figuras}

1.1 A Avaliação Visual da Qualidade dos Dados (Fonte: Elaborado pelo autor) 25

2.1 O Processo de Avaliação da Qualidade dos Dados (Fonte: Elaborado pelo autor $\ldots \ldots \ldots \ldots \ldots \ldots \ldots$

2.2 Arcabouço de Componentes dos Critérios de Qualidade (Fonte: Elaborado pelo autor $\ldots \ldots \ldots \ldots$. . . . . . . . . . . . . . . 36

2.3 Cadeia de impacto entre defeitos em diferentes granularidades (Fonte: Ela-

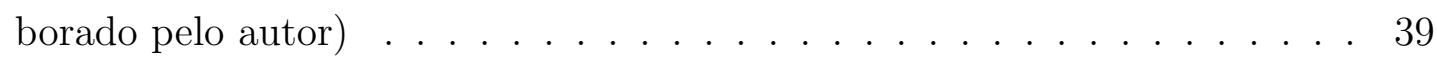

2.4 Modelo de Processo de Visualização de Dados (Fonte: Elaborado pelo autor) 42

2.5 Transformações de Mapeamento Geométrico e Visual (Adaptado de [Telea,

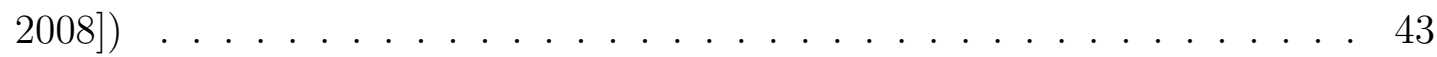

2.6 Modelos de Transformação e Sessão do Processo de Visualização de Dados (Fonte: Elaborado pelo autor) . . . . . . . . . . . . . . . . . . . . . . . . 44

2.7 Anotações e Compartilhamento de resultados do sense.us (Fonte: [Heer et al. , 2009]) . . . . . . . . . . . . . . . . . . 4 46

2.8 Exemplo de distorção espacial em resolução de $10^{6}$ (Fonte: Elaborado pelo

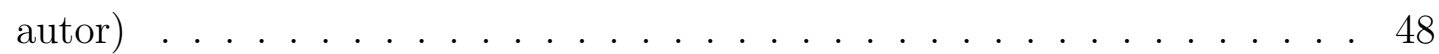

2.9 Exemplo de navegação visual sobre histórico de análises visuais (Fonte: [Jankun-Kelly et al., 2002]) . . . . . . . . . . . . . . . . . . . 49

2.10 Exemplo de mudança de Opacidade em resolução $10^{5}$ tuplas (Fonte: Ela-

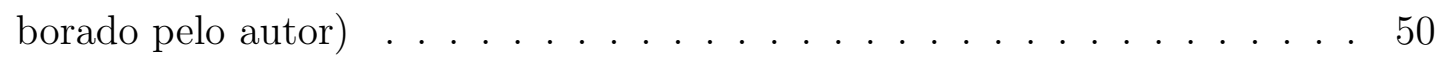

2.11 Exemplo de Ordenação e Seriação (Fonte: [Heer e Shneiderman, 2012]) . 50

2.12 Exemplo de Reformulação (Fonte: $[$ Few, 2009]) . . . . . . . . . . . . . . . . 51

2.13 Exemplos de Seleção e Destaque e, Seleção e Ligação (Fonte: [Cook e Swayne

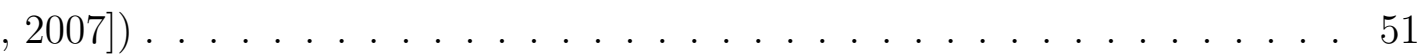

2.14 Exemplo de divisão do espaço visual por Treliça (Fonte: [Keim e Krigel , 1994]) . . . . . . . . . . . . . . . . . 52

2.15 Exemplo de visões concorrentes múltiplas (Fonte: [Kandel et al., 2012b]) 53

2.16 Disposição dos pixels de um objeto qualquer (Fonte: [Chan, 2006]) . . . . . 54

2.17 Exemplos de variáveis visuais (Fonte: Elaborado pelo autor) . . . . . . . . 59 
2.18 Sistema dual de processamento perceptual e cognitivo (Adaptadado de: $[$ Marr, 1982; Palmer, 1999]) _. . . . . . . . . . . . 61

3.1 Representações visuais do Manet (Fonte: ([Theus et al., 1997]) . . . . . . . 74

3.2 Representações Visuais concorrentes múltiplas do GGobi (Fonte: ([Cook e Swayne , 2007]) . . . . . . . . . . . . . . . . . . . . . 75

3.3 Representação visual do DaVis (Fonte: [Sulo et al., 2005]) . . . . . . . . . . 77

3.4 Representação visual do $X M D V T O O L^{Q}$ (Fonte: [Xie et al., 2006]) . . . . 78

3.5 Controle auxiliar para navegação na hierarquia de grupos (Adaptado de [Fua et al., 1999]) . . . . . . . . . . . . . . . . . . . . 79

3.6 Representação visual do D-DUPE (Fonte: [Kang et al., 2008]) . . . . . . . 80

3.7 Representação visual do VIQTOR (Fonte: [Führing e Naumann, 2007]) 82

3.8 Representação visual do Visual Profiling (Fonte: [Tennekes et al., 2011]) 83

3.9 Representações visuais do VIM (Fonte: [Templ et al., 2012]) . . . . . . . . 84

3.10 Representações visuais do Mondrian (Fonte: [Malik e Unwin, 2012]) . . . . 85

3.11 Representação visual do Profiler (Fonte: [Kandel et al., 2012b]) . . . . . . . 87

3.12 Representação visual em 3D do VDQAM (Fonte: [Teng et al., 2012]) . . . . 89

3.13 Representações visuais do DQVis (Fonte: [Wang et al., 2013]) . . . . . . . 90

3.14 Representação visual do Identity Explorer (Fonte: [Chen, 2015]) . . . . . . 91

3.15 Sistemas de visualização para avaliação da qualidade dos dados - Síntese Visual Parte I (Fonte: Elaborado pelo autor) . . . . . . . . . . . . . . 93

3.16 Sistemas de visualização para avaliação da qualidade dos dados - Síntese Visual Parte II (Fonte: Elaborado pelo autor) . . . . . . . . . . . . . . . . 94

4.1 Propriedades herdadas da regra violada (Fonte: Elaborado pelo autor) . . . 107

4.2 Taxonomia de Defeitos nos Dados (Fonte: [Josko et al., 2016]) . . . . . . . 108

4.3 Modelo lógico de dados relativo a caso do domínio financeiro (Fonte: Elaborado pelo autor $\ldots$. . . . . . . . . . . . . . . . . . . . 111

5.1 Espaços visuais do Vis4DD (Fonte: Elaborado pelo autor) . . . . . . . . . 130

5.2 Os componentes do Vis4DD e suas interligações (Fonte: Elaborado pelo autor $\ldots \ldots \ldots \ldots \ldots 131$

5.3 Esquema em BPMN do procedimento de trabalho do estudo de caso com múltiplas unidades de estudo (Fonte: Elaborado pelo autor) . . . . . . . 135

5.4 Resultados das configurações na avaliação da primeira variante de Tupla Atípica (Fonte: Elaborado pelo autor) ～. . . . . . . . . . . . . . . . 138

5.5 Fragmentos visuais da avaliação da primeira variante de Tupla Atípica (Fonte: Elaborado pelo autor) . . . . . . . . . . . . . . . . . . . . . . 139

5.6 Resultados das configurações na avaliação da segunda variante de Tupla Atípica (Fonte: Elaborado pelo autor) . . . . . . . . . . . . . . . . . . . . . 140 
5.7 Fragmentos visuais da avaliação da segunda variante de Tupla Atípica (Fonte: Elaborado pelo autor) . . . . . . . . . . . . . . . . . . . . . . . . . 141

5.8 Resultados das configurações na avaliação da terceira variante de Tupla Atípica (Fonte: Elaborado pelo autor) . . . . . . . . . . . . . . . . . . . . . 142

5.9 Fragmentos visuais da terceira variante de Tupla Atípica (Fonte: Elaborado pelo autor . . . . . . . . . . . . . . . . . . . . . . . . . . . 142

5.10 Resultados das configurações na avaliação da quarta variante de Tupla Atípica (Fonte: Elaborado pelo autor) . . . . . . . . . . . . . . . . . . . . . 143

5.11 Fragmentos visuais da avaliação da quarta variante de Tupla Atípica (Fonte: Elaborado pelo autor $)$. . . . . . . . . . . . . . . . . . . . . . . 144

5.12 Resultados das configurações na avaliação da Tupla Falsa (Fonte: Elaborado

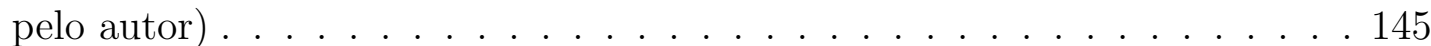

5.13 Fragmentos visuais da avaliação de Tupla Falsa (Fonte: Elaborado pelo autor)146

5.14 Resultados das configurações para a primeira variante de Granularidade Heterogênea (Fonte: Elaborado pelo autor) . . . . . . . . . . . . . . . . . . 147

5.15 Fragmentos visuais da avaliação da primeira variante de Granularidade Heterogênea (Fonte: Elaborado pelo autor) . . . . . . . . . . . . . . . . . . 148

5.16 Resultados das configurações para a segunda variante de Granularidade Heterogênea (Fonte: Elaborado pelo autor) . . . . . . . . . . . . . . . . . . 149

5.17 Fragmentos visuais da avaliação da segunda variante de Granularidade Heterogênea (Fonte: Elaborado pelo autor) . . . . . . . . . . . . . . . . . . . 149

5.18 Resultados das configurações na avaliação da Unidade de Medida Heterogênea (Fonte: Elaborado pelo autor) . . . . . . . . . . . . . . . . . . . . 150

5.19 Fragmentos visuais da avaliação da Unidade de Medida Heterogênea (Fonte: Elaborado pelo autor $)$. . . . . . . . . . . . . . . . . . . 151

5.20 Resultados das configurações para referência ausente e incorreta (Fonte:

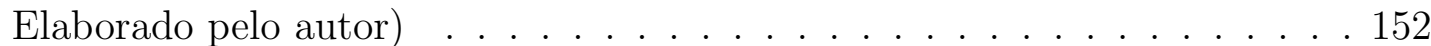

5.21 Fragmentos visuais da avaliação de referência ausente e incorreta (Fonte:

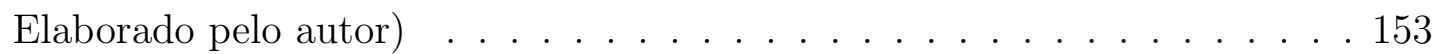

5.22 Valores sinônimos destacados em pequeno conjunto de vernáculos (Fonte: Elaborado pelo autor $)$. . . . . . . . . . . . . . . . . . . . . . 154

5.23 Tuplas potencialmente duplicadas comunicadas por abordagens computacionais . . . . . . . . . . . . . . . . . . . . . 160

A.1 Fragmento do registro de interações realizado pelo Vis4DD (Fonte: Elaborado pelo autor . . . . . . . . . . . . . . . . . . . . 169

A.2 Fragmento de resumo analítico - Tupla Atípica (Fonte: Elaborado pelo autor) 170 
xviii

LISTA DE FIGURAS 


\section{Lista de Tabelas}

2.1 Instância de certos Critérios de Qualidade (Fonte: Adaptado de [Loshin , 2010]) . . . . . . . . . . . . . . . . . 36

2.2 Subconjunto dos principais Critérios de Qualidade (Fonte: Elaborado pelo

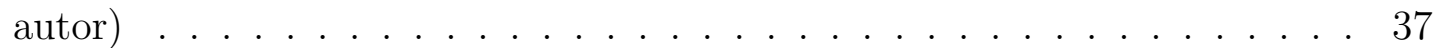

2.3 Técnicas de interação agrupadas pela principal intenção do agente humano (Fonte: Elaborado pelo autor) . . . . . . . . . . . . . . . . . . 45

2.4 Técnicas de visualização categorizadas por abordagem de projeção (Fontes: [Chan, 2006; Herman et al., 2000; Keim, 2002; Schulz et al., 2011]) . . . 55

2.5 Primitivas visuais otimizadas (Fonte: [Ware, 2004]) . . . . . . . . . . . . 61

2.6 Demonstração do estímulo das primitivas visuais otimizadas (Adaptado de: $[$ Ware, 2004]) . . . . . . . . . . . . . . . . . . 62

3.1 Trabalhos analisados e selecionados por Periódicos (Fonte: Elaborado pelo

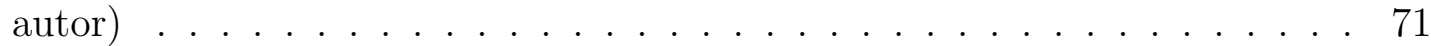

3.2 Trabalhos analisados e selecionados por Conferências e Simpósios (Fonte: Elaborado pelo autor . . . . . . . . . . . . . . . . . 72

3.3 Correlação dos Defeitos, Técnicas de Detecção e de Visualização do Profiler (Fonte: [Kandel et al., 2012b]) . . . . . . . . . . . . . . . . . . . . . 87

3.4 Sistemas de visualização para avaliação da qualidade dos dados - Síntese Tabular (Fonte: Elaborado pelo autor) _ . . . . . . . . . . . . . . . . 97

3.5 Projeto de Sistemas de Visualização - Resumo das Codificações (Fonte: Elaborado pelo autor $)$. . . . . . . . . . . . . . . . . . . . 101

4.1 Relação entre Tópicos, Regras ou Restrições e Defeitos nos Dados (Fonte:

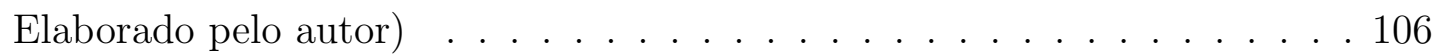

4.2 Critérios de Qualidade versus Defeitos nos Dados (Font: Elaborado pelo

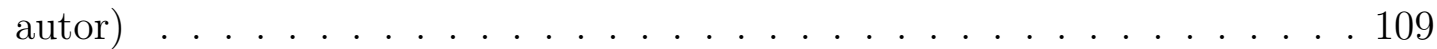

4.3 Uma instância da relação Cliente (Fonte: Elaborado pelo autor) . . . . . . 111

4.4 Uma instância da relação ContaCartaoCredito (Fonte: Elaborado pelo autor) 111

4.5 Uma instância da relação ContaCreditoCliente (Fonte: Elaborado pelo autor)111

4.6 Uma instância da relação ContaCartaoDebito (Fonte: Elaborado pelo autor)111 
4.7 Uma instância da relação ContaDebitoCliente (Fonte: Elaborado pelo autor)112

5.1 Padrões agrupados por Classe (Fontes: Adaptado de [Andrienko e Andrienko , 2006; Few, 2009]) . . . . . . . . . . . . . . . 127

5.2 Matriz de configurações e respectivas propriedades (Fonte: Elaborado pelo autor) . . . . . . . . . . . . . . . . . . 137

5.3 Resumo da relação propriedade-defeito baseados nas configurações (Fonte: Elaborado pelo autor $)$. . . . . . . . . . . . . . . . . 156 


\section{Lista de Quadros}

2.1 Critérios de Qualidade classificados por Aspecto e Objeto Alvo (Fonte:

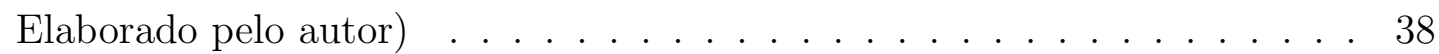

3.1 Lista de Termos Gerais para a seleção das Publicações Científicas (Fonte: Elaborado pelo autor $)$. . . . . . . . . . . . . . . . . . 70

4.1 Resumo da Linguagem de Formalização e Conceitos de Bancos de Dados Relacionais (Fonte: [Josko et al., 2016]) . . . . . . . . . . . . . . . . . 109

5.1 Esquema e metadados das Relações utilizadas no Estudo de Caso (Fonte: Elaborado pelo autor $)$. . . . . . . . . . . . . . . . . . . . . 132

5.2 Características e critérios de geração dos dados defeituosos por Defeito e Variante - Parte I (Fonte: Elaborado pelo autor) . . . . . . . . . . . . . . . 133

5.3 Características e critérios de geração dos dados defeituosos por Defeito e Variante - Parte II (Fonte: Elaborado pelo autor) . . . . . . . . . . . . . . 134

5.4 Características e critérios de geração dos dados defeituosos por Defeito e Variante - Parte III (Fonte: Elaborado pelo autor) . . . . . . . . . . . . . . 135 
xxii 


\section{Capítulo 1}

\section{Introdução}

Na última década, o aprimoramento dos dispositivos de armazenamento e dos mecanismos de criação e coleta de dados proporcionaram o crescimento contínuo do volume e da variedade de dados persistidos em diferentes sistemas de bancos de dados.

Diferentes exemplos ilustram a magnitude desse cenário na indústria e na ciência. Em 2010, o Facebook relatou 21 petabytes - PB - no seu data warehouse. No ano seguinte, estimativas revelaram que o Google armazenava cerca de 70 PB em seu BigTable ${ }^{1}$. Ainda, uma joint venture estabelecida entre vinte nações europeias para pesquisas nucleares e de engenharia declarou a produção de 13 PB anuais de dados derivados de experimentos junto ao seu acelerador de partículas [Gorton e Gracio, 2012].

A mera posse de dados não caracteriza uma vantagem ou valor intrínseco. O estímulo a coleta massiva de dados provém do potencial desses dados revelarem fenômenos sobre fatos ou eventos de interesse. Em outras palavras, o valor dos dados resulta da oportunidade proporcionada aos processos analíticos disponibilizarem respostas a questões relevantes de um contexto.

Entretanto, a constituição de espaços massivos de dados estabelece desafios aos processos analíticos. O primeiro remete a agilidade de prover resultados nos momentos adequados a certa necessidade. Ainda que relevante, suplantar essa questão não assegura a utilidade dos referidos resultados. Em um mundo de dados imperfeitos, o maior desafio aos processos analíticos é a confiabilidade de seus resultados cujo nível é fortemente determinado pela qualidade dos dados utilizados [Dasu, 2013; English, 2009; Olson, 2003; Redman et al., 2011].

\subsection{Caracterização do Problema}

A qualidade dos dados é uma questão tão antiga quanto o próprio dado e remete a características multifacetadas e indesejadas nos dados. Os impactos provocados pela

\footnotetext{
${ }^{1}$ Banco de dados orientado a colunas e escalável desenvolvido pelo Google e utilizado no Google File System para permitir acesso rápido a PB de dados [Gorton e Gracio, 2012]
} 
qualidade inadequada dos dados nos custos, nos processos de tomadas de decisões, na satisfação dos clientes, dentre outros, são amplamente discutidos na literatura [English , 2009; Loshin, 2010; Redman et al., 2011; Redman, 1998]. De fato, o tema qualidade de dados é recorrente na literatura científica nos últimos cinquenta anos [De Veaux e Hand, 2005].

Aperfeiçoar e reter a qualidade dos dados no patamar reivindicado pelos processos analíticos requer a identificação de uma alternativa baseada em diferentes procedimentos, métodos, técnicas e abordagens tecnológicas. No entanto, determinar quais elementos são mais adequados a uma realidade implica em conhecer o estado da qualidade corrente dos dados [Lee et al., 2009; Loshin, 2010]. Proporcionar esse conhecimento é o objetivo do processo de Avaliação da Qualidade dos Dados - pAQD.

Esse processo exige ponderar variados aspectos organizacionais, culturais, funcionais, humanos e da natureza dos defeitos nos dados de modo a evitar que seu custo supere os benefícios. À medida que associar eficiência e eficácia é uma necessidade para o pAQD, o apoio de soluções automatizadas assume um papel de importância [Dasu, 2013; Loshin , 2010; Malik et al., 2010; Naumann, 2002].

Relevantes abordagens computacionais apoiam esse processo, especialmente para defeitos cujas regras de deteç̧ão são mais precisas. Essas abordagens utilizam métodos quantitativos [Chandola et al., 2009] ou baseados em restrições [Naumann, 2014] que limitam o papel humano a interpretação de seus resultados [Dasu, 2013; Keim et al., 2010].

Contudo, o pAQD depende fortemente do conhecimento do contexto dos dados uma vez que é impossível confirmar ou refutar a presença de defeitos com base exclusiva nos dados [Bertossi et al., 2011; Dasu, 2013; Lee, 2003]. O contexto determina a estrutura semântica - como aquela relativa as perspectivas do produtor e consumidor, Seção 2.2.3.1 - entre os dados e o ambiente, como departamentos de uma organização. Portanto, a supervisão humana é imprescindível no decorrer da avaliação da qualidade de dados.

A visualização de dados pertence a uma classe de abordagens supervisionadas que combina a capacidade computacional com as habilidades humanas de detecção de padrões e distinção semânticas necessárias a avaliação visual da qualidade dos dados [Keim et al., 2010; Ware, 2004]. No entanto, projetar um sistema de visualização de dados que integre as propriedades visuais e interativas adequadas a um domínio de problema é um desafio visto que inexiste uma engenharia estabelecida [Casner, 1991; Craft e Cairns, 2008; Keim et al., 2010; Thomas e Cook, 2005].

Como exemplo desse desafio, estudos de avaliação revelaram impactos no desempenho e no resultado de processos analíticos conduzidos em sistemas de visualização cujas representações utilizavam propriedades visuais distintas [Hegarty, 2011; Tory e Moller , 2004]. Nos casos mais agudos, a representação visual inadequada as demandas do processo analítico em questão suscitou uma considerável moldagem dos dados. Desse modo, qualquer sistema de visualização não é condição suficiente para favorecer a avaliação visual 
da qualidade de dados. Um sistema de visualização adequado a esse propósito deve favorecer a extração de padrões e relacionamentos que remetam aos defeitos e não simplesmente disponibilizar dados.

Baseado na exposição acima, a questão problema do presente trabalho é:

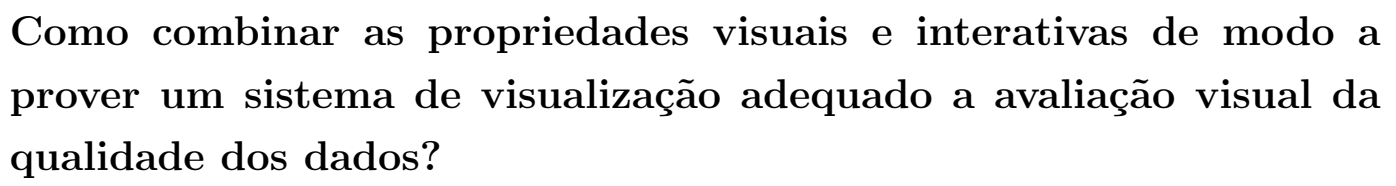

\subsection{Objetivo}

Responder a questão acima requer esclarecer as características da avaliação visual da qualidade de dados - Seção 5.2. Tal avaliação denota um processo não-linear de compreensão da qualidade dos dados mediado por sistemas de visualização. Por meio de representações visuais interativas, um agente avaliador da qualidade concentra seus recursos cognitivos para buscar, extrair, correlacionar e compreender significados - padrões e relacionamentos - relativos a estrutura dos defeitos até reunir evidências semânticas capazes de determinar a qualidade dos dados - Figura 1.1. Essas características demonstram a importância da estrutura dos defeitos nos dados e da utilização de propriedades dos sistemas de visualização que salientem tais estruturas.

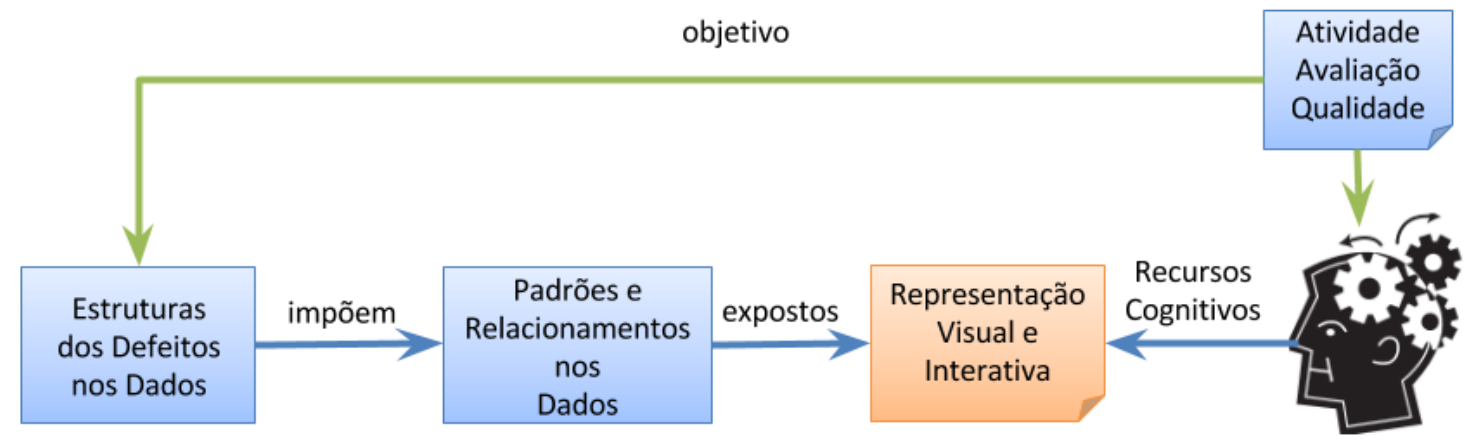

Figura 1.1: A Avaliação Visual da Qualidade dos Dados (Fonte: Elaborado pelo autor)

Isto posto, o primeiro objetivo deste trabalho é proporcionar a compreensão estrutural do problema associado a cada defeito relativo ao conteúdo dos dados - critérios de qualidade da acuracidade, completude ou consistência, Seção 2.2.3.2. Para esse fim, é necessário organizar os defeitos segundo um nível de abstração coerente, bem como prover uma descrição baseada em linguagem, terminologia e nomenclatura não ambíguas e adequadas ao contexto da avaliação da qualidade de dados. A análise do estado-da-arte da literatura - Seção 3.4 - revelou acentuadas discrepâncias na cobertura, na descrição e no nível de abstração dos defeitos. Essa situação dificulta responder questões como: Quais são os defeitos relacionados a acuracidade? Qual é a estrutura de certo defeito? Quais defeitos denotam a integridade de dados? 
Conforme discutido acima, a estrutura dos defeitos determina os padrões e os relacionamentos nos dados defeituosos para os quais o processamento cognitivo e as ações do agente avaliador da qualidade são dirigidos. Portanto, o projeto de sistemas de visualização deve selecionar as propriedades que melhor favoreçam a identificação visual dos significados essenciais a determinação de defeitos nos dados. Muito embora exista uma considerável literatura que aborde o projeto dos referidos sistemas, há limitado apoio ao domínio da avaliação visual da qualidade dos dados - Seção 3.5.

Em vista disso, o segundo objetivo deste trabalho é estabelecer um mapeamento entre propriedades visuais-interativas e os defeitos nos dados - de acordo com as estruturas correspondentes. Para investigar esse mapeamento, é necessário considerar como cada propriedade visual sustenta o procedimento de detecção e quantificação de cada defeito em dados com diferentes resoluções. Além disso, também é necessário identificar qual a contribuição das propriedades interativas no referido procedimento.

Neste trabalho, essa investigação é de natureza qualitativa realizada por meio de um estudo de caso exploratório e múltiplo. O escopo desse estudo de caso é restrito a uma parcela relevante de propriedades visuais e interativas, bem como ao subconjunto dos defeitos que demandam maior supervisão humana - Seção 5.3.1.

\subsubsection{Objetivo Principal}

O presente trabalho é consciente de que os fatores humanos - incluindo acuidade visual, estilo cognitivo e preferências pessoais - podem influenciar na detecção visual de defeitos, bem como dos limites de escalabilidade das diferentes propriedades visuais. O objetivo deste trabalho é definido como:

\footnotetext{
Identificar, classificar, organizar e descrever os defeitos em dados estruturados e atemporais relativos aos critérios de acuracidade, completude e consistência e, então, estabelecer um mapeamento entre aqueles defeitos que demandam maior supervisão humana e as propriedades visuais-interativas que favoreçam as respectivas avaliações em resoluções crescentes de dados.
}

\subsection{Hipótese}

Conforme apresentado em diferentes trabalhos [Malik et al., 2010; Marghescu, 2007; Tennekes et al., 2013; Ward e Theroux, 1997; Ware, 2004], a visualização de dados pode tornar perceptível a estrutura dos defeitos dos dados e propiciar a confirmação ou rejeição correspondentes por um agente avaliador da qualidade. Assim, a hipótese norteadora deste trabalho é: 


\section{A avaliação visual da qualidade de dados pode ser mediada por um sistema de visualização projetado a partir do mapeamento entre propriedades visuais-interativas e a estrutura dos defeitos dos dados.}

\subsection{Justificativa da Hipótese}

Sistemas de visualização apoiam a avaliação da qualidade dos dados por meio de duas abordagens. A abordagem Quality-Aware denota o uso de recursos computacionais para extrair métricas de qualidade dos dados comunicadas por meio de glifos, textos ou elementos de destaques. A Visualização de Incertezas - Uncertainty Visualization - e a Qualidade Espacial dos Dados - Spatial Data Quality - são áreas com larga contribuição no mapeamento das propriedades visuais mais apropriadas na comunicação dessas métricas mensuradas em dados com referência geométrica [Potter et al., 2012; Thomson et al., 2005].

Interesse do presente trabalho, a abordagem Visual Diagnosis-Driven denota o uso intensivo da avaliação visual da qualidade de dados, inclusive daqueles sem mapeamento espacial óbvio - dados sobre clientes e vendas, por exemplo. Dessa forma, essa abordagem requer a utilização de propriedades visuais e interativas que facilitem a percepção dos objetivos de análise das atividades de avaliação da qualidade, quais sejam os significados relativos a defeitos nos dados - Seção 2.4. Contudo, a Visual Diagnosis-Driven não conta com o mesmo nível de organização da abordagem supracitada.

Certos estudos comparativos [Grinstein et al., 2002; Hoffman, 1999; Marghescu, 2007; Ward e Theroux, 1997] reportam o benefício de um subconjunto de propriedades visuais na detecção de tuplas atípicas e violações de restrições semânticas - Seção 4.4. De outro modo, algumas implementações [Kang et al., 2008; Templ et al., 2012; Tennekes et al. , 2013] também observam o papel das propriedades visuais de salientar a estrutura de defeitos particulares, mas de modo não metódico.

As propriedades interativas são pouco exploradas pelos referidos trabalhos em razão da utilização de baixas resoluções de dados, majoritariamente. No entanto, é notório que as representações visuais devem ser capazes de atender novas indagações decorrentes das análise visuais [Card et al., 1999; Jun et al., 2011; Ware, 2004]. O envolvimento com os dados proporcionado pela interatividade é crítico na avaliação visual da qualidade dos dados [Heer e Shneiderman, 2012].

Com base na exposição acima, o presente trabalho acredita que estabelecer uma relação entre as propriedades visuais-interativas e os defeitos dos dados - segundo as capacidades das primeiras em beneficiar a detecção da estrutura dos últimos - oferece indicações bases relevantes ao projeto de sistemas de visualização que apoiem a avaliação visual da qualidade dos dados de modo adequado. 


\subsection{Resultados Obtidos}

Para alcançar os objetivos do presente trabalho, a primeira etapa foi criar uma taxonomia de defeitos nos dados. A análise das características e limites dos trabalhos relacionados contribuíram para estabelecer a abordagem metodológica de desenvolvimento da taxonomia. Essa abordagem determinou a revisão da teoria relacional para identificar os defeitos e definir a linguagem e a terminologia da descrição, bem como a classificação dos defeitos de acordo com as granularidades de ocorrência e as propriedades compartilhadas.

A etapa seguinte desenvolveu o relacionamento propriedades-defeitos a partir das carências verificadas na literatura da área de visualização de dados. Este trabalho conduziu um estudo de caso exploratório para delinear esse relacionamento uma vez que a relevância das propriedades visuais e interativas eram desconhecidas de modo prévio. A metodologia desse estudo de caso reuniu observações relativas as atividades de detecção e quantificação dos defeitos modeladas a partir de um arcabouço de atividades. A ferramenta $V i s 4 D D$ foi construída para apoiar esse procedimento e capturar informações adicionais sobre as interações realizadas.

Como resultado direto dessas etapas, foram publicados: um artigo completo em periódico internacional da área de visualização de dados [Josko e Ferreira, 2016], um artigo completo em conferência internacional da área de banco de dados [Josko et al., 2016] e um artigo com resultados parciais em simpósio nacional da área de banco de dados [Josko e Ferreira, 2014]. Cumpre ainda destacar que a caracterização da ferramenta Vis4DD e das abordagens visuais de avaliação da qualidade de dados constituem oportunidades de publicação futura.

\subsubsection{Originalidade}

A taxonomia e os relacionamentos propriedades-defeitos revelaram um conjunto de aspectos singulares em relação ao estado-da-arte da literatura. Tais aspectos são sumarizados abaixo e tratados na íntegra nas Seções 4.5.1 e 5.6.3, respectivamente.

\section{Taxonomia}

- Uso de metodologia objetiva para identificar e classificar os defeitos nos dados. Tal fato propiciou a cobertura de vinte e seis defeitos, sendo nove não abordados por taxonomia alguma;

- Arranjo visual hierárquico dos defeitos nos dados, facilitando a compreensão das propriedades compartilhadas;

- Uso de três elementos distintos baseados na terminologia da área de banco de dados para explicitar a estrutura dos defeitos nos dados; 
- Consolidação e descrição dos defeitos de acordo com a respectiva estrutura, garantindo o mesmo nível de abstração.

\section{Relacionamentos propriedades-defeitos}

- Uso de um arcabouço para descrever as atividades de avaliação da qualidade de dados. Essas atividades foram relevantes como apoio ao trabalho de análise desempenhado pelo participante, bem como auxiliou na determinação das técnicas de interação incorporadas a ferramenta de apoio;

- Desenvolvimento de uma ferramenta de apoio - Vis4DD - específica as necessidades do estudo de caso;

- Análise das propriedades visuais que compõem as técnicas de visualização, fato que torna os resultados deste trabalho mais abrangentes, isto é, independente da técnica de visualização. Tal abordagem diferente drasticamente dos trabalhos relacionados - Seções 5.4 e 3.5 - que analisam técnicas de visualização específicas;

- Cobertura de diferentes defeitos nos dados e variantes correspondentes em resoluções crescentes de dados;

- Análise das propriedades quanto as ações de detecção e a quantificação dos defeitos nos dados. A segunda representa um enfoque inédito em relação aos trabalhos relacionados.

\subsection{Organização do Trabalho}

A apresentação do conteúdo e contribuições desta tese de doutoramento seguem a estrutura a seguir:

- O Capítulo 2 caracteriza os conceitos e os componentes dos principais fundamentos que norteiam o presente trabalho, quais sejam o processo de avaliação da qualidade de dados, a visualização de dados e os procedimentos realizados pelos sistemas humanos de percepção visual e de raciocínio analítico.

- O Capítulo 3 apresenta uma extensa revisão do estado-da-arte da literatura relevante ao contexto do presente trabalho. O objetivo é retratar os limites dessa literatura e facilitar o enquadramento da contribuição desta tese. Em suas duas primeiras seções, esse capítulo caracteriza as principais abordagens de avaliação da qualidade dos dados: a computacional e a mediada por visualizações. A terceira seção confronta e correlaciona as diferentes maneiras de descrição da estrutura dos defeitos nos dados, enquanto a última seção descreve como o conhecimento sobre o projeto de 
sistemas de visualização considera aspectos relativos a avaliação visual da qualidade dos dados.

- O Capítulo 4 reporta uma taxonomia de defeitos relacionados aos critérios de qualidade da acurácia, completude e consistência. A construção dessa taxonomia obedeceu uma metodologia que: revisou a teoria dos bancos de dados relacionais para obter uma cobertura sistemática dos defeitos; estabeleceu a terminologia e nomenclatura alinhadas a área de banco de dados; organizou os defeitos no mesmo nível de abstração; classificou os defeitos segundo as respectivas granularidades de ocorrência e propriedades compartilhadas.

- O Capítulo 5 caracteriza os limites de um conjunto de propriedades relevantes dos sistemas de visualização no apoio a avaliação visual da qualidade dos dados. Tal caracterização é resultado de um estudo de caso exploratório conduzido para compreender a capacidade das referidas propriedades em revelar significados de diferentes defeitos em resoluções crescentes de dados.

- Por fim, o Capítulo 6 sintetiza o presente trabalho e descreve suas principais contribuições, limitações e oportunidades de pesquisa futura.

- O Anexo A apresenta fragmentos do registro das interações ocorridas sobre a ferramenta que apoiou o estudo de caso, bem como do artefato utilizado para registrar os resumos analíticos relativos sobre cada unidade de estudo. 


\section{Capítulo 2}

\section{Fundamentos}

\subsection{Introdução}

Este capítulo aborda os principais fundamentos utilizados no presente trabalho. A primeira parte - Seção 2.2 - caracteriza o processo de avaliação da qualidade dos dados situando seu propósito, seus componentes e conceitos correlatos relevantes, incluindo qualidade, qualidade de dados e critérios de qualidade. Seguindo o propósito do presente trabalho - Seção 1.2 -, os critérios da acuracidade, completude e consistência são discutidos detalhadamente.

A segunda parte - Seção 2.3 - descreve os conceitos e elementos que compõem a disciplina de criar representações visuais e interativas que favoreçam o desempenho de processos cognitivos sobre dados complexos; a visualização de dados. Nessa oportunidade é também discutido o relacionamento entre ramificações da visualização de dados - denominadas de visualização de incertezas e qualidade espacial dos dados - e a qualidade de dados.

Por fim, a Seção 2.4 delineia o funcionamento do processo cognitivo humano e os papéis desempenhados por seus sistemas de percepção visual e de raciocínio. Esse conhecimento é essencial para a compreensão do cerne da visualização de dados.

\subsection{Avaliação da Qualidade dos Dados}

\subsubsection{A Qualidade}

Qualidade remete a um conceito complexo uma vez que sua compreensão é determinada por perspectivas disjuntas. Uma dessas perspectivas denota qualidade como um elemento subjetivo, isto é, reconhecível por um observador embora não definido. Outras perspectivas relacionam qualidade as perspectivas do usuário - adequação a uma finalidade -, do produto - características aferidas do produto - ou ao valor intrínseco percebido por um usuário [English, 1999; Eppler, 2003; Schulmeyer e McManus, 1999]. Em uma perspectiva 
de produção, a ISO 9000 define qualidade como o grau de conformidade das características de um objeto em relação a um conjunto de requisitos [Schulmeyer e McManus, 1999].

\subsubsection{A Qualidade dos Dados}

A qualidade dos dados é uma propriedade que denota o nível de utilidade dos dados para um certo propósito. A incompatibilidade entre o nível de qualidade dos dados requerido e aquele vigente causa impactos ao referido propósito, incluindo a redução do desempenho de processos analíticos [Eppler, 2003], aumento da complexidade na condução de projetos estratégicos - incluindo data warehouse e reengenharia de processos - [English, 1999; Redman e Blanton, 1997] e a distribuição de dados e informações não fidedignas a clientes e parceiros comerciais [Redman e Blanton, 1997].

A deterioração do nível de qualidade decorre dos elementos ${ }^{1}$ que realizam cooperativamente as atividades de aquisição, manutenção, utilização e descarte dos dados [Redman e Blanton, 1997]. O número considerável de combinações entre atividades e elementos estabelecem múltiplas fontes de deterioração dos dados de natureza sistêmica ou randômica [Olson, 2003].

Parte da literatura denota um duplo significado ao termo "qualidade dos dados". Nesses casos, "qualidade dos dados" é utilizada como sinônimo do termo "qualidade da informação". No entanto, tais termos representam assuntos com objetos de qualidade disjuntos, porém complementares [Hu e Feng, 2005; Stvilia et al., 2007].

A qualidade de dados denota o grau de correspondência dos dados - enquanto estrutura e conteúdo - ao Universo de Discurso - UdD. Em contraste, a qualidade da informação representa o grau de satisfação na qual a informação é percebida por, acessada por ou representada para um público-alvo [Fox et al., 1994; Hu e Feng, 2005; Lee et al., 2009; Redman e Blanton, 1997; Stvilia et al., 2007]. Tais definições explicitam que a qualidade dos dados não é condição suficiente para garantir a qualidade da informação. O presente trabalho está alinhado a definição de qualidade de dados supracitada.

\subsubsection{O Processo de Avaliação da Qualidade dos Dados}

O propósito do processo de Avaliação da Qualidade dos Dados - pAQD - é prover um diagnóstico preciso da qualidade corrente dos dados. Esse diagnóstico é um insumo relevante para a realização das etapas envolvidas com a melhoria da qualidade dos dados [Lee et al., 2009; Loshin, 2010].

A melhoria da qualidade apresenta duas estratégias principais, quais sejam a orientada a conteúdo e a orientada a processos. A motivação da primeira estratégia é corrigir os dados defeituosos sem atuar sobre as origens dos defeitos [Lee et al., 2009; Redman et al., 2011]. Em contraste, a estratégia orientada a processo atua no redesenho dos elementos do ciclo

\footnotetext{
${ }^{1} \mathrm{O}$ software, o hardware, os processos de trabalho e os agentes humanos [Redman e Blanton, 1997].
} 
de vida dos dados que provocam os defeitos, bem como promove a organização de pessoas e demais recursos em favor da melhoria contínua da qualidade dos dados [Batini et al. , 2009; Redman et al., 2011].

A Figura 2.1 ilustra as três atividades sequenciais do pAQD. A primeira atividade é responsável por planejar e definir a forma e o escopo da avaliação dos dados, enquanto a segunda representa o ato de avaliar a qualidade propriamente dito. O papel da última etapa é sintetizar e publicar os resultados da avaliação na forma de um mapa informacional da qualidade dos dados com métricas e descrições que retratem o nível de qualidade e a lista dos defeitos identificados.

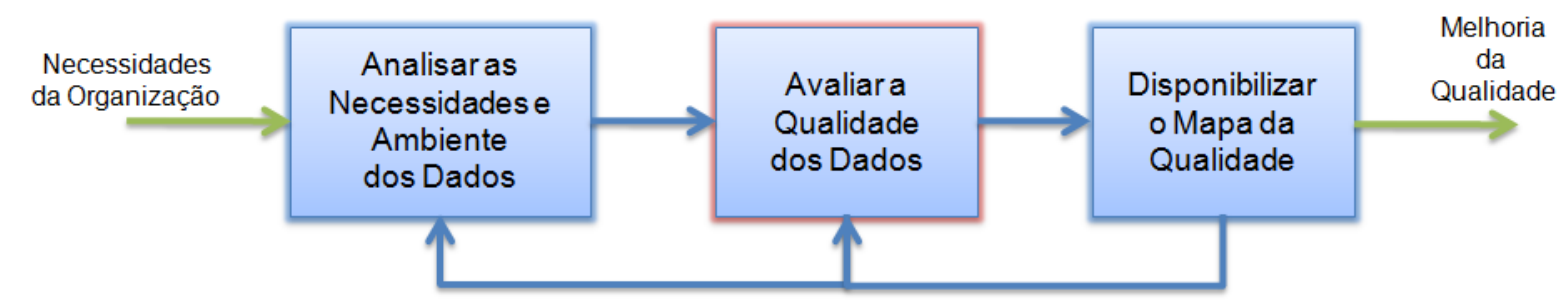

Figura 2.1: O Processo de Avaliação da Qualidade dos Dados (Fonte: Elaborado pelo autor)

A atividade de avaliar a qualidade dos dados envolve as tarefas de compreender integralmente a estrutura dos defeitos alvos, identificar tais estruturas nos dados e diagnosticar os casos identificados. Assim, essa atividade pode ser representada como uma função não bijetora de análise $\mathcal{Q}$ que mapeia as divergências $D$ entre os fatos sobre objetos de um universo de discurso $N$ e as correspondentes representações em um banco de dados $B$, denotado por $\mathcal{Q}: B \times N \rightarrow D$. Essa função explicita que o conhecimento acerca da estrutura de um defeito determina a forma de sua detecção e análise [Lee et al., 2009; Smith, 1998].

A seguir, as Seções 2.2.3.1 e 2.2.3.2 caracterizam os fatores e as perspectivas de avaliação dos dados que determinam aspectos operacionais do pAQD. Já a Seção 2.2.3.3 conceitua o objeto de interesse do pAQD considerando o escopo do presente trabalho: defeitos no conteúdo dos dados - ver Quadro 2.1.

\subsubsection{Fatores de Influência}

O pAQD é oneroso e exige a prévia análise - Figura 2.1 - dos fatores provenientes das necessidades organizacionais e das características dos dados [Lee et al., 2009; Loshin, 2010]. O fator humano também é outro elemento relevante a medida que a personalidade e o conhecimento das pessoas tem efeito sobre a avaliação dos dados [Klein et al., 1997; Lee, 2003; Smith, 1998]. Reunidos, esses fatores influenciam como, quando e quais dados serão avaliados, sendo os principais delineados a seguir.

- A Dimensionalidade e a Resolução dos Dados

Essas características dos dados estabelecem restrições práticas ao universo de da- 
dos considerados, sendo agravadas pelo tempo disponível para avaliação. Desse modo, ambientes constituídos por relações com grande número de tuplas e atributos impõem a necessária determinação das regiões de dados ${ }^{2}$ com e sem monitoramento constante da qualidade.

\section{- Acessibilidade e Gestão de Fontes de Dados Distribuídas}

Dados distribuídos e administração independente representa uma realidade para diferentes organizações. A distribuição aumenta o esforço da avaliação uma vez que dificulta a reunião dos dados para evidenciar defeitos, tais como tuplas duplicadas. Por sua vez, a gestão autônoma das unidades distribuídas possibilita uma acentuada variação na qualidade dos dados e dos respectivos metadados [Naumann, 2002].

\section{- O Momento da Avaliação dos Dados}

O momento de avaliação denota um ou mais instantes no tempo no qual diferentes regiões dos dados estão adequadas para avaliação. Determinar esses instantes requer conhecimentos sobre os processos de trabalho e os sistemas de informação que manipulam as regiões de dados de interesse [English, 1999].

\section{- Múltiplas Formas de Avaliação da Qualidade}

Os critérios de qualidade - Seção 2.2.3.2 - determinam múltiplas perspectivas de observação dos dados cujas especificidades demandam abordagens heterogêneas de avaliação. Enquanto certas perspectivas são objetivas e candidatas a automação consistência dos dados, por exemplo -, outras dependem do público-alvo e envolvem o uso de técnicas não determinísticas, tais como entrevistas e questionários [Klein et al., 1997; Lee et al., 2009; Loshin, 2010].

\section{- Facilidade de Evolução}

A renovação dos cenários de negócio ou dos aparatos tecnológicos pressionam o pAQD a incorporar essa nova realidade [Dasu e Johnson, 2003; Naumann, 2002]. Utilização de novos tipos de dados - incluindo áudio, imagem, documentos texto -, novas abordagem de distribuição dos dados, aumento súbito do volume de dados e fusão entre organizações representam alguns dos exemplos de mudanças que impactam o pAQD.

\section{- Conhecimento do Contexto dos Dados}

O contexto representa uma camada semântica que relaciona os dados e as unidades organizacionais, como áreas funcionais ou células de negócio [Bertossi et al. , 2011; Jiang et al., 2008; Lee, 2003]. Essa camada denota significados que variam conforme a unidade organizacional, incluindo o objetivo de captura e uso dos dados e a semântica dos dados a partir das perspectivas do produtor e consumidor. Assim,

\footnotetext{
${ }^{2}$ Uma região de dados denota uma porção do conjunto ou espaço total dos dados disponíveis.
} 
o contexto pode ser expresso como uma função bijetora $\mathcal{F}$ que explica aos dados $D$ em uma unidade organizacional $U$ por meio de um significado $S, \mathcal{F}: D \times U \longrightarrow S$. Na prática, o contexto é um elemento implícito do pAQD que corrobora a incapacidade de determinar defeitos com base exclusiva nos dados [Bertossi et al., 2011; Dasu, 2013; Jiang et al., 2008; Lee et al., 2009]. A ausência do contexto impede a avaliação dos dados a partir dos significados estabelecidos pelas unidades organizacionais. A dependência do pAQD em relação ao contexto dos dados ressalta a importância da distinção semântica humana para confirmar ou refutar a presença de defeitos nos dados [Dasu, 2013; Kandel et al., 2012b; Kim et al., 2003; Olson , 2003].

\section{- Disparidade de Relevância}

O nível de severidade dos defeitos não é uniforme entre diferentes regiões dos dados [Dasu, 2013; Loshin, 2010]. Naturalmente, as unidades organizacionais podem estabelecer níveis de relevância distintos para regiões de dados de comum interesse [Lee et al., 2009; Loshin, 2010; Redman e Blanton, 1997]. Essa situação impõe a tarefa $^{3}$ não trivial de consolidar uma lista priorizada com os critérios de qualidades e demais componentes - Seção 2.2.3.2.

\section{- Motivação}

O desempenho da avaliação da qualidade dos dados também está relacionado ao comportamento dos indivíduos envolvidos [Klein, 2001; Klein et al., 1997]. Assim, diferentes instrumentos motivacionais podem ser aplicados para manter o valor crítico dos indivíduos em prol da avaliação da qualidade dos dados [Mueller e Coppoolse , 2013] e modificar comportamentos [Klein et al., 1997; Smith, 1998].

\subsubsection{Critérios de Qualidade}

Os critérios de qualidade representam as diferentes perspectivas de avaliação dos dados ou informações, salientando a natureza multidimensional do pAQD. Cada critério reúne um conjunto de propriedades que especifica os tópicos de qualidade definidos pelas unidades organizacionais. Essas propriedades podem ser quantificadas por meio de métricas associadas a determinados limites de conformidade. Reunidos, tais componentes estabelecem um mapa de referência para o monitoramento da qualidade e a gestão dos dados como um ativo [Lee et al., 2009; Loshin, 2010]. A Figura 2.2 ilustra o relacionamento dos conceitos supracitados, enquanto a Tabela 2.1 provê uma instância desse relacionamento.

A literatura provê vários trabalhos que definem e classificam os critérios de qualidade por abordagens distintas [Scannapieco e Catarci, 2002]. A abordagem teórica utiliza o

\footnotetext{
${ }^{3}$ As abordagens de [Loshin, 2010] e [Redman e Blanton, 1997] sistematizam o levantamento e a organização das necessidades possivelmente díspares de múltiplos consumidores de dados.
} 


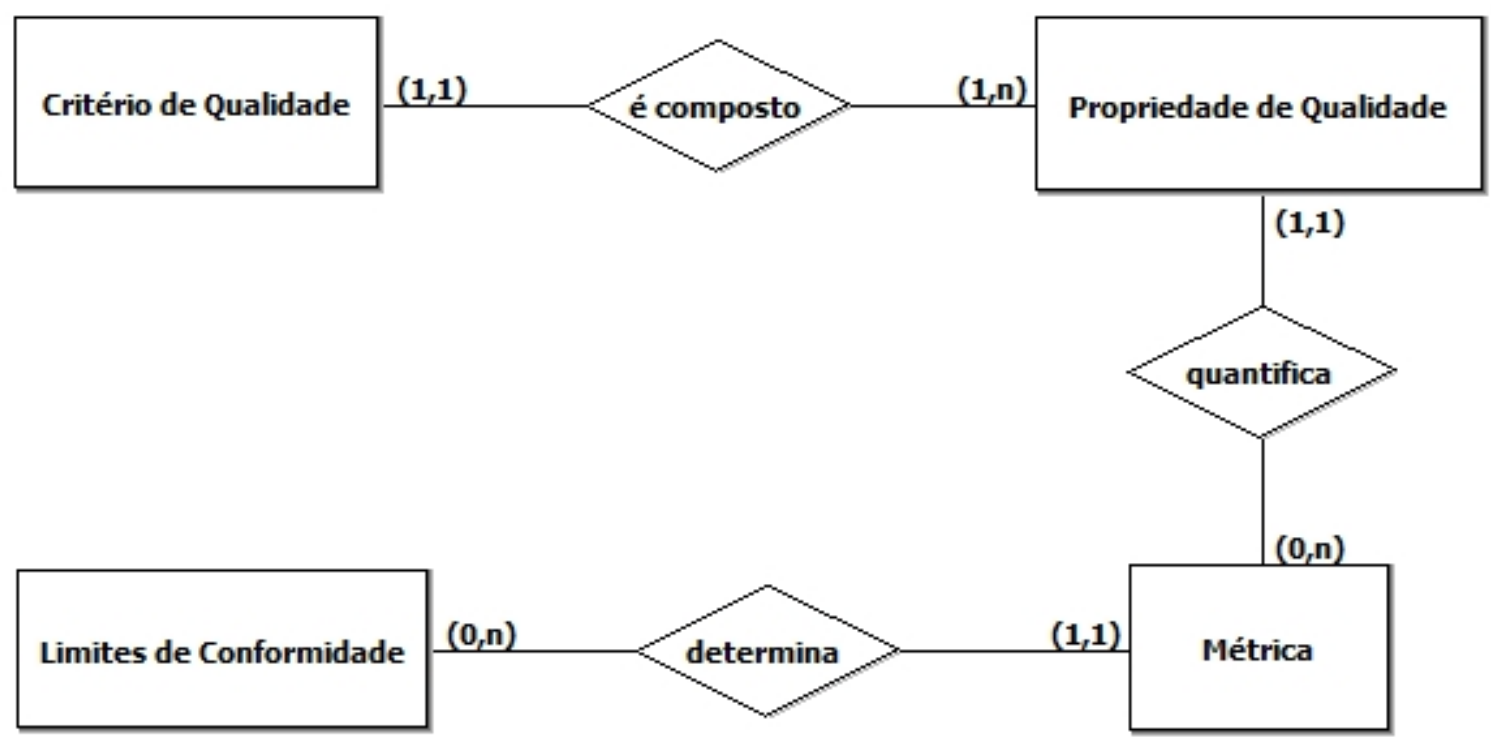

Figura 2.2: Arcabouço de Componentes dos Critérios de Qualidade (Fonte: Elaborado pelo autor)

\begin{tabular}{llll}
\hline Critério & Propriedade & Métrica & $\begin{array}{l}\text { Limite de } \\
\text { Conformidade }\end{array}$ \\
\hline Completude & $\cdot$ Densidade de ocupação dos & $\cdot$ Atributos críticos Nulos & $\cdot 0 \%$ das tuplas \\
& atributos da relação $X$ & $\cdot$ Atributos secundários Nulos & $\cdot 3 \%$ das tuplas \\
\hline Consistência & $\cdot$ Densidade de & $\cdot$ Violação de Participações & $\cdot 0 \%$ das relações \\
& $\begin{array}{l}\text { relacionamentos nas } \\
\text { relações do assunto de }\end{array}$ & $\cdot$ Referências Incorretas & $\cdot 2 \%$ das relações \\
& negócio Financeiro & & \\
\hline
\end{tabular}

Tabela 2.1: Instância de certos Critérios de Qualidade (Fonte: Adaptado de [Loshin, 2010])

apoio de um modelo formal para definir os critérios [Wand e Wang, 1996], enquanto a empírica apresenta resultados a partir de experimentos e entrevistas [Jarke et al., 1999; Wang e Strong, 1996]. Ainda, a abordagem intuitiva estabelece as definições de acordo com o senso comum da comunidade de qualidade [Bovee et al., 2003; English, 1999; Eppler, 2003; Mosley et al., 2010; Naumann, 2002; Redman e Blanton, 1997].

A Tabela 2.2 ilustra um subconjunto dos principais critérios de qualidade definidos por trabalhos relevantes das abordagens supracitadas. Apesar das diferenças entre as definições, esses trabalhos compartilham dois modos de classificar os critérios de qualidade. O primeiro estabelece o objeto alvo do critério de qualidade, quais sejam os dados ou as informações [Scannapieco e Catarci, 2002], visão essa alinhada a percepção deste trabalho - Seção 2.2.2. O segundo modo classifica os critérios de acordo com o aspecto da qualidade a ser avaliado, conforme definição a seguir. O Quadro 2.1 representa a aplicação das referidas classificações sobre os critérios de qualidade listados na Tabela 2.2.

i. Conteúdo: Critérios de qualidade cujas propriedades endereçam os conteúdos dos dados; 
ii. Estrutura: Critérios de qualidade cujas propriedades endereçam as estruturas dos dados e metadados correspondentes;

iii. Contexto: Critérios de qualidade cujas propriedades endereçam a visão particular e contextualizada dos diferentes públicos que utilizam as informações em suas atividades;

iv. Processo: Critérios de qualidade cujas propriedades endereçam o processo de disponibilização das informações que variam conforme tempo e contexto.

\begin{tabular}{|c|c|c|c|c|c|c|c|c|c|}
\hline Critérios de Qualidade & 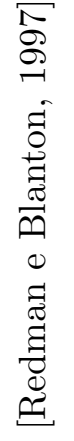 & 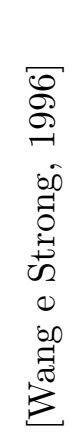 & 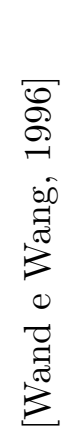 & 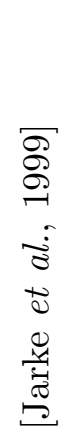 & 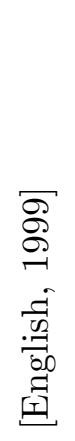 & 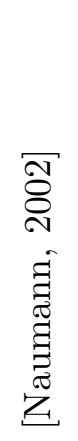 & 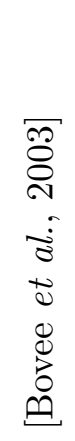 & 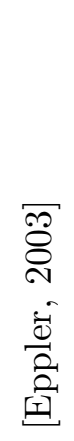 & 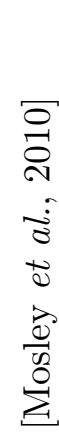 \\
\hline Acessibilidade & $\bullet$ & $\bullet$ & & & $\bullet$ & & $\bullet$ & $\bullet$ & \\
\hline Acuracidade & $\bullet$ & $\bullet$ & $\bullet$ & $\bullet$ & $\bullet$ & $\bullet$ & $\bullet$ & $\bullet$ & $\bullet$ \\
\hline Completude & $\bullet$ & $\bullet$ & $\bullet$ & & $\bullet$ & $\bullet$ & $\bullet$ & $\bullet$ & $\bullet$ \\
\hline Consistência & $\bullet$ & $\bullet$ & $\bullet$ & $\bullet$ & & $\bullet$ & $\bullet$ & $\bullet$ & $\bullet$ \\
\hline Credibilidade & & $\bullet$ & & $\bullet$ & & & $\bullet$ & & \\
\hline Definição em Conformidade & - & & & $\bullet$ & $\bullet$ & & & & \\
\hline Desempenho (Eficiência) & & $\bullet$ & $\bullet$ & $\bullet$ & $\bullet$ & $\bullet$ & $\bullet$ & $\bullet$ & \\
\hline Disponibilidade (Confiança) & & $\bullet$ & $\bullet$ & & & & & $\bullet$ & \\
\hline Facilidade de Compreensão & $\bullet$ & $\bullet$ & & & & $\bullet$ & $\bullet$ & $\bullet$ & $\bullet$ \\
\hline Flexibilidade & $\bullet$ & & & & & & & $\bullet$ & \\
\hline Precisão (Granularidade) & $\bullet$ & $\bullet$ & $\bullet$ & $\bullet$ & $\bullet$ & $\bullet$ & $\bullet$ & $\bullet$ & \\
\hline Precisão (Domínio) & $\bullet$ & & & & & & & & $\bullet$ \\
\hline Relativas ao Tempo & $\bullet$ & - & - & $\bullet$ & - & - & $\bullet$ & - & $\bullet$ \\
\hline Relevância & & $\bullet$ & $\bullet$ & $\bullet$ & & $\bullet$ & $\bullet$ & $\bullet$ & \\
\hline Reputação & & $\bullet$ & $\bullet$ & $\bullet$ & & & $\bullet$ & & \\
\hline Segurança & & $\bullet$ & & $\bullet$ & & $\bullet$ & $\bullet$ & $\bullet$ & $\bullet$ \\
\hline Volume de Informação & & $\bullet$ & & & & & $\bullet$ & & \\
\hline
\end{tabular}

Tabela 2.2: Subconjunto dos principais Critérios de Qualidade (Fonte: Elaborado pelo autor)

Seguindo o propósito do presente trabalho - Seção 1.2 -, a seguir são definidos os critérios de qualidade do entroncamento entre qualidade dos dados e conteúdo, quais sejam acuracidade, consistência e completude. As definições refletem a visão compartilhada dos significados extraídos dos trabalhos analisados - Tabela 2.2 -, apesar das variações existentes. Vale ressaltar que o objetivo não é esgotar o tema ou mesmo contrastar as diferentes definições de modo a obter uma conceituação definitiva. 


\begin{tabular}{|c|c|c|c|}
\hline \multicolumn{2}{|c|}{ Qualidade da Informação } & \multicolumn{2}{|c|}{ Qualidade dos Dados } \\
\hline Contexto & $\begin{array}{c}\text { Credibilidade } \\
\text { Relevância } \\
\text { Reputação } \\
\text { Relativas ao Tempo } \\
\text { Facilidade de Compreensão } \\
\text { Volume de Informação } \\
\text { Precisão (Granularidade) }\end{array}$ & $\begin{array}{l}\text { Acuracidade } \\
\text { Completude } \\
\text { Consistência }\end{array}$ & Conteúdo \\
\hline Processo & $\begin{array}{c}\text { Acessibilidade } \\
\text { Desempenho (Eficiência) } \\
\text { Segurança } \\
\text { Disponibilidade (Confiança) }\end{array}$ & $\begin{array}{c}\text { Precisão (Domínio) } \\
\text { Flexibilidade } \\
\text { Definição em Conformidade }\end{array}$ & Estrutura \\
\hline
\end{tabular}

Quadro 2.1: Critérios de Qualidade classificados por Aspecto e Objeto Alvo (Fonte: Elaborado pelo autor)

\section{- Acuracidade}

Não existe uma definição consensuada para acuracidade [Scannapieco e Catarci , 2002]. Tal critério é observado por [Wang e Strong, 1996] como "a medida na qual os dados estão corretos, confiáveis e certificados". Essa definição é ampliada com o conceito de que um valor é denominado livre de defeito com base em valores previamente conhecidos ou designados [Eppler, 2003]. Uma perspectiva mais técnica aborda a acuracidade como uma medida de proximidade entre um valor $v$ e um valor considerado correto $v^{\prime}$ [Redman e Blanton, 1997].

Com base nessas e outras definições - [Mosley et al., 2010; Scannapieco e Catarci , 2002] -, este trabalho define acuracidade como o grau de fidelidade de um valor representado em uma relação ao respectivo valor do mundo real ou a um valor de referência estabelecido em sua definição - situação onde a contraposição ao valor real é inviável ou impossível [Batini et al., 2009; Fox et al., 1994; Wand e Wang, 1996].

\section{- Consistência}

Com uma definição mais consensuada, esse critério denota a não violação das regras e restrições impostas a um conjunto de dados para satisfazer as necessidades de um UdD - definição assumida neste trabalho. Porém, certos trabalhos estendem essa definição de modo a abranger aspectos de qualidade relativos à estrutura e o contexto [Naumann, 2002; Redman e Blanton, 1997; Wang e Strong, 1996].

\section{- Completude}

As definições de completude variam de acordo com a perspectiva adotada. Certos trabalhos adotam a visão específica de um domínio de aplicação, tais como o percentual de dados incorporados a um data warehouse [Jarke et al., 1999] e a capacidade de um sistema de informação em representar os estados do mundo real 
[Wand e Wang, 1996]. Ainda, outros trabalhos utilizam um ponto de vista processual e expressam completude como a suficiência de dados para realizar uma atividade [Wang e Strong, 1996] ou como a presença de valores para todos os atributos requeridos para um conjunto de dados [Bovee et al., 2003; Mosley et al., 2010; Naumann , 2002; Redman e Blanton, 1997]. Apoiado pelas definições acima, o critério completude indica o grau de representação dos dados de uma relação em referência aos respectivos fatos dos objetos de um UdD. Quanto maior for o grau de representação de uma relação, mais completa é a representação dos objetos de um UdD.

\subsubsection{Defeitos de Conteúdo dos Dados}

Defeitos de conteúdo estão relacionados com discrepâncias entre os valores correntes representados em um banco de dados e os valores do UdD correspondentes. Cada defeito possui uma estrutura particular que retrata o perfil do problema nos dados e pode apresentar mais do que uma variante de manifestação. No entanto, os defeitos compartilham certas propriedades que exprimem a complexidade da avaliação da qualidade dos dados. Tais propriedades são implícitas e intuitivas para a literatura de qualidade de dados, muito embora não sejam retratadas explicitamente como segue.

A primeira propriedade remete a complexa relação entre os defeitos [Berti-Equille et al. , 2015]. Defeitos estão presentes em diferentes granularidades de um banco de dados, quais sejam valor de atributo, atributo como um todo, tupla, relação e inter-relações. A ocorrência simultânea de certos defeitos nos dados pode induzir a uma reação em cadeia, conforme ilustrado na Figura 2.3. Por exemplo, a violação de uma regra semântica pode decorrer da transgressão da restrição de domínio imposta a um dos atributos que compõem a referida regra.

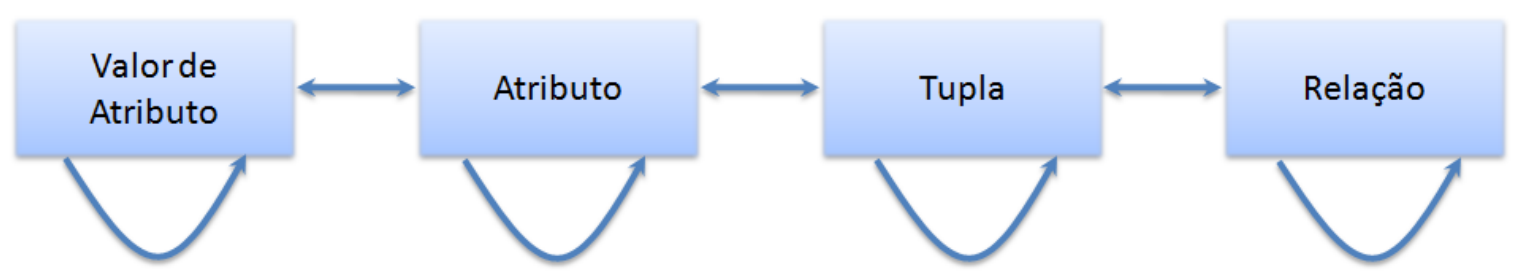

Figura 2.3: Cadeia de impacto entre defeitos em diferentes granularidades (Fonte: Elaborado pelo autor)

Contudo, a noção de cadeia de impacto não garante que a solução de um defeito "pai" será necessariamente propagada para o defeito "filho". A cadeia de defeitos não explicita o fato de que certos defeitos podem mascarar a presença de outros defeitos. Logo, a avaliação separada dos defeitos é mais segura [Schmid, 2005]. Considerando o exemplo anterior, uma tupla pode ser avaliada como atípica mesmo após a correção dos defeitos de violação de regra semântica e de restrição de domínio - Seção 4.4.

A segunda propriedade remete ao nível de supervisão humana para detectar um defeito. Conforme já abordado, a supervisão humana é necessária para detectar qualquer 
defeito nos dados uma vez que o pAQD depende do conhecimento do contexto dos dados - Seção 2.2.3.1. No entanto, a intensidade dessa supervisão apresenta níveis distintos. Avaliar defeitos nos dados compreende os estágios de definir o que detectar, o ato de detectar e analisar os casos suspeitos - Seção 2.2.3. Baseado nessas características, os defeitos nos dados podem ser empiricamente divididos entre aqueles que demandam alta ou baixa-moderada supervisão humana. O primeiro especifica um grupo de defeitos que exige o pleno conhecimento do contexto dos dados combinado a distinção semântica para desempenhar todos os três estágios de avaliação. Em contraste, o segundo denota defeitos que demandam uma menor supervisão humana para algum dos estágios de avaliação.

Defeitos ainda denotam diferentes modos de perturbação nas operações de utilização dos dados, a terceira propriedade. Alguns defeitos causam inconsistências que obstruem ou limitam a realização dessas operações, como aqueles defeitos relativos a violações de restrições. Em contrapartida, outros defeitos são mais "tolerados" por não reprimirem tais operações em razão de provocarem inconsistências menos óbvia, tais como valores homônimos e imprecisos.

A última propriedade reflete que os defeitos não são estáticos e acompanham a natureza dinâmica dos dados. Banco de dados continuamente transacionam sobre os dados e podem provocar a mutação dos defeitos ou a dificuldade em determinar as causas dos defeitos. Como exemplo, no estado $e_{1}$, um dos atributos da relação $R$ possui uma ocorrência sem conteúdo. Após sofrer uma transação $t$, a relação $R$ passa ao estado $e_{2}$ na qual a referida ocorrência apresenta um conteúdo, embora incorreto.

\subsection{A Visualização de Dados}

\subsubsection{A Área de Pesquisa}

A visualização de dados é uma área de pesquisa cujo objetivo é produzir representações visuais interativas que favoreçam a análise de dados complexos [Card et al., 1999; Patterson et al., 2014; Ware, 2004]. O objetivo dessa ciência é combinar de modo efetivo a capacidade dos recursos computacionais a habilidade inata de detecção de padrões e distinções semânticas dos seres humanos para beneficiar o desempenho de processos cognitivos, incluindo a resolução de problemas [Matlin, 2009] e a compreensão de características e defeitos dos dados [Malik e Unwin, 2012; Smith, 1998; Thomas e Cook, 2005; Ware, 2004]. Dentre as formas de benefício aos processos cognitivos estão:

- Utilização de propriedades visuais que favoreçam o monitoramento de múltiplos eventos [Card et al., 1999];

- Organização visual dos dados de modo a facilitar a busca e extração de padrões, relacionamentos ou mesmo informações elementares [Hegarty, 2011; Patterson et al., 
2014; Ware, 2010];

- Representação de grandes volumes de dados combinada a capacidade de interagir com granularidades e perspectivas distintas [Card et al., 1999; Hegarty, 2011]. Ambos elementos liberam a mente humana para outros aspectos do processamento cognitivo.

A natureza da visualização de dados é multidisciplinar, integrando contribuições provenientes da ciência da computação, psicologia cognitiva, matemática, computação gráfica e interface homem-computador. Essa área apresenta ramificações que abordam dados com referência geométrica inerente - Visualização Científica -, dados desprovidos de mapeamento espacial óbvio - Visualização de Informação - e dados incertos - Visualização de Incertezas.

\subsubsection{A Visualização e a Qualidade de Dados}

A exposição dos dados adjacente as suas imperfeições representa uma questão de reconhecida importância na área de visualização de dados. Tal relevância decorre da necessária consciência sobre tais situações de modo a reduzir os impactos negativos sobre os resultados dos processos analíticos. Referenciada na literatura como Visualização de Incertezas do inglês Uncertainty Visualization -, esse ramo da visualização de dados provê modelos e classificações para a adequada comunicação das incertezas estatisticamente quantificadas [Potter et al., 2012].

O termo incerteza é cercado de definições não consensuadas que abrangem denominações como dúvida, imprecisão, acentuada variação estatística, imperfeição da representação visual, dado incompleto, dentre outras elencadas nos trabalhos de [Potter et al. , 2012], [Skeels et al., 2010] e [Correa et al., 2009]. Essa situação dificulta correlacionar quais critérios de qualidade de dados - Seção 2.2.3.2 - apresentam relação ao termo incerteza.

A literatura provê certas classificações de incerteza que auxiliam na referida correlação. Uma notória classificação estabelece cinco classes para rotular as noções de incerteza, incluindo a classe "Completude" que congrega os casos de dados ausentes e defeituosos [Skeels et al., 2010]. Uma segunda abordagem secciona as incertezas entre as epistêmicas - variabilidade estatística e valores incorretos - e as aleatórias [Potter et al., 2012]. Outra ainda categoriza os trabalhos relacionados a visualização da incerteza entre aqueles que tratam de modelagem matemática da incerteza ou da propagação da incerteza no processo de visualização [Correa et al., 2009].

Contudo, é a Qualidade de Dados Espacial - Spatial Data Quality - que proporciona a melhor classificação devido ao pioneirismo no trato das incertezas [Gahegan, 1999; Gahegan e Ehlers, 2000; MacEachren et al., 2005]. Esse importante ramo da comunidade 
de Sistemas de Informação Geográfica provê diferentes conhecimentos que habilitam o acesso a dados espaciais descritos por métricas de qualidade. Uma relevante referência define um conjunto de categorias de "qualidade dos dados" que devem estar presentes nos dados e metadados cartográficos [Thomson et al., 2005]. Desse conjunto, certas categorias - como completeness, logical completeness e positional accuracy - apresentam maior proximidade aos critérios de acuracidade, completude e consistência discutidos na Seção 2.2.3.2.

Importante ressaltar que ambos os ramos supracitados abordam a qualidade em dados com referências físicas e temporais, tais como aqueles relacionados a mapas cartográficos ou visualizações tridimensionais de dados genômicos. No entanto, o presente trabalho aborda dados desprovidos de mapeamento espacial - vendas, faturamento, conta corrente, por exemplo - persistidos em bancos de dados relacionais.

\subsubsection{O Processo de Visualização de Dados}

Criar representações visuais envolve aplicar múltiplas transformações sobre os dados brutos com a participação humana. A visão por processo provê um modelo que favorece determinar tais transformações, organizar as respectivas interdependências e representar o envolvimento do agente humano [Telea, 2008]. Além disso, essa visão proporciona uma descrição conceitual da estrutura arquitetural de um sistema de visualização de dados.

A Figura 2.4 apresenta um modelo de processo de visualização de dados considerando as proposições intercomplementares dos trabalhos de [Upson et al., 1989], [Card et al. , 1999] e [Telea, 2008]. O papel de cada transformação é resumido a seguir.

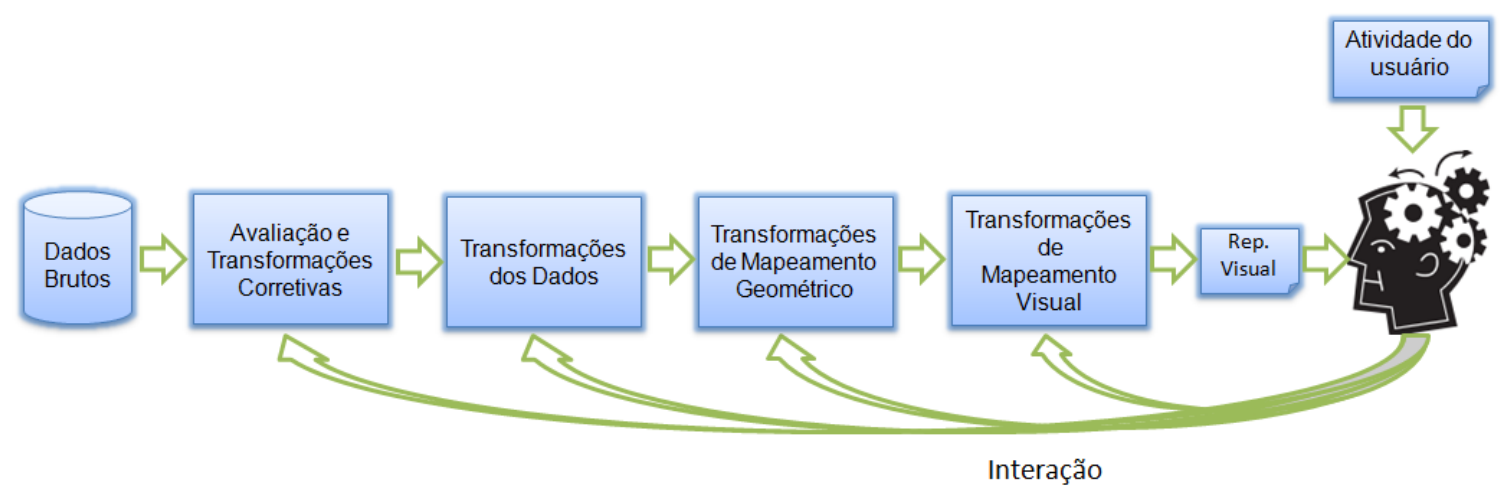

Figura 2.4: Modelo de Processo de Visualização de Dados

(Fonte: Elaborado pelo autor)

- Avaliação e Transformações Corretivas

O processo de visualização tem início com a importação de dados brutos provenientes de múltiplas fontes de dados. Essa operação implica na conversão dos diferentes formatos de armazenamento para um formato destino à medida que preserva as 
características dos dados. Técnicas de imputação de dados, de resolução de duplicados e mecanismos supervisionados de correção dos dados representam as principais operações realizadas nessa transformação.

\section{- Transformações dos Dados}

Com os dados disponíveis, essa transformação denota as operações que moldam os dados a conveniência de uma necessidade de análise. Operações de seleção e agregação restringem o volume de dados a ser representado. De outra maneira, técnicas de redução de dimensionalidade formatam conjuntos de atributos em estruturas mais simples que preservam certas propriedades originais de seus dados. Mineração de dados, normalização e discretização correspondem a outras operações mais comumente aplicadas nessa transformação.

\section{- Transformações de Mapeamento Geométrico}

Essa transformação mapeia os dados de interesse para propriedades visuais - forma, posição, por exemplo - codificando o aspecto geométrico de uma visualização preliminar, conforme ilustrado na Figura 2.5. As propriedades utilizadas dependem das características dos dados e da técnica de visualização - Seção 2.3.4.2 - utilizados.
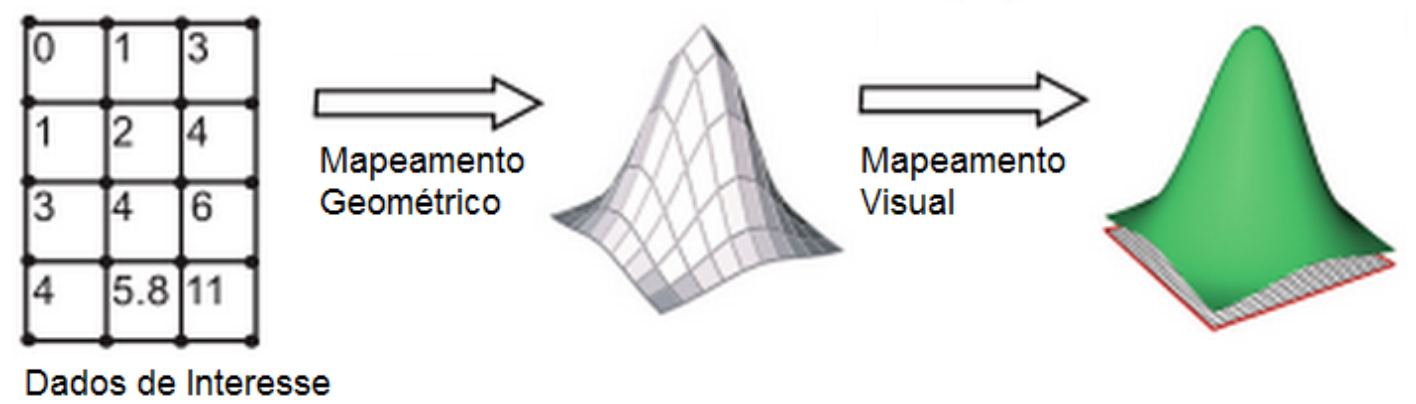

Figura 2.5: Transformações de Mapeamento Geométrico e Visual (Adaptado de [Telea, 2008])

\section{- Transformações de Mapeamento Visual}

O mapeamento visual - ou rendering - aplica técnicas de computação gráfica sobre a imagem preliminar criada pelo mapeamento geométrico para acrescentar propriedades visuais relacionadas a textura, a sombra e a luz [Telea, 2008]. Essa transformação resulta na representação visual final - Figura 2.5 à esquerda - sob a qual um agente humano pode interagir e realimentar o processo de visualização.

\section{- Tarefas ou Atividades do Usuário}

Ao interagir com um sistema de visualização, o agente humano parte de um conjunto de atividades definidas para analisar os dados [Andrienko e Andrienko, 2006], como no caso da análise visual da qualidade dos dados. A natureza dessas atividades é relevante à medida que afeta o modo pelo qual um agente humano percebe e interage 
com os dados [Jun et al., 2011; Sedig et al., 2014; Yi et al., 2007, 2008], conforme será explorado na Seção 2.4.3.

O modelo de sessão estende a visão do modelo baseado em transformações ao destacar as interações [Jankun-Kelly et al., 2002]. Nesse modelo, uma sessão $S$ denota uma representação visual em um novo estado após uma interação $I$ que aplica um conjunto de parâmetros $P$, denotado por $I=\left\{P_{1}, P_{2}, \ldots, P_{k}\right\}, k \geqslant 1$. A Figura 2.6 ilustra o relacionamento entre os modelos de transformação e sessão, destacando que a repetição das interações cria um conjunto de sessões $S_{n}=\left\{S_{1}, S_{2}, \ldots, S_{n}\right\}, n \geqslant 1$.

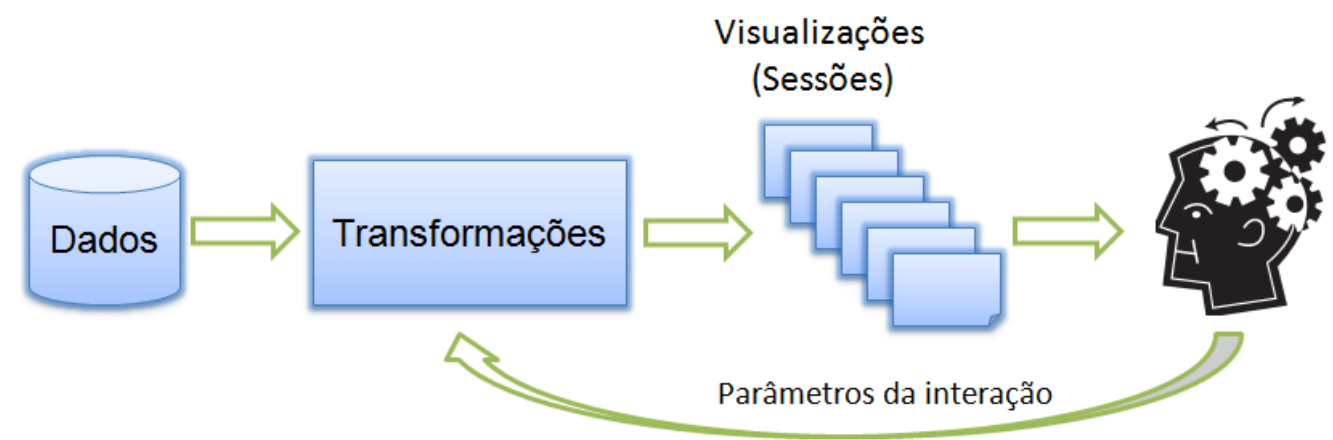

Figura 2.6: Modelos de Transformação e Sessão do Processo de Visualização de Dados (Fonte: Elaborado pelo autor)

\subsubsection{Sistema de Visualização de Dados}

Um sistema de visualização de dados incorpora um conjunto de capacidades em resposta as necessidades de um domínio de problema. Essas capacidades são derivadas da integração apropriada de abordagens computacionais, técnicas de pré-processamento, de interação e de visualização [Keim et al., 2010] delineados conceitualmente na Seção 2.3.3. Técnicas de pré-processamento atuam nas transformações relacionadas a disponibilização e correção dos dados, enquanto as abordagens computacionais denotam métodos analíticos de investigação dos dados - mineração de dados, por exemplo. Relevantes para o presente trabalho, as técnicas de interação e visualização são descritas a seguir, nessa ordem.

\subsubsection{Técnicas de Interação}

Visualização de dados estáticos restringe o número de questões que pode sanar, pois é incapaz de atender as novas indagações inerentes aos processos cognitivos de análise e exploração dos dados [Dix e Ellis, 1998; Ware, 2004]. As técnicas de interação são mecanismos que alavancam a percepção e interpretação visual dos dados por meio da modificação dinâmica da representação visual conforme a necessidade [Jun et al., 2011; Keim, 2002; Thomas e Cook, 2005]. Em outras palavras, a modificação dinâmica propicia a um agente 


\begin{tabular}{ll}
\hline Principal Intenção & Técnica de Interação \\
\hline Abstração Visual dos Dados & Aproximação \\
& Detalhes sob Demanda \\
\hline Aparência Visual & Definição Escala de Cores \\
& Modificação da Densidade \\
& Modificação da Opacidade \\
& Modificação do tamanho do glifo (como ponto ou linha) \\
& Troca de Técnica de Visualização \\
\hline Arranjo Espacial & Arranjo de Atributos \\
& Distorção Espacial \\
& Redimensionar \\
& Reformular \\
& Rotação \\
& Ordenação \\
& Treliça \\
\hline Colaboração & Compartilhamento de Resultados \\
\hline Conexão & Seleç̃ão e Ligação \\
& Visões Concorrentes Múltiplas \\
\hline Limpeza & Correção de Dados \\
\hline Navegação nos Dados & Animação \\
& Derivação \\
& Foco e Contexto \\
& Direct-Walk \\
\hline Proveniência & Anotação \\
\hline Realce & Histórico \\
\hline Simplificar Dados & Seleção e Destaque \\
& Agregação dos dados \\
\hline
\end{tabular}

Tabela 2.3: Técnicas de interação agrupadas pela principal intenção do agente humano (Fonte: Elaborado pelo autor)

humano obter introspecções, gerar novas questões ou hipóteses e continuar a explorar os dados.

Além de propiciar o diálogo entre o agente humano e os dados, certas técnicas de interação possibilitam a análise e a resolução de problemas de modo colaborativo, bem como a compreensão do próprio processo analítico [Silva et al., 2007]. Denominadas de proveniência analítica, essas técnicas recolhem informações acerca das interações e permitem o agente humano registrar introspecções sobre uma representação visual inteira ou itens de dados particulares.

A Tabela 2.3 elenca as técnicas de interação frequentemente citadas na literatura [Dix e Ellis, 1998; Ellis e Dix, 2007; Heer e Shneiderman, 2012; Keim, 2002; Shneiderman, 1996; Ware, 2004; Yi et al., 2007] organizadas segundo a principal intenção ${ }^{4}$ do agente humano. Os princípios funcionais das técnicas de interação mais relevantes são apresentados a seguir.

\section{- Anotação}

Durante o processo da análise, as visualizações de dados podem suscitar variadas in-

\footnotetext{
${ }^{4}$ Certas técnicas podem evidenciar múltiplas intenções devido suas características [Yi et al., 2007]
} 
trospecções cujas investigações podem ser postergadas ou compartilhadas. As introspecções representam ideias, conclusões, suspeitas, contextos de negócio, dentre outros. Técnicas de anotação permitem vincular tais informações a uma representação visual como um todo ou a dados específicos de modo textual ou gráfico-textual.

Na Figura 2.7, a porção (e) ilustra a anotação textual ancorada na representação visual, enquanto a porção $(a)$ demonstra várias anotações gráfica sobre dados particulares da visualização. O vínculo dados-introspecção estabelecido pela anotação gráfica permite o seu reuso por qualquer técnica de visualização em qualquer representação visual.

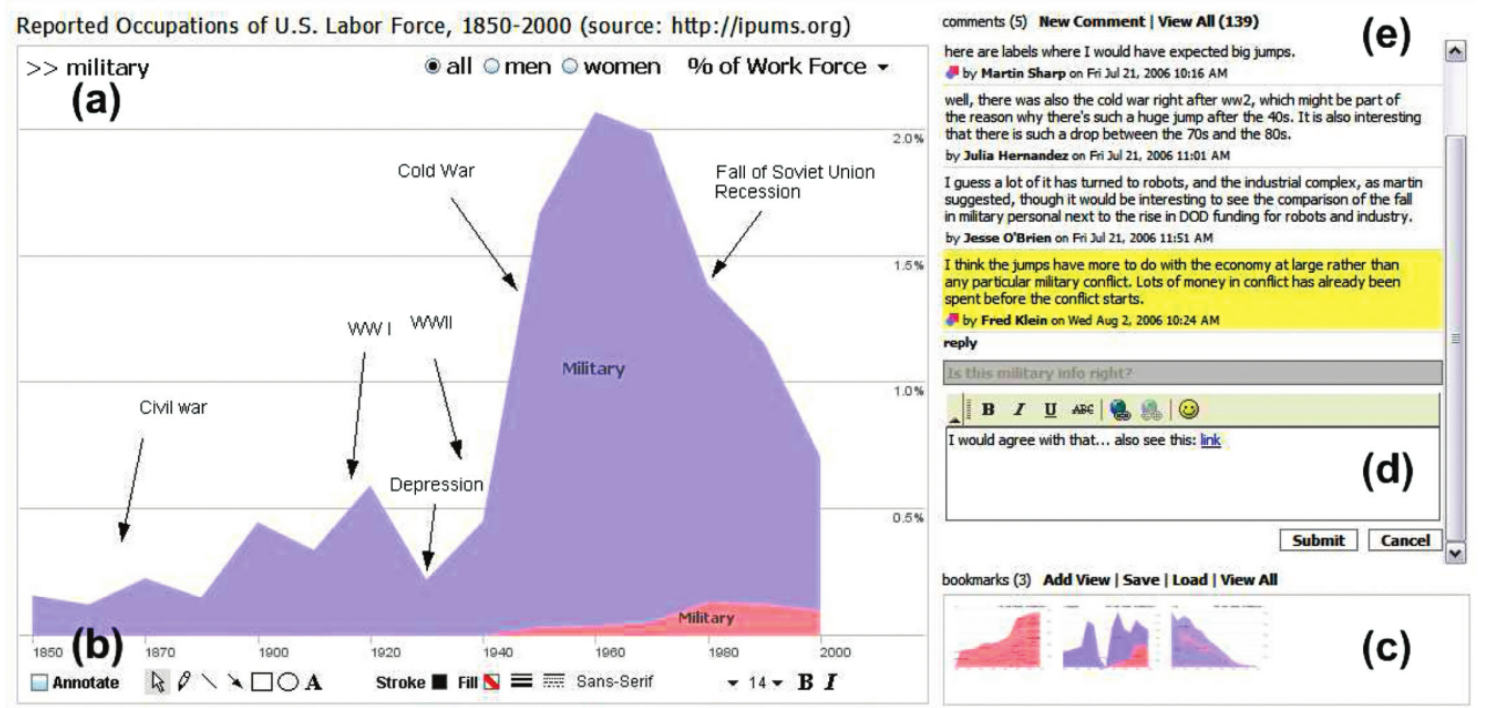

Figura 2.7: Anotações e Compartilhamento de resultados do sense.us (Fonte: [Heer et al., 2009])

\section{- Aproximação}

A técnica de aproximação geométrica - do inglês geometric zoom - permite ajustar a escala de granularidade sobre uma região específica de uma visualização de dados. Tal ajuste permite variar entre as visões panorâmica e pormenorizada dos dados, ações conhecidas como zoom out e zoom in, respectivamente. A redução da granularidade implica na supressão dos dados no entorno da região detalhada [Keim , 2002].

\section{- Compartilhamento de Resultados}

O processo de análise é um ato social e envolve a disseminação e a discussão de resultados [Silva et al., 2007]. Tal fato torna relevante a incorporação de técnicas que permitam compartilhar as introspecções obtidas ao longo das análises visuais dos dados [Heer e Shneiderman, 2012].

Disponibilizar imagens estáticas - formato PNG, por exemplo - representa a opção mais elementar de distribuição de representações visuais. Uma alternativa mais apri- 
morada consiste na publicação da representação visual como uma página WWW com interatividade restrita.

Alternativas robustas de colaboração facilitam a distribuição do estado corrente da representação visual acompanhado de suas anotações e histórico a um público maior. Contudo, tal robustez exige a consideração de diferentes questões durante o projeto do sistema de visualização de dados, incluindo o grau de sincronismo, a distância geográfica e o controle de acesso. A Figura 2.7 ilustra uma solução de visualização de dados com colaboração assíncrona, isto é, uma cena deve ser exportada para estar disponível ao acesso público.

\section{- Correção de Dados}

Essa técnica compreende diferentes transformações que permitem a limpeza interativa dos dados [Kandel et al., 2011]. Formatação, conversão, correção de valores e integração de diferentes fontes de dados são exemplos de transformações dentre as quais algumas estão disponíveis nas soluções descritas nas Seções 3.3.4.5 e 3.3.4.10.

\section{- Derivação}

Essa técnica provê meios para derivar novos valores a partir daqueles disponíveis em uma visualização [Few, 2009]. A derivação pode corresponder a resultados de sumarizações, expressões aritméticas, aplicações de técnicas de teste de hipóteses, dentre outros.

\section{- Detalhes sob demanda}

Muito embora a exploração dos dados ocorra predominantemente sobre uma representação visual, existem momentos que particularidades sobre certos dados são requeridas. Para atender a essa necessidade, as técnicas de detalhes sobre demanda - do inglês details on demand - retratam textualmente essas particularidades em janelas do estilo pop-up [Heer e Shneiderman, 2012].

A técnica hover queries apresenta os detalhes relativos ao item de dado indicado pelo ponteiro do dispositivo de apontamento, após certo retardo. A janela correspondente desaparece com a simples movimentação do ponteiro. Uma segunda técnica utiliza uma janela maior para simultaneamente detalhar vários itens de dados, situação que promove certa desordem na cena de visualização.

\section{- Distorção Espacial}

A distorção espacial é um recurso que reduz a sobreposição excessiva de pontos ou linhas por meio da introdução de ruído que provoca uma pequena dissipação dos dados, conforme observado na Figura 2.8. A técnica de oscilação - do inglês jittering - adiciona um ruído a um par ordenado de pontos $\left(a_{i}, b_{i}\right), i=[1, n]$, aplicando as expressões $a_{i}+\Theta_{a} u_{i}$ e $b_{i}+\Theta_{b} u_{i}$, na qual $u_{i}$ denota valores igualmente espaçados e 
randômicos entre -1 e 1 , e $\Theta_{a}$ e $\Theta_{b}$ representam fatores calculados por $\frac{\max \left(a_{i}\right)-\min \left(a_{i}\right)}{5}$ e $\frac{\max \left(b_{i}\right)-\min \left(b_{i}\right)}{5}$, respectivamente [Chambers, 1983].

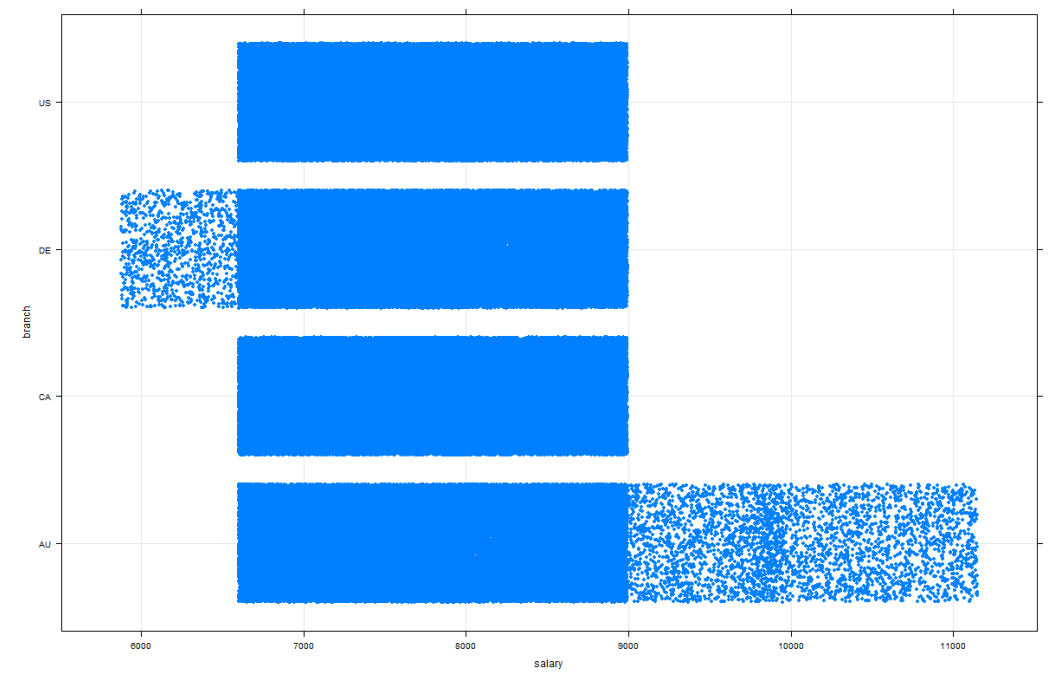

Figura 2.8: Exemplo de distorção espacial em resolução de $10^{6}$ (Fonte: Elaborado pelo autor)

\section{- Filtro}

Técnicas de filtro utilizam diferentes abordagens para selecionar os dados de interesse. As abordagens mais simples permitem a indicação direta dos itens de dados não desejados - ver técnica Seleção e Ligação. Outras abordagens adotam controles widgets - relacionados a parâmetros de seleção. Cada ação sobre o controle é refletida na visualização de dados com pequeno retardo, proporcionado a sensação de proximidade com os dados [Ahlberg e Shneiderman, 1994; Ware, 2004]. Ainda, técnicas mais robustas oferecem mecanismos flexíveis de especificação de predicados com conectores lógicos ou mesmo linguagens plenas de consulta [Heer e Shneiderman , 2012].

\section{- Foco e Contexto}

A técnica de foco e contexto - do inglês focus+context - promove a exibição de dados detalhados e não detalhados de forma contínua. Em outras palavras, uma certa região do espaço de dados é ampliada à medida que os dados no seu entorno sofrem uma ação de compressão visual ou redução de nitidez.

\section{- Histórico}

Técnicas de histórico registram - de modo automático ou sob demanda - as interações e seus efeitos no decorrer de uma análise visual de dados. Essa narrativa permite desfazer ou reaplicar interações, retomar análises inacabadas ou revisitar análises completas para extrair conhecimentos relativos ao próprio processo de análise [Shneiderman, 1996]. A Figura 2.9 exemplifica a navegação visual sobre a 


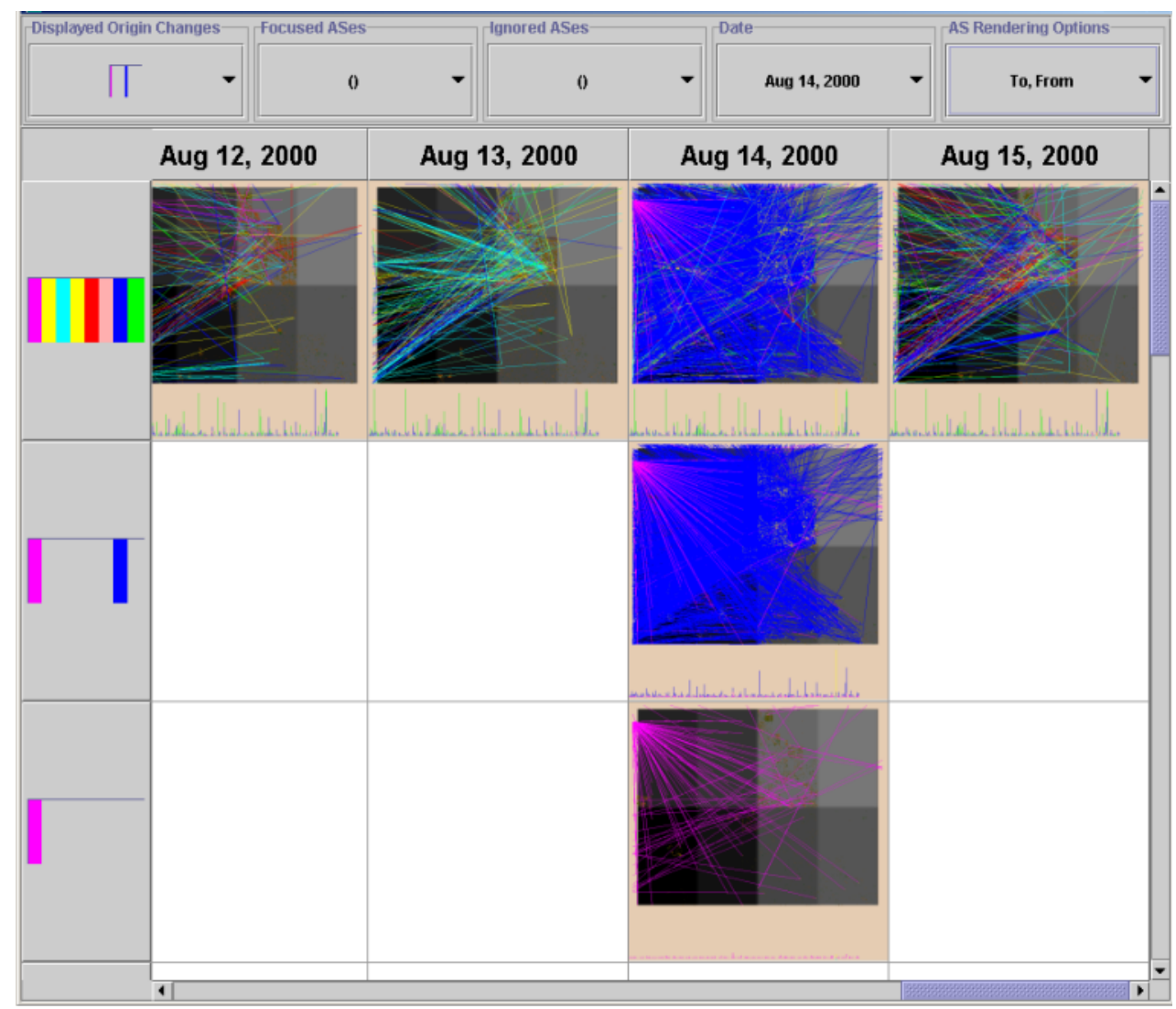

Figura 2.9: Exemplo de navegação visual sobre histórico de análises visuais (Fonte: [Jankun-Kelly et al., 2002])

narrativa de uma análise, enquanto a porção $(c)$ da Figura 2.7 ilustra o registro sob demanda.

\section{- Modificação de Opacidade}

Esse recurso permite determinar a transparência de uma representação visual, isto é, o nível de cobertura dos seus pixels ${ }^{5}$. A técnica de Alpha Blending representa cada pixel por uma 4 - upla $(r, g, b, \alpha)$ composta pelas cores correspondentes ao modelo RGB - do inglês red, green, blue - e o canal $\alpha$ que define a transparência [Porter e Duff, 1984]. Esse último componente assume valores no intervalo [0,1] que determinam a cobertura da tonalidade de um pixel. Valores de $\alpha$ tendendo a 1 determinam a maior a cobertura do pixel - opacos -, enquanto valores tendendo a 0 determina a menor cobertura - transparência -, conforme observado na Figura 2.10.

\section{- Ordenação}

Consiste em organizar e aproximar os dados segundo um ou mais atributos base de análise. Essa aproximação de valores por magnitude facilita a comparação e favorece a explicitação de agrupamentos ou tendências [Heer e Shneiderman, 2012]. Embora efetiva em várias situações, essa abordagem de ordenação possui limitações quando

\footnotetext{
${ }^{5} \mathrm{O}$ pixel compreende a menor área da tela de um computador que pode ser particularizada por uma
} cor. 


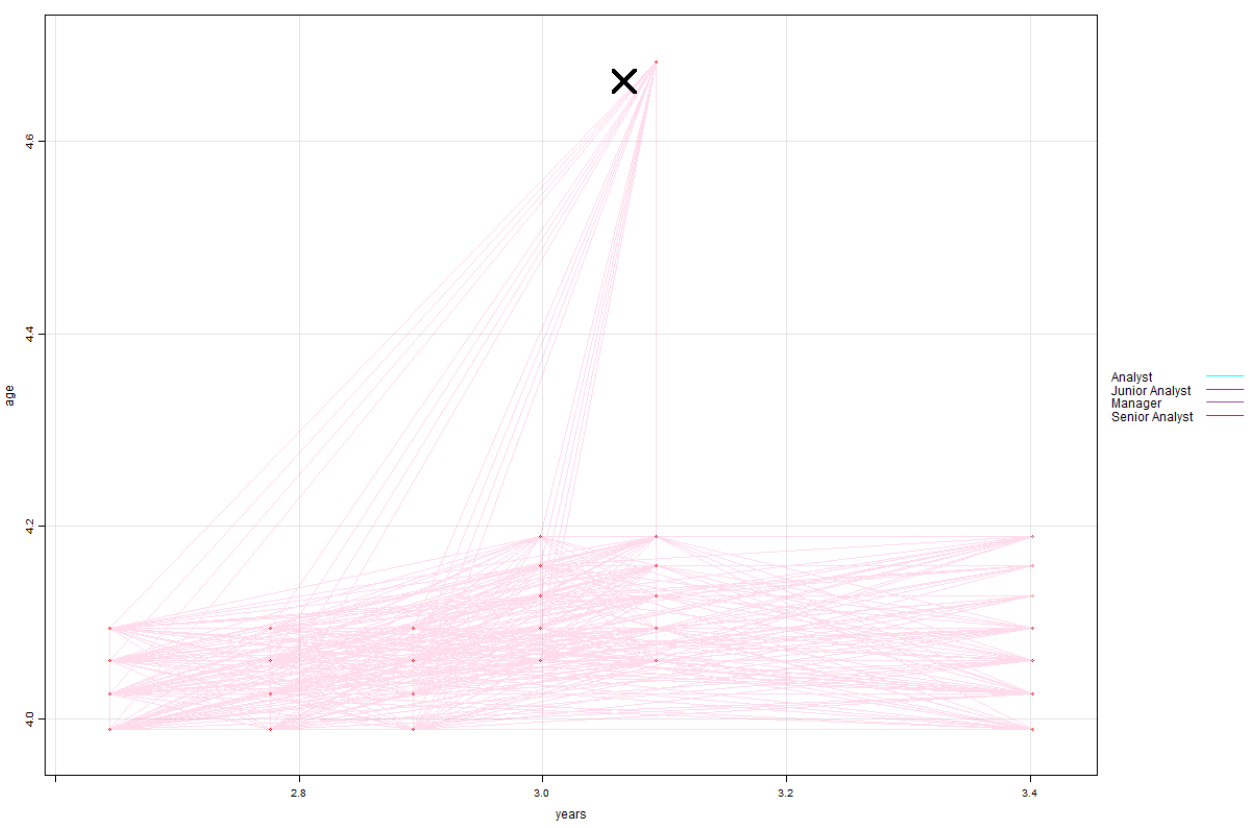

Figura 2.10: Exemplo de mudança de Opacidade em resolução $10^{5}$ tuplas (Fonte: Elaborado pelo autor)

aplicada a dados complexos, incluindo multivariados ou com estruturas em rede [Heer e Shneiderman, 2012].

A seriação é uma abordagem sofisticada de ordenação que organiza os dados em uma dimensão simples - linha - conforme sua similaridade a um atributo de referência [Liiv, 2010]. A Figura 2.11 revela a efetividade da seriação - ilustração à direita frente a ordenação simples - ilustrada à esquerda.
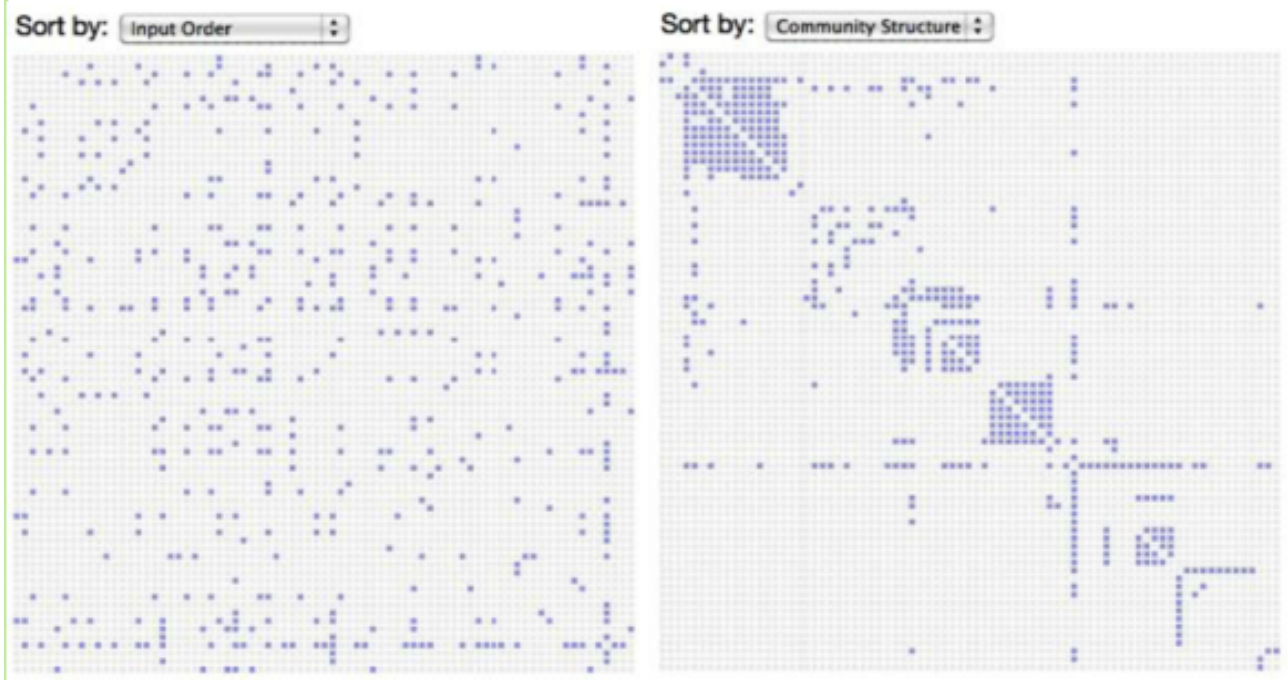

Figura 2.11: Exemplo de Ordenação e Seriação (Fonte: [Heer e Shneiderman, 2012])

- Reformular

A técnica de reformulação favorece diferentes introspecções por meio da manipulação de características da representação dos dados. Certas abordagens de reformulação 
permitem expressar valores quantitativos sob diferentes formas - por exemplo, percentual, normalizada, raiz quadrada e logarítmica - ou, ainda, ajustar diferentes propriedades visuais relacionadas a cor, textura e posição.

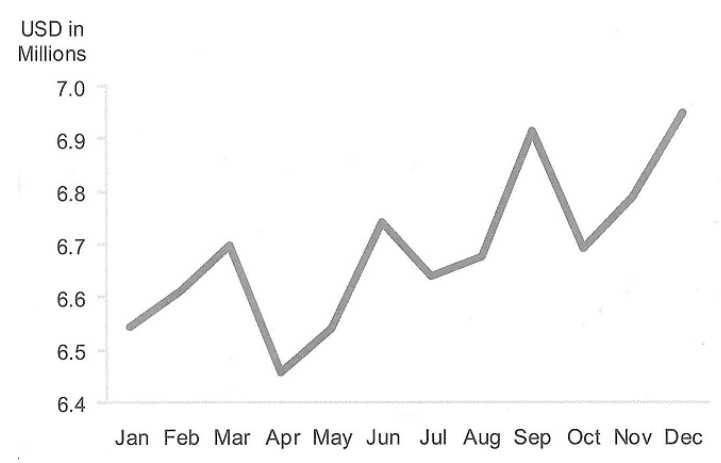

(a) Visualização antes da reformulação

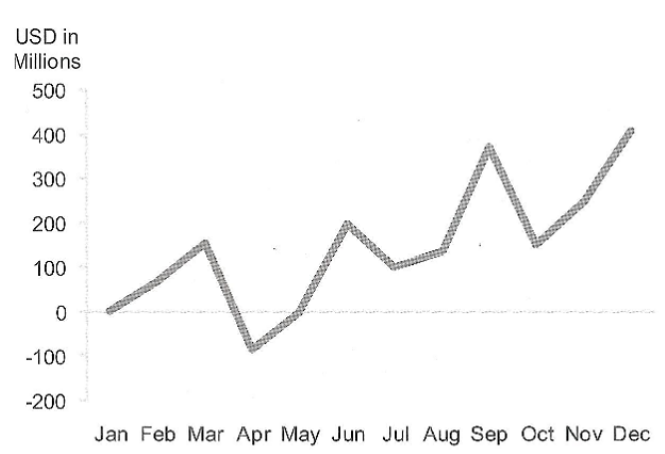

(b) Visualização após a reformulação

Figura 2.12: Exemplo de Reformulação (Fonte: [Few, 2009])

Outra forma de reformulação consiste em expressar valores de um ou mais atributos em relação a um atributo ou valor de referência previamente definido. A Figura 2.12b ilustra a reformulação de um gráfico contendo uma série temporal - Figura 2.12a salientando a diferença de cada intervalo do tempo frente ao intervalo de tempo de referência: o mês de janeiro.

\section{- Seleção e Destaque}

Essa técnica de interação elementar permite destacar os itens de dados de interesse por meio da alteração da tonalidade, da forma, do brilho ou da transparência. Um exemplo de seleção e destaque por alteração de tonalidade é ilustrado na Figura 2.13 à esquerda. Seu princípio é fundamental para todas as técnicas que utilizam a noção de ação sobre dados previamente demarcados.
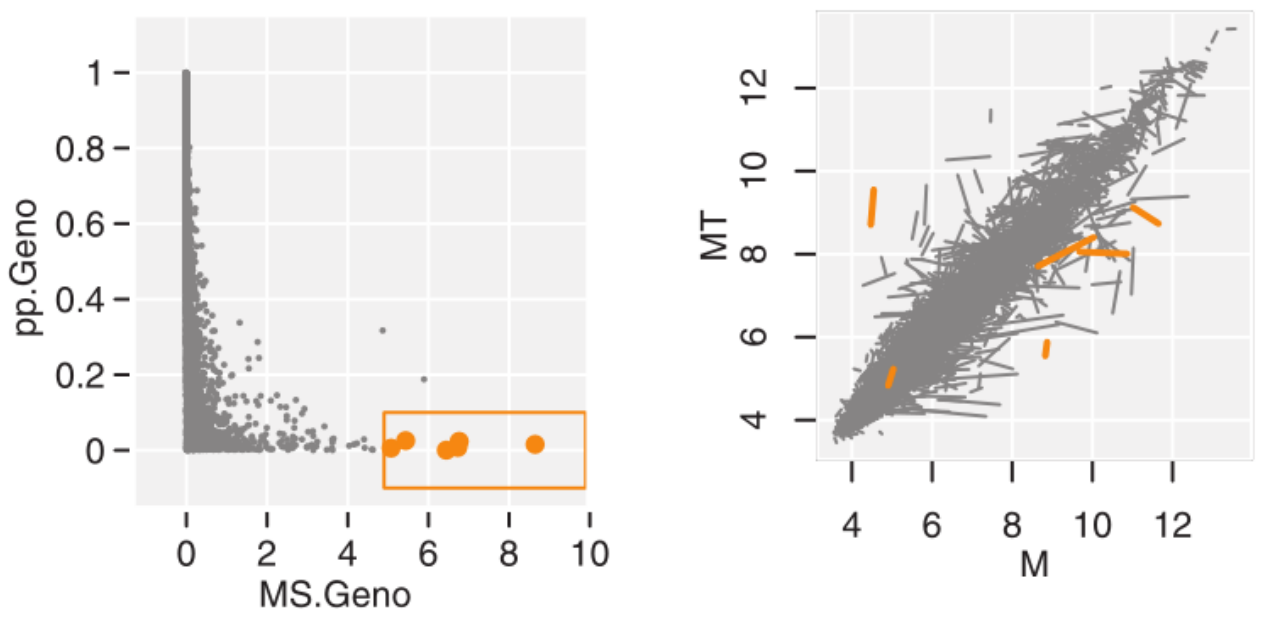

Figura 2.13: Exemplos de Seleção e Destaque e, Seleção e Ligação

(Fonte: [Cook e Swayne, 2007]) 
- Seleção e Ligação

A técnica de seleção e ligação - do inglês brushing and linking - possibilita selecionar um ou mais itens de dados representados em uma visualização para aplicar uma ação subsequente. Essa ação pode resultar na supressão dos itens selecionados filtro visual - ou na propagação do contraste dos itens selecionados para as demais visões concorrentes múltiplas, conforme observado na Figura 2.13.

- Treliça

Um dos princípios utilizados para representar simultaneamente múltiplos atributos em uma visualização de dados envolve a divisão do seu espaço de dados em subespaços de mesmo tamanho. Fundeada nesse princípio, a técnica da treliça - do inglês trellis display - utiliza um conjuntos de painéis que representam atributos disjuntos por meio da mesma técnica de visualização - Figura 2.14 .

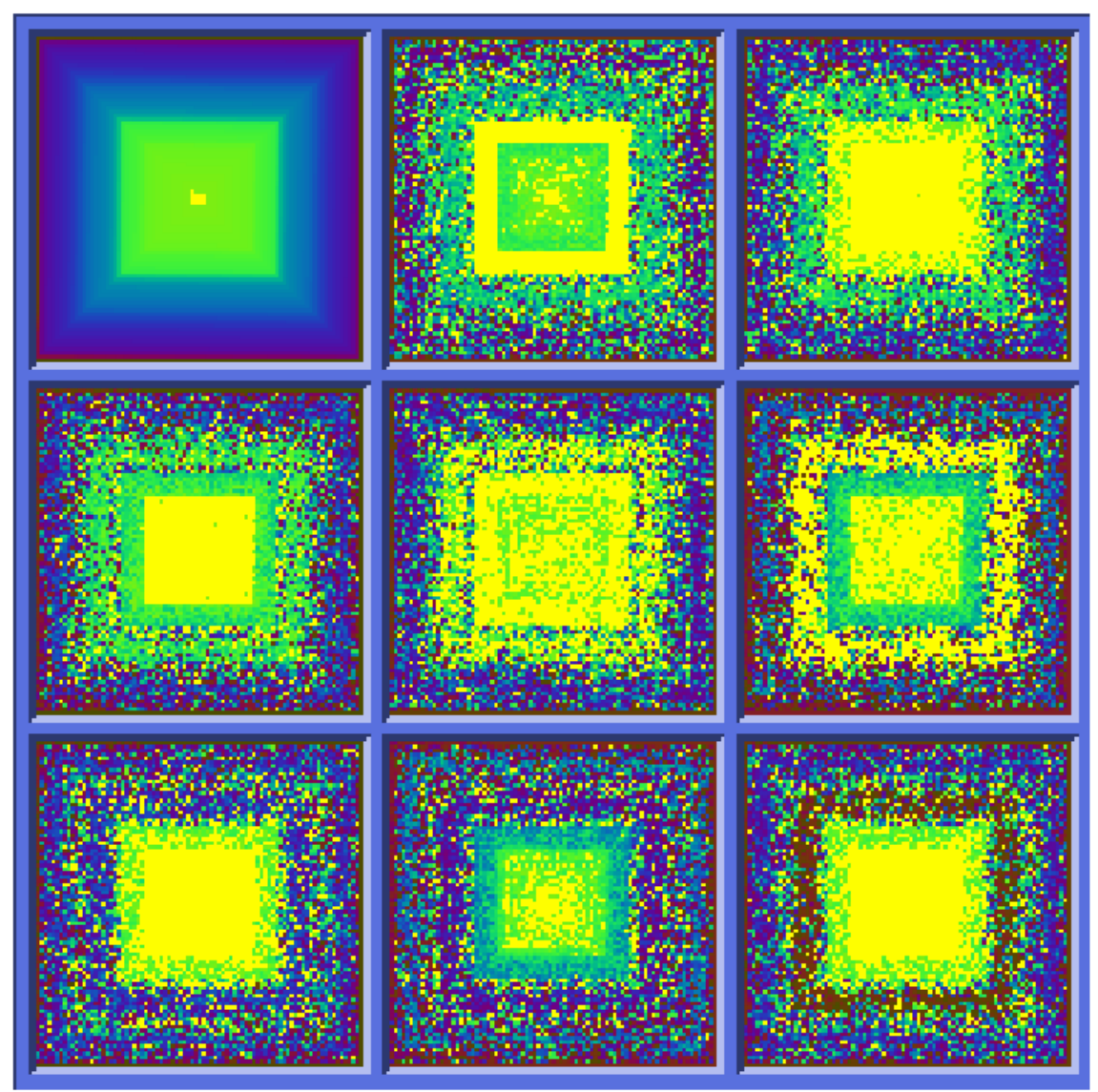

Figura 2.14: Exemplo de divisão do espaço visual por Treliça

(Fonte: [Keim e Krigel, 1994])

- Visões Concorrentes Múltiplas

A técnica de visões múltiplas também está baseada no princípio de divisão do espaço de dados. Contudo, os subespaços estão dispostos em janelas com tamanho, posição e técnica de visualização independentes. As janelas apresentam acoplamento dinâmico, isto é, ações - incluindo filtro ou seleção e ligação - realizadas sobre uma 
janela são propagadas as demais [Few, 2009; Keim, 2002], conforme observado na Figura 2.15.
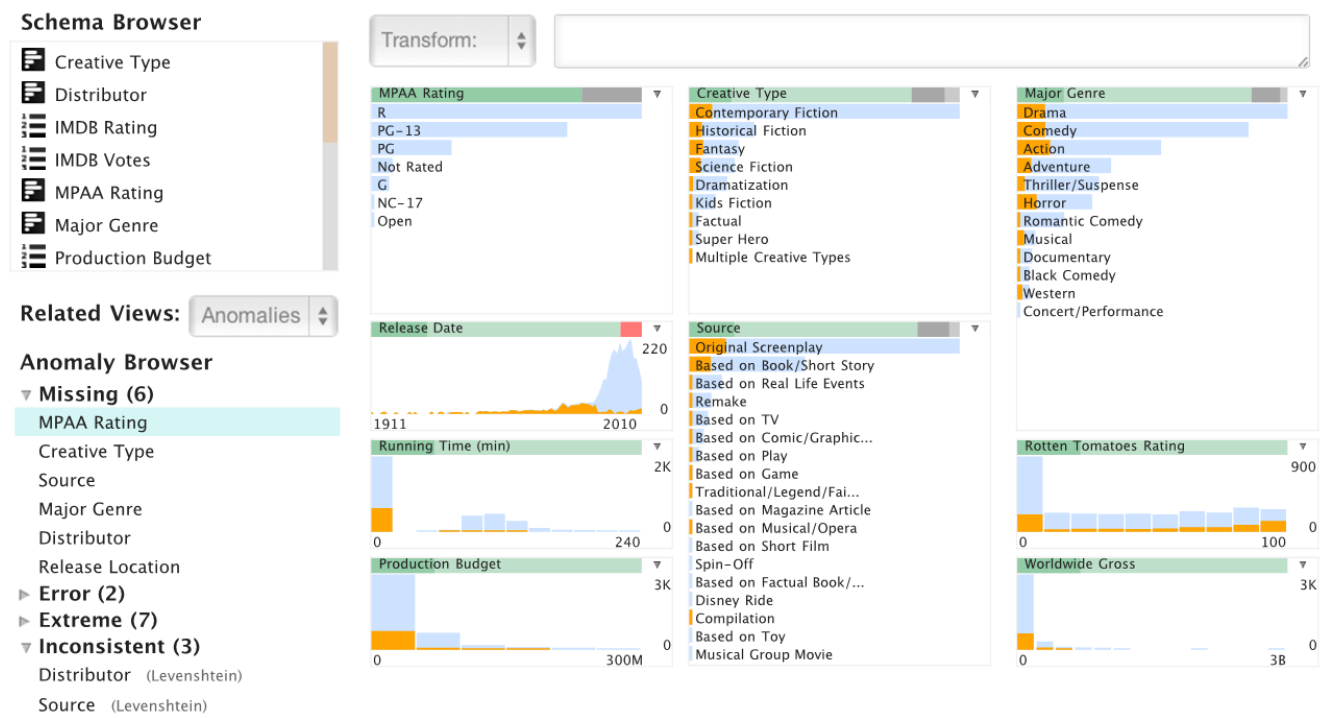

Figura 2.15: Exemplo de visões concorrentes múltiplas

(Fonte: [Kandel et al., 2012b])

\subsubsection{Técnicas de Visualização}

As técnicas de visualização determinam como o espaço visual será utilizado para expor os dados de interesse [Card et al., 1999]. Adicionalmente, essas técnicas constituem o meio pelo qual o agente humano interage com um sistema de visualização para moldar os dados conforme suas necessidades de análise.

A literatura oferece um conjunto de taxonomias que classificam as técnicas de visualização por perspectivas distintas, incluindo tarefas definidas em função dos tipos de dados [Shneiderman, 1996] e por expressividade visual [Rodrigues et al., 2007]. Este trabalho adotou a organização proposta por [Keim, 2002], pois classifica as técnicas de visualização segundo a abordagem de representação gráfica dos $\operatorname{dados}^{6}$, conforme discutido a seguir. Cumpre lembrar que tais técnicas podem ser combinadas e dar origem a técnicas híbridas.

\section{- Uma, Duas ou Três Dimensões}

Corresponde a uma gama de técnicas - muitas das quais provenientes da Estatística que utilizam até três coordenadas no espaço para projetar dados de modo planar ou em profundidade - três dimensões. A noção de dimensionalidade está ligada a quantidade de atributos a serem representados visualmente. Um conjunto de dado com até três atributos são citados como sendo de uma, duas ou três dimensões - 1D, 2D ou

\footnotetext{
${ }^{6}$ Essa perspectiva possui maior proximidade a uma das características do presente trabalho, isto é, observar as propriedades visuais da técnicas de visualização em relação a avaliação da qualidade dos dados.
} 
3D, respectivamente. Uma vez superado esse número, a denominação usual é multidimensional multivariado que denota atributos inter-relacionados [Shneiderman , 1996].

\section{- Hierárquica e Grafo}

Compreende as técnicas de visualização que tornam a estrutura inerente de um conjunto de dados perceptível. Essa estrutura denota relações entre objetos que podem ou não apresentar uma ordem de prioridade entre si.

\section{- Orientada a Ícones}

Certas técnicas orientadas a ícones mapeiam os valores dos atributos para um conjunto discreto de propriedade gráficas de um ícone [Keim e Kriegel, 1996]. Uma vez que cada ícone representa uma instância de um conjunto de dados, essas técnicas não são escaláveis e podem dificultar a interpretação dos dados devido a pequena distinção entre suas propriedades [Chan, 2006]. Em contraste, outras técnicas icônicas representam entidades que possuem mapeamento geométrico, tais como mapas e diagramas.

\section{- Orientada a Pixel}

Técnicas orientadas a pixel mapeiam cada valor de um atributo para um pixel baseado em uma escala de cores. Para representar objetos com $N$ atributos são necessários $N$ pixels dispostos simetricamente em painéis que denotam um atributo específico, conforme observado na Figura 2.16.

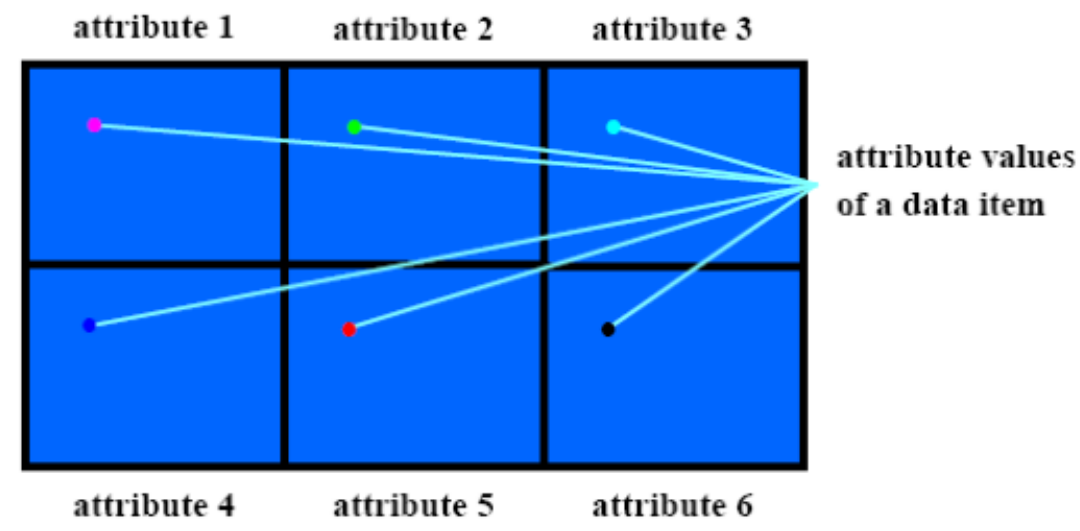

Figura 2.16: Disposição dos pixels de um objeto qualquer (Fonte: [Chan, 2006])

Essas técnicas podem ser decompostas em duas subclasses: a dependente e a independente da consulta - do inglês query-dependent e query-independent, respectivamente. Na primeira subclasse, as cores dos pixels são determinadas com base na proximidade entre os valores de um atributo e o predicado da consulta. Essa abordagem é propícia para revelar agrupamentos, correlações e dependências funcionais 
[Keim e Kriegel, 1996]. Em contraste, na segunda subclasse a escala de cores dos pixels é derivada diretamente do valor dos atributos, fato que favorece a observação da ordem natural dos dados - caso das séries temporais.

\section{- Projeção Geométrica}

Representam técnicas que aplicam funções matemáticas para determinar a posição dos valores dos atributos no espaço visual. Embora relevantes na detecção de correlações e valores atípicos, certas técnicas geométricas sobrepõem objetos e limitam o processo de análise mesmo volumes moderados de dados [Keim e Kriegel, 1996].

\begin{tabular}{|c|c|}
\hline Abordagem de Projeção & Técnica de Visualização \\
\hline Uma, Duas ou Três & Histograma \\
\hline \multirow[t]{9}{*}{ Dimensões } & Gráfico de Barras \\
\hline & Gráfico de Barras Empilhadas \\
\hline & Gráfico de Bolha (Bubble Chart) \\
\hline & Gráfico de Caixa (BoxPlot) \\
\hline & Gráfico de Dispersão \\
\hline & Gráfico de Flutuação \\
\hline & Gráfico de Linha \\
\hline & Gráfico Mosaico \\
\hline & Mapa de Calor \\
\hline \multirow[t]{3}{*}{ Grafos } & Grafo Radial Dirigido \\
\hline & Grafo Linear Não Dirigido \\
\hline & Grafos Hiperbólicos \\
\hline \multirow[t]{2}{*}{ Hierarquias } & Cone Tree \\
\hline & Tree Map \\
\hline \multirow[t]{2}{*}{ Orientada a Ícones } & Chernoff Faces \\
\hline & Glifos em Estrela \\
\hline \multirow[t]{3}{*}{ Orientada a Pixel } & Space Filling Curve \\
\hline & Pixel Bar Chart \\
\hline & Circle Segments \\
\hline \multirow[t]{6}{*}{ Projeção Geométrica } & Coordenadas em Estrela Radial \\
\hline & Coordenadas Paralelas \\
\hline & Hyperslice \\
\hline & Matriz de Gráficos de Dispersão \\
\hline & Table Plot \\
\hline & Table Lens \\
\hline Textual & Tabela Textual \\
\hline
\end{tabular}

Tabela 2.4: Técnicas de visualização categorizadas por abordagem de projeção (Fontes: [Chan, 2006; Herman et al., 2000; Keim, 2002; Schulz et al., 2011])

A Tabela 2.4 apresenta um conjunto relevante de técnicas de visualização agrupadas segundo o critério de organização supracitada. Desse conjunto, as características das técnicas utilizadas pelo presente trabalho - Capítulo 5 - são descritas formalmente com base na seguinte notação:

(1) As letras $X, Y, Z, W$ denotam atributos simples de um conjunto de dados multivariado

(2) As letras $x, y, z, w$ indicam um valor arbitrário de um atributo 
(3) As letras $x^{\prime}, y^{\prime}, z^{\prime}, w^{\prime}$ representam um subconjunto de valores arbitrários de um atributo

(4) A letra $o$ denota um objeto ou instância em um conjunto de dados $C$ cujo tamanho é denotado por $n, n \geqslant 1$

(5) A representação $|a t t|$ denota o número de diferentes valores - ou cardinalidade - presentes no domínio do atributo att, $|a t t| \geqslant 1$

(6) A representação dos dados no espaço gerado pelas técnicas de visualização utiliza a letra grega $\omega$ - Ômega

(7) As letras $f, f^{\prime}$ são empregadas para denotar funções

(8) Letras cursivas são utilizadas para denotar a imagem ou domínio de uma função, respectivamente im e dom

\section{- Chernoff Faces}

Essa técnica representa cada objeto de um conjunto de dados por meio de $k$ características de ícone que remete a face humana, incluindo o formato dos olhos e da boca [Chernoff, 1973]. A função $f$ definida por um par $(x, i), x \in \bigcup_{i=1}^{k} X_{i}$, calcula a $i$ - ésima característica da face para o valor $x$. Assim, cada objeto $o_{j}, j=[1, n]$, é expresso por uma $k$-upla $o_{j}=\left(f\left(x_{1}, 1\right), \ldots, f\left(x_{k}, k\right)\right)$. O Chernoff Faces $\omega$ é disposto em um plano matricial $M$ de ordem $l \times c$, onde $l * c \approx 420$. Cada $i-e ́ s i m a$ linha e $j$-ésima coluna de $M$ contém um objeto $o_{i j}$ extraído da ordem natural em $C$.

\section{- Glifos em Estrela}

Esse tipo de gráfico representa cada objeto de um conjunto de dados como um símbolo capaz de expor até oito atributos quantitativos. Para representar $p$ atributos, $p \geqslant 1$, os elementos - linhas ou áreas - do símbolo são espaçados de modo equânime, onde o $j$-ésimo elemento, $j=[1, p]$, está a um ângulo de $\theta_{j}=\frac{2 \pi(j-1)}{p}$ da horizontal [Chambers, 1983]. Antes da representação, os valores dos atributos são redimensionados para uma faixa entre $c$ e 1 , na qual $c$ denota o menor tamanho que o elemento pode assumir. O valor redimensionado $x_{i j}, i-e ́ s i m o$ valor do $j$-ésimo atributo, é expresso por $x_{i j}=\frac{(1-c)\left(x_{i j}-m_{i n}\right)}{\left(\max _{i}-\min _{i}\right)+c}$. Assim, cada objeto $o$ é definido por uma $p$ - upla $o=\left(x_{i 1}, \ldots, x_{i p}\right), i \in n$. Um glifo em estrela $\omega$ é expresso por uma matriz $M$, de ordem $l \times c$, onde $l * c \approx 420$. Cada $i$-ésima linha e $j$-ésima coluna de $M$ contém um objeto $o_{i j}$ extraído da ordem natural em $C$.

\section{- Gráfico de Barras}

O gráfico de barras apresenta a relação $R$ entre dois atributos $X$ e $Y$ denotada por um conjunto de pares ordenados de valores $(x, y), x \in X, y \in Y$. A função $f$ definida por um par ordenado $(x, y)$ determina o tamanho da barra proporcional ao valor de $x$ [Unwin et al., 2006]. Um gráfico de barras $\omega$ é expresso no plano cartesiano por $\omega=\left\{f\left(x_{1}, y_{1}\right), \ldots, f\left(x_{n}, y_{n}\right)\right\}$.

\section{- Gráfico de Barras Empilhadas}


Em sua versão mais simples, a visualização de barras empilhadas expõe a relação $R$ entre três atributos $X, Y, Z$ expressa por $3-$ upla $(x, y, z), x \in X, y \in Y$ e $z \in Z$ [Unwin et al., 2006]. A função $f$ definida por $(x, y, z)$ determina o tamanho da barra empilhada pelo valor de $x$ e a respectiva tonalidade $c$ de acordo com o valor de $z$, na qual $\bigcap_{i=1}^{|Z|} c_{i}=\oslash$. O gráfico de barras empilhadas $\omega$ expresso no plano cartesiano por $\omega=\left\{f\left(x_{1}, y_{1}, z_{1}\right), \ldots, f\left(x_{n}, y_{n}, z_{n}\right)\right\}$.

- Gráfico de Bolha

Essa visualização apresenta a relação $R$ entre quatro atributos $X, Y, Z, W$ por meio de um conjunto de 4-upla $\left(x, y, \operatorname{im} f, \operatorname{im} f^{\prime}\right), x \in X, y \in Y$ [Tufte e Graves-Morris, 1983]. A função $f$ definida por $z, z \in Z$, determina o raio do círculo proporcional ao valor de $z$. A função $f^{\prime}$ definida por um valor $w, w \in W$, atribui uma tonalidade $c$ segundo o valor de $w$, na qual $\bigcap_{i=1}^{|W|} c_{i}=\oslash$. O gráfico bolha $\omega$ expresso no plano cartesiano é denotado por $\omega=\left\{\left(x_{1}, y_{1}, f\left(z_{1}\right), f^{\prime}\left(w_{1}\right)\right), \ldots,\left(x_{n}, y_{n}, f\left(z_{n}\right), f^{\prime}\left(w_{n}\right)\right)\right\}$.

- Gráfico de Dispersão

Essa técnica expressa a relação $R$ entre dois atributos $X$ e $Y$ por um conjunto de pares ordenados $(x, y), x \in X, y \in Y$ [Chambers, 1983]. Logo, um gráfico de dispersão $\omega$ representa no plano cartesiano um conjunto de pares ordenados na forma de pontos por $\omega=\left\{\left(x_{1}, y_{1}\right), \ldots,\left(x_{n}, y_{n}\right)\right\}$.

\section{- Gráfico de Flutuação}

Essa visualização é utilizada para representar a tabela de contingência entre dois atributos $X$ e $Y$. Tal tabela representa uma matriz $M$, de ordem $|Y| \times|X|$. Cada $i-$ ésima linha e $j$-ésima coluna da matriz $M$ contém o resultado de uma função $f$ que calcula a frequência do par de valores $\left(x_{j}, y_{i}\right)$, onde $x_{j} \in X$ e $y_{i} \in Y$ [Unwin et al., 2006].

- Gráfico de Linha

Essa técnica apresenta a relação $R$ entre dois atributos $X$ e $Y$ por pares ordenados $(x, y), x \in X, y \in Y$ [Chambers, 1983]. A função $f$ definida por dois pares ordenados $\left(x_{1}, y_{1}\right)$ e $\left(x_{2}, y_{2}\right)$, determina a reta de ligação entre os respectivos pares. Um gráfico de linha $\omega$ representa no plano cartesiano as retas entre pares ordenados por $\omega=$ $\left\{f\left(\left(x_{1}, y_{1}\right),\left(x_{2}, y_{2}\right)\right), f\left(\left(x_{2}, y_{2}\right),\left(x_{3}, y_{3}\right)\right), \ldots, f\left(\left(x_{n-1}, y_{n-1}\right),\left(x_{n}, y_{n}\right)\right)\right\}$.

\section{- Grafo Radial Dirigido}

Um dígrafo $\omega$ é representado por $\omega=(V, A, f)$, onde $V$ é um conjunto não vazio de vértices, $A$ denota arestas e $f$ é uma função que relaciona cada elemento de $A$ a um par ordenado $(u, w)$ de $V$, onde $u, w \in V$ e $A \subseteq V$ [Feofiloff et al., 2011]. Ainda, a propriedade dirigido estabelece que $(u, w)$ e $(w, u)$ representam duas arestas distintas em $A$. 


\section{- Grafo Linear Não Dirigido}

Esse grafo é análogo ao grafo radial, exceto pela disposição espacial linear dos vértices e pelo uso de arcos para representar as arestas não dirigidas.

\section{- Histograma}

Em uma de suas variantes, o histograma provê a frequência absoluta de valores $x^{\prime}$ presentes em $k^{7}$ intervalos de dados de um atributo $X$, onde $\bigcap_{i=1}^{k} x_{i}^{\prime}=\oslash$ [Chambers, 1983]. A função $f$ definida por $x^{\prime}$ determina a frequência do intervalo por $\sum_{x \in x^{\prime}} 1$. Já a função $f^{\prime}$ definida por im $f$ determina o tamanho da barra. Assim, um histograma $\omega$ representa barras uniformes por $\omega=\left\{f^{\prime}\left(f\left(x_{1}^{\prime}\right)\right), \ldots, f^{\prime}\left(f\left(x_{k}^{\prime}\right)\right)\right\}$.

\section{- Matriz de Gráficos de Dispersão}

Esse gráfico representa em um plano matricial $M$, de ordem $k \times k$, todos os gráficos de dispersão relativos aos relacionamentos binários de um conjunto de atributos $X_{1}, \ldots, X_{k}, k \geqslant 2$ [Chambers, 1983]. Cada $i$-ésima linha e $j$-ésima coluna da matriz $M$ representa o gráfico de dispersão $\omega_{i j}$ da relação $R$ dos atributos $X_{i}$ e $X_{j}$. Por outro lado, a $j$-ésima linha e $i$-ésima coluna contém o gráfico $\omega_{j i}$ da relação invertida $R^{-1}$ dos mesmos atributos.

\section{- Mapa de Calor}

O Mapa de calor representa a relação $R$ entre dois atributos $X$ e $Y$ em uma matriz $M$ de ordem $|Y| \times|X|$ [Bertin, 1983]. Cada $i$-ésima linha e $j$-ésima coluna da matriz $M$ contém o resultado de uma função $f$ definida por um valor $z, z \in Z$, que determina uma tonalidade $c_{i}$ com base no valor de $z$. Cada tonalidade $c$ representa um dos $k$ intervalos de valores $s$, onde $\bigcap_{i=1}^{k} c_{i}=\oslash$ e $\bigcap_{i=1}^{k} s_{i}=\oslash$.

\section{- Coordenadas Paralelas}

Essa visualização dispõem linhas poligonais verticais $l_{1}, \ldots, l_{k}$ com espaçamento $D$ e vértices no eixo $\mathrm{x}$, onde $k=[1,12]$ e cada linha $l_{i}$ representa um atributo $X_{i}$ [Inselberg e Dimsdale, 1990]. A função $f$ definida pela $k-u p l a\left(x_{1}, \ldots, x_{k}\right), x_{i} \in$ $X_{i}$, determina as coordenadas de representação de um objeto o por meio de uma linha poligonal não-colinear no plano cartesiano. Assim, uma paralela coordenada $\omega$ expressa polígonos por $\omega=\left\{f\left(x_{1}^{1}, \ldots, x_{k}^{1}\right), \ldots, f\left(x_{1}^{n}, \ldots, x_{k}^{n}\right)\right\}$.

\section{- Table Plot}

Essa visualização representa os dados em uma matriz $M$ de ordem $l \times c, c=[1,12]$ e $l=\max \left(1, \frac{n}{1000}\right)$ [Malik et al., 2010]. Cada $i$-ésima linha e $j$-ésima coluna da matriz $M$ contém o resultado de uma função $f$, definida por $x^{\prime}, x^{\prime} \subset X$ e $1 \leqslant\left|x^{\prime}\right| \leqslant 1000$, que calcula o valor médio em $x^{\prime}$ por $\left(\sum_{x \in x^{\prime}} x\right) /\left|x^{\prime}\right|$ ou a frequência

\footnotetext{
${ }^{7} \mathrm{~A}$ determinação de $k$ apresenta múltiplas estratégias desenvolvidas na área da Estatística, incluindo $k=\log _{2}(n)$ [Chambers, 1983]. Caracterizar tais estratégias está além do escopo do presente trabalho.
} 
das diferentes categorias $x_{i} \in x^{\prime}, i=\left[1,\left|x^{\prime}\right|\right]$. O primeiro resultado determina o tamanho da barra, enquanto o segundo determina uma relação percentual entre as categorias expressa em uma barra.

- Tree Map

Essa visualização representa em divisões recursivas a estrutura de árvores com raiz [Shneiderman, 1992]. Uma árvore é um grafo $G=(V, A)$ não dirigido, conexo, sem ciclos e onde $|A|=|V|-1$ [Feofiloff et al., 2011]. A propriedade conexo determina que na árvore $\forall(u, w) \in V$ existe um caminho $u_{1} u_{2} \ldots u_{n}$, onde $u=u_{1}$ e $w=u_{n}$. Ainda, a ausência de ciclos da árvore determina que $\sum_{u \in V} \operatorname{grau}(u)=|A|$.

O percurso em ordem na árvore determina a disposição e proporção das divisões no espaço visual. Nós em níveis ímpares estabelecem divisões verticais, enquanto os níveis pares determinam divisões horizontais. O tamanho de cada divisão $p a_{i}$, $i=[1,|V|]$, obedece a expressão de proporção $p a_{i}=k+\left(\operatorname{valor}\left(u_{i}\right) / \operatorname{valor}\left(u_{\text {raiz }}\right)\right) * l$, onde $k$ denota a posição da última divisão vertical, $l$ representa o espaço visual disponível e valor é uma função que recupera o valor associado a um nó. Cada vértice da árvore possui uma $n$ - upla de elementos, sendo um deles utilizado para determinar a proporção [Shneiderman, 1992]. Assim, tomando $f$ como a função que cria a árvore e $g$ a função que opera as divisões recursivas, o Tree Map é denotado por $\omega=(g \circ f)$.

\subsection{Propriedades Visuais}

As técnicas de visualização são formadas por diferentes elementos que determinam suas capacidades de codificação dos dados. Neste trabalho, o termo "propriedade visual" denota esse conjunto de elementos, quais sejam as variáveis visuais, o tipo de descrição, as dimensões e suas referências de codificação, a estratégia de representação dos objetos e a estratégia de arranjo dos objetos. Os referidos elementos são definidos como:

- Variáveis Visuais denotam as abordagens visuais que codificam os atributos, incluindo tamanho - mudança na área ou comprimento -, saturação/luminosidade, tonalidade, posição - localização em um plano -, forma, conexão, textura e volume [Bertin, 1983; Mackinlay , 1986], conforme ilustrado na Figura 2.17. A propriedade movimento denota o uso de diferentes parâmetros para promover o movimento aparente dos dados [Ware, 2004]

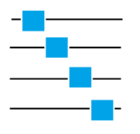

Posição

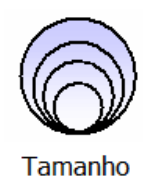

Tamanho

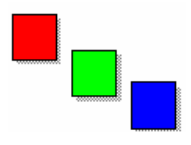

Tonalidade

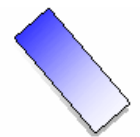

Saturação e Luminosidade

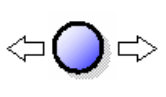

Movimento

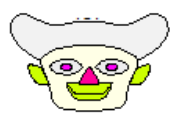

Forma

Figura 2.17: Exemplos de variáveis visuais (Fonte: Elaborado pelo autor) 
- Tipo de Descrição denota como o valor de um atributo alvo é codificado pela variável visual escolhida, incluindo ponto, linha e tonalidades;

- Dimensões determinam o número máximo de atributos que podem ser codificados;

- Referência de Codificação denota o tipo de dado aceito por um atributo e a referência de codificação, quais sejam contínua ou discreta. Desse modo, tais referências determinam a capacidade de representação de atributos com domínio extenso ou discreto;

- Estratégia de Representação determina a abordagem de representação dos objetos por meio das variáveis visuais. Na abordagem individual, cada variável representa um objeto. Já na abordagem de compactação uma variável visual denota um certo número de objetos, conforme a técnica de visualização;

- Estratégia de Arranjo denota a abordagem de codificação dos objetos no espaço e tempo, quais sejam a codificação dos objetos sem sobreposição - justaposição - ou no mesmo sistema de coordenadas - superimposição.

\subsection{A Cognição Humana e seus Sistemas}

Conforme discutido na Seção 2.3.1, a essência da visualização de dados é impulsionar os processos de cognição humana por meio do aumento da percepção de padrões relevantes nos dados. Por consequência, projetar um sistema de visualização com esse propósito requer apreciar as características fundamentais de tais processos. Neste trabalho, utilizamos a teoria de sistema dual de processamento de informações [Anderson, 2005; Matlin, 2009; Palmer, 1999; Patterson et al., 2014] para apresentar uma visão geral da cognição humana.

A base dessa teoria determina que a cognição humana ocorre por meio da cooperação e influência mútua dos processamentos realizados pelos sistemas de percepção visual e de raciocínio analítico [Marr, 1982; Matlin, 2009; Patterson et al., 2014]. Esse processamento determina a experiência e a resposta de um agente humano a um estímulo do ambiente externo. O primeiro sistema remete a complexa habilidade humana de converter imagens do ambiente em representações neurais na memória humana - processamento do exterior para o interior. Já o sistema de raciocínio denota o processo de dirigir a atenção para a aquisição, transformação ou uso do conhecimento utilizando ou não tais imagens processamento do interior para o exterior.

A Figura 2.18 ilustra a referida cooperação, retratando a direção do processamento realizado pelos sistemas de percepção e raciocínio - parte inferior - e as respectivas etapas de processamento - parte superior. Devido a complexidade, o processamento do sistema de percepção é dividido nas etapas de captura - inicial da visão - e organização de elementos da imagem no ambiente. O papel de cada etapa é delineado a seguir. 


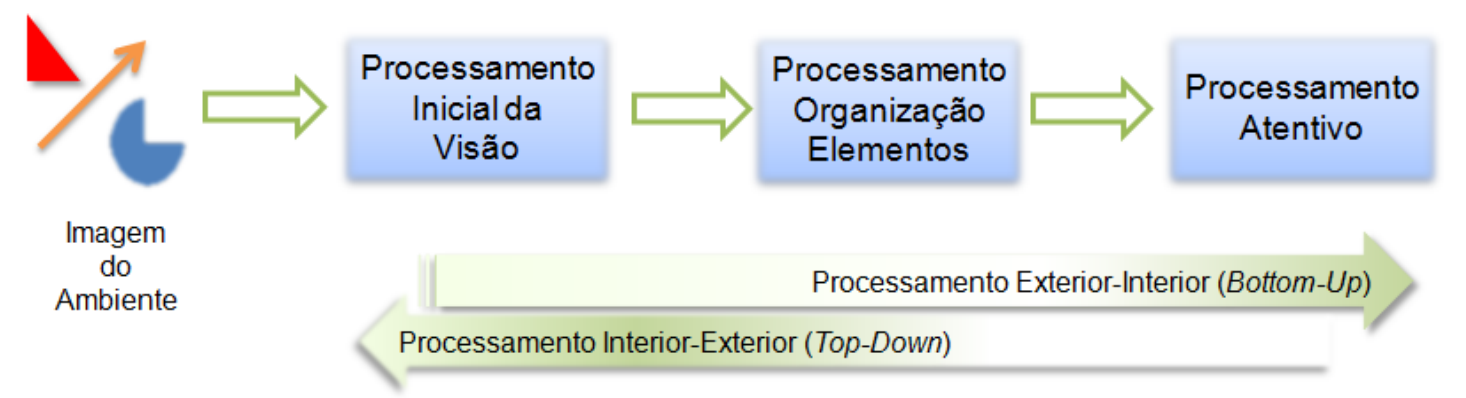

Figura 2.18: Sistema dual de processamento perceptual e cognitivo (Adaptadado de: [Marr, 1982; Palmer, 1999])

\subsubsection{Processamento Inicial da Visão}

Nessa etapa, uma estrutura eficiente e autônoma de neurônios trata de modo seletivo e paralelo os estímulos provenientes do ambiente de acordo com suas primitivas visuais. Certas primitivas visuais, denominadas de otimizadas - Tabela 2.5 -, estimulam o sistema visual humano tão intensamente que "saltam aos olhos" - efeito parallel pop-out - mesmo quando situadas em regiões periféricas do campo visual [Marr, 1982; Treisman, 1985; Ware, 2004].

\begin{tabular}{ll}
\hline Categoria & Atributo \\
\hline Posição & 1, 2,ou 3 dimensões, Profundidade Estereoscópica \\
\hline Forma & Linha, área, Volume, Orientação, Comprimento, Curvatura, \\
& Tamanho, Marcas, Numerosidade, Côncavo e Convexo \\
\hline Cor & Tonalidade, Saturação, Brilho, Textura \\
\hline Movimento & Direção, Intermitência, Duração, Trajetória, Velocidade \\
\hline
\end{tabular}

Tabela 2.5: Primitivas visuais otimizadas (Fonte: [Ware, 2004])

Para demonstrar essa capacidade, é interessante um breve exercício de busca visual. Ao observar a Tabela 2.6a, o símbolo alvo "•" é detectado sem qualquer esforço e de modo imediato. Em contrapartida, a identificação do mesmo símbolo alvo na Tabela 2.6b exige uma busca visual atentiva e serial. O maior esforço da segunda busca decorre do efeito de distração provocado pela ausência de contraste entre a primitiva visual - tonalidade - do símbolo alvo e dos demais símbolos [Matlin, 2009; Treisman, 1985; Ware, 2004].

\subsubsection{Processamento de Organização dos Elementos}

O ser humano percebe o mundo exterior como objetos complexos relacionados no espaço e no tempo. Porém, o sistema sensorial detecta conjuntos de características primitivas de modo fragmentado, conforme tratado na seção anterior. O papel dessa etapa é organizar tais características para moldar as estruturas visuais correspondentes àquelas observadas no ambiente [Marr, 1982; Palmer, 1999]. Mais especificamente, ocorre um processo de detecção e organização dos elementos - contornos, linhas, superfície, volume - 
135827458785729378135462345
$98539 \bullet 928462969247682363262$
687346724672486284686943456
245872486724698246924457346
$3835728952458724 \bullet 4255365675$
238538753875387539754467367

(a) Uma primitiva otimizada

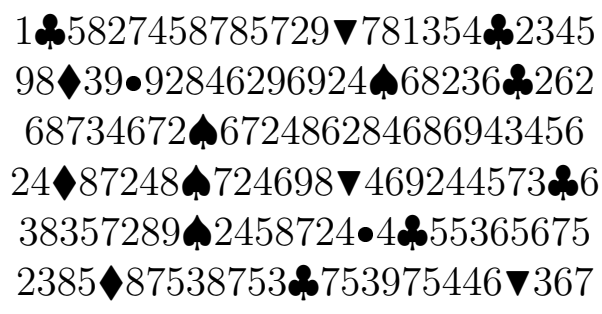

(b) Várias primitivas otimizadas

Tabela 2.6: Demonstração do estímulo das primitivas visuais otimizadas (Adaptado de: [Ware, 2004])

que determinam a estrutura e a ordem da imagem em termos espaciais [Palmer, 1999; Ware, 2004]. Os processamentos inicial da visão e de organização são ambos inconscientes e eficientes na extração de padrões provenientes dos estímulos visuais [Patterson et al. , 2014], sendo as atividades correspondentes apoiadas pela memória de trabalho. O papel da memória de trabalho é propiciar a manipulação e o armazenamento temporário dos objetos extraídos do ambiente [Palmer, 1999].

\subsubsection{Processamento Atentivo}

O processo atentivo representa a atividade mental que aplica de modo serial os recursos cognitivos - capacidade analítica e memória de longo prazo - sobre informações discretas provenientes de uma imagem no ambiente. Esse processo pode ser ativado por controles exógenos ou endógenos. O primeiro tipo de controle representa o direcionamento automático da atenção a um estimulo otimizado, tal como um sinal visual intermitente. Por outro lado, o controle endógeno denota a direção voluntária da atenção a aspectos relacionados ao desempenho de uma atividade [Matlin, 2009; Ware, 2004].

A direção voluntária reflete a interferência do conhecimento e das expectativas de um agente humano na busca e reconhecimento de significados - padrões, relacionamentos, dados elementares - no ambiente compatíveis com a atividade em mãos [Ware, 2004]. O conhecimento remete ao conjunto de saberes relativos a padrões, processos e procedimentos de ação associados ao desempenho de uma atividade. Os agentes humanos organizam esses saberes como membros de categorias que remetem a unidade de representação de significados na memória semântica humana [Anderson, 2005; Smith, 1998]. Componente da memória de longo prazo, a memória semântica possui o conhecimento conceitual que necessitamos para efetuar leituras, tomar decisões, detectar e resolver problemas. Além dessa, a memória de longo prazo é subdivida em memória de procedimentos e episódica [Palmer, 1999]. A primeira contém conhecimentos sobre habilidades genéricas, como andar de bicicleta ou segurar um martelo. Já a episódica contém informações sobre eventos vivenciados por um indivíduo.

A referida interferência do conhecimento é relevante a medida que agentes humanos 
utilizam sistemas de visualização com um objetivo determinado pela atividade correspondente [Anderson, 2005; Andrienko e Andrienko, 2006; Jun et al., 2011; Patterson et al. , 2014]. Como exemplo, agentes avaliadores da qualidade dos dados utilizam sistemas de visualização com o propósito de detectar ou refutar a presença de determinados defeitos nos dados [Kandel et al., 2012a].

Essa síntese do processo cognitivo evidencia que a adequação de um sistema de visualização a um domínio de problema envolve considerar as capacidades da percepção visual e as características das atividades a serem apoiadas [Hegarty, 2011; Jun et al. , 2011; Kosslyn, 2006; Patterson et al., 2014; Tory e Moller, 2004; Ware, 2004]. Com esse objetivo, o presente trabalho observa a necessidade de salientar os significados nos dados determinados pelos defeitos de modo a atender os objetivos das atividades de avaliação da qualidade.

\subsection{Conclusão}

Este capítulo caracterizou os princípios necessários ao desenvolvimento do presente trabalho, quais sejam a Avaliação da Qualidade de Dados, a Visualização de Dados e a Cognição Humana. O primeiro representa o processo que apoia organizações de vários setores da economia na melhoria e manutenção da qualidade de seus dados. Esse complexo processo requer a ponderação de aspectos organizacionais, culturais, funcionais, humanos e da natureza dos defeitos nos dados de modo que o custo envolvido na sua condução não supere os benefícios. Essa necessidade de alinhar eficiência e eficácia torna indispensável o apoio de soluções automatizadas [Dasu, 2013; Loshin, 2010; Naumann, 2002].

Por sua vez, a visualização de dados é uma área de pesquisa multidisciplinar que busca criar representações visuais e interativas capazes de facilitar a compreensão de fenômenos em dados complexos. No tocante à qualidade de dados, essa área de pesquisa possui as ramificações da Visualização de Incertezas e da Qualidade de Dados Espacial que reúnem denso conhecimento de como comunicar visualmente métricas de incertezas identificadas matematicamente. O presente trabalho adiciona a perspectiva do uso das capacidades da visualização para avaliar a qualidade dos dados de modo visual e interativo.

A cognição humana reflete o inter-relacionamento entre a percepção visual e o raciocínio para a aquisição de conhecimentos. Compreender esses elementos possibilita criar sistemas de visualização que utilizam apropriadamente as capacidades inatas humanas, bem como favoreçam a extração de significados necessários a realização de uma atividade.

O próximo capítulo - Capítulo 3 - descreve as capacidades e as limitações das soluções automatizadas de avaliação da qualidade de dados baseadas nas abordagens computacionais e visuais. Com o mesmo objetivo, o capítulo aborda os trabalhos que descrevem os defeitos nos dados, bem como os conhecimentos relativos ao projeto de sistemas de visualização de dados no domínio do pAQD. 


\section{Capítulo 3}

\section{Trabalhos Relacionados}

\subsection{Introdução}

A viabilização do $\mathrm{pAQD}$ requer o apoio da automação para revelar o nível de qualidade corrente dos dados [Malik et al., 2010; Naumann, 2002; Rahm e Do, 2000]. Este capítulo caracteriza as duas abordagens mais relevantes de automação da avaliação da qualidade dos dados, quais sejam a computacional e a baseada na visualização de dados respectivamente, Seções 3.2 e 3.3 .

Contudo, projetar e aplicar sistemas ou soluções baseados nessas abordagens requer o domínio prévio da estrutura do problema adjacente aos defeitos. Devido essa importância, a Seção 3.4 caracteriza os diferentes trabalhos que organizam e descrevem defeitos nos dados relativos aos critérios de qualidade da classe conteúdo: acurácia, completude e consistência - Seção 2.2.3.2. Por fim, a Seção 3.5 descreve como o conhecimento corrente sobre o projeto de sistemas de visualização considera as necessidades relativas a avaliação visual da qualidade dos dados.

O objetivo deste capítulo é expor os limites do estado-da-arte da literatura e propiciar o enquadramento mais preciso das contribuições do presente trabalho.

\subsection{Avaliação da Qualidade dos Dados por Aborda- gens Computacionais}

As abordagens computacionais de análise da qualidade dos dados contam com numerosas e importantes contribuições provenientes das áreas de bancos de dados, da estatística e da mineração de dados. Tal fato marca a presença de um conjunto diversificado de técnicas de identificação de padrões que podem remeter a defeitos nos dados.

Tradicionalmente, tais abordagens operam por meio do exame extensivo dos dados e podem ser separadas em duas categorias principais: a baseada em asserções e a baseada em métodos quantitativos [Loshin, 2010]. Os representantes da primeira categoria 
aplicam procedimentos para determinar o grau de conformidade dos dados as asserções previamente estabelecidas. Em contraste, a segunda categoria denota o uso de técnicas estatísticas - incluindo a distribuição gaussiana e análise multivariada -, de mineração de $\operatorname{dados}^{1}$ ou aprendizado de máquina - do inglês Machine Learning - para a extração de assinaturas matemáticas dos dados.

As seções subsequentes sintetizam as características e limites de duas soluções representativas das categorias supracitadas, quais sejam a categorização de dados e a mineração de dados, respectivamente. Embora não abordado, cumpre ressaltar que o aprendizado de máquina e a mineração de dados compartilham similaridades relacionadas a abordagem, ao arcabouço e as limitações.

A categorização de dados e a mineração de dados apresentam decisões distintas de projeto que implicam em diferentes limites no apoio ao pAQD. De modo a retratar sinteticamente os referidos limites, o presente trabalho analisou os seguintes aspectos: i) a capacidade de manipulação de grandes volumes de dados, ii) o grau de favorecimento a supervisão humana, iii) os obstáculos para confirmar ou refutar a presença de defeitos nos dados.

Todos os referidos aspectos são ubíquos ao pAQD - Seção 2.2.3.1 -, bem como permitem situar a contribuição da visualização de dados no domínio da avaliação da qualidade de dados.

\subsubsection{Categorização de dados}

\subsubsection{Características}

A categorização de dados - do inglês Data Profiling - é uma solução que disponibiliza um conjunto variado de informações empíricas sobre os dados por meio da aplicação de diferentes algoritmos de análise. Além de apoiar o pAQD, a categorização também é utilizada em necessidades envolvendo migrações de esquemas de bancos de dados, processos de integração de dados, construção da arquitetura empresarial de dados, dentre outros [Do, 2009; Loshin, 2010].

A categorização de dados pode operar no modo de validação ou exploração. O objetivo do primeiro modo é revelar não conformidades dos dados frente a asserções definidas com base em metadados ou definições de especialistas do UdD [Olson, 2003]. Em contrapartida, o modo de exploração produz uma coleção de informações relativas aos dados mediante análises reversas. Essas análises ocorrem em níveis de granularidades distintos, quais sejam atributos isolados, cruzamento entre atributos da mesma relação e inter-relações [Loshin, 2010; Olson, 2003].

\footnotetext{
${ }^{1}$ Neste texto, o termo mineração de dados remete a métodos não supervisionados de aprendizagem de máquina. Por outro lado o termo aprendizagem de máquina remete a métodos supervisionados de aprendizagem.
} 
A análise de atributos isolados aplica técnicas da estatística descritiva e de sumário textual - como Minhash Signature e Approximate String [Do, 2009] - para expor diferentes características dos dados, incluindo aquelas relativas a unicidade, a nulidade e a frequência de valores. Por sua vez, a análise cruzada de atributos usa outro conjunto de técnicas como Approximate Keys [Do, 2009] - para revelar atributos candidatos a chave primária, inferir dependências funcionais e indicar tuplas potencialmente duplicadas. Por último, a análise de inter-relações identifica questões inerentes ao relacionamento entre relações, incluindo tuplas órfãs e cardinalidade.

\subsubsection{Limites}

A característica central da categorização de dados é a capacidade de parametrizar e aplicar diferentes algoritmos de análise dos dados. Contudo, a natureza não supervisionada desses algoritmos impede a análise de resultados intermediários e a calibragem de parâmetros. Além disso, a parametrização é um ato complexo que requer profissionais especializados com raros conhecimentos sobre o contexto dos dados [Naumann, 2014]. Esse afastamento entre quem aplica a avaliação nos dados e quem analisa os resultados da avaliação afeta o desempenho e os resultados da atividade de avaliação dos dados.

Outro ponto de atenção da categorização dos dados remete ao formato de comunicação dos respectivos resultados. Usualmente, esses resultados são apresentados na forma de relatórios tabulares estáticos baseados em texto ou em painéis de indicadores sintéticos dashboards - com reduzida interatividade. Tais opções de visualização dificultam a exploração e a interpretação do conteúdo informacional gerado pela categorização de dados.

Por fim, essa solução apresenta restrita escalabilidade em razão de uma arquitetura baseada na disponibilidade de dados em memória. Essa premissa estabelece uma oposição prática entre os requisitos de agilidade na entrega dos resultados e o volume de dados analisados [Naumann, 2014]. O processamento em lote e a amostragem dos dados são os recursos que contornam parcialmente a referida situação [Loshin, 2010].

\subsubsection{Mineração de Dados}

\subsubsection{Características}

A mineração de dados é conhecida pela capacidade de extrair propriedades desconhecidas de grandes volumes de dados, inclusive aquelas relacionadas a possíveis defeitos nos dados. A detecção de anomalia - do inglês Anomaly Detection - compreende técnicas de mineração aplicadas na identificação de objetos com comportamentos que destoam daquele esperado: os atípicos [Chandola et al., 2009].

As técnicas baseadas em proximidade e densidade pontuam cada objeto de acordo com sua distância aos $k$-ésimos objetos vizinhos considerados globalmente ou circunscritos em 
um raio, respectivamente [Tan et al., 2006]. Por sua vez, técnicas estatísticas inferem a aderência probabilística dos objetos frente a um modelo de distribuição dos dados. Já as técnicas baseadas em agrupamentos - do inglês clustering - identificam objetos não fortemente relacionados aos demais segundo seu grau de isolamento ou por meio de funções objetivas que determinam o relacionamento de pertinência de um objeto a um agrupamento [Chandola et al., 2009; Tan et al., 2006].

Abordagens adicionais combinam a mineração de dados a outras técnicas para revelar outros defeitos nos dados. Como exemplo, técnicas de agrupamento e de lógica difusa - do inglês fuzzy logic - são aplicadas para determinar o grau de acurácia das tuplas de uma relação [Khosravani, 2012]. Outra abordagem adota uma estratégia semi-supervisionada que mescla o agrupamento de subespaço - do inglês sub-space clustering - e a técnica de classificação [Januzaj e Januzaj, 2009]. Nessa abordagem cada interação representa o agrupamento dos dados por um novo atributo até a determinação do agrupamento mais adequado, segundo o julgamento do agente avaliador da qualidade. Esse agrupamento é base para a aplicação de uma função de classificação que pode determinar os atributos vazios, os atributos incorretos - conteúdo igual a zero - e as tuplas duplicadas.

\subsubsection{Limites}

A mineração de dados realiza a simplificação e abstração dos dados por meio de arcabouço matemático-estatístico que exclui a capacidade de análise de um agente avaliador da qualidade [Tan et al., 2006], sendo os limites similares àqueles apresentados para a categorização de dados - Seção 3.2.1.2. O conhecimento humano é restrito a seleção dos algoritmos mais apropriados a detecção de um defeito particular, a calibragem dos respectivos parâmetros e a análise dos padrões revelados pelos referidos algoritmos [Dasu, 2013; Dasu e Johnson, 2003]. Inclusive, essa última operação estimulou o uso dos recursos da visualização de dados para alavancar a compreensão dos referidos padrões - Visual Data Mining [Keim, 2002].

O arcabouço de mineração de dados compreende conhecimentos matemáticos e estatísticos - de certa complexidade - utilizados de maneiras diferentes por diversos algoritmos mineradores [Dasu, 2013]. Tal diversidade torna a seleção e a parametrização dos algoritmos mineradores para conjuntos de dados de características distintas um desafio [Rahm e Do, 2000]. Usualmente, esse procedimento pode envolve várias calibragens até atingir a parametrização ideal de certo algoritmo para um dado conjunto de dados [Dasu e Johnson, 2003].

Certos algoritmos de mineração de dados apresentam tempo e espaço de memória na ordem de $O\left(N^{2}\right)$, fato que delimita o volume de dados manipulado. Contudo, a literatura provê várias técnicas que permitem a mineração de grandes volumes de dados, incluindo técnicas de redução do número de atributos - como FastMap, ISOMAP e PCA [Tan et al., 2006] -, de redução de cálculos de proximidade - como $k$-d tree [Tan et al., 2006] - e de 
processamento distribuído ou paralelo - como Peer-to-Peer e algoritmos baseados em GPU [Zeng et al., 2012].

\subsection{Avaliação da Qualidade dos Dados por Aborda- gens Visuais}

O uso de sistemas de visualização na avaliação da qualidade de dados apresenta pesquisas com certo grau de isolamento em diferentes áreas de pesquisa, incluindo mineração de dados, banco de dados, estatística e gestão da qualidade de dados. Integrar os resultados das referidas pesquisas de modo a revelar pontos conflitantes, insuficientes e oportunidades de novos estudos requer uma revisão sistemática [Castro, 2013]. O objetivo dessa técnica é conduzir um estudo retrospectivo que ofereça um alicerce informacional sobre uma questão ou fenômeno [Castro, 2013].

O presente trabalho utilizou como base essa técnica para realizar um levantamento bibliográfico mais rigoroso dos principais sistemas de visualização que apoiam a avaliação da qualidade dos dados relativos aos critérios de qualidade da classe conteúdo. As Seções 3.3.1 a 3.3.3 descrevem os protocolos de triagem dos trabalhos pertinentes ao objetivo do referido levantamento, enquanto a Seção 3.3.4 caracterizam os trabalhos selecionados quanto as funcionalidades e limitações.

\subsubsection{O Protocolo de Identificação dos Trabalhos}

A identificação dos trabalhos foi realizada em três passos sequenciais: a seleção das publicações científicas, a definição dos termos gerais e a triagem dos trabalhos. O primeiro passo considerou diferentes mecanismos para identificar as publicações científicas periódicos, conferências e simpósios - mais fortemente vinculadas ao objetivo do levantamento bibliográfico.

Os periódicos identificados predominaram da classificação oferecida pelo Journal Citation Report [Reuters, 2011]. Outros mecanismos permitiram identificar certos periódicos relacionados as áreas da Estatística e de Sistemas de Informação, respectivamente The ERA Journal List [Council, 2012] e [Sadiq et al., 2011]. Por sua vez, a identificação das conferências e simpósios considerou as classificações presentes no The ERA Conference Ranking Exercise [Research e of Australasia, 2010] e o respectivo vínculo aos periódicos selecionados. Este trabalho selecionou as publicações científicas cuja linha editorial apresentava correlação ao objetivo do levantamento bibliográfico - Seção 3.3.

O segundo passo estipulou termos gerais e seletivos considerando as áreas das publicações científicas selecionadas, conforme observado no Quadro 3.1. Por exemplo, os termos outlier e missing foram incorporados por representarem denominações comuns na área da Estatística. O passo de busca aplicou os referidos termos - conectados por junção 


\begin{tabular}{|l|}
\hline Termo \\
\hline Anomaly Detection \\
Data Anomaly \\
Data Assessment \\
Data Consistency \\
Data Diagnostic \\
Data Evaluation \\
Data Glitches \\
Data Profile \\
Data Quality \\
Data Uncertainty \\
Diagnosing Data \\
Dirty Data \\
Error Detection \\
Missing Data \\
Missing Values \\
Outlier \\
Variable Quality \\
\hline
\end{tabular}

Quadro 3.1: Lista de Termos Gerais para a seleção das Publicaçôes Científicas (Fonte: Elaborado pelo autor)

- sobre o título, palavras-chave e o resumo dos trabalhos disponíveis nas publicações selecionadas.

\subsubsection{O Protocolo de Triagem dos Trabalhos}

O passo de triagem realizou dois procedimentos de análise de trabalhos completo ou em progresso. O primeiro procedimento selecionou trabalhos candidatos por meio da análise do título, das palavras chaves e do resumo correspondentes. Por sua vez, o segundo procedimento ponderou trechos ou o texto na íntegra de cada um dos trabalhos candidatos para determinar a sua aderência ao objetivo desse levantamento. Os critérios de seleção utilizados foram:

i. Visualização como mediadora da avaliação da qualidade dos dados

Esse critério desqualificou os trabalhos que utilizam a visualização para comunicar métricas do controle estatístico de qualidade, apresentar resultados de procedimentos de categorização de dados, limpeza dos dados e ou mesmo facilitar a interpretação dos resultados de modelos de mineração de dados.

ii. Caracterização de Sistemas de Visualização

Esse critério desqualificou trabalhos que avaliam isoladamente técnicas de visualização na detecção de defeitos - [Kandogan, 2001; Ward e Theroux, 1997] -, bem como aqueles que discutem arcabouços ou recursos de visualização na avaliação da qualidade dos dados [Campello et al., 2015; Fernstad e Glen, 2014]. 


\section{iii. Dados desprovidos de mapeamento espacial óbvio e atemporais}

Sistemas de visualização aplicados na avaliação da qualidade de dados com referência geométrica foram desclassificados - Seção 2.3.2. Esse é o caso do sistema que aborda a avaliação da qualidade da distribuição espacial de dados fotográficos [Kachkaev e Wood , 2012], sendo ainda outros elencados em [Potter et al., 2012].

iv. Defeitos relativos aos critérios de qualidade da classe conteúdo

Trabalhos que abordam defeitos diferentes de acuracidade, de completude ou de consistência foram desconsiderados. Como exemplo, esse critério desqualificou o sistema de visualização que apoia a integração de esquemas de banco de dados [Robertson et al. , 2005].

As Tabelas 3.1 e 3.2 expõem todas as publicações pesquisas separadas por periódicos e conferências-simpósios, respectivamente. Tais publicações estão agrupadas por grandes áreas de pesquisa, o respectivo editor - ver Lista de Abreviações e Acrônimos -, o intervalo de tempo considerado na seleção dos trabalhos e o mecanismo de busca empregado. As colunas "Colet." " "Selec." - respectivamente, número de soluções coletadas² e selecionadas - indicam a quantidade de sistemas de visualização únicos na respectiva publicação e não o número do trabalhos desdobrados do mesmo.

\begin{tabular}{|c|c|c|c|c|}
\hline Periódico (Editor) & Período & Colet. & Selec. & $\begin{array}{c}\text { Mecanismo } \\
\text { Busca }\end{array}$ \\
\hline \multicolumn{5}{|l|}{ Banco de Dados } \\
\hline Advances in Data Analysis and Classification (Springer) & $2007-2016$ & 1 & 1 & Sringer Link \\
\hline Data Mining and Knowledge Discovery (Springer) & $1997-2016$ & - & - & Sringer Link \\
\hline Transactions on Database Systems (ACM) & $1976-2016$ & - & - & Digital Library \\
\hline Transactions on Knowledge Discovery from Data (ACM) & $2007-2016$ & 1 & 0 & Digital Library \\
\hline VLDB Journal (Endowment) & $1992-2016$ & 1 & 0 & DBLP \\
\hline \multicolumn{5}{|l|}{ Estatística } \\
\hline Computational Statistics and Data Analysis (Elsevier) & $1978-2016$ & - & - & SciVerse \\
\hline Journal of Computational and Graphical Statistics (ASA) & $1992-2013$ & 3 & 2 & Taylor and Francis \\
\hline Journal of Data Science (NYU,CFJ,RDM) & 2003-2016 & 1 & 1 & Google Scholar \\
\hline Statistical Analysis and Data Mining (Wiley) & 2008-2016 & - & - & Wiley Searcher \\
\hline Statistics and Computing (Springer) & $1991-2016$ & 1 & 0 & Springer Link \\
\hline \multicolumn{5}{|l|}{ Sistemas de Informação } \\
\hline Journal of Data and Information Quality (ACM) & 2009-2016 & 1 & 0 & Digital Library \\
\hline International Journal of Applied Information Systems (FCS) & $2010-2016$ & - & - & IJAIS Searcher \\
\hline \multicolumn{5}{|l|}{ Visual Analítica, Visualização e IHC } \\
\hline Transactions on Computer-Human Information (ACM) & 1994-2016 & - & - & Digital Library \\
\hline Transactions on Visualization and Computer Graphics (IEEE) & $1995-2016$ & 5 & 1 & Xplore \\
\hline Transactions on Knowledge and Data Engineering (IEEE) & $1989-2016$ & - & - & Xplore \\
\hline Information Visualization (SAGE) & $2002-2016$ & 2 & - & Sage Searcher \\
\hline
\end{tabular}

Tabela 3.1: Trabalhos analisados e selecionados por Periódicos (Fonte: Elaborado pelo autor)

\footnotetext{
${ }^{2}$ Remete ao número de soluções analisadas pelo segundo procedimento de triagem, isto é, os trabalhos candidatos.
} 


\begin{tabular}{|c|c|c|c|c|}
\hline Conferência, Simpósio e Workshop (Editor) & Período & Colet. & Selec. & $\begin{array}{c}\text { Mecanismo } \\
\text { Busca }\end{array}$ \\
\hline \multicolumn{5}{|l|}{ Banco de Dados } \\
\hline International Conference on Management of Data (ACM) & $1970-2015$ & 7 & 0 & Digital Library \\
\hline International Conference on Very Large Databases (Endowment) & $1976-2016$ & 6 & 0 & DBLP \\
\hline International Conference on Data Engineering (IEEE) & $1984-2015$ & 4 & 0 & Xplore \\
\hline International Conference on Data Mining (IEEE) & $2001-2015$ & - & - & Xplore \\
\hline \multicolumn{5}{|l|}{ International Conference on Knowledge Discovery and } \\
\hline Data Mining $(\mathrm{ACM})$ & $1999-2015$ & 1 & 0 & Digital Library \\
\hline \multicolumn{5}{|l|}{ International Workshop on Information Quality } \\
\hline in Information Systems $(\mathrm{ACM})^{1}$ & $2004-2008$ & - & - & DBLP \\
\hline Special Interest Group on Management of Data (ACM) & $1969-2016$ & 4 & 0 & Digital Library \\
\hline Visual Database System $(\text { IFIP })^{1}$ & 1989-2002 & - & - & DBLP \\
\hline \multicolumn{5}{|l|}{ Estatística } \\
\hline \multicolumn{5}{|l|}{ New Techniques and Technologies for } \\
\hline Statistics Conference (Eurostat) & $1992-2015$ & 1 & 1 & Google Scholar \\
\hline \multicolumn{5}{|l|}{ Sistemas de Informação } \\
\hline Americas Conference on Information Systems (AIS) & $1995-2015$ & - & - & Eletronic Library \\
\hline International Conference on Information Quality (MITIQ) & $1996-2015$ & 9 & 2 & Google Scholar \\
\hline \multicolumn{5}{|l|}{ Visual Analítica, Visualização e IHC } \\
\hline Conference on Human Factors in Computing Systems (ACM) & $1981-2016$ & 3 & 0 & Digital Library \\
\hline Conference on Visualization $\left(\right.$ IEEE) ${ }^{1}$ & $1990-2005$ & 2 & 0 & Xplore \\
\hline Conference on Visual Analytics Science and Technology (IEEE) ${ }^{2}$ & $2006-2015$ & 10 & 2 & Xplore \\
\hline \multicolumn{5}{|l|}{ International Conference on Computer Graphics, Imaging } \\
\hline and Visualization (IEEE) & 2004-2016 & - & - & Xplore \\
\hline International Conference on Information Visualization (IEEE) & $1997-2015$ & 7 & 1 & Xplore \\
\hline \multicolumn{5}{|l|}{ International Working Conference on Advanced } \\
\hline Visual Interfaces (ACM) & $1994-2014$ & 3 & 1 & Digital Library \\
\hline Symposium on Information Visualization (IEEE) ${ }^{1}$ & $1995-2006$ & 1 & 1 & Xplore \\
\hline Symposium on Large Data Analysis and Visualization (IEEE) & $2011-2015$ & - & - & Xplore \\
\hline
\end{tabular}

1 : Descontinuados ou incorporados por outras Conferências/Simpósios

2 : Simpósio até 2012. Conferência a partir de 2013

Tabela 3.2: Trabalhos analisados e selecionados por Conferências e Simpósios (Fonte: Elaborado pelo autor)

\subsubsection{O Protocolo de Interpretação dos Resultados}

Avaliar um sistema constitui uma etapa complexa na área de visualização, pois deve ponderar diferentes aspectos associados a forma e a perspectiva de avaliação [Thomas e Cook , 2005]. A composição final desses aspectos determina a abrangência dos resultados, o esforço e o custo correspondentes. Com o crescente emprego da visualização de dados em diferentes domínios, essa etapa é relevante ao beneficiar testes de hipóteses e revelar desafios de pesquisa [Keim et al., 2010; Lam et al., 2012].

As formas de avaliação determinam o grau de formalização e a duração da avaliação, incluindo técnicas como estudos longitudinais ${ }^{3}$, heurísticas ${ }^{4}$ e estudo de casos. Por outro lado, a perspectiva de avaliação denota a amplitude das características observadas em um sistema de visualização [Thomas e Cook, 2005], compreendendo de componentes ou técnicas isoladas até o sistema na íntegra - ambiente de uso e características das tarefas apoiados.

\footnotetext{
${ }^{3}$ Abordagem de estudo que observa o uso de um sistema de visualização por um longo período de tempo [Shneiderman e Plaisant, 2006].

${ }^{4}$ Abordagem na qual usuários experientes julgam se um sistema de visualização atende as diretrizes da heurística [Lam et al., 2012]
} 
Apenas 33\% dos trabalhos selecionados descrevem certos resultados dos sistemas de visualização implementados por meio de estudo de casos, majoritariamente. Contudo, a profundidade díspar e a incompletude das descrições - metodologia do estudo de caso não relevada, por exemplo - impediram a confrontação direta dos trabalhos ou a condução de meta-análises [Castro, 2013].

Desse modo, o presente trabalho adotou três aspectos para caracterizar os trabalhos selecionados ao longo da Seção 3.3.4. Tais aspectos correspondem as necessidades da avaliação visual da qualidade de dados mediada por sistema de visualização de dados Seção 5.2 -, quais sejam volume, interação e representação visual.

$\mathrm{O}$ aspecto volume considera as técnicas empregadas para propiciar o acesso a grandes resoluções de dados, como compressão de dados e hierarquias de multiresolução [Unwin et al., 2006]. A interação observa como as técnicas de interação são utilizadas na manipulação dos dados de modo a beneficiar a avaliação da qualidade. Por fim, a representação visual observa as propriedades visuais - Seção 2.3.4.2.1 - das técnicas de visualização na avaliação visual da qualidade dos dados.

\subsubsection{Caracterização dos Trabalhos}

Esta seção descreve resumidamente as características e os limites dos trabalhos selecionados de acordo com os aspectos definidos na Seção 3.3.3. Cumpre lembrar que tais descrições apresentam variações de detalhes provocadas pela ausência do relato ou mera menção de elementos relacionados aos referidos aspectos.

\subsubsection{Manet}

\subsection{Características}

O propósito do sistema Manet - acrônimo de Missings Are Now Equally Treated [Theus et al., 1997; Unwin et al., 1996] é a exposição da ausência de valores em atributos de uma relação. Para tal, esse sistema utiliza um conjunto de técnicas de visualização representadas em visões concorrentes múltiplas ou treliça com capacidades de seleção e ligação de dados entre as visões e detalhes sobre demanda no estilo hover queries.

Para analisar um atributo isolado, os gráficos de barra horizontal e barra vertical utilizam tonalidades contrastantes para denotar a proporção de valores ausentes e não ausentes. Por sua vez, o histograma mantém sua forma clássica e destaca em barra à parte a frequência de valores ausentes para o atributo em questão - Figura 3.1a.

Quando considerado dois atributos, o gráfico de dispersão indica com um círculo branco ao longo do eixo $x$ ou $y$ a existência de valores ausentes para um dos atributos em questão. Porém, essa representação não é aplicável quando ambos atributos detém valores ausentes. O gráfico mosaico correlaciona até oito atributos categóricos e salienta em tonalidade 


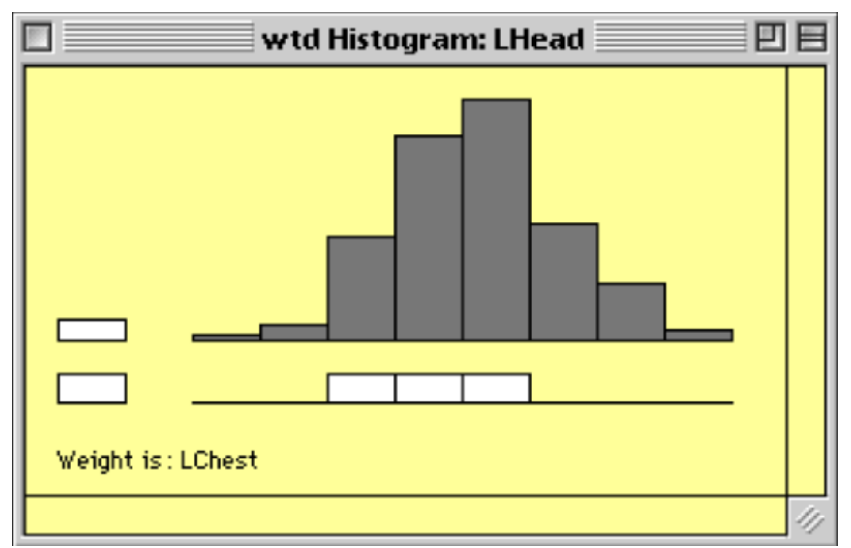

(a) Histograma

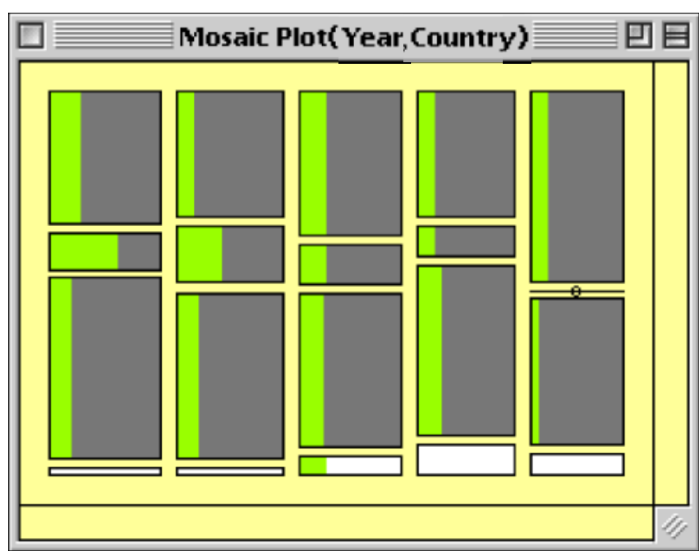

(b) Gráfico Mosaico

Figura 3.1: Representações visuais do Manet (Fonte: ([Theus et al., 1997])

vibrante a proporção de valores ausentes dentro de cada ladrilho, conforme observado na Figura 3.1b.

\subsection{Limites}

Esse sistema molda um conjunto de técnicas de visualização para comunicar valores ausentes - uma das variantes do defeito Violação de Restrição de Domínio, Seção 4.4 - em atributos de uma relação. Naturalmente, essa premissa limita o uso do Manet para detectar outros defeitos nos dados devido a distração provocada pelas propriedades otimizadas Seção 2.4.1. Além disso, a ausência de escalas em todas as visualizações impede a realização de análises comparativas [Kosslyn, 2006], embora o gráfico de dispersão ainda permita a percepção dos casos atípicos não situados entre grupos de pontos [Ward e Theroux, 1997].

O Manet restringe o volume de dados manipulado - até $10^{5}$ tuplas - devido a carência de recursos e técnicas de interação. Essa carência provoca diferentes adversidades. Como exemplo, o gráfico de dispersão experimenta o crescimento da sobreposição de pontos e do consumo de memória [Unwin et al., 2006]. Ainda, a natureza discreta do gráfico mosaico pode ultrapassar o limite humano de distinção de até 100 ladrilhos mesmo para relações com volume modesto de dados [Unwin et al., 2006].

\subsubsection{GGobi}

\subsection{Características}

Similar ao sistema anterior, o objetivo do GGobi [Cook e Swayne, 2007; Swayne et al. , 2003] é apoiar análises dados com valores ausentes. Esse sistema representa a evolução em termos visuais e arquitetônicos do predecessor XGobi [Swayne e Buja, 1998; Swayne et al. , 1998]. 
Os atributos com valores ausentes são estimados por métodos de imputação randômicos ou baseados em um percentual sobre o valor máximo ou mínimo do atributo em questão. A localização dos valores ausentes no conjunto de dados é mantida pelo GGobi por meio de uma matriz binária - denominada de matriz sombra - de tamanho proporcional ao conjunto de dados tratado. Essa matriz binária permite destacar posicionalmente os valores ausentes que foram imputados, conforme ilustrado na Figura 3.2a.

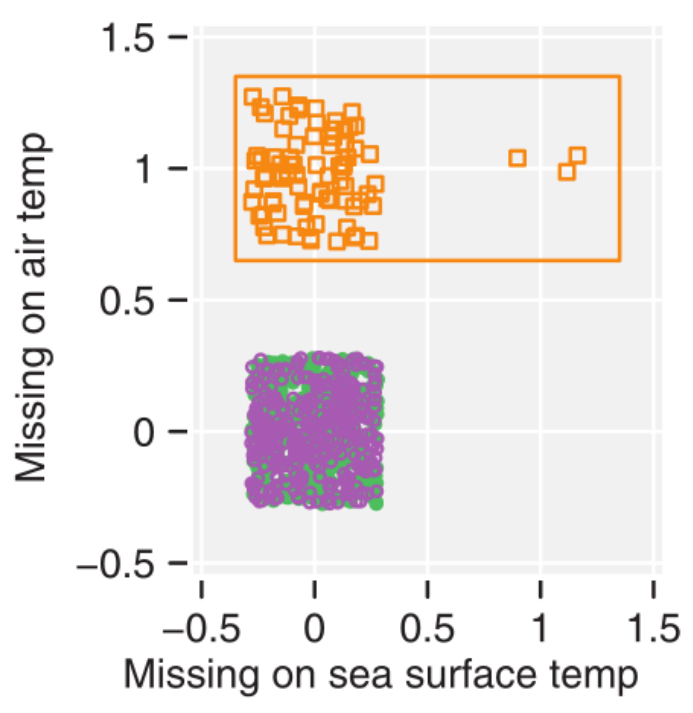

(a) Agrupamento de valores imputados

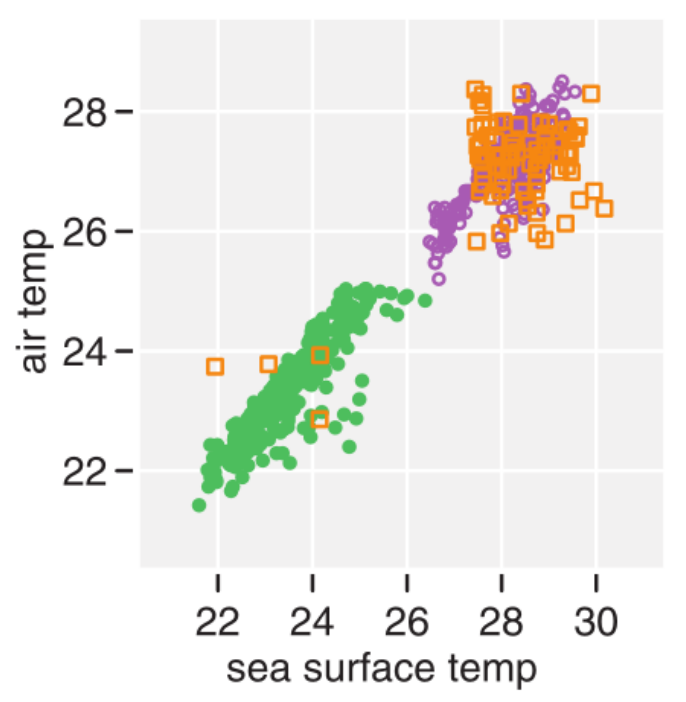

(b) Correlação entre valores imputados e os demais

Figura 3.2: Representações Visuais concorrentes múltiplas do GGobi (Fonte: ([Cook e Swayne, 2007])

O gráfico de dispersão - formato bivariado e matriz -, o gráfico de pontos e as coordenadas paralelas são as técnicas de visualização utilizadas para a montagem de representações visuais concorrentes múltiplas e capacidade de interação de seleção e ligação, conforme observado na Figura 3.2. Em especial, os gráficos de pontos e de dispersão bivariado ainda contam com interações de aproximação, rotação manual e rotação automática - Grand Tour.

Técnicas de amostragem - não informadas - permitem o GGobi manipular conjuntos de dados com até $5 * 10^{5}$ tuplas. Porém, as amostras devem apresentar o tamanho máximo de $10^{4}$ tuplas para garantir um tempo de resposta adequado das interações [Swayne e Buja, 1998]. Além da amostragem, o GGobi oferece a técnica de distorção espacial - Seção 2.3.4.1 - para minorar a oclusão visual das técnicas de visualização que descrevem os dados por meio de pontos. 


\subsection{Limites}

O sistema GGobi foi projetado para apoiar a análise e compreensão de valores ausentes, limitando seu uso na avaliação de outros defeitos nos dados - análogo à discussão do Manet na Seção 3.3.4.1.2. Além disso, esse sistema utiliza uma conjunto de técnicas de visualização baseadas em pontos e linhas que são deficientes na representação de relações acima de $10^{4}$ tuplas. Por exemplo, o excesso de sobreposição e cruzamento de linhas nas coordenadas paralelas torna imperceptível qualquer padrão de defeito nos dados [Unwin et al., 2006].

O GGobi disponibiliza duas abordagens para minorar essa situação, quais sejam as técnicas de amostragem e de deslocamento espacial. A primeira atua na redução do número das tuplas manipuladas, enquanto a segunda reduz o efeito da sobreposição de pontos. Todavia, as técnicas de amostragem são ineficazes uma vez que as amostras podem não conter dados defeituosos - amostra não representativa. Já a técnica de deslocamento espacial é dependente da característica dos dados, isto é, seu efeito é muito tênue para dados altamente concentrados em pequenas regiões visuais [Unwin et al., 2006].

Outro ponto de atenção recai sobre as visões concorrentes múltiplas. O GGobi - assim como o Manet - adotada visões múltiplas dispostas em janelas não-modais e flutuantes. Essa abordagem aumenta o número de atividades operacionais - como a coordenação entre janelas - para a realização da análise dos dados [Maciel et al., 2008].

\subsubsection{DaVis}

\subsection{Características}

O propósito do sistema de visualização DaVis - Data Quality Visualization - [Sulo et al. , 2005] é auxiliar na avaliação de quatro defeitos específicos nos dados, incluindo tuplas duplicadas e valores ausentes. O DaVis utiliza uma técnica de visualização tabular na qual cada coluna representa um atributo e cada linha reflete uma tupla. Os valores são expressos por barras horizontais que apresentam tamanho fixo e tonalidade variada para atributos categóricos ou tamanho proporcional aos valores para atributos quantitativos. Detalhes sobre as tuplas são representados de forma textual na porção inferior, conforme observado na Figura 3.3.

Filtros estáticos situados no menu permitem selecionar qual dos defeitos nos dados será observado. Valores ausentes e zerados são denotados por barras ausentes ou por barras na tonalidade amarela - respectivamente, Figuras 3.3b e 3.3a. Já os casos de tuplas potencialmente duplicadas - técnica de deduplicação não informada - são destacadas com cor vistosa, conforme ilustra a Figura 3.3b. 


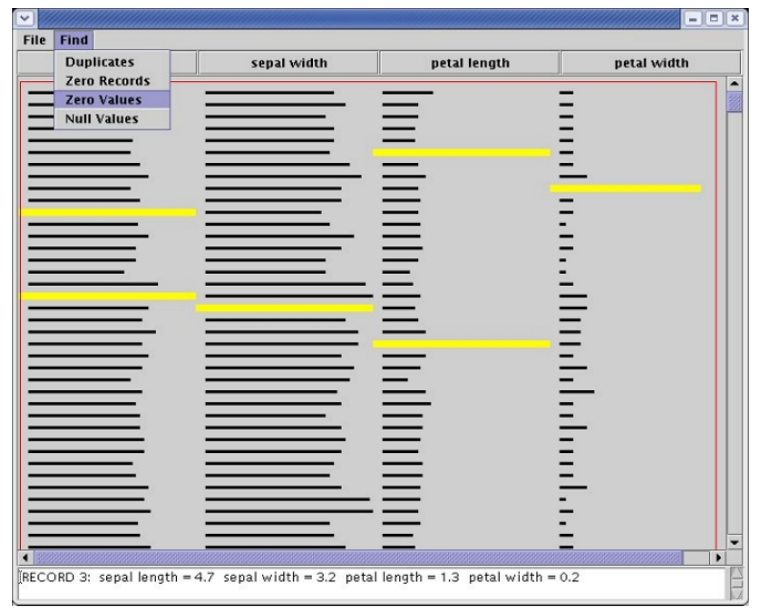

(a) Atributos com valores zerados

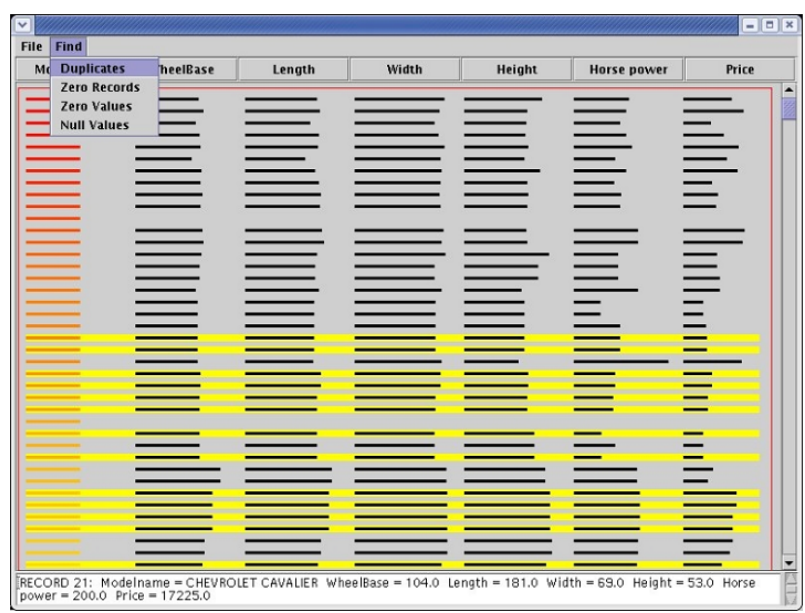

(b) Tuplas possivelmente duplicadas

Figura 3.3: Representação visual do DaVis (Fonte: [Sulo et al., 2005])

\subsection{Limites}

As características da técnica de visualização utilizada pelo sistema DaVis criam várias dificuldades a avaliação da qualidade dos dados. O espaçamento entre as barras reduz a capacidade de correlacionar os dados e detectar padrões de defeito em razão da violação do princípio da proximidade ${ }^{5}$. Ainda, a representação na granularidade de tupla provoca a difusão das tuplas por várias telas, obrigando operações de rolagem. Essa situação aumenta o esforço de avaliação uma vez que impõem ao agente avaliador o trabalho de considerar padrões suspeitos entre diferentes pontos de rolagem [Bennett et al., 2006; Thomas e Cook, 2005]. Uma vez que o DaVis não oferece técnicas de interação, seu uso é inviável para relações de resolução superior a $10^{3}$ tuplas.

\subsubsection{XMDVTOOL ${ }^{Q}$}

\subsection{Características}

O sistema XMDVTOOL ${ }^{Q}$ [Cui et al., 2006; Fua et al., 1999; Rundensteiner et al. , 2007; Xie et al., 2006] informa sobre a ausência de valores em atributos por meio de métricas que determinam a qualidade para um valor individual, um atributo e uma tupla.

A execução de um algoritmo de imputação múltipla antecede a apuração das métricas. Tal dependência decorre da métrica fundamental - o valor do atributo - utilizar o desvio padrão $\delta_{k}$ entre as $k$-ésimas imputações como um dos parâmetros de sua fórmula. Os demais parâmetros requeridos correspondem aos valores extremos do atributo questão, conforme a equação 3.1. Essa métrica, por sua vez, é base para apurar a qualidade no nível

\footnotetext{
${ }^{5} \mathrm{O}$ princípio da proximidade denota que elementos próximos são processados como um conjunto ao invés de serem processados isoladamente. Logo, a proximidade favorece a compreensão mais rápida de informações [Matlin, 2009].
} 
do atributo e da tupla, seguindo as respectivas equações 3.2 e 3.3, na qual $A$ representa a quantidade de atributos e $T$ a de tuplas.

$$
\begin{gathered}
\text { Valor }_{i}=1-\frac{\delta_{k}}{\text { Valor Atributo }_{\max }-\text { Valor Atributo }_{\min }} \\
\text { Atributo }_{j}=\frac{\sum_{i=1}^{T} V_{i j}}{T} \\
\text { Tupla }_{i}=\frac{\sum_{j=1}^{A} V_{i j}}{A}
\end{gathered}
$$

Tais métricas são normalizadas dentro do domínio de valores entre zero e um que determinam baixa e alta qualidade, respectivamente. Ao término do cômputo, todas as métricas são combinadas ao conjunto de dados original, implicando a geração de novo conjunto de dados com o dobro de atributos.

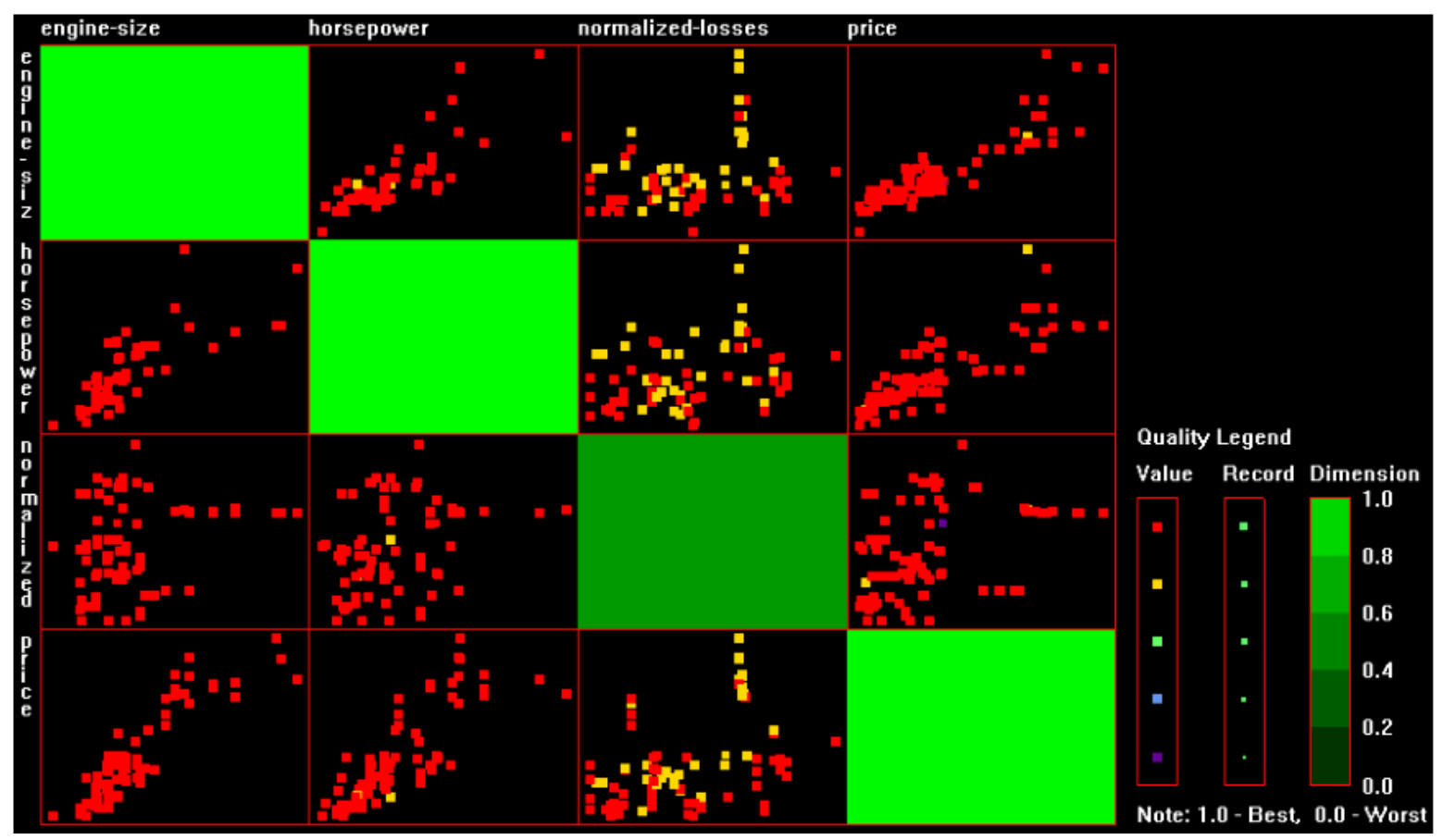

Figura 3.4: Representação visual do XMDVTOOL ${ }^{Q}$ (Fonte: [Xie et al., 2006])

Durante o mapeamento visual, as métricas prescrevem propriedades visuais de acordo com as técnicas de visualização utilizadas. Nas coordenadas paralelas, as métricas de qualidade no nível do valor individual e do atributo modificam a largura da linha e do eixo vertical correspondentes, enquanto para a tupla a métrica afeta a cor da linha.

No caso da matriz de gráficos de dispersão, a tonalidade e o tamanho de cada ponto representam a qualidade no nível do valor individual e da tupla, respectivamente. O nível de saturação da diagonal do gráfico reflete a qualidade do atributo, conforme observado na Figura 3.4. Independentemente da técnica, é possível filtrar os dados segundo o nível 
de qualidade.

O XMDVTOOL ${ }^{Q}$ utiliza dois métodos para manipular volumes de dados crescentes, quais sejam a amostragem e a hierarquia de multiresolução de dados. Essa última corresponde a uma hierarquia de grupos de dados - baseada em clustering recursivos navegável por meio de um controle auxiliar que possibilita selecionar o grupo no nível desejado [Cui et al., 2006; Fua et al., 1999]. A Figura 3.5 ilustra a posição na hierarquia escolhida - feixe do topo a base da hierarquia - e os grupos selecionados.

Esse controle possui a capacidade de realizar a pré-busca de dados - do inglês data prefetching - com base na previsibilidade das ações de navegação e no princípio da localidade na exploração visual [Doshi et al., 2003]. Métricas determinam a probabilidade da próxima ação baseada nas anteriores. Uma probabilidade alta determina o uso da pré-busca dos dados.

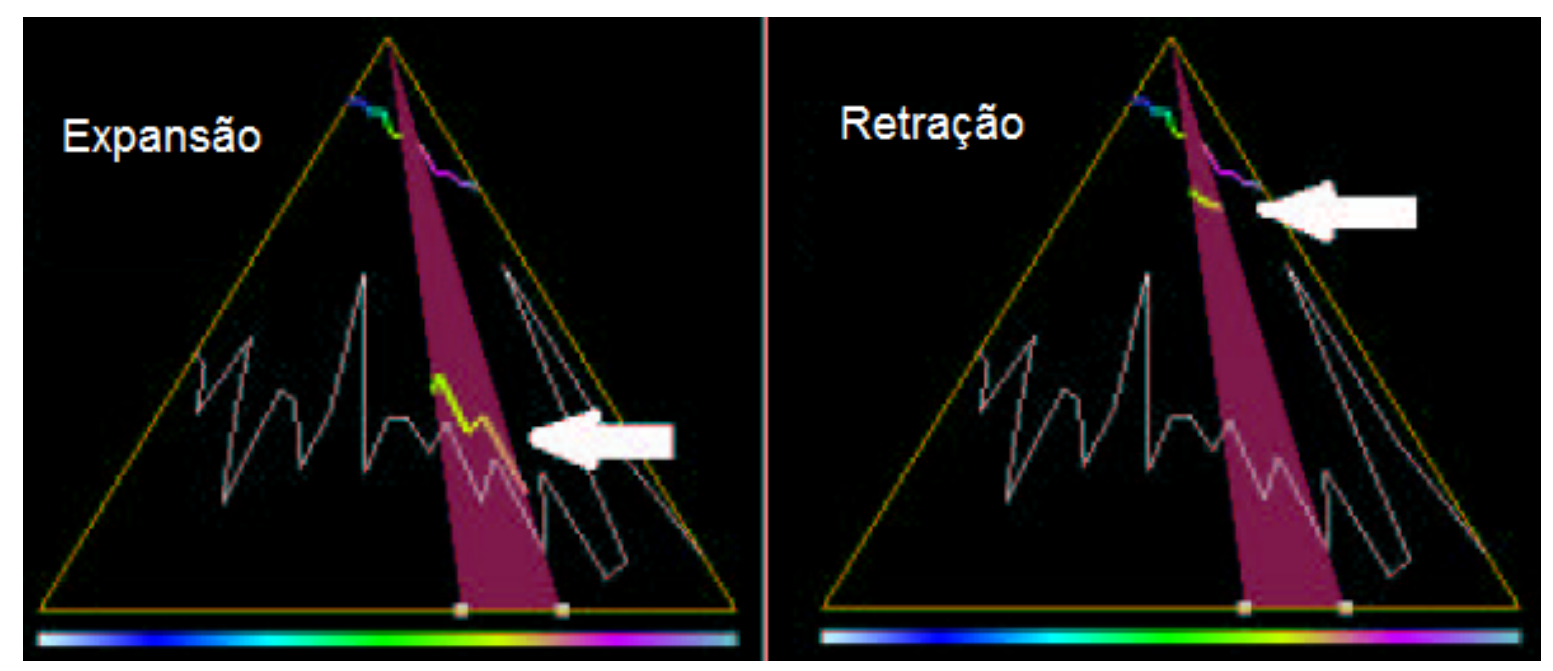

Figura 3.5: Controle auxiliar para navegação na hierarquia de grupos (Adaptado de [Fua et al., 1999])

\subsection{Limites}

Esse sistema integra certas capacidades da automação e da visualização. Um dos seus destaques remete a persistência de métricas que pontuam a situação de atributos e tuplas quanto a defeitos de valores ausentes. Porém, essas métricas são baseadas na imputação de valores que não são usualmente significativos no contexto da indústria. Um aspecto restritivo do $X M D V T O O L^{Q}$ recai sobre suas técnicas de visualização. A premissa dessas técnicas é salientar as referidas métricas, característica que causa o efeito de distração na avaliação de outros defeitos - análogo ao Manet e GGobi, Seções 3.3.4.1.2 e 3.3.4.2.2.

No tocante a dados volumosos, esse sistema oferece técnicas de amostragem e de hierarquia de multiresolução que possibilitam um agente avaliador navegar por entre regiões de diferentes resoluções de dados. Para obter o agrupamento hierárquico, o XMDVTOOL ${ }^{Q}$ utiliza o algoritmo BIRCH - Balanced Iterative Reducing and Clustering using Hierarquies 
- cujo desempenho é inferior a $O\left(N^{2}\right)$ em termos de memória e tempo [Zhang et al., 1996]. Em contrapartida, esse algoritmo possui um passo que suprime valores atípicos que, para efeitos de avaliação de qualidade, não é desejável.

\subsubsection{D-DUPE}

\subsection{Características}

O sistema D-DUPE [Kang et al., 2008] adota uma fluxo supervisionado de parametrização, definição e análise dos resultados de certos algoritmos de deduplicação de tuplas. O primeiro passo nesse fluxo compreende a delimitação dos atributos que compõem a métrica de similaridade e o respectivo limiar que delimita os possíveis casos de tuplas duplicadas. O passo seguinte consiste na definição e aplicação do algoritmo de deduplicação desejado, quais sejam a comparação exaustiva ou a blocagem. A característica central do algoritmo de blocagem - do inglês blocking algorithm - é dividir as tuplas de acordo com um critério de modo a obter blocos de tuplas que são analisadas isoladamente [Kang et al., 2008]. Existem vários algoritmos de blocagem cuja definição está além do escopo do presente trabalho.
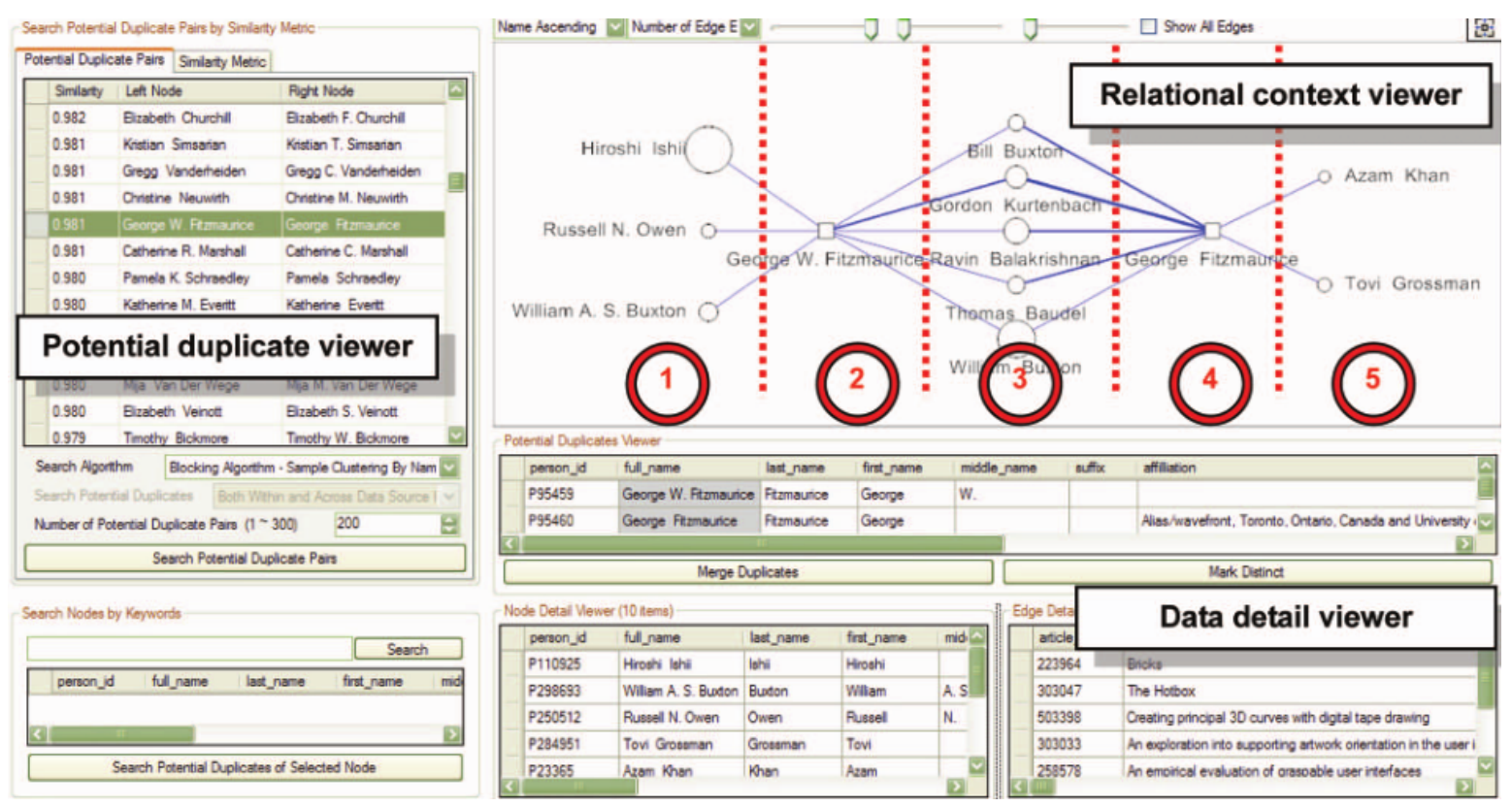

Figura 3.6: Representação visual do D-DUPE (Fonte: [Kang et al., 2008])

Ao concluir os passos citados, as potencias duplicações podem ser visualizadas em uma representação visual com três visões coordenadas e estáticas, conforme observado na Figura 3.6. A visão à esquerda elenca os casos de tuplas potencialmente duplicadas e destaca aquele escolhido para análise. A visão superior exibe um grafo que salienta o relacionamento das tuplas potencialmente duplicadas - raias 2 e 4 da Figura 3.6 - com as demais tuplas do conjunto de dados - raias 1, 3 e 5 da Figura 3.6. Por fim, a visão inferior provê detalhes das tuplas selecionadas na visão superior. As interações disponíveis 
permitem a ordenação dos dados, exibir ou suprimir raias e rever visualmente o histórico das ações de deduplicação.

\subsection{Limites}

A representação visual com visões concorrentes múltiplas estáticas do D-DUPE explicita o cenário que cerca tuplas potencialmente duplicadas. Contudo, seu apoio a avaliação visual desse defeito decresce à medida que aumenta o volume de dados manipulados. A ausência de interações ou recursos que permitam controlar a resolução dos dados representados provoca a oclusão visual no grafo. Concomitantemente, cresce a dificuldade no uso das tabelas textuais em razão do consumo de memória e a necessidade de rolagens sucessivas. Vale lembrar que o algoritmo de blocagem utilizado pelo D-DUPE endereça exclusivamente o desempenho relacionado a identificação dos duplicados, operação que ocorre durante a transformação dos dados.

\subsubsection{VIQTOR}

\subsection{Características}

O sistema VIQTOR - VIsual Quality evaluaTOR - [Führing e Naumann, 2007] permite a múltiplos agentes avaliadores diagnosticarem os dados considerando diferentes critérios de qualidade. Por meio de uma técnica de visualização tabular textual, cada agente seleciona um critério - incluindo completude e acurácia - e determina pontuações para diferentes regiões de dados, conforme observado na Figura 3.7. Ao término das avaliações individuais, o nível de qualidade geral por critério é apurado com base na média aritmética das pontuações atribuídas por todos os agentes. O VIQTOR oferece interações de ordenação, filtragem e agregação de dados por coluna.

\subsection{Limites}

A visualização tabular textual do VIQTOR é desprovida de propriedades visuais que beneficiem a avaliação visual da qualidade de dados. Embora amplamente difundida e de fácil compreensão, esse tipo de visualização transfere todo o esforço da busca por significados relativos aos defeitos para o agente avaliador [Telea, 2008; Unwin et al., 2006]. Tal situação é exacerbada à medida que a visualização tabular apresenta de 20 a 30 tuplas por tela, implicando em sucessivas rolagens de telas. Essas características tornam esse sistema pouco atrativo para a avaliação dos dados mesmo em cenários de pequena resolução de dados - algumas centenas de tuplas. 


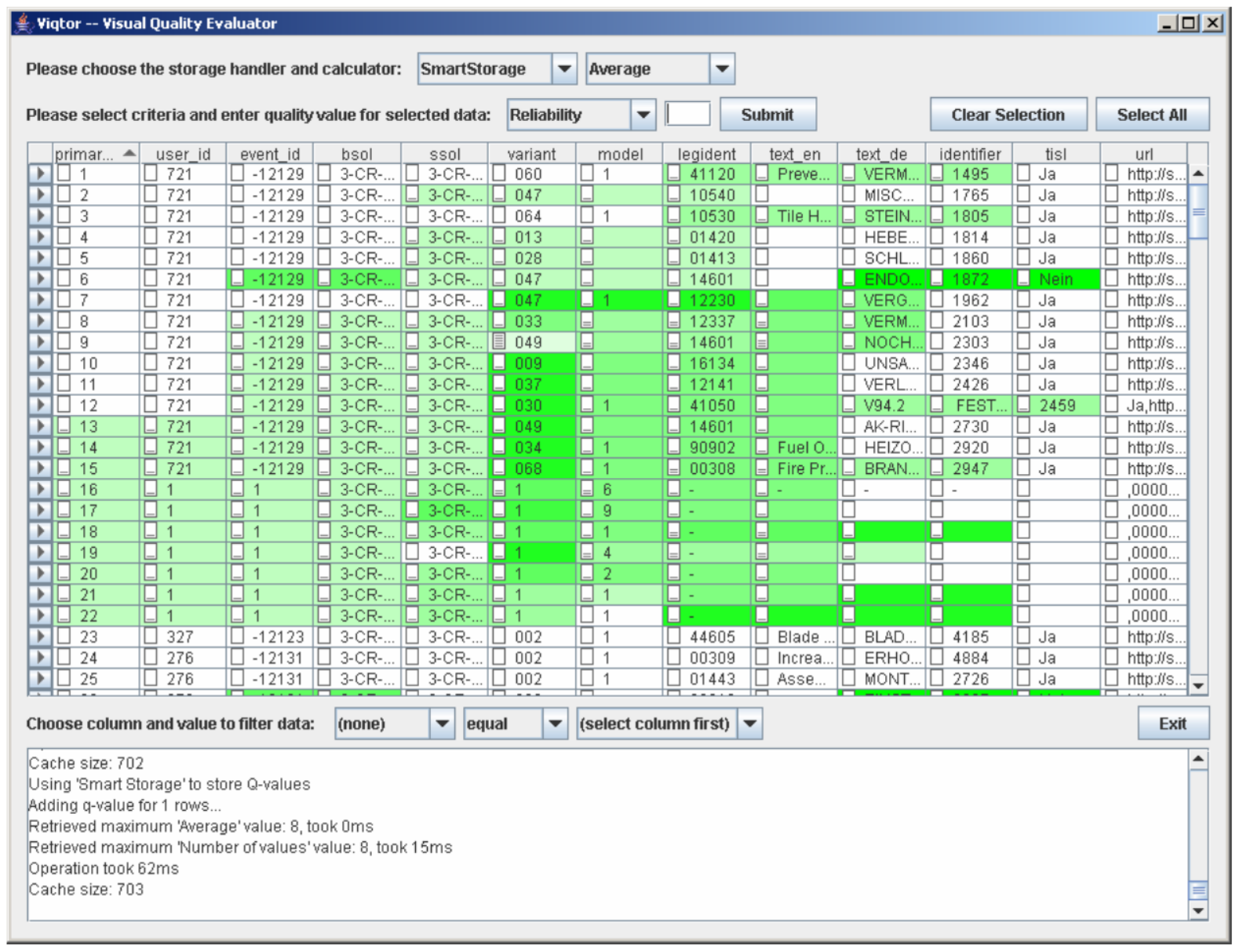

Figura 3.7: Representação visual do VIQTOR (Fonte: [Führing e Naumann, 2007])

\subsubsection{Visual Profiling}

\subsection{Características}

O sistema Visual Profiling [Malik et al., 2010; Tennekes et al., 2011, 2013] combina a técnica de visualização Tableplot com funcionalidades de ordenação, aproximação e arranjo dos atributos para proporcionar a avaliação simultânea de múltiplos atributos.

O Tableplot é uma visualização tabular na qual cada coluna representa um atributo. O conteúdo desses atributos são expressos em barras horizontais que compactam uma quantidade de valores definidos pelo agente avaliador da qualidade. Para atributos quantitativos, as barras possuem tamanho proporcional a média aritmética dos valores compactados. O número de valores ausentes entre aqueles compactados determina a redução da saturação da barra, conforme observado na segunda e sétima colunas da Figura 3.8. Para os atributos categóricos, a barra representa em tonalidades distintas a proporção entre os diferentes elementos do domínio compactados, conforme ilustra as duas últimas colunas da Figura 3.8. O tom vermelho indica ocorrências sem valor para o atributo.

Segundo [Tennekes et al., 2013], o Visual Profiling permite interagir com aproximada- 
mente $5,4 * 10^{7}$ tuplas. Para tal, esse sistema utiliza um arcabouço ${ }^{6}$ que permite o uso otimizado da memória virtual para o acesso a dados granulares. Contudo, os estudos de desempenho e as características dos dados utilizados não foram descritos.
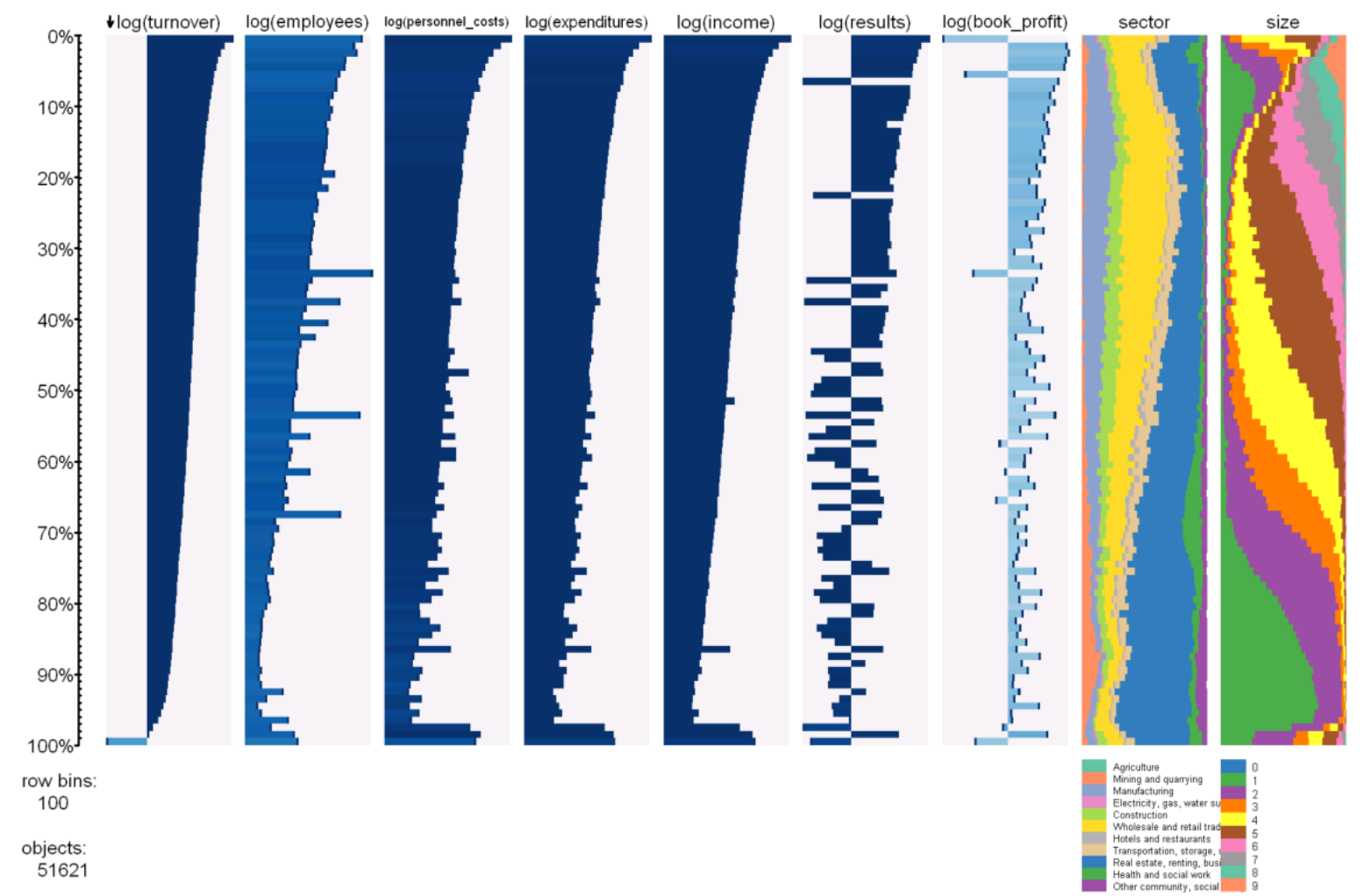

Figura 3.8: Representação visual do Visual Profiling (Fonte: [Tennekes et al., 2011])

\subsection{Limites}

Esse sistema utiliza a técnica Table Plot que mantém a organização intuitiva da tabela ao mesmo tempo que atenua muitas das restrições da visão tabular textual. Adicionalmente, essa técnica propicia a visão global dos dados em única tela - cerca de 12 atributos - e a análise pormenorizada de regiões de dados por meio da interação de aproximação. Tal capacidade é complementada pela técnica de ordenação que facilita o exame e a detecção dos padrões em e entre colunas [Hur et al., 2012], incluindo valores atípicos.

Contudo, ao adotar a abordagem de ordenação por um único atributo e impedir a permutação entre colunas, o Visual Profiling restringe o rol de padrões de defeitos àqueles observados em relacionamentos bivariados. No caso da análise de três ou mais atributos, a referida abordagem conduz a busca visual transversal dos atributos em virtude da composição randômica das colunas em relação a coluna ordenada [Hur et al., 2012; Pirolli e Rao, 1996].

\footnotetext{
${ }^{6}$ Esse arcabouço mantém na memória principal uma estrutura de mapeamento que permite o acesso direto as paginas da memória virtual que contém os dados desejados [Adler et al., 2013].
} 
O Visual Profiling combina as estratégias de uso otimizado da memória virtual e a compactação visual para manipular relações com volumes expressivos de dados. No entanto, a função de compactação utilizada - a média aritmética - distorce a representação visual daqueles atributos com valores extremos [Tukey, 1977].

\subsubsection{VIM}

\subsection{Características}

O propósito do sistema VIM - Visualization and Imputation of Missing Values - é apoiar a seleção do método de imputação ao propiciar a exploração visual da relação entre valores de atributos ausentes e não-ausentes [Templ et al., 2012]. Diferentes técnicas de visualização estão disponíveis para facilitar a exploração visual, incluindo opções tradicionais - incluindo gráficos de barras e de dispersão - e certas técnicas diferenciadas discutidas a seguir.

No gráfico de matriz - Figura 3.9a -, as colunas representam atributos cujos valores são expressos em barras horizontais de tamanho fixo. A tonalidade vermelha salienta casos de valores ausentes, enquanto a luminosidade da tonalidade cinza são calculados a partir da expressão (Valor Atributo - Média)/(Valor ${ }_{\max }-$ Valor $\left._{\min }\right)$. Quanto mais próximo de um, mais escuro é o cinza.

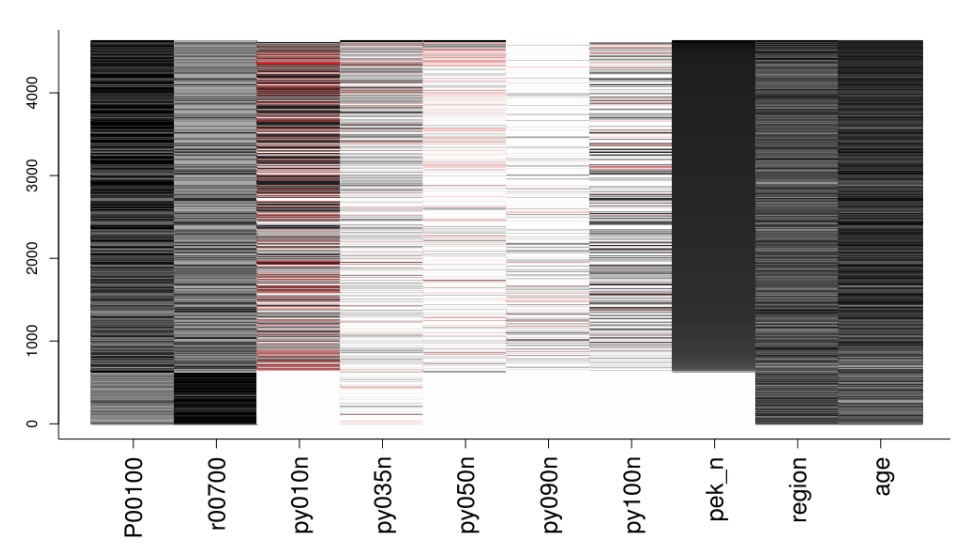

(a) Gráfico de Matriz

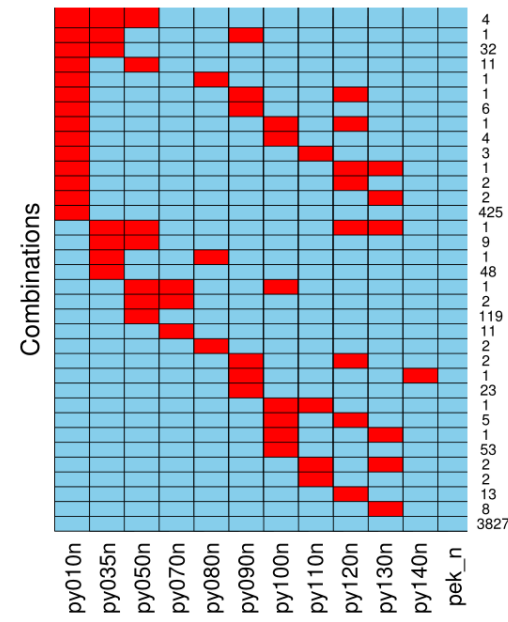

(b) Gráfico de Agregação

Figura 3.9: Representações visuais do VIM (Fonte: [Templ et al., 2012])

Outras técnicas permitem analisar a relação de atributos base a um atributo de referência, tais como o gráfico de caixas paralelas, histograma, coordenadas paralelas e o gráfico de agregação. Esse último explicita a quantidade de tuplas que compartilham um certo padrão de ausência-presença de valores. O padrão explicita quais atributos possuem valor - ladrilhos na cor azul - e quais não possuem conteúdo - ladrilhos na cor vermelha -, conforme observado na Figura 3.9b. 


\subsection{Limites}

O sistema VIM oferece um conjunto de visualizações especializadas na comunicação de valores ausentes. Consequentemente, esse enviesamento aumenta o esforço de detecção de outros defeitos devido o efeito distração - análogo aos sistemas Manet, GGobi e $X M D V T O O L^{Q}$. Outras restrições expressivas desse sistema recaem sobre a ausência completa de interatividade e de recursos que permitam a manipulação de relações com resoluções crescentes de dados.

\subsubsection{Mondrian}

\subsection{Características}

O sistema Mondrian [Malik e Unwin, 2012; Theus, 2003] é composto por diferentes gráficos estatísticos com capacidades distintas de interação para assistir a avaliação dos dados. Dentre as técnicas de interação disponíveis estão: visões concorrentes múltiplas, treliça, seleção e ligação, ordenação, redimensionamento e detalhes sobre demanda no estilo hover queries.

Semelhante ao Manet, certos gráficos - incluindo o mosaico - expõem a proporção de valores ausentes de um atributo. Já outro conjunto de visualizações - incluindo spinogram, gráfico de dispersão e gráfico de densidade condicional - permitem representar os atributos base em relação a um atributo de referência.

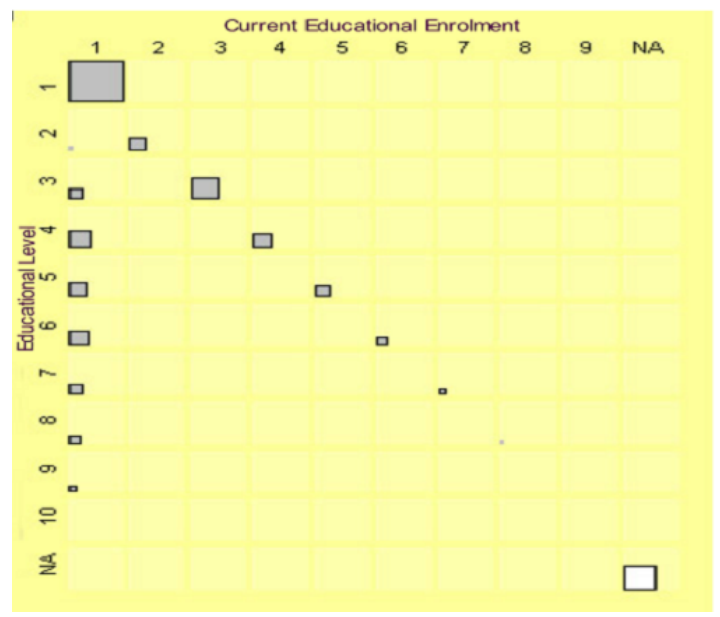

(a) Visão panorâmica dos Dados

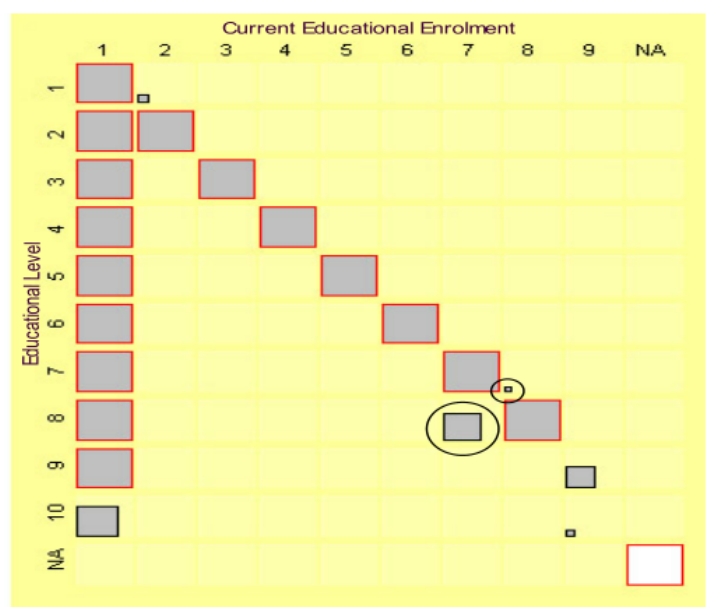

(b) Visão com a aproximação dos dados

Figura 3.10: Representações visuais do Mondrian (Fonte: [Malik e Unwin, 2012])

O diagrama de flutuação utiliza células justapostas para correlacionar a frequência de valores entre dois atributos, conforme observado na Figura 3.10a. Os círculos à direita salientam violações de integridade semântica, enquanto a célula branca no canto inferior direito representa a presença de valores ausentes. Essa visualização conta com um mecanismo de aproximação especial que aumenta a percepção das células com pequena 
quantidade de dados. As células com alta frequência crescem até um limiar determinado pelo agente avaliador da qualidade. Caso esse liminar seja ultrapassado, as células são destacadas na tonalidade vermelho - Figura 3.10b.

\subsection{Limites}

O sistema Mondrian oferece um grande conjunto de visualizações e interações para a avaliação dos dados. Essa variedade pode decorrer da preocupação dos autores - embora informal e sem parâmetros específicos - desse sistema apoiar a detecção visual de padrões de defeitos. Essa preocupação é observada em vários gráficos na forma de recursos que permitem confrontar atributos base a um atributo de referência ou usufruir da facilidade do ser humano identificar posição e tamanho.

Em contrapartida, o Mondrian oferece tênues recursos para sustentar relações com expressivas resoluções de dados. Somente a técnica de mudança de opacidade é discutida para minorar a oclusão visual no gráfico de dispersão, embora os autores apontem a capacidade do sistema de manipular $10^{6}$ tuplas [Theus, 2003].

\subsubsection{Profiler}

\subsection{Características}

O Profiler [Kandel et al., 2012b] utiliza diferentes técnicas de análise dos dados - incluindo mineração de dados - cujos resultados subsidiam a geração automática de visões concorrentes de gráficos clássicos.

Para alcançar tal efeito, a estratégia do Profiler é mapear cada tipo de dado presente em um conjunto de dados a uma tipificação interna. Tal operação ocorre por associação manual ou automática ${ }^{7}$. Cada tipo interno está associado a um grupo de funções - executadas na etapa de transformação corretiva, Seção 2.3.3 - responsáveis por revelar a presença de certos defeitos nos dados, conforme destaca a Tabela 3.3.

Ao selecionar um atributo com defeito, o Profiler associa as diferentes visões da representação visual a um atributo particular - da direita para esquerda e de cima para baixo - e a uma técnica de visualização, conforme indica a Tabela 3.3. Vale lembrar que a primeira visão contém o atributo escolhido para análise, enquanto os demais representam atributos correlatos determinados por uma métrica de proximidade não descrita.

A Figura 3.11 ilustra uma representação visual gerada para o atributo em destaque na seção Anomaly Browser. A partir dessa representação, o agente avaliador pode selecionar e substituir os atributos apresentados, filtrar dados e escolher outra técnica de visualização - dentre as disponíveis existe um mapa mundi planar.

\footnotetext{
${ }^{7}$ A associação automática utiliza o princípio da descrição de comprimento mínimo - do inglês Minimum Description Length - que estabelece o menor número de bits possível para armazenar o conteúdo de um atributo.
} 


\begin{tabular}{lll}
\hline Defeito no Dado & Função & Técnica de Visualização \\
\hline $\begin{array}{l}\text { Violação de Restrição } \\
\text { de Domínio }\end{array}$ & $\begin{array}{l}\text { Agrupamento } \\
\text { (Distância Levenshtein e }\end{array}$ & Gráfico de Barras \\
Grafia) & $\begin{array}{l}\text { Atomic Strings e } \\
\text { Phonetic-Based Soundex }\end{array}$ & \\
\hline Unidade Medida & $\begin{array}{l}\text { Agrupamento } \\
\text { Heterogênea }\end{array}$ & Histograma \\
\hline Valor de Atributo & Detecção de Anomalia & Gráfico de Dispersão \\
Atípico & (Z-Scores, HAMPEL X84 e) & Gráfico de Dispersão \\
& (Mahalanobis distance) & \\
\hline Valor de Atributo & Inferência por verificação & Histograma \\
Ausente & (existência de valor vazio) & Gráfico de Área \\
\hline Violação de & Frequency Outilier Detection & Gráfico de Barras \\
Dependência de & (Unique Value Ratio) & \\
Chave & & \\
\hline
\end{tabular}

Tabela 3.3: Correlação dos Defeitos, Técnicas de Detecção e de Visualização do Profiler (Fonte: [Kandel et al., 2012b])

Outra interação relevante dessa solução é aquela que possibilita corrigir valores de atributos diagnosticados como defeituosos. Posicionado na visão do referido atributo, o agente avaliador pode aplicar uma transformação que substitua o valor defeituoso pelo correto. Cumpre lembrar que inexistem detalhes sobre o conjunto de transformações corretivas disponíveis e o modo de operação correspondente.

O Profile utiliza um SGBD em memória e orientado a coluna para prover mais agilidade as interações disponibilizadas. Um conjunto de dados com $10^{7}$ tuplas e cinco atributos é a base do estudo de desempenho apresentado sobre os referidos recursos.
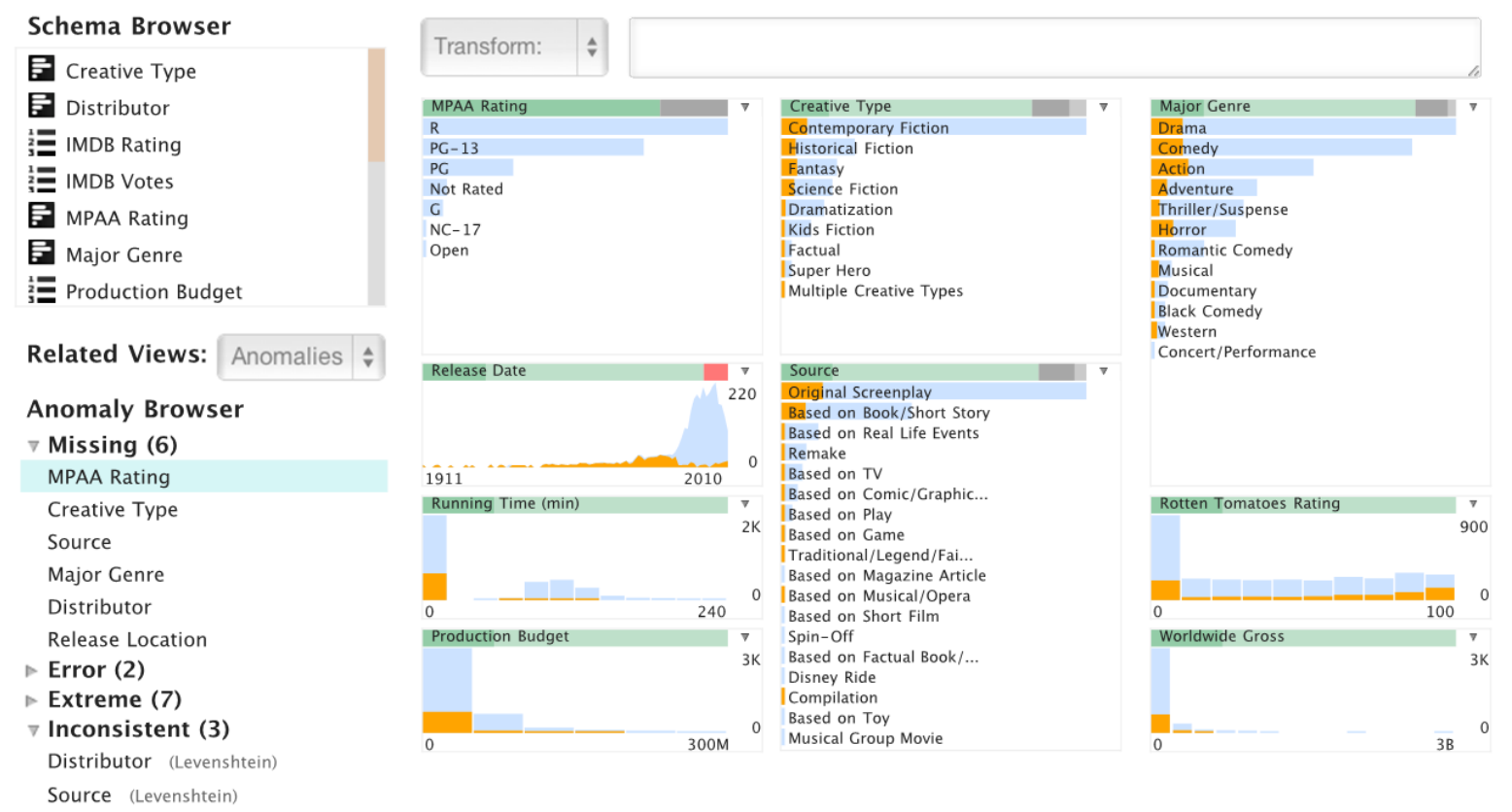

Figura 3.11: Representação visual do Profiler (Fonte: [Kandel et al., 2012b]) 


\subsection{Limites}

O sistema Profiler oferece a combinação das capacidades de análises computacionais e visuais para apoiar a avaliação dos dados. A estratégia desse sistema de manter dados residentes em memória reduz o tempo de mapeamento geométrico e visual, favorece a interação sobre os dados e permite atender a resoluções crescentes de dados - limitado pela memória principal disponível.

No entanto, as características da representação visual desse sistema interfere no discernimento dos significados relativos aos defeitos nos dados. A exposição simultânea de numerosas informações visuais representadas com a mesma técnica de visualização aumentam o esforço de integração mental de fatos ao longo das transições de contexto entre as visões [Baldonado et al., 2000; Convertino et al., 2003].

\subsubsection{VDQAM}

\subsection{Características}

A solução VDQAM [Teng et al., 2012] combina técnicas de visualização 3D com interações de rotação e redimensionamento para promover a navegação hierarquizada entre três níveis distintos de detalhes sobre um esquema de banco de dados relacional.

O primeiro nível provê uma visão panorâmica das relações e seus relacionamentos por meio de um grafo. Nesse nível cada relação é representada como uma pizza de tamanho proporcional ao seu volume de dados cujos pedaços indicam um assunto de informação organizacional. No segundo nível o agente avaliador pode visualizar em detalhes o conjunto de relacionamentos entre diferentes relações e observar violações de integridade referencial salientadas em vermelho, conforme observado na Figura 3.12. No último nível, o VDQAM destaca a presença de valores ausentes nos atributos de uma relação selecionada por meio do gráfico de barras, artifício idêntico ao sistema Manet - Seção 3.3.4.1.

\subsection{Limites}

A proposta desse sistema é possibilitar a navegação entre níveis distintos de detalhes de um esquema de banco de dados. O primeiro nível fornece informações panorâmicas a respeito do esquema que não subsidiam qualquer atividade de avaliação de qualidade.

Em contraste, o segundo nível permite analisar detalhes da estrutura de relacionamentos de um esquema de banco de dados por meio de um grafo em 3D. Essa visualização promove a compreensão global da referida estrutura de modo mais próximo a percepção do ambiente pelo ser humano [Tavanti e Lind, 2001]. Contudo, o referido grafo apresenta oclusão visual diretamente proporcional a resolução de dados apresentados - Figura 3.12b. Para suavizar essa situação, o VDQAM oferece as interações de rotação e redimensionamento limitadas devido a falta de um guia que possibilite a localização da interação cor- 


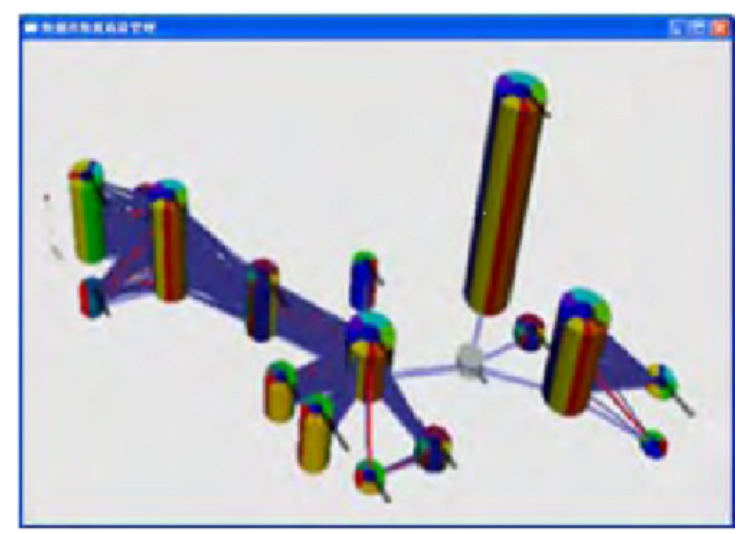

(a) Visão panorâmica das relações e relacionamentos

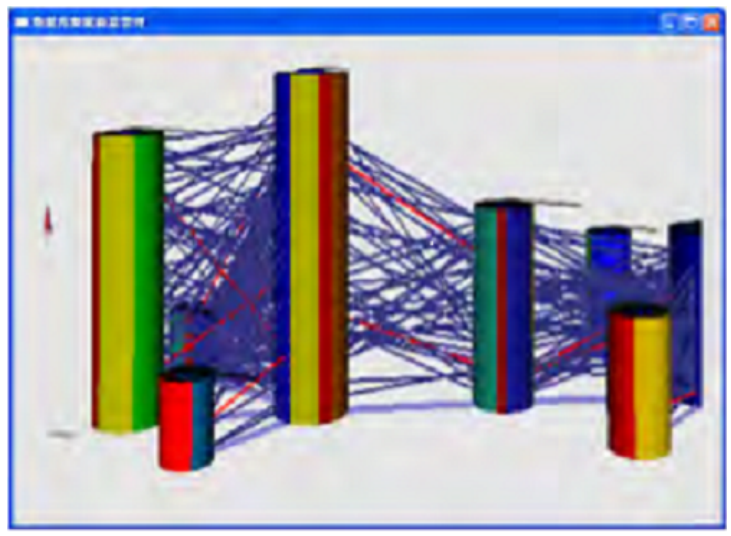

(b) Visão panorâmica e rotacionada das relações e relacionamentos

Figura 3.12: Representação visual em 3D do VDQAM (Fonte: [Teng et al., 2012])

rente em relação ao todo. O terceiro nível provê um gráfico de barras que expõe a presença de valores ausentes - semelhante ao Manet - dos atributos de uma relação selecionada.

\subsubsection{DQVis}

\subsection{Características}

A solução DQVis [Wang et al., 2013] combina modelos computacionais e uma perspectiva hierarquizada sobre um banco de dados de modo a proporcionar a avaliação da qualidade. O primeiro nível da hierarquia apresenta as relações de um banco de dados agrupadas pelos relacionamentos compartilhados. Cada relação é representada por um círculo cujo raio é proporcional a quantidade de tuplas e a tonalidade remete ao agrupamento. Já o segundo nível permite verificar a estrutura das relações e as respectivas regras de integridade referencial, conforme observado na Figura 3.13a.

No terceiro nível, uma representação visual similar a Figura 3.13a explicita uma análise computacional do tipo de forma normal - segunda, terceira ou BCNF - obedecida por uma relação específica. Por fim, o quarto nível utiliza gráficos de linhas ou de dispersão para permitir a análise visual de defeitos relativos a valores atípicos ou violações de domínios violação de obrigatoriedade - para um atributo em particular. Ainda nesse nível, o gráfico de dispersão representa as tuplas potencialmente duplicadas pelo cruzamentos nos eixos $x$ e $y$ de suas chaves primárias correspondentes, conforme observado na Figura 3.13b.

\subsection{Limites}

$\mathrm{Na}$ abordagem hierárquica do DQVis, os dois primeiros níveis somente oferecem informações esquemáticas e gerais que pouco subsidiam a avaliação da qualidade dos dados. O terceiro nível também é restrito à medida que não informa ao agente de qualidade sobre 


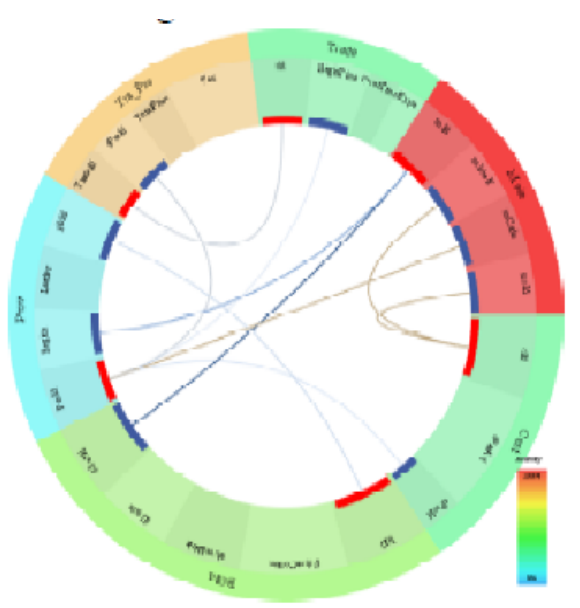

(a) Visão panorâmica da integridade referencial entre relações

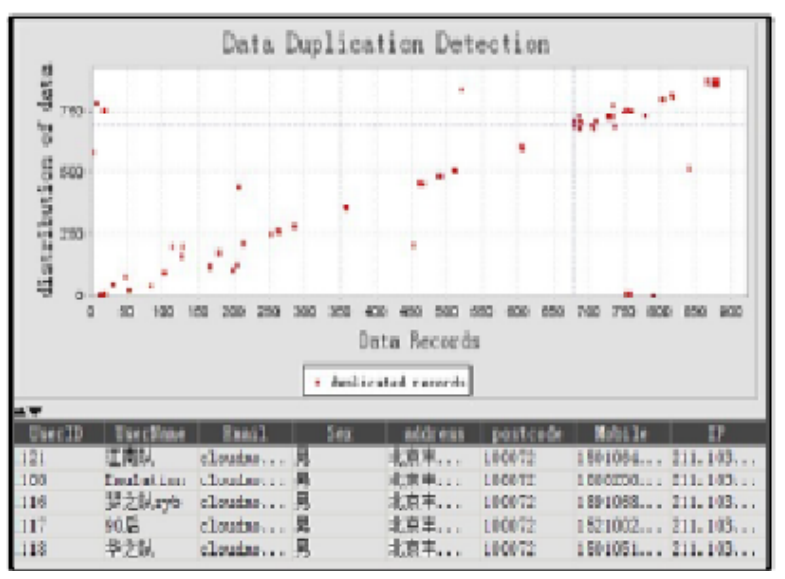

(b) Gráfico de dispersão expõe as tuplas potencialmente duplicadas

Figura 3.13: Representações visuais do DQVis (Fonte: [Wang et al., 2013])

violações de dependência funcionais.

Somente o último nível oferece recursos para análise de atributos e tuplas duplicadas, mas com inúmeros limites. Ambos os casos não dispõem de interações que permitam navegar ou simplificar os dados, fato que impõe uma restrição natural ao número de representadas visualmente. Essa situação é amplificada devido a ausência de recursos para contornar os desafios de resoluções crescentes de dados.

A análise dos casos potencialmente duplicados é complexa devido a inadequação da representação visual. Essa representação expõe os casos duplicados utilizando o cruzamento dos eixos $x$ e $y$ que apresenta pontos de oclusão. Além disso, os conjuntos de tuplas duplicadas não são dispostos de uma forma que propicie a análise.

\subsubsection{Identity Explorer}

\subsection{Características}

O objetivo do Identity Explorer [Chen, 2015] é possibilitar a avaliação visual dos agrupamentos de tuplas potencialmente duplicadas. Tais agrupamentos são determinados e quantificados pelo módulo de identificação de duplicados OYSTER [Zhou e Talburt, 2012]. Baseada em asserções de equivalências entre tuplas definidas pelo agente avaliador, esse módulo determina dois grupos de duplicados, quais sejam falso positivo e falso negativo. Para o primeiro grupo são utilizados os conceitos de entropia e padrão de unicidade, enquanto o segundo usa somente entropia.

Uma técnica de visualização tabular e textual apresenta cada agrupamento e os respectivos casos de tuplas duplicadas assinalados em tonalidades distintas, conforme observado na Figura 3.14. Ordenação dos grupos por entropia, filtros por entropia e filtros baseados em predicados - denominado de "Search Mode" - são as interações disponíveis. 
Identity Explorer Home Search Mode Negative Resolution Review Mode Positive Resolution Review Mode cheng ReviewedTestidty Assertion Cart (2)

Negative Resolution Review Mode

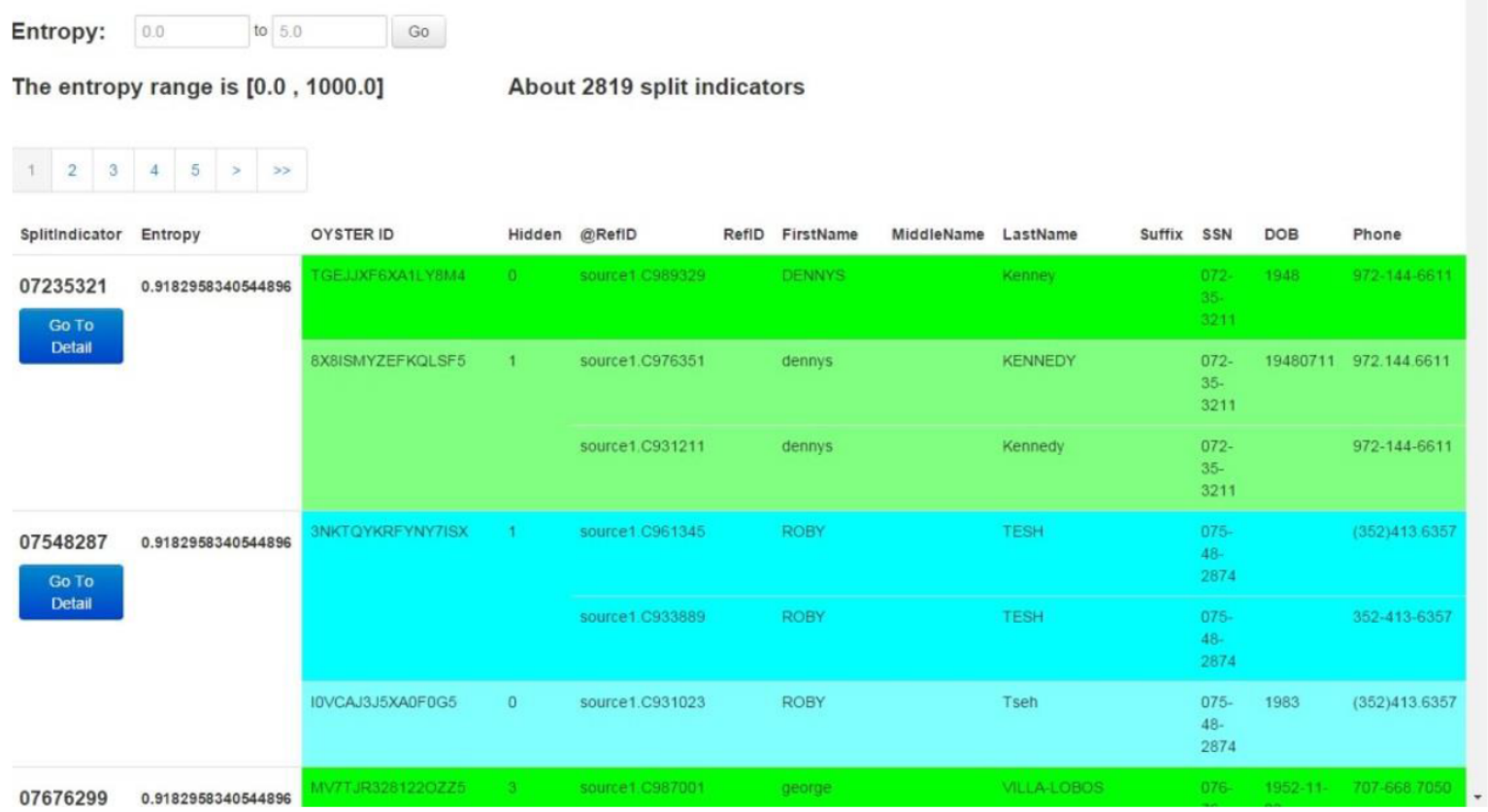

Figura 3.14: Representação visual do Identity Explorer

(Fonte: [Chen, 2015])

\subsection{Limites}

O Identity Explorer possui certas similaridades a solução VIQTOR . Sua visualização tabular textual transfere todo o esforço de comparação e determinação dos casos duplicados ao agente avaliador [Telea, 2008; Unwin et al., 2006]. Tal situação é exacerbada à medida que a visualização tabular representa menos de 10 tuplas por tela, implicando em sucessivas rolagens de telas. Embora os filtros possam minorar essa situação, as características do Identity Profiler torna seu apoio a avaliação da qualidade restrito a pequenas resoluções de dados.

\subsubsection{Síntese dos Trabalhos}

Esta seção apresenta dois formatos de síntese das caracterizações apresentadas na Seção 3.3.4. As Figuras 3.15 e 3.16 explicitam para cada defeito no dado - e variantes correspondentes, quando aplicável - as técnicas de trato de volume de dados, as classes de técnicas de visualização - Seção 2.3.4.2 - e de interação - Seções 2.3.4.1. Ao lado de cada defeito é destacado o número de sistemas de visualização que a detectam, enquanto ao lado de cada classe é representado quantos desses sistemas utilizam a referida classe.

Em contraste, a Tabela 3.4 oferece mais detalhes sobre as técnicas de visualização e interação. Os conteúdos relativos as colunas "Defeito no Dado" e "Interatividade" se- 
guem a nomenclatura expressa nas Seções 4.1 e 2.3.4.1, respectivamente. A coluna "Atr." denota o número de atributos que podem ser codificados por uma técnica de visualização. Essa coluna utiliza a representação $x \mathrm{D}$ na qual $x$ reflete o número de dimensões que podem ser representadas pela técnica de visualização. Por fim, os itens assinalados com o símbolo " " destacam elementos mencionados nos respectivos trabalhos, porém desprovidos de explanação adicional.

\begin{tabular}{|c|c|c|c|c|c|}
\hline Defeito & Técnica Visualização & Atr. & Técnica Interação & Técnica Volume & Sistema \\
\hline \multirow{21}{*}{$\begin{array}{l}\text { Tupla Atípica } \\
\text { (Var. Valor } \\
\text { Atípico em } \\
\text { Atributo) }\end{array}$} & Gráfico de Caixa & $2 \mathrm{D}$ & Aproximação, & - & Mondrian \\
\hline & & & Detalhes sob Demanda, & & \\
\hline & & & Filtro, & & \\
\hline & & & Seleção e Ligação & & \\
\hline & Gráfico de Dispersão & $2 \mathrm{D}$ & Arranjo Atributo, & SGBD em memória & Profiler \\
\hline & & & Correção de Dados $\mathbf{\nabla}$, & & \\
\hline & & & Detalhes sob Demanda, & & \\
\hline & & & Filtro, & & \\
\hline & & & Seleção e Ligação & & \\
\hline & Histograma & 1D & & & \\
\hline & Gráfico de Dispersão, & $2 \mathrm{D}$ & Detalhes sob Demanda & - & Mondrian \\
\hline & Gráfico de Caixa, & & Filtro & & \\
\hline & Gráfico de Pontos, & & Seleção e Ligação & & \\
\hline & $\begin{array}{l}\text { Gráfico Mosaico, } \\
\text { Spinogram }\end{array}$ & & Treliça & & \\
\hline & Tabular Textual & $\mathrm{nD}$ & Agregação, & - & VIQTOR \\
\hline & & & Filtro, & & \\
\hline & & & Ordenação 1 coluna & & \\
\hline & Tableplot & $\mathrm{nD}$ & Aproximação, & Compactação, & Visual \\
\hline & & & Arranjo Atributos, & Uso eficiente de & Profiling \\
\hline & & & Ordenação 1 coluna & Memória Virtual & \\
\hline & $\begin{array}{l}\text { Gráfico de Linha, } \\
\text { Gráfico de Dispersão }\end{array}$ & 1D & - & - & DQVis \\
\hline \multirow{7}{*}{$\begin{array}{l}\text { Tupla Duplicada } \\
\text { (Var. } \\
\text { indeterminada) }\end{array}$} & Grafo & $1 \mathrm{D}$ & Detalhes sob Demanda, & Partição $\mathbf{\nabla}$, & D-Dupe \\
\hline & & & Histórico, & Algoritmo Blocagem & \\
\hline & & & Ordenação 1 coluna, & & \\
\hline & Tabular Visual & $\mathrm{nD}$ & $\begin{array}{l}\text { Detalhes sob Demanda, } \\
\text { Filtro }\end{array}$ & - & $\mathrm{DaV}$ is \\
\hline & Tabular Textual & $\mathrm{nD}$ & Ordenação 1 coluna, & - & Identity \\
\hline & & & Filtro & & Explorer \\
\hline & Gráfico de Dispersão & 1D & - & - & DQVis \\
\hline \multirow{5}{*}{$\begin{array}{l}\text { Unidade de Medida } \\
\text { Heterogênea } \\
\text { (Var. } \\
\text { indeterminada) }\end{array}$} & Histograma & $1 \mathrm{D}$ & \multirow{5}{*}{$\begin{array}{l}\text { Arranjo Atributo, } \\
\text { Correção de Dados } \mathbf{\nabla}, \\
\text { Detalhes sob Demanda, } \\
\text { Filtro, } \\
\text { Seleção e Ligação }\end{array}$} & \multirow[t]{5}{*}{ SGBD em memória } & \multirow[t]{5}{*}{ Profiler } \\
\hline & & & & & \\
\hline & & & & & \\
\hline & & & & & \\
\hline & Gráfico de Dispersão & $2 \mathrm{D}$ & & & \\
\hline Valor de & Tabular Visual & $\mathrm{nD}$ & Detalhes sob Demanda, & - & $\mathrm{DaV}$ is \\
\hline Atributo & & & Filtro & & \\
\hline \multicolumn{6}{|l|}{ Incorreto } \\
\hline Violação de & Gráfico de Barras & 1D & Arranjo Atributos, & SGBD em memória & Profiler \\
\hline Dependência & & & Correção de Dados $\mathbf{\nabla}$ & & \\
\hline de Chave & & & Detalhes sob Demanda, & & \\
\hline
\end{tabular}




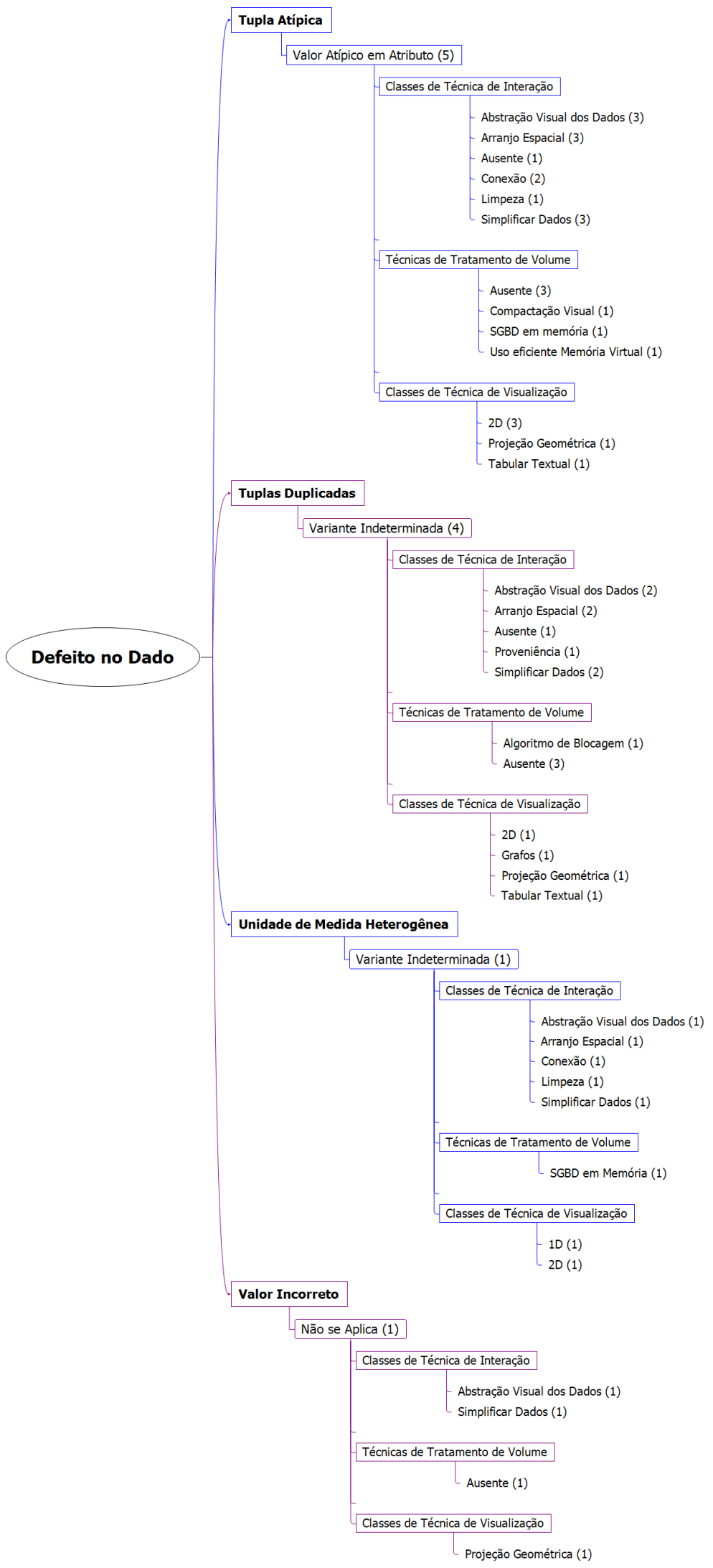

Figura 3.15: Sistemas de visualização para avaliação da qualidade dos dados - Sintese Visual Parte I (Fonte: Elaborado pelo autor) 


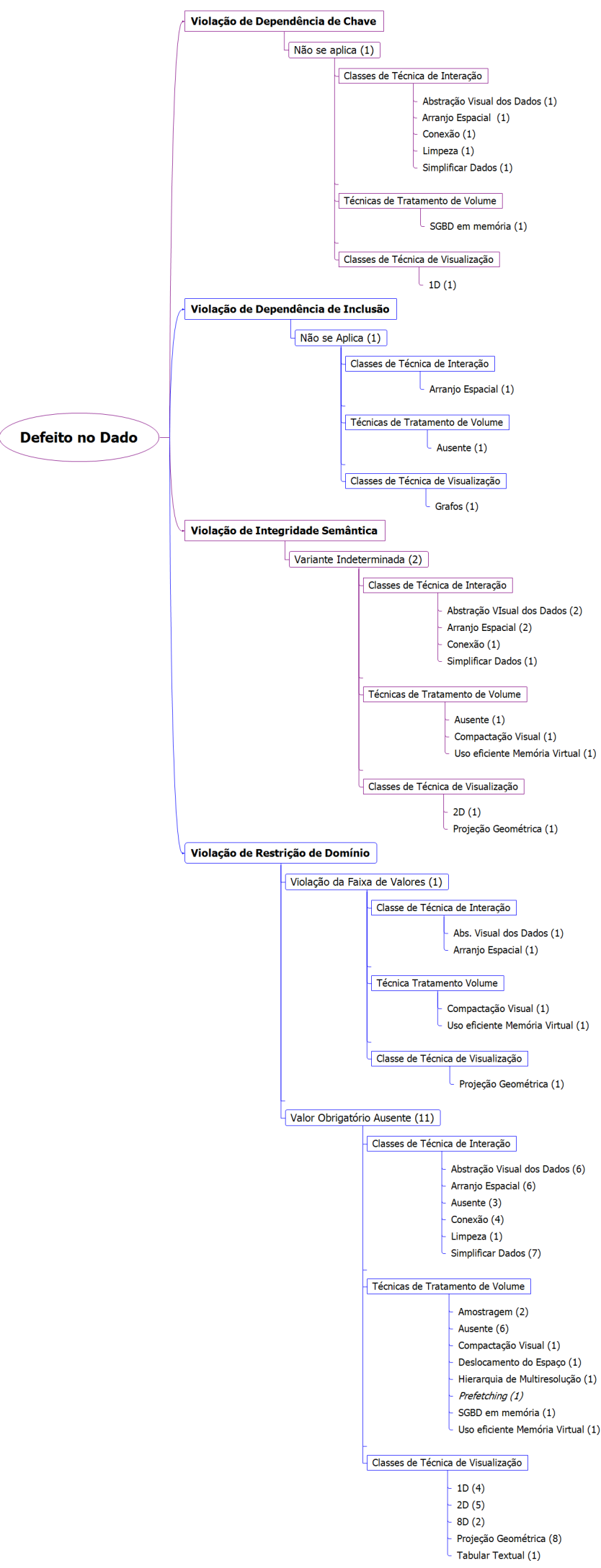

Figura 3.16: Sistemas de visualização para avaliação da qualidade dos dados - Sintese Visual Parte II (Fonte: Elaborado pelo autor) 


\begin{tabular}{|c|c|c|c|c|c|}
\hline Defeito & Técnica Visualização & Atr. & Técnica Interação & Técnica Volume & Sistema \\
\hline & & & $\begin{array}{l}\text { Filtro, } \\
\text { Seleção e Ligação } \\
\end{array}$ & & \\
\hline $\begin{array}{l}\text { Violação de } \\
\text { Dependência } \\
\text { de Inclusão } \\
\end{array}$ & Grafo & $1 \mathrm{D}$ & $\begin{array}{l}\text { Rotação, } \\
\text { Redimensionamento }\end{array}$ & - & VDQAM \\
\hline \multirow[t]{3}{*}{$\begin{array}{l}\text { Violação de } \\
\text { Integridade } \\
\text { Semântica } \\
\text { (Var. } \\
\text { indeterminada) }\end{array}$} & Diagrama Flutuação & $2 \mathrm{D}$ & $\begin{array}{l}\text { Aproximação, } \\
\text { Detalhes sob Demanda, } \\
\text { Filtro, } \\
\text { Redimensionamento, } \\
\text { Seleção e Ligação, } \\
\text { Visão Conc. Múltipla }\end{array}$ & - & Mondrian \\
\hline & $\begin{array}{l}\text { Gráfico de Caixa } \\
\text { Paralela } \\
\text { Gráfico de } \\
\text { Densidade Condicional }\end{array}$ & $2 \mathrm{D}$ & $\begin{array}{l}\text { Filtro, } \\
\text { Seleção e Ligação, } \\
\text { Treliça }\end{array}$ & & \\
\hline & Tableplot & $\mathrm{nD}$ & $\begin{array}{l}\text { Aproximação, } \\
\text { Arranjo Atributos, } \\
\text { Ordenação } 1 \text { coluna }\end{array}$ & $\begin{array}{l}\text { Compactação, } \\
\text { Uso eficiente de } \\
\text { Memória Virtual }\end{array}$ & $\begin{array}{l}\text { Visual } \\
\text { Profiling }\end{array}$ \\
\hline $\begin{array}{l}\text { Violação Restrição } \\
\text { de Domínio } \\
\text { (Var. Violação } \\
\text { de Grafia) }\end{array}$ & Gráfico de Barras & $1 \mathrm{D}$ & $\begin{array}{l}\text { Detalhes sobre Demanda } \\
\text { Filtro } \\
\text { Seleção-ligação } \\
\text { Correção de Dados }\end{array}$ & SGBD em memória & Profiler \\
\hline \multirow{10}{*}{$\begin{array}{l}\text { Violação Restrição } \\
\text { de Domínio } \\
\text { (Var. Valor } \\
\text { Obrigatório } \\
\text { Ausente) }\end{array}$} & $\begin{array}{l}\text { Coordenadas } \\
\text { Paralelas }\end{array}$ & $\mathrm{nD}$ & $\begin{array}{l}\text { Seleção e Ligação, } \\
\text { Visão Conc. Múltipla }\end{array}$ & Amostragem $\mathbf{\nabla}$ & GGobi \\
\hline & & & $\begin{array}{l}\text { Aproximação } \\
\text { Filtro }\end{array}$ & $\begin{array}{l}\text { Amostragem, } \\
\text { Hier. Multiresolução, } \\
\text { Data Prefetching } \\
\end{array}$ & $\begin{array}{l}X M D V- \\
T O O L^{Q}\end{array}$ \\
\hline & & & - & - & VIM \\
\hline & Diagrama Flutuação & $2 \mathrm{D}$ & $\begin{array}{l}\text { Aproximação, } \\
\text { Detalhes sob Demanda, } \\
\text { Filtro, } \\
\text { Redimensionamento, } \\
\text { Seleção e Ligação, } \\
\text { Visão Conc. Múltipla }\end{array}$ & - & Mondrian \\
\hline & Histograma & $1 \mathrm{D}$ & $\begin{array}{l}\text { Detalhes sob Demanda, } \\
\text { Seleção e Ligação, } \\
\text { Visão Conc. Múltipla }\end{array}$ & - & Manet \\
\hline & & & $\begin{array}{l}\text { Detalhes sob Demanda, } \\
\text { Filtro, } \\
\text { Seleção e Ligação, } \\
\text { Visão Conc. Múltipla }\end{array}$ & - & Mondrian \\
\hline & & & $\begin{array}{l}\text { Arranjo Atributos, } \\
\text { Correção de Dados } \mathbf{v}, \\
\text { Detalhes sob Demanda, } \\
\text { Filtro, } \\
\text { Seleção e Ligação }\end{array}$ & SGBD em memória & Profiler \\
\hline & & $2 \mathrm{D}$ & - & - & VIM \\
\hline & Gráfico de Agregação & $\mathrm{nD}$ & - & - & VIM \\
\hline & Gráfico de Área & $1 \mathrm{D}$ & $\begin{array}{l}\text { Arranjo Atributos, } \\
\text { Correção de Dados } \mathbf{\nabla}, \\
\text { Detalhes sob Demanda, } \\
\text { Filtro, }\end{array}$ & SGBD em memória & Profiler \\
\hline
\end{tabular}




\begin{tabular}{|c|c|c|c|c|c|}
\hline Defeito & Técnica Visualização & Atr. & Técnica Interação & Técnica Volume & Sistema \\
\hline & & & \multicolumn{3}{|l|}{ Seleção e Ligação } \\
\hline & \multirow[t]{4}{*}{ Gráfico de Barra } & \multirow[t]{3}{*}{$1 \mathrm{D}$} & $\begin{array}{l}\text { Detalhes sob Demanda, } \\
\text { Seleção e Ligação, } \\
\text { Visão Conc. Múltipla }\end{array}$ & - & Manet \\
\hline & & & - & - & VDQAM \\
\hline & & & $\begin{array}{l}\text { Detalhes sob Demanda, } \\
\text { Filtro, } \\
\text { Seleção e Ligação, } \\
\text { Treliça }\end{array}$ & - & Mondrian \\
\hline & & $\mathrm{nD}$ & - & - & VIM \\
\hline & Gráfico de Caixa $\mathbf{\nabla}$ & $1 \mathrm{D}$ & $\begin{array}{l}\text { Detalhes sobre Demanda, } \\
\text { Treliça, } \\
\text { Seleção e Ligação }\end{array}$ & - & Manet \\
\hline & \multirow[t]{2}{*}{$\begin{array}{l}\text { Gráfico de Caixas } \\
\text { Paralelas }\end{array}$} & $\mathrm{nD}$ & - & - & VIM \\
\hline & & & $\begin{array}{l}\text { Detalhes sob Demanda, } \\
\text { Filtro, } \\
\text { Seleção e Ligação, } \\
\text { Visão Conc. Múltipla }\end{array}$ & - & Mondrian \\
\hline & \multirow[t]{3}{*}{ Gráfico Dispersão } & \multirow[t]{3}{*}{$2 \mathrm{D}$} & $\begin{array}{l}\text { Seleção e Ligação, } \\
\text { Visão Conc. Múltipla }\end{array}$ & - & Manet \\
\hline & & & $\begin{array}{l}\text { Aproximação, } \\
\text { Rotação, } \\
\text { Seleção e Ligação, } \\
\text { Visão Conc. Múltipla }\end{array}$ & $\begin{array}{l}\text { Amostragem } \mathbf{\nabla}, \\
\text { Jittering }\end{array}$ & GGobi \\
\hline & & & - & - & VIM \\
\hline & \multirow[t]{2}{*}{ Gráfico Mosaico } & \multirow[t]{2}{*}{$8 \mathrm{D}$} & $\begin{array}{l}\text { Detalhes sob Demanda, } \\
\text { Seleção e Ligação, } \\
\text { Visão Conc. Múltipla }\end{array}$ & - & Manet \\
\hline & & & $\begin{array}{l}\text { Filtro, } \\
\text { Seleção e Ligação, } \\
\text { Visão Conc. Múltipla }\end{array}$ & - & Mondrian \\
\hline & Gráfico Matriz & $\mathrm{nD}$ & Ordenação 1 coluna & - & VIM \\
\hline & \multirow[t]{2}{*}{ Gráfico de Pontos } & \multirow[t]{2}{*}{$1 \mathrm{D}$} & $\begin{array}{l}\text { Aproximação, } \\
\text { Rotação, } \\
\text { Seleção e Ligação, } \\
\text { Visão Conc. Múltipla }\end{array}$ & $\begin{array}{l}\text { Amostragem } \mathbf{\nabla}, \\
\text { Jittering }\end{array}$ & GGobi \\
\hline & & & - & - & VIM \\
\hline & \multirow[t]{2}{*}{$\begin{array}{l}\text { Matriz Gráfico } \\
\text { Dispersão }\end{array}$} & \multirow[t]{2}{*}{$\mathrm{nD}$} & $\begin{array}{l}\text { Filtro, } \\
\text { Aproximação }\end{array}$ & $\begin{array}{l}\text { Amostragem, } \\
\text { Hier. Multiresolução, } \\
\text { Data Prefetching }\end{array}$ & $\begin{array}{l}X M D V- \\
T O O L^{Q}\end{array}$ \\
\hline & & & $\begin{array}{l}\text { Seleção e ligação, } \\
\text { Visão Conc. Múltipla }\end{array}$ & $\begin{array}{l}\text { Amostragem } \mathbf{\nabla} \\
\text { Jittering }\end{array}$ & GGobi \\
\hline & Tabular Visual & $\mathrm{nD}$ & $\begin{array}{l}\text { Detalhes sob Demanda, } \\
\text { Filtro }\end{array}$ & - & $\mathrm{DaVis}$ \\
\hline & Tableplot & $\mathrm{nD}$ & $\begin{array}{l}\text { Aproximação, } \\
\text { Arranjo Atributos, } \\
\text { Ordenação } 1 \text { coluna }\end{array}$ & $\begin{array}{l}\text { Compactação, } \\
\text { Uso eficiente de } \\
\text { Memória Virtual }\end{array}$ & $\begin{array}{l}\text { Visual } \\
\text { Profiling }\end{array}$ \\
\hline & Tabular Textual & $\mathrm{nD}$ & $\begin{array}{l}\text { Agregação, } \\
\text { Filtro, } \\
\text { Ordenação } 1 \text { coluna }\end{array}$ & - & VIQTOR \\
\hline & Gráfico de Linha, & $1 \mathrm{D}$ & - & - & DQVis \\
\hline
\end{tabular}




\begin{tabular}{llllll}
\hline Defeito & Técnica Visualização & Atr. & Técnica Interação & Técnica Volume & Sistema \\
\hline & Gráfico de Dispersão & & & & \\
\hline Violação Restrição & Tableplot & $\mathrm{nD}$ & Aproximação, & Compactação, & Visual \\
de Domínio & & & Arranjo Atributos, & Uso eficiente de & Profiling \\
(Var. Violação de & & & Ordenação 1 coluna & Memória Virtual & \\
Faixa de Valores) & & & & & \\
\hline
\end{tabular}

Tabela 3.4: Sistemas de visualização para avaliação da qualidade dos dados

- Sintese Tabular (Fonte: Elaborado pelo autor)

\subsection{Limites das Abordagens de Descrição dos Defei- tos nos Dados}

Trabalhos que descrevem defeitos nos dados são comuns em certas áreas de pesquisa, incluindo Gestão da Qualidade da Informação, Data Warehouse, Mineração de Dados, Estatística e Limpeza de Dados - do inglês Data Cleaning. Este trabalho analisou como tais trabalhos responde as seguintes perguntas: Qual é o conjunto representativo de defeitos nos dados relacionados aos critérios de qualidade de acuracidade, completude e consistência? Qual é a estrutura do problema adjacente a cada defeito?

Certos trabalhos descrevem defeitos nos dados como um tópico complementar ao assunto principal de interesse. Essa abordagem adotada por [Ambler e Sadalage, 2006; Borek et al., 2011; English, 1999; Helfert e Ge, 2006; Schmid, 2005] produz descrições ambíguas e breves. Os defeitos tratados são majoritariamente selecionados por um modelo intuitivo, isto é, a representatividade dos defeitos é determinada pelo senso comum circunscrito em um contexto. Como exemplo, a descrição de "Instâncias Duplicadas" abaixo permite extrair algumas das causas prováveis da duplicação de tuplas, mas impede qualquer compreensão relativa a estrutura desse defeito.

"Multiple records that represent one single real-world entity. This may be caused by poor edit rules, business procedures that do not effectively determine duplication, data that has changed since its original data capture causing a failure to match, or incentives of productivity in the information producers." por [English, 1999]

Em contraste, os defeitos nos dados correspondem ao objetivo central das comunidades da Categorização de Dados [Naumann, 2014], Estatística - parcialmente - [Winkler, 2004] e Limpeza de Dados [Chaudhuri et al., 2003; Chu et al., 2013; Fan e Geerts, 2012; Ganti e Sarma, 2013]. O conhecimento aprofundado das estruturas dos defeitos permite tais comunidades prover relevantes contribuições a melhoria da qualidade de dados.

"Data deduplication is the problem of identifying tuples from one or more relations that refer to the same real-world entity. Consider the relational schemas below, one needs to check whether for all tuples $t \in I_{c}$ and $t^{\prime} \in I_{b}$, if $t[c]=t^{\prime}[c]$ then $t\left[Y_{c}\right]$ and $t^{\prime}\left[Y_{b}\right]$ refer to the same person, where $Y_{c}$ and $Y_{b}$ are: $Y_{c}=[F N, L N, a d d r, t e l]$ and $Y_{b}=[F N, L N$, post,phn]." por Fan e Geerts [2012] 


\begin{tabular}{|c|c|c|c|c|c|c|c|}
\hline $\mathrm{c}$ & $\mathrm{FN}$ & $\mathrm{LN}$ & addr & tel & email & gender & type \\
\hline 111 & Mark & Maier & 10 Oak St. MH, NJ 07974 & $908-2345678$ & mc@gm.com & M & master \\
\hline 222 & Dave & Smith & 620 Elm St., MH, NJ 07976 & $908-8955664$ & ds@hm.com & M & visa \\
\hline $\mathrm{c}$ & FN & LN & post & phn & email & item & price \\
\hline 111 & Marx & Maier & 10 Oak St. MH, NJ 07974 & 908 & $\mathrm{mc}$ & iPad & 169 \\
\hline 111 & Marx & Maier & & $908-2345678$ & & book & 19 \\
\hline 111 & M. & Maire & 10 Oak St. MH. NJ 07974 & 2345678 & mc@gm.com & PSP & 269 \\
\hline
\end{tabular}

O trecho acima expõe parcialmente uma descrição de duas páginas de tuplas duplicadas. Através da conjunção dos recursos de explicação textual, exemplos e formalização, essa descrição parcial revela muito mais detalhes sobre a estrutura do defeito do que a anterior. Porém, trabalhos dessa comunidade usualmente abordam um conjunto restrito de defeitos ou mesmo um único.

Por sua vez, as taxonomias ${ }^{8}$ [Almutiry et al., 2016; Kim et al., 2003; Li et al., 2011; Müller e Freytag, 2005; Oliveira et al., 2005; Rahm e Do, 2000] propõem alinhar descrições assertivas a uma ampla cobertura de defeitos nos dados. Contudo, uma revisão das taxonomias estado-da-arte revelam descrições e coberturas heterogêneas devido a questões relacionadas ao modelo de descrição, a terminologia, ao modelo de triagem dos defeitos, ao nível de abstração e o escopo.

O modelo de descrição denota o grau de precisão oferecida pela descrição do defeito. As descrições de tuplas duplicadas abaixo explicitam as variações entre as taxonomias e a suscetibilidade da comunicação incorreta da estrutura do defeito em contraste ao modelo baseado na descrição formal, textual e com exemplos por [Fan e Geerts, 2012].

"Same employee represented twice due to some data entry errors. Example: emp1= $($ name= "John Smith",...), emp2=(name="J. Smith",...). " por [Rahm e Do, 2000] "Duplicated data (violating non-null uniqueness constraint)" por [Kim et al., 2003] "Duplicates are two or more tuples representing the same entity from the mini-world. The values of these tuples do not need to be complete identical. Inexact duplicates are specific cases of contradiction between two or more tuples. They represent the same entity but with different values for all or some of its properties. This hardens the detection of duplicates and there mergence." por [Müller e Freytag, 2005]

"Let $\mathrm{S}$ be a set of attribute names, defined as: $S=\{a \mid a \in R(A) \wedge$ a does not belong to the primary key\}, i.e., $S \subseteq R(A)$. Let $\Theta$ be a real number between 0 and 1 . Let similarity be a function that receives two values of an attribute, computes the similarity between them, and returns it (also as a real number between 0 and 1 ). There are inconsistent duplicate tuples in relation $\mathrm{R}$ iff: $\exists a_{2} \in S, t_{1}, t_{2} \in r, \forall a_{1} \in$ $S \backslash\left\{a_{2}\right\}$ : similarity $\left(v\left(t_{1}, a_{1}\right), v\left(t_{2}, a_{1}\right)\right) \geq \Theta \wedge \operatorname{similarity}\left(v\left(t_{1}, a_{2}\right), v\left(t_{2}, a_{2}\right)\right)<\Theta$.

\footnotetext{
${ }^{8}$ Trabalhos que abordam critérios de qualidade diferentes de acuracidade, completude e consistência foram omitidos. Ademais não foram abordados certos trabalhos [Barateiro e Galhardas, 2005; Do, 2009; Helfert e Ge, 2006] cujas descrições dos defeitos são idênticas àquelas de outros trabalhos predecessores, como [Rahm e Do, 2000] e [Kim et al., 2003]. Por fim, trabalhos que debatem defeitos específicos do contexto de modelos de dados multidimensionais [de Almeida et al., 2013], de Data Warehouse [Singh e Singh, 2010] e temporais [Gschwandtner et al., 2012] também não foram considerados.
} 
The tuple Customer (10, 'Smith Barney', 'Flowers Street, 123', 502899106) is an approximate duplicate of the tuple Customer (72, 'S. Barney', 'Flowers St., 123', 502899106)" por [Oliveira et al., 2005]

"Duplicate records may happen for example, when a person's name and address are represented in different ways, the same entity may be represented more than once in the same or different data sources." por [Li et al., 2011]

A terminologia determina a precisão e clareza técnica dos termos empregados na nomenclatura e na descrição dos defeitos. No vocabulário informal predomina o uso de termos genéricos em detrimento ao jargão técnico. Por conseguinte, essa generalidade requer a interpretação quando considerada a partir da perspectiva técnica da avaliação da qualidade de dados. Como exemplo, "Domain format errors" [Müller e Freytag, 2005] e "Wrong data type" [Kim et al., 2003; Li et al., 2011] representam diferentes nomenclatura para o mesmo defeito "Domain Constraint Violation" - um jargão na área de banco de dados.

O modelo de triagem denota a técnica de seleção do conjunto de defeitos discutidos. No modelo intuitivo, o grau de representatividade do defeito é atribuído pelo senso comum dentro de um contexto, fato observado em certos trabalhos [English, 1999; Eppler, 2003; Müller e Freytag, 2005; Schmid, 2005]. Em contraste, os trabalhos restantes utilizam revisões, entrevistas ou técnicas de classificação ${ }^{9}$ na identificação dos defeitos. Contudo, a ausência de um referencial teórico e o cuidado com a consolidação das descrições contribuem para a cobertura incompleta dos defeitos nos dados entre as taxonomias. A título de exemplo, apesar da sequência de citação entre [Rahm e Do, 2000], [Oliveira et al., 2005] e [Li et al., 2011], defeitos nos dados como "Wrong Reference" por [Rahm e Do, 2000] e "Existence of synonyms" por [Oliveira et al., 2005] não são discutidos em [Li et al. , 2011]. Além disso, defeitos relativos as regras de modelagem de dados - incluindo "Cardinality Ratio" - e às falhas no ciclo de vida dos dados - incluindo "False Tuple" - não são endereçados por taxonomia alguma. Exemplos adicionais relativos a heterogeneidade na descrição de defeitos são discutidos em [Laranjeiro et al., 2015].

O nível de abstração determina o agrupamento de diferentes variantes de um defeito no entorno de sua estrutura. Certos trabalhos apresentam definições separadas para variantes de defeitos, tais como "Approximate duplicate tuples" e "Inconsistent duplicate tuples" por [Oliveira et al., 2005] - remetem ao defeito "Tuplas Duplicadas" -, bem como "Missing value", "Data value out of value range" e "Data value constraint violation" por [Li et al., 2011] que remetem ao defeito "Violação de Restrição de Domínio".

O escopo denota o tipo de dado - estruturado, espacial, semi-estruturado, não estruturado -, o aspecto temporalidade e os critérios de qualidade sobre os quais os defeitos serão observados. Nenhuma das taxonomias apresenta explicitamente os respectivos escopos. Como exemplo, certas taxonomias tangenciam defeitos relativos a dados espaciais

\footnotetext{
${ }^{9}$ Heurísticas de classificação hierárquica dos defeitos baseadas no local de manifestação ou no modo de contornar o referido defeito, por exemplo.
} 
[Kim et al., 2003] e temporais [Li et al., 2011].

\subsection{Limites das Abordagens de Projeto de Sistemas de Visualização}

O conhecimento relativo ao projeto de sistemas de visualização está codificado em trabalhos com diferentes perspectivas e níveis de profundidade. Devido a extensa literatura, somente certos trabalhos serão apresentados.

As taxonomias identificam, relacionam e organizam os conceitos centrais que caracterizam os sistemas de visualização e, por isso, são consideradas uma literatura base [Heer e Shneiderman, 2012; Keim, 2002; Shneiderman, 1996; Valiati et al., 2006]. Guias de Orientação descrevem recomendações para o projeto de sistemas de visualização regidas por certos pressupostos. Enquanto certos guias oferecem direções para elementos particulares [Baldonado et al., 2000], outras adotam a orientação de aspectos arquiteturais [Tang et al., 2004].

Em contraste, implementações descrevem exemplos reais de projeto de sistemas de visualização para um domínio específico. Para o domínio da avaliação da qualidade de dados - Seção 3.3 -, implementações utilizam descrições com maior apelo visual-sistêmico que pouco esclarecem a respeito das decisões de projeto da implementação, bem como os pontos fortes e fracos de suas representações visuais [Kandel et al., 2012b; Kang et al. , 2008; Tennekes et al., 2013; Zaixian et al., 2007].

Avaliações denotam estudos comparativos [Kehrer et al., 2013] ou perceptual-cognitivo [Robertson et al., 2008; Yang et al., 2014] que analisam certas técnicas - técnicas de visualização, por exemplo - para identificar os respectivos pontos fortes e fracos dentro de certo domínio de problema. As avaliações podem utilizar diferentes técnicas, incluindo experimentos em laboratório, heurísticas e estudos etnográficos. Fortemente relacionado ao presente trabalho, certos estudos avaliativos [Grinstein et al., 2002; Hoffman, 1999; Marghescu, 2008; Ward e Theroux, 1997] discutem a capacidade de um conjunto restrito de técnicas de visualização para detectar valores atípicos em atributos - defeito denominado neste trabalho como "Tupla Atípica". Contudo, os resultados desses trabalhos estão limitados a: técnicas de visualização com forte sobreposição de propriedades visuais; pequena ou nenhuma discussão sobre o apoio das técnicas de interação; utilização de pequenas resoluções de dados - até $4 * 10^{3}$ tuplas -; abordagem da variante mais simples de tupla atípica, exceto por [Ward e Theroux, 1997] que endereça valores atípicos em categorias interpostas - Seção 4.4.

Os Modelos de Referência oferecem o conjunto de descrições mais robusta para o projeto de sistemas de avaliação com diferentes bases teóricas e ênfases. Certos modelos estão baseados em teorias psicofísicas [Csinger, 1992], da percepção visual [Ware, 2004] 
ou da psicologia cognitiva [Patterson et al., 2014]. Em termos de ênfase, certos modelos estão empenhados na geração automática de visualizações [Casner, 1991; Mackinlay, 1986; Zhu et al., 2009] e na modelagem do espaço da representação visual - design space modelling - [Bertin, 1983; Schulz et al., 2013; Wilkinson et al., 2006]. Próximo ao objetivo do presente trabalho, a modelagem do espaço proporciona relevantes modelos conceituais que organizam as propriedades visuais de acordo com a ordem de percepção e compreensão de certas características dos dados ou atividades visuais elementares.

Igualmente relacionada ao presente trabalho, a Qualidade de Dados Espacial - Spatial Data Quality ou SDQ - e a Visualização de Incertezas - Uncertainty Visualization ou UV - exploram o relacionamento entre a qualidade de dados e os processos de tomada de decisão. Ambas áreas de pesquisa sistematicamente descrevem modelos de referência e outros que combinam as características dos dados, do espaço e do tempo para determinar as propriedades visuais apropriadas a exposição das incertezas estatisticamente apuradas [Potter et al., 2012; Thomson et al., 2005].

\begin{tabular}{|c|c|}
\hline Codificações do Conhecimento & Principais Características \\
\hline Taxonomia & $\begin{array}{l}\text { - Organiza os conceitos relativos aos sistemas de visualização } \\
\text { - Apoio de alto nível a etapa de projeto }\end{array}$ \\
\hline Implementação & $\begin{array}{l}\text { - Endereça o processo de Avaliação da Qualidade de Dados - certos casos } \\
\text { - Não descreve decisões de projeto baseado na avaliação visual da qualidade } \\
\text { - Endereça defeitos em dados abstratos de baixa-moderada supervisão humana, } \\
\text { principalmente } \\
\text { - Não revela como ou se as estruturas dos defeitos foram consideradas } \\
\text { - Não provê uma abordagem sistemática para projetistas } \\
\text { - Visualização é um meio de comunicar resultados de abordagens computacionais }\end{array}$ \\
\hline $\begin{array}{l}\text { Modelo de Referência } \\
\text { (SDQ e UV) }\end{array}$ & $\begin{array}{l}\text { - Endereça o processo de Avaliação da Qualidade de Dados } \\
\text { - Provê um abordagem sistemática para a etapa de projeto } \\
\text { - Base matemática para mensurar incertezas em dados com referência física } \\
\text { - Visualização é um meio de comunicação das incertezas mensuradas }\end{array}$ \\
\hline
\end{tabular}

Tabela 3.5: Projeto de Sistemas de Visualização - Resumo das Codificações (Fonte: Elaborado pelo autor) 
A Tabela 3.5 sintetiza o conhecimento estado-da-arte do projeto de sistemas de visualização e suas limitações perante o domínio da avaliação da qualidade de dados. Apesar da representatividade e da abrangência, esse conhecimento não contempla a estrutura dos defeitos nos dados e não determina quais são as propriedades visuais e interativas - Seção 5.1 - dos sistemas de visualização mais indicadas a detecção visual dessas estruturas. A estrutura dos defeitos determina os padrões e os relacionamentos nos dados defeituosos para os quais o processamento cognitivo e as ações do agente avaliador da qualidade são dirigidos - Seção 2.4.1. Em outras palavras, os padrões e relacionamentos são os significados a serem extraídos de um estímulo visual para subsequente processamento cognitivo. Portanto, o projeto de sistemas de visualização deve considerar as propriedades que facilitam a extração visual desses significados necessários ao julgamento da qualidade dos dados [Patterson et al., 2014; Tory e Moller, 2004; Ware, 2004].

\subsection{Conclusão}

O papel do pAQD é prover informações capazes de auxiliar a condução das iniciativas de melhoria e manutenção da qualidade dos dados - Seção 2.2.3. Porém, esse processo é cercado por desafios que torna sua viabilização dependente da automação [Loshin, 2010; Naumann, 2002; Rahm e Do, 2000]. Este capítulo sintetizou duas relevantes abordagens de automação: a computacional e a visual.

A abordagem computacional - Seção 3.2 - inclui soluções que partilham um arcabouço baseado em objetivos bem específicos e que restringe o papel do avaliador da qualidade de dados a apreciação dos respectivos resultados [Dasu, 2013; Dasu e Johnson , 2003; Naumann, 2014]. Em contraste, a avaliação da qualidade dos dados é fortemente dependente do conhecimento do contexto dos dados uma vez que é impossível confirmar ou refutar um defeito com base exclusiva nos dados [Bertossi et al., 2011; Dasu e Johnson , 2003; Fan e Geerts, 2012; Lee et al., 2009]. Desse modo, a supervisão humana é essencial para realizar a avaliação, conforme corrobora trabalhos recentes baseados na referida abordagem [Angiulli e Fassetti, 2014; Naumann, 2014; Sluban et al., 2014].

De outro modo, a abordagem visual - Seção 3.3 - representa uma classe de soluções supervisionadas que combinam a capacidade computacional as habilidades de detecção de padrões e distinção semântica inatas do ser humano. Essa característica vêm estimulando o uso dos sistemas de visualização de dados para atender diferentes necessidades da avaliação dos dados [Naumann, 2014]. O levantamento bibliográfico rigoroso conduzido por este trabalho selecionou e delineou trabalhos de diferentes áreas que compartilham essa visão. Tal artefato proporcionou a extração de um conjunto de características singulares discutidas a seguir.

- Nenhum dos trabalhos descreve se e como as características dos dados balizaram a 
seleção das técnicas de visualizações e a disposição dos dados de modo a favorecer a extração de significados;

- Nenhum dos trabalhos descreve se e como as características das atividades de avaliação de cada defeito balizaram as decisões do projeto dos respectivos sistemas de visualização. A visão geral dessas atividades fornecem elementos capazes de selecionar técnicas de interação mais adequadas a passos específicos;

- Nenhum dos trabalhos descreve se e como os conhecimentos relativos a estrutura dos defeitos nos dados balizaram a seleção das técnicas de visualização. Uma vez que o objetivo é permitir a detecção e análises de defeitos, esse conhecimento representa um dos critérios para determinar as técnicas mais apropriadas;

- Nenhum dos trabalhos descreve se os requisitos dos respectivos sistemas foram determinados a partir de técnicas de envolvimento dos usuários, incluindo prototipação ou estudos etnográficos de longo prazo;

- Majoritariamente, os trabalhos adotam a abordagem de especializar o uso das técnicas de visualizações a defeitos particulares por meio de primitivas visuais otimizadas - Seção 2.4.1. Embora esse recurso favoreça a avaliação dos defeitos contemplados, o enviesamento das técnicas de visualização dificulta ou até impede a detecção de outros padrões de defeitos - efeito de distração. Interessante ressaltar que os poucos trabalhos que não adotaram a referida estratégia corroboram que o conhecimento do contexto dos dados e das atividades de avaliação dos dados afetam o uso do sistema de visualização;

- Nenhum dos trabalhos fornece quantificações - precisas ou inferidas - dos defeitos presentes no conjunto de dados avaliado;

- Majoritariamente, os trabalhos estão preocupados com defeitos das granularidades valor de atributo ou atributo - 84\% -, especialmente a violação de domínio e valores atípicos - respectivamente. Cerca de $46 \%$ dos trabalhos observaram defeitos nas granularidades de tupla, de relação e de inter-relações;

- Reunidos, os trabalhos empregam cerca de 16 representantes do variado conjunto de técnicas de visualização disponíveis. Aquelas originárias da área da estatística e restritas a até dois atributos correspondem a cerca de $51 \%$ dos casos, enquanto somente uma das técnicas oferece compactação que proporciona a transição entre a visão global e granular dos dados. A ausência de critérios de seleção das técnicas de visualização somada a estratégia de especialização das técnicas a um defeito particular pode representar uma das causas dessa situação; 
- Apenas três trabalhos utilizam recursos que propiciam uma certa escalabilidade no volume de dados manipulados. Contudo, nenhum dos trabalhos considerou o uso do processamento paralelo ou distribuído, e recursos da GPU - Graphics Processing Unit - para maximizar as transformações geométricas, visuais ou de dados - Seção 2.3.3;

- Todos os trabalhos partem da disponibilidade total dos dados para a avaliação. Logo, os desafios da avaliação da qualidade de dados distribuídos não são considerados;

- Somente um dos trabalhos - Profiler - discute e apresenta uma arquitetura que oferece uma certa facilidade de evolução - acrescentar novos métodos computacionais. Esse fato pode decorrer da dificuldade de criar sistemas genéricos de avaliação de dados devido a variação na características dos dados e do contexto dos dados [Dasu e Johnson, 2003];

- A questão social é elemento relevante na realização de processos cognitivos mediados pela visualização de dados [Heer e Shneiderman, 2012; Silva et al., 2007]. Tal questão também é relevante na avaliação da qualidade dos dados devido a interação constante entre avaliadores da qualidade e especialistas do domínio do negócio [Dasu e Johnson, 2003; Karr et al., 2006; Olson, 2003]. Apesar da relevância, nenhum dos trabalhos possui a capacidade de anotar e compartilhar as introspecções geradas ao longo da avaliação da qualidade dos dados.

A Seção 3.4 retratou a dificuldade do estado-da-arte da literatura em responder certas perguntas relativas aos defeitos nos dados. Contudo, o apoio do pAQD à melhoria da qualidade dos dados fortemente depende da clara compreensão da estrutura dos defeitos nos dados a serem avaliados - Seção 2.2.3. Devido a relevância do tema [Laranjeiro et al., 2015], o Capítulo 4 irá apresentar uma taxonomia que organiza e descreve os defeitos de modo a responder as referidas questões com relação aos critérios de qualidade da acurácia, completude e consistência.

Por fim, a Seção 3.5 revelou que o estado-da-arte da literatura relativo ao projeto de sistemas de visualização não considera a estrutura dos defeitos nos dados. Esse limite dificulta responder questões relevantes ao projeto de sistemas que apoiem adequadamente a avaliação visual de defeitos que demandam alta supervisão humana: Quais propriedades visuais salientam um defeito de acordo com sua estrutura? Quais propriedades adicionais podem minorar o efeito de oclusão em crescentes resoluções de dados e assegurar a capacidade reveladora das propriedades visuais? Quais propriedades interativas são mais apropriadas na avaliação visual da qualidade dos dados? O Capítulo 5 irá descrever um estudo de caso exploratório conduzido para delinear as primeiras respostas às referidas questões. 


\section{Capítulo 4}

\section{Uma Taxonomia Formal de Defeitos nos Dados}

\subsection{Introdução}

Bancos de dados com níveis adequados de qualidade dependem de um pAQD efetivo Seção 2.2.3. Para tanto, esse processo requer o conhecimento sobre a estrutura do problema associado a cada defeito de modo a: fundamentar pesquisas relacionadas sobre o projeto de métodos ou soluções automatizadas de avaliação da qualidade de dados [Borek et al., 2011; Loshin, 2010]; amparar a determinação da aplicabilidade de abordagens computacionais na avaliação de certos defeitos; colaborar na definição de regras e parâmetros de certas abordagens computacionais [Naumann, 2014; Rahm e Do, 2000; Zhang e Wu, 2010]. Em suma, a compreensão plena da estrutura dos defeitos nos dados é necessária para saber como realizar uma efetiva avaliação da qualidade dos dados.

Este capítulo descreve a primeira contribuição do presente trabalho: uma taxonomia de defeitos em dados estruturados e relacionais relativos aos critérios de qualidade da acuracidade, completude e consistência. Sua primeira parte - Seção 4.2 - apresenta a abordagem metodológica utilizada na organização da taxonomia, enquanto a parte seguinte - Seção 4.3 - detalha os elementos utilizados na descrição dos defeitos nos dados. A última parte - Seção 4.4 - descreve os defeitos nos dados por meio de recursos combinados de explicação textual, representação formal e ilustração por meio de exemplos.

\subsection{A Abordagem Metodológica}

A taxonomia proposta para responder as questões discutidas na Seção 3.4 resultou de três etapas sequenciadas. A primeira etapa revisou um amplo conjunto de tópicos da teoria relacional. Dentre os tópicos estão: a modelagem de dados conceitual, as transformações 
entre modelos de dados conceituais e lógicos e, a teoria relacional ${ }^{1}$ [Elsmari e Navathe , 2010; Fan e Geerts, 2012; Grefen, 1993; Maier, 1983].

Tais tópicos revelaram um conjunto abrangente de regras utilizadas pelo modelo de dados relacional para representar características e comportamentos do UdD, conforme observado na Tabela 4.1. Cada regra foi base para identificar uma ou mais violações os defeitos - que conduzem os dados a estados defeituosos. Ademais, a etapa de revisão também determinou a terminologia, a nomenclatura e o modelo de descrição adotados. Esse último combina o formalismo matemático, textos assertivos e exemplos baseados em instâncias de tuplas para explicitar a estrutura de cada defeito.

\begin{tabular}{|c|c|c|}
\hline Tópico & Regra ou Restrição & Defeito no Dado (Violação) \\
\hline \multirow[t]{2}{*}{$\begin{array}{l}\text { Características inerentes } \\
\text { dos Atributos }\end{array}$} & $\begin{array}{l}\text { Deve conter um valor único } \\
\text { do domínio do atributo }{ }^{2,4}\end{array}$ & Subdomínios Disjuntos \\
\hline & Semântica de um UdD ${ }^{4}$ & $\begin{array}{l}\text { Granularidade Heterogênea, } \\
\text { Tupla Atípica, Unidade Medida Heterogênea, } \\
\text { Valor Impreciso, Valor Incorreto, } \\
\text { Valores Homônimos e Valores Sinônimos } \\
\text { Ver Dependência Funcional }\end{array}$ \\
\hline \multirow{4}{*}{$\begin{array}{l}\text { Características inerentes } \\
\text { das Relações }\end{array}$} & Não deve conter tuplas duplicadas ${ }^{4}$ & Tuplas Duplicadas \\
\hline & $\begin{array}{l}\text { Tupla representa um único objeto } \\
\text { do } \mathrm{UdD}^{2,4}\end{array}$ & Tupla Sobrecarregada \\
\hline & $\begin{array}{l}\text { Tupla representa um relacionamento } \\
\text { entre objetos do } \mathrm{UdD}^{2,4}\end{array}$ & Referência Incorreta e Referência Ausente \\
\hline & $\begin{array}{l}\text { Tuplas devem representam objetos } \\
\text { de interesse para o } \mathrm{UdD}^{2,4}\end{array}$ & Tupla Ausente e Tupla Falsa \\
\hline \multirow[t]{7}{*}{ Dependências } & Inferência $^{1,4}$ & Viol. de Regra de Inferência \\
\hline & Dependência de Chave ${ }^{1}$ & Viol. de Dependência de Chave \\
\hline & Dependência Funcional ${ }^{1,2,3,4,5}$ & Viol. de Dependência Funcional e \\
\hline & Dependência Funcional Condicional ${ }^{5}$ & $\begin{array}{l}\text { KepHcaçao Incompativel } \\
\text { Viol. de Dependência Funcional Condicional }\end{array}$ \\
\hline & Dependência de Inclusão ${ }^{1,5}$ & Viol. de Dependência de Inclusão \\
\hline & Dependência de Inclusão Condicional ${ }^{5}$ & Viol. de Dependência de Inclusão Condicional \\
\hline & Transição de Estado de uma Relação ${ }^{1,3,4}$ & Viol. de Restrição de Transição \\
\hline \multirow[t]{6}{*}{ Domínio } & Condicional $^{3,4}$ & Viol. de Restrição de Domínio \\
\hline & Convenções ${ }^{4}$ & \\
\hline & Faixa de Valores ${ }^{2,3,4}$ & \\
\hline & Formato $^{2,4}$ & \\
\hline & Valor Obrigatório $^{2,4}$ & \\
\hline & Valores Enumerados ${ }^{3,4}$ & \\
\hline \multirow[t]{3}{*}{ Integridade dos Dados } & Integridade Referencial $^{1,3,4}$ & Ver Dependência de Inclusão \\
\hline & Semânticas de um UdD ${ }^{4}$ & Viol. de Integridade Semântica \\
\hline & Unicidade $^{3,4}$ & Ver Dependência de Chave \\
\hline \multirow[t]{4}{*}{ Modelagem de Dados } & Tipos de Relacionamento $^{4}$ & Viol. de Razão de Cardinalidade \\
\hline & & Viol. de Restrição de Participação \\
\hline & Especializações Disjuntas ${ }^{4,5}$ & Ver Dependência de Inclusão Condicional \\
\hline & Subclasse de tipo união ${ }^{4}$ & Ver Dependência de Inclusão Condicional \\
\hline
\end{tabular}

Fontes:

1 [Abiteboul et al., 1995]

2 [Maier, 1983]

3 [Grefen, 1993]

4 [Elsmari e Navathe, 2010]

5 [Fan e Geerts, 2012]

Tabela 4.1: Relação entre Tópicos, Regras ou Restrições e Defeitos nos Dados (Fonte: Elaborado pelo autor)

Contudo, a identificação e organização das referidas violações foi trabalhosa à medida que certos tópicos revelaram violações inter-relacionadas - dependência dos dados, por

\footnotetext{
${ }^{1}$ Incluem restrições nos relacionamentos, parcialidade de dados em tuplas e especialização e generalização.
} 
exemplo - ou com regras complexas e específicas ao UdD - regras particulares ao domínio de Cartão de Crédito ou Hospital, por exemplo.

No primeiro caso, as violações foram dispostas de modo a garantir a exposição clara e acurada das respectivas estruturas. Assim, as violações de dependência de dados foram segmentadas em defeitos de dependência funcional, chave, condicional funcional, dentre outros. Já o segundo caso induziu a descrições genéricas dos defeitos - regras de inferência e de integridade semântica -, pois inexiste um modo de representação simplificado e abrangente de especificidades [Elsmari e Navathe, 2010]. As violações não pertinentes aos casos acima foram diretamente mapeadas para defeitos nos dados.

A lista final dos defeitos nos dados foi confrontada àquela obtida a partir das taxonomias estado-da-arte de modo a determinar possíveis ausências. No entanto, esse procedimento revelou que a taxonomia do presente trabalho descreve nove defeitos inéditos, conforme observados na Figura 4.2.

A segunda etapa classificou os defeitos nos dados em camadas de acordo com as propriedades compartilhadas. Essas propriedades foram herdadas das respectivas regras violadas, conforme exemplificado na Figura 4.1.

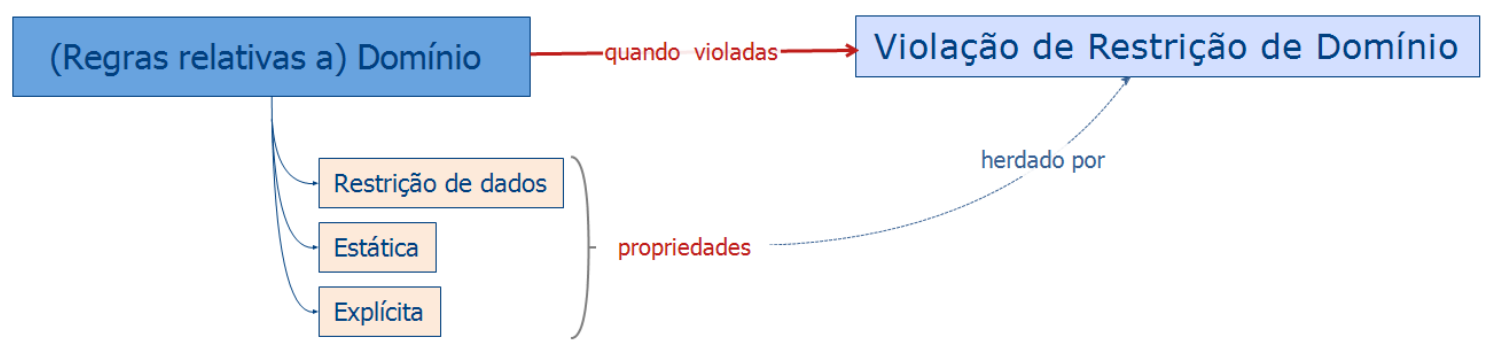

Figura 4.1: Propriedades herdadas da regra violada (Fonte: Elaborado pelo autor)

A primeira camada segmentou os defeitos nos dados entre aqueles que representam ou não violações às regras de um UdD, denominados respectivamente de "Restrições de Dados" e "Desvio de Representação do Fato". A classe "Restrições nos Dados" reúne defeitos nos dados que violam regras estáticas ou dinâmicas. A primeira denota regras explícitas ou características inerentes do modelo relacional - regras implícitas - que um estado válido de uma relação deveria satisfazer, incluindo regras de domínio, integridade e participação em relacionamentos. Em contraste, as regras dinâmicas compreendem regras aplicadas durante as transições de estado de uma relação. A classe "Desvio de Representação do Fato" denotam defeitos relativos as diferenças entre a representação dos dados e o correspondente fato sobre um objeto no UdD, incluindo significado, conteúdo e elemento de representação.

A terceira etapa classificou cada defeito no dado com base no seu local ou granularidade de ocorrência - Seção 2.2.3.3 -, incluindo valor de atributo, atributo, tupla, relação simples ou inter-relações - relacionamento binário - envolvendo uma ou mais instâncias de banco de dados. 
O resultado das três etapas é expresso na Figura 4.2 que representa ao lado de cada defeito os correspondentes níveis de granularidades envoltos por parênteses. De outra forma, a Tabela 4.2 retrata a associação entre os defeitos nos dados e os critérios de qualidade endereçados pela presente taxonomia - conforme Seção 4.1.

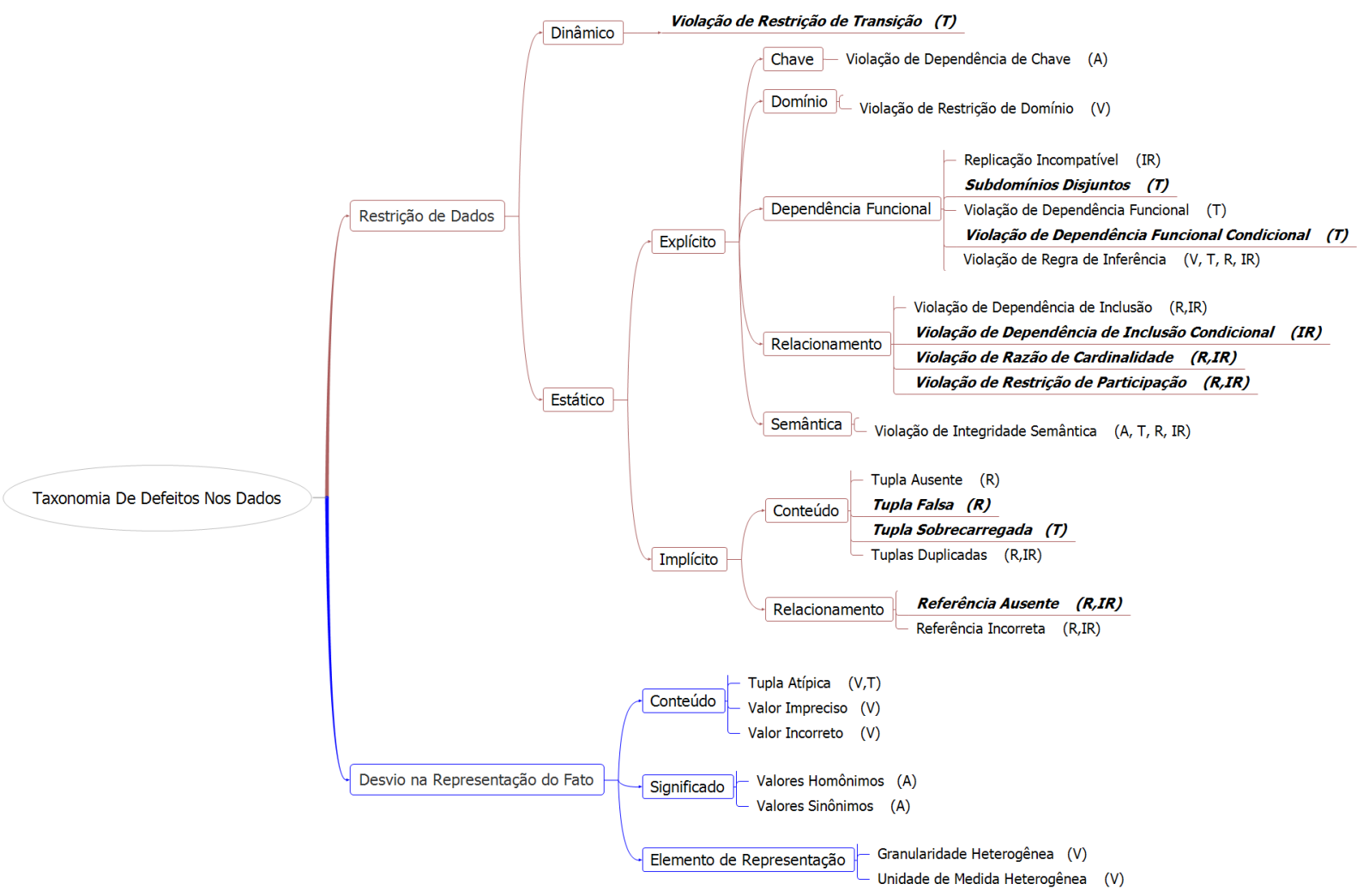

Figura 4.2: Taxonomia de Defeitos nos Dados (Fonte: [Josko et al., 2016])

Nivel de Granularidade: V-Valor de Atributo, A-Atributo, T-Tupla, R-Relação Simples, IR-Inter-relações

Nota: Defeitos nos dados destacados em itálico, negrito e sublinhado não foram endereçados por quaisquer taxonomias estado-da-arte.

\subsection{Os Conceitos Estruturais Base}

Existem várias linguagens relevantes para a formalização da taxonomia, incluindo variantes da lógica de primeira ordem [Abiteboul et al., 1995], restrições de integridade [Grefen, 1993] e restrições de recusa [Fan e Geerts, 2012].

Este trabalho aplicou uma linguagem de formalização baseada em [Fan e Geerts, 2012; Grefen, 1993; Maier, 1983; Ramaswamy et al., 2000] cujos elementos são apresentados em detalhes abaixo e resumidos no Quadro 4.1. Tal formalização é bem conhecida na comunidade de banco de dados e proporciona os elementos necessários a descrição dos defeitos nos dados. A avaliação da linguagem mais apropriada para descrever os defeitos está além do escopo deste trabalho. 


\begin{tabular}{ll}
\hline Critério de Qualidade & Defeito no Dado \\
\hline Acuracidade & Granularidade Heterogênea \\
& Referência Incorreta \\
& Tupla Atípica \\
& Tupla Sobrecarregada \\
& Tuplas Duplicadas \\
& Unidade Medida Heterogênea \\
& Valor Impreciso \\
& Valor Incorreto \\
& Valores Homônimos \\
& Valores Sinônimos \\
& Referência Ausente \\
& Subdomínios Disjuntos \\
& Tupla Ausente \\
Replicação Incompatível \\
Tupla Falsa \\
Violação de Dependência de Chave \\
Violação de Dependência de Inclusão \\
Violação de Dependência de Inclusão Condicional \\
Violação de Dependência Funcional \\
Violação de Dependência Funcional Condicional \\
Violação de Integridade Semântica \\
Violação de Razão de Cardinalidade \\
Violação de Regra de Inferência \\
Violação de Restrição de Domínio \\
Violação de Restrição de Participação \\
Violação de Restrição de Transição \\
\hline
\end{tabular}

Tabela 4.2: Critérios de Qualidade versus Defeitos nos Dados (Font: Elaborado pelo autor)

\begin{tabular}{|c|c|c|}
\hline & $\begin{array}{l}\text { Banco Dados Relacional } \\
\text { Esquema da Relação } \\
\text { Subconjunto da Relação } \\
\text { Estado da Relação } \\
\text { Tupla } \\
\text { Valores da Tupla } \\
\text { Relacionamento } \\
\text { Enciclopédia Universal }\end{array}$ & $\begin{array}{l}\text { Conjunto de esquemas de relações, denotado por } B D=\left\{R_{1}, R_{2}, R_{3} \ldots, R_{m}\right\}, m \geq 1 \\
\text { Conjunto de atributos, denotado por } R(A)=\left\{a_{1}, \ldots, a_{k}\right\}, k \text { é a aridade da relação } \\
\text { Lista de atributos } X, Y \subset R(A), R \in B D \text { e }(X \cap Y)=\oslash \\
\text { Conjunto de tuplas, denotado por } r\left(R_{i}\right)=\left\{t_{1}, t_{2}, t_{3} \ldots, t_{n}\right\} \\
\text { Cada tupla } t_{p}, p \in[1, n] \text {, é uma lista de } q \text { valores } t_{p}=\left\{v_{1}, v_{2}, \ldots, v_{q}\right\} \\
\text { Cada valor } v_{s}, s \in[1, q] \text {, é um elemento do domínio de um atributo } a_{s}, \\
\text { denotado por } t\left[a_{s}\right] \\
\text { Regra de integridade referencial entre relações } R_{W} \text { (referencia) e } R_{U} \text { (referenciada), } \\
\text { denotada por } R e l: R_{W} \rightarrow R_{U} \text {, onde } R_{W}, R_{U} \in B D \text { e } R e l=\left\{\left(a_{1}^{w}, a_{1}^{u}\right), \ldots,\left(a_{g}^{w}, a_{g}^{u}\right)\right\} \\
\text { Definições léxicas, relacionamentos e graus de similaridade dos termos de uso } \\
\text { comum, denotado por } L E X\end{array}$ \\
\hline & $\begin{array}{l}\text { Predicados para Valores } \\
\text { Predicados para Conjuntos } \\
\text { Conectores Lógicos } \\
\text { Conectores Unários } \\
\text { Quantificadores } \\
\text { Operadores de Conjunto }\end{array}$ & $\begin{array}{l}\ominus=\{<, \leq,=, \neq, \approx, \geq,>\} \\
Q=\{\in, \notin, \subseteq, \subset\} \\
\{\wedge, \vee\} \text { do tipo Boolean } \times \text { Boolean } \rightarrow \text { Boolean } \\
\{\neg\} \text { do tipo Boolean } \rightarrow \text { Boolean } \\
\{\forall, \exists\} \text { são os quantificadores universal e existencial } \\
\{\cup, \cap\}\end{array}$ \\
\hline
\end{tabular}

Quadro 4.1: Resumo da Linguagem de Formalização e Conceitos de Bancos de Dados Relacionais (Fonte: [Josko et al., 2016])

Definição A. (Banco de Dados Relacional): Um esquema de banco de dados relacional $B D$ compreende um conjunto de esquemas de relação representado por $B D=$ $\left\{R_{1}, \ldots, R_{m}\right\}, m \geq 1$.

Definição B. (Esquema da Relação): Um esquema da relação, denominado $R, R \in$ 
$B D$, é um conjunto finito de atributos $A=\left\{a_{1}, \ldots, a_{k}\right\}$ representado por $R\left\{a_{1}, \ldots, a_{k}\right\}$ ou $R(A)$. O valor $k$ denota o grau ou aridade de uma relação. Cada atributo $a_{j}, j=[1, k]$, é regulado por um domínio $D_{j}$ indicado na forma de $\operatorname{dom}\left(a_{j}\right)$. Cada domínio é um conjunto não vazio de valores atômicos e finitos.

Definição C. (Subconjunto da Relação): Subconjuntos de um esquema da relação, denominados $X, Y$, representam listas finitas de atributos, na qual $X, Y \subset R(A), R \in B D$ $\mathrm{e}(X \cap Y)=\oslash$.

Definição D. (Estado da Relação): Um estado da relação $r$ de uma relação $R$ representa um conjunto de $n$ tuplas na forma de $r=\left\{t_{1}, t_{2}, \ldots, t_{n}\right\}$, denotado por $r(R)$. Cada tupla $t_{p}, p=[1, n]$, constitui uma lista de $q$ valores representado por $t=\left\{v_{1}, v_{2}, \ldots, v_{q}\right\}$. Cada valor $v_{s}, s=[1, q]$, representa um elemento do domínio do respectivo atributo $\operatorname{dom}\left(a_{s}\right)$ - cuja referência é realizada por $t\left[a_{s}\right]$. Cada tupla descreve uma coleção de valores relacionados que representam afirmações verdadeiras ou fatos sobre objetos - entidades, relacionamentos ou fenômenos - do UdD.

Definição E. (Relacionamento): Um relacionamento Rel denota uma regra de integridade referencial entre as relações $R_{W}$ - referencia - e $R_{U}$ - referenciada - na forma de Rel $: R_{W} \rightarrow R_{U}$, na qual $R_{W}, R_{U} \in B D$ e $\operatorname{Rel}=\left\{\left(a_{1}^{w}, a_{1}^{u}\right),\left(a_{2}^{w}, a_{2}^{u}\right), \ldots,\left(a_{g}^{w}, a_{g}^{u}\right)\right\}$. Cada $a_{x}^{u}, x=[1, g]$, é um elemento do subconjunto de atributos $U$ que identifica univocamente cada tupla da relação $R_{U}$, tal que $U \subseteq R_{U}(A)$ e não há subconjunto $U^{\prime} \subset U$ com essa propriedade. Cada $a_{x}^{w}, x=[1, g]$, é um elemento do subconjunto de atributos $W$ da relação $R_{W}$ - no qual $W \subseteq R_{W}(A)$ - que referencia $R_{U}$.

Definição F. (Enciclopédia Universal): Uma enciclopédia universal - do inglês Universal Thesaurus - provê as definições léxicas dos termos de uso comum e seus respectivos relacionamentos e graus de similaridades, denotado por $L E X$.

Ademais, cada defeito é ilustrado mediante exemplos hipotéticos extraídos de um caso simplificado do domínio financeiro [Alves e Menezes, 2007], expresso no modelo de dados lógico da Figura 4.3. Nesse modelo, a entidade Cliente possui certas propriedades de Pessoas Físicas e Jurídicas proprietárias de produtos cartão de crédito ou débito. A entidade ContaCartaoCredito denota as propriedades dos produtos de cartão crédito adquiridos. A entidade ContaCreditoCliente representa todos os diferentes papéis de relacionamentos titular ou co-titular - entre clientes e os cartões de crédito. Por sua vez, o produto cartão de débito apresenta entidades com significados análogos, respectivamente ContaCartaoDebito e ContaDebitoCliente. Uma instância $I_{0}$ para cada uma das relações mencionadas é apresentada nas Tabelas 4.3 a 4.7 . 


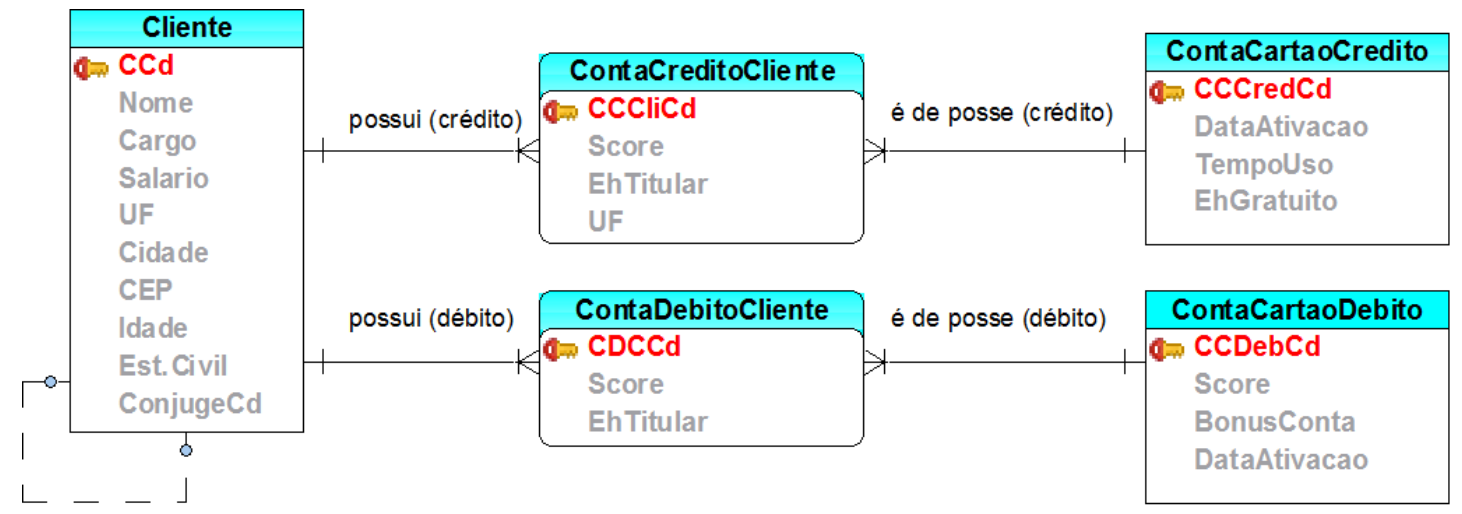

casado com

Figura 4.3: Modelo lógico de dados relativo a caso do domínio financeiro (Fonte: Elaborado pelo autor)

\begin{tabular}{|c|c|c|c|c|c|c|c|c|c|c|}
\hline & $\mathrm{CCd}$ & Nome & Cargo & Salario & UF & Cidade & CEP & Idade & Est.Civil & ConjugeCd \\
\hline c1: & 1 & John Taylor & Bassist & $20 \mathrm{k}$ & $\mathrm{SP}$ & $\mathrm{SP}$ & 08000 & 52 & $\mathrm{E}$ & 19 \\
\hline c2: & 3 & Joan Ripley & Tapster & $320 \mathrm{k}$ & BHZ & BHZ & 03000 & 20 & M & 40 \\
\hline c3: & 8 & John T. & Bartender & $20 \mathrm{k}$ & MG & $\mathrm{BHZ}$ & 08200 & 52 & W & NULL \\
\hline c4: & 13 & Ann P. Taylor & Barkeeper & $249 \mathrm{k}$ & MG & $\mathrm{BHZ}$ & 03200 & 44 & $\mathrm{U}$ & 1 \\
\hline c5: & 19 & Chris Taylor & NULL & $8 \mathrm{k}$ & SP & $\mathrm{SP}$ & 08100 & 39 & $\mathrm{~J}$ & 28 \\
\hline c6: & 28 & Carl de la Poll & Student & $21 \mathrm{k}$ & SP & SP & 08400 & 34 & M & 13 \\
\hline c7: & 29 & James Bond & Bassist & $22 \mathrm{k}$ & SP & SJC & 08000 & 53 & W & NULL \\
\hline c8: & 40 & Alice Bond & Bassist & $1 \mathrm{k}$ & $\mathrm{SP}$ & $\mathrm{SP}$ & 08051 & 53 & $\mathrm{E}$ & 49 \\
\hline c9: & 41 & John N. T. & Principle Manager & $40 \mathrm{k}$ & MG & $\mathrm{BHZ}$ & 03099 & 17 & $\mathrm{Y}$ & NULL \\
\hline c10: & 3 & Ann P. Taylor & Writer & $38 \mathrm{k}$ & MG & $\mathrm{BHZ}$ & 03200 & 44 & $\vec{J}$ & 1 \\
\hline c11: & 52 & Jean P. Jones & Student & $33 \mathrm{k}$ & SP & SJC & 08400 & 15 & S & NULL \\
\hline c12: & 53 & Dick Rhodes & Writer & $35 \mathrm{k}$ & SP & SJC & 12200 & 45 & W & NULL \\
\hline c13: & 59 & Laus Kisley & Principal Manager & NULL & SP & $\mathrm{SP}$ & 08501 & 39 & $\mathrm{~W}$ & NULL \\
\hline
\end{tabular}

Tabela 4.3: Uma instância da relação Cliente (Fonte: Elaborado pelo autor)

\begin{tabular}{lllll} 
& CCCredCd & DataAtivacao & TempoUso & EhGratuito \\
\cline { 2 - 5 } cr1: & 100 & $07 / 30 / 2001$ & 13 & Não \\
cr2: & 155 & $01 / 19 / 2004$ & 10 & Não \\
cr3: & 199 & $05 / 12 / 2005$ & 9 & Sim \\
cr4: & 200 & $01 / 19 / 2004$ & 1 & Não \\
cr5: & 201 & $04 / 11 / 2013$ & 1 & Não \\
\cline { 2 - 4 }
\end{tabular}

Tabela 4.4: Uma instância da relação ContaCartaoCredito (Fonte: Elaborado pelo autor)

\begin{tabular}{rllllll} 
& CCCliCd & CCCredCd & CCd & Score & EhTitular & UF \\
\cline { 2 - 6 } cc1: & 120 & 100 & 1 & 2.12307 & Sim & SP \\
cc2: & 312 & 100 & 13 & 3.00999 & Não & MG \\
cc3: & 138 & 100 & 19 & 1.80500 & Não & SP \\
cc4: & 813 & 100 & 3 & 3.10999 & Sim & SP \\
cc5: & 883 & 155 & 28 & 2.11001 & Sim & SP \\
cc6: & 901 & 199 & 44 & 3.89099 & Sim & SP \\
cc7: & 902 & 200 & 40 & 2.12320 & Sim & MG \\
cc8: & 903 & 201 & 52 & 1.83449 & Sim & MG \\
cc9: & 909 & 201 & 41 & 1.80011 & Não & MG \\
cc10: & 911 & 100 & 3 & 19.13329 & Não & SP \\
\cline { 2 - 6 }
\end{tabular}

Tabela 4.5: Uma instância da relação ContaCreditoCliente (Fonte: Elaborado pelo autor)

\begin{tabular}{lllll} 
& CCDebCd & Score & BonusConta & DataAtivacao \\
\cline { 2 - 5 } da1: & 54 & 1.77707 & 50 & $12 / 23 / 2009$ \\
da2: & 70 & 1.68123 & 50 & $01 / 20 / 2001$ \\
da3: & 79 & 1.71167 & 25 & $04 / 11 / 2014$ \\
da4: & 29 & 1.62344 & 33 & $04 / 11 / 2014$ \\
\hline
\end{tabular}

Tabela 4.6: Uma instância da relação ContaCartaoDebito (Fonte: Elaborado pelo autor) 


\begin{tabular}{llllll} 
& CDCCd & CCDebCd & CCd & Score & EhTitular \\
\cline { 2 - 6 } dc1: & 62 & 54 & 8 & 2.77707 & Sim \\
dc2: & 37 & 70 & 53 & 1.68123 & Sim \\
dc3: & 39 & 79 & 41 & 1.71167 & Sim \\
dc4: & 45 & 29 & 59 & 1.60000 & Não \\
\hline
\end{tabular}

Tabela 4.7: Uma instância da relação ContaDebitoCliente (Fonte: Elaborado pelo autor)

\subsection{A Descrição dos Defeitos nos Dados}

Esta seção descreve formalmente a maior granularidade dos defeito nos dados, conforme a ordem observada na Figura 4.2. A descrição de cada defeito segue uma apresentação formal, textual e orientada a exemplos baseada na terminologia, nomenclatura e linguagem estabelecidas pela abordagem metodológica - Seções 4.2 e 4.3. A taxonomia possui um subconjunto de defeitos que demanda alta supervisão humana para determinar sua ocorrência - Seção 2.2.3.3. Em consequência, a descrição desse subconjunto utiliza elementos que denotam um especialista humano.

Definição 1 (Violação de Restrição de Transição): Seja tran $R \rightarrow R$ uma função de transição que conduz o estado original de $R$ para outro estado $R^{\prime}$, de acordo com um sistema de inferência $R \rightarrow^{\text {tran }} R^{\prime}$. Uma violação de restrição de transição ocorre sse $\exists t \in R$ tal que $t\left[R^{\prime}(A)\right] \neq t[\operatorname{tran}(R(A))]$

As restrições de transição denotam um conjunto de regras dinâmicas que asseguram a transição de uma relação $R$ entre estados de dados válidos ao longo de transações. Essas regras avaliam um par sucessivo de estados pré e pós transação da relação. Uma violação ocorre se e somente se uma tupla possui estado de pós-transação inválido, isto é, uma das regras de transição foi desobedecida.

Exemplo 1: Existe uma regra que regula a transição entre estados válidos do atributo Est.Civil - "Estado Civil". A tupla c13 viola essa regra uma vez que seu estado civil foi modificado de "S" para "W", isto é, de solteiro - do inglês single - para viúvo - do inglês widower.

Exemplo 2: Existe uma regra de transição que determina que os valores dos salários modificados devem ser sempre superiores aos anteriores. A tupla $c 10$ da relação Cliente viola tal regra, pois o respectivo salário passou de $40 k$ para $38 k$.

Definição 2 (Violação de Dependência de Chave): Seja $X$ um subconjunto de atributos da relação $R$, tal que $X \subseteq R(A)$. Seja $R(A)$ dependente da chave $X$, representado por $X \rightarrow R(A)$. Essa dependência é violada sse $\exists t_{i}, t_{j} \in r(R), i \neq j$, tal que $t_{i}[X]=t_{j}[X]$.

O propósito de um subconjunto de atributos identificadores é distinguir univocamente cada tupla de uma relação de modo a possibilitar o relacionamento entre tuplas. Essa situação é violada se e somente se os atributos identificadores de duas ou mais tuplas da mesma relação compartilham o mesmo valor. 
Exemplo: As tuplas c2 e c10 da relação Cliente compartilham o mesmo CCd, embora representam clientes distintos no UdD.

Definição 3 (Violação de Restrição de Domínio): A violação de domínio ocorre sse $\exists t \in R, \exists a \in R(A)$ tal que $t[a] \notin \operatorname{dom}(a)$.

Uma restrição de domínio regula os valores permitidos para um atributo - semântica -, bem como o respectivo formato e tipo. Neste trabalho, uma restrição de domínio denota enumerações, restrições de faixa de valores, restrições de valores obrigatórios - diferente de nulos -, expressões regulares ou regras de convenção que regulam o uso e a disposição de caracteres especiais e abreviações e, regras de grafia. A violação de uma restrição de domínio ocorre se e somente se um valor não atende aos valores permitidos a um atributo.

Exemplo 1: O atributo Est.Civil - abreviação de "Estado Civil" - da relação Cliente possui um domínio definido como: "M", "E", "J", "U", "D", "W", ou "S". Contudo, a tupla $c 9$ contém "Y" para esse atributo.

Exemplo 2: Certo cliente - tupla c13 - possui uma ocorrência vazia para o atributo Salario cujo conteúdo é mandatório.

Exemplo 3: O atributo Score da relação ContaDebitoCliente possui uma restrição que estabelece seu domínio para os valores compreendidos entre 0 and 1.9999. No entanto, a tupla $d c 1$ apresenta o score de 2.77707 .

Definição 4 (Replicação Incompatível): Sejam $X \subset R_{1}$ e $Y \subset R_{2}$. Uma replicação $X \rightrightarrows Y$ ocorre se $\forall t_{i} \in R_{1}, t_{j} \in R_{2}, t_{i}[W]=t_{j}[U] \Rightarrow t_{i}[X]=t_{j}[Y]$. Um defeito de replicação ocorre sse $\exists t_{i} \in r\left(R_{1}\right), t_{j} \in r\left(R_{2}\right)$, tal que $t_{i}[W]=t_{j}[U]$ e $t_{i}[X] \neq t_{j}[Y]$.

Por razões diferentes razões - incluindo desempenho e modelagem de dados pobre -, um atributo base pode ter seu conteúdo replicado para múltiplos atributos cópia. Existe uma situação de contradição se e somente se os valores dos atributos cópia divergem do valor do atributo base.

Exemplo: O atributo UF da relação Cliente deveria ser replicado para o atributo de mesmo nome na relação ContaCreditoCliente. Contudo, essas relações apresentam valores divergentes para o mesmo cliente (tuplas $c c 4, c c 7, c c 8$ ).

Definição 5 (Subdomínios Disjuntos): O problema de subdomínios disjuntos ocorre quando existem subdomínios $S_{1}, S_{2}, \ldots, S_{n}$ para um atributo $a_{j}$ tal que $\operatorname{dom}\left(a_{j}\right)=\bigcup_{i=1}^{n} S_{i}$, e existe uma função $f: a_{i} \rightarrow\left\{S_{1}, S_{2}, \ldots, S_{n}\right\}$ que mapeia $a_{i}$ para um subdomínio de $a_{j}$, $i \neq j$ e $a_{i}, a_{j} \in R(A)$. Tal situação estabelece que o valores de $a_{j}$ dependem dos valores de $a_{i}$.

Um atributo possui subdomínios disjuntos (ou múltiplos usos) se e somente se seus valores representam diferentes fatos sobre objetos do UdD, segundo algum predicado.

Exemplo: O atributo Salário pode representar a remuneração ajustada pela realização de algum serviço (por exemplo, tupla c1) ou a renda familiar estimada (por exemplo, 
tuplas $c 6, c 11)$. O último caso ocorre quando um cliente não possui renda própria, isto é, o cargo é igual a "Estudante" ou a idade é inferior ou igual a dezesseis anos.

Definição 6 (Violação de Dependência Funcional): Seja $Y$ dependente funcionalmente de $X$, denotado por $X \rightarrow Y, X, Y \subseteq R(A)$. Essa dependência é violada sse $\exists t_{i}, t_{j} \in R, i \neq j$, tal que $t_{i}[X]=t_{j}[X]$ e $t_{i}[Y] \neq t_{j}[Y]$.

Um dependência funcional $A \rightarrow B$ denota que os valores de $B$ dependem funcionalmente dos valores de $A$. Em outras palavras, cada valor de $B$ está associado com precisamente um valor de $A$. A violação ocorre se e somente se tal restrição não é obedecida por algum valor de $B$.

Exemplo: A relação Cliente possui uma dependência funcional entre os atributos UF e Cidade, representada por $U F \rightarrow$ Cidade. Porém, essa dependência é violada pela tupla $c 2$ no caso da cidade $B H Z$.

Definição 7 (Violação de Dependência Funcional Condicional): Seja Tp uma tabela de padrões - pattern tableau - para o conjunto de atributos $X_{1}$ e $Y_{1}$, onde para cada atributo $a \in X_{1} \cup Y_{1}$ e para cada tupla de padrão $t p \in T p, t p[a]$ é uma constante em dom(a) ou um símbolo "coringa" "_" que denota valores de dom(a). Seja $Y_{1}$ dependente condicionalmente de $X_{1}$ definido como $\left(X_{1} \rightarrow Y_{1}, T p\right)$ na relação $R$. Uma dependência condicional é violada sse $\exists t_{i}, t_{j} \in r(R), i \neq j$, tal que $t_{i}\left[X_{1}\right]=t_{j}\left[X_{1}\right]=t p\left[X_{1}\right]$ e $t_{i}\left[Y_{1}\right]=t_{j}\left[Y_{1}\right] \neq t p\left[Y_{1}\right]$ ou $t_{i}\left[Y_{1}\right] \neq t_{j}\left[Y_{1}\right]$.

Uma dependência funcional condicional $[A \rightarrow B, T p]$ na relação $R$ denota que valores de $B$ dependem funcionalmente de valores de $A$ somente para aquelas tuplas de $R$ que satisfazem um padrão especificado em $T p$. Uma violação ocorre se e somente se essa restrição não é obedecida por algum valor de $B$.

Exemplo: A relação Cliente possui uma dependência funcional condicional entre os atributos UF, Cidade e CEP, denotado por $[U F, C i d a d e \rightarrow C E P, T p]$. Entre outros padrões, $T p$ especifica que a unidade de federação "SP" e cidade "SP" usam a faixa de CEP entre 08000 e 08499, enquanto a mesma unidade e cidade "SJC" tem a faixa de CEP de 12200 a 12248. Contudo, as tuplas $c 7$ e $c 11$ violam esses padrões.

Definição 8 (Violação de Regra de Inferência): Seja Rel : $R_{1} \rightarrow R_{2}$ um conjunto de relacionamentos entre as relações $R_{1}, R_{2}$. Seja $i r: R e l \rightarrow\{$ true, false $\}$ uma função que retorna se uma instância do relacionamento Rel cumpre a respectiva regra de inferência. Existe uma violação de regra de inferência sse $\exists\left(t_{i}, t_{j}\right) \in \operatorname{Rel}$ tal que $\operatorname{ir}\left(t_{i}, t_{j}\right)$ é false.

Uma regra de inferência é um procedimento que gera novos fatos baseados naqueles disponíveis em um banco de dados. Uma violação ocorre se e somente se um valor de atributo, tupla ou instância de relacionamento inferido não é representado ou é diferente daquele apurado pela regra de inferência. 
Exemplo: O atributo Score da relação ContaCreditoCliente é inferido por uma complexa análise dos últimos seis meses de uso do cartão de crédito. Essa relação possui uma tupla - cc8 - cujo Score é 1.83449 no lugar do valor inferido de 1.01553.

Definição 9 (Violação de Dependência de Inclusão): Seja $R e l: R_{1} \rightarrow R_{2}$ o conjunto de relacionamentos entre as relações $R_{1}$ e $R_{2}$. Existe a violação de dependência de inclusão sse $\exists t_{i} \in r\left(R_{1}\right), \forall t_{j} \in r\left(R_{2}\right)$ tal que $t_{i}[W] \neq t_{j}[U]$.

Dependências de inclusão impõem condições de aceitação das ações realizadas sobre instâncias de relacionamentos para garantir a consistência. A violação de tal regra é criada se e somente se uma tupla $t_{1}$ referencia uma tupla $t_{2}$ que não está disponível na relação referenciada.

Exemplo 1: A tupla cc6 da relação ContaCreditoCliente referencia um cliente que não existe na relação Cliente.

Exemplo 2: Por meio do auto-relacionamento de papel "casado com" - atributo ConjugeCd -, a tupla $c 8$ referencia um cliente que inexiste na relação Cliente.

Definição 10 (Violação de Dependência de Inclusão Condicional): Seja Tp uma tabela de padrões - pattern tableau - com os atributos em $X_{p}$ e $Y_{p}$, tal que para cada atributo $a \in X_{p} \cup Y_{p}$ e cada tupla padrão $t p \in T p, t p[a]$ é uma constante no $\operatorname{dom}(a)$. Seja $R_{1}$ dependente condicionalmente de $R_{2}$, denotado por $\left(R_{1}\left[X ; X_{p}\right] \subseteq R_{2}\left[Y ; Y_{p}\right], T p\right)$. Essa dependência é violada sse $\exists t_{i} \in r\left(R_{1}\right), \exists t_{j} \in r\left(R_{2}\right)$ tal que $\left(t_{i}\left[X_{p}\right]=t p\left[X_{p}\right]\right.$ e $t_{j}\left[Y_{p}\right]=t p\left[Y_{p}\right]$ e $\left.t_{i}[X] \neq t_{j}[Y]\right)$ ou $\left(\left(t_{i}\left[X_{p}\right] \neq t p\left[X_{p}\right]\right.\right.$ ou $\left.t_{j}\left[Y_{p}\right] \neq t p\left[Y_{p}\right]\right)$ e $\left.t_{i}[X]=t_{j}[Y]\right)$.

O modelo relacional é indiferente a participação das tuplas de uma relação $R$ nos vários relacionamentos estabelecidos por essa relação as demais relações de um $D B$ [Maier, 1983]. Entretanto, há ocasiões na qual a participação disjunta é necessária. A regra $O U$ exclusivo especifica que conjuntos de relacionamentos binários entre as relações $R_{i}, R_{j}$ a uma relação raíz $R_{r}$ devem ser disjuntos. Por exemplo, no caso das hierarquias de generalização e especialização, essa regra é requerida quando subclasses devem ser disjuntas ou uma subclasse irá representar um conjunto de superclasses - modelagem do tipo união. A violação a tal regra surge se e somente se existem tuplas da relação raíz que participam de dois ou mais relacionamentos mutuamente exclusivos.

Exemplo 1: Uma restrição de disjunção proíbe clientes de possuírem cartões de crédito e débito simultaneamente. Contudo, existe um cliente - $c 9$ - relacionado aos dois produtos - $c c 9$ e $d c 3$.

Exemplo 2: Uma restrição de disjunção proíbe que os papéis de titular e co-titular sejam exercidos pelo mesmo cliente. Contudo, existe um cliente - $c 2$ - com ambos os papéis sobre o mesmo cartão de crédito ( $c c 4$ e $c c 10)$.

Definição 11 (Violação de Razão de Cardinalidade): Seja $\mathrm{cr}: R_{1} \times R_{2} \rightarrow \mathbb{N}$ uma função que mapeia a associação de cardinalidade de $\operatorname{Rel}: R_{1} \rightarrow R_{2}$. Seja $s: r\left(R_{1}\right) \times$ 
$r\left(R_{2}\right) \rightarrow \mathbb{N}$ uma função definida como segue:

$$
s(a, b)= \begin{cases}1 & \text { se } a=b, \\ 0 & \text { se } a \neq b .\end{cases}
$$

A violação de cardinalidade ocorre sse $\exists t_{i} \in R_{1}, t_{j} \in R_{2}$ tal que $\sum s\left(t_{i}[W], t_{j}[U]\right)>$ $\operatorname{cr}\left(R_{1}, R_{2}\right)$

A razão de cardinalidade ou de cardinalidade máxima estabelece o número máximo de instâncias de relacionamento na qual cada tupla de uma dada relação pode participar em um relacionamento binário. Uma violação existe se e somente se uma tupla não respeitar a restrição maximal no papel de referencia ou referenciada.

Exemplo 1: Um cartão de crédito deve estar associado a três clientes, no máximo. Essa regra é violada pelas tuplas $c c 1, c c 2, c c 3, c c 4, c c 10$ da relação ContaCreditoCliente para o cartão de crédito de número 100.

Exemplo 2: O auto-relacionamento que designa o vínculo de "casado com" na relação Cliente determina que cada cliente deve ser referenciado uma única vez, no máximo. Porém, um certo cliente da tupla $c 1$ é referenciado duas vezes - tuplas $c 4, c 10$.

Definição 12 (Violação de Restrição de Participação): Seja $p c: R_{1} \times R_{2} \rightarrow \mathbb{N}$ uma função que mapeia a participação mínima das tuplas de $R_{1}$ em $R_{2}$. Seja $s: r\left(R_{1}\right) \times r\left(R_{2}\right) \rightarrow$ $\mathbb{N}$ uma função definida como segue:

$$
s(a, b)= \begin{cases}1 & \text { se } a=b \\ 0 & \text { se } a \neq b\end{cases}
$$

Uma restrição de participação é violada sse $\exists t_{i} \in R_{1}, t_{j} \in R_{2}$ tal que $\sum s\left(t_{i}[W], t_{j}[U]\right)<$ $\operatorname{pc}\left(R_{1}, R_{2}\right)$

A regra de participação ou de cardinalidade mínima determina o número mínimo de instâncias de relacionamento na qual cada tupla de uma dada relação pode participar em um relacionamento binário. Uma violação ocorre se e somente se uma tupla não respeita a restrição de mínimo para os papéis de referencia ou referenciada.

Exemplo : Um cartão de crédito deve estar associado a dois clientes, no mínimo. Porém, existem cartões de crédito na relação ContaCreditoCliente com um único cliente - tuplas cc5 a $c c 7$.

Definição 13 (Violação de Integridade Semântica): Seja Rel : $R_{1} \rightarrow R_{2}$ um conjunto de relacionamentos entre as relações $R_{1}$ e $R_{2}$. Seja rule $:$ Rel $\rightarrow\{$ true, false $\}$ uma função que retorna se uma instância do relacionamento Rel cumpre sua regra de integridade semântica. Seja $R U^{R e l}$ um conjunto de regras semânticas sobre o relacionamento 
Rel, denotada por $R U^{\text {Rel }}=\left\{\right.$ rule $_{1}, \ldots$, rule $\left._{z}\right\}, z \geqslant 1$. Existe uma violação de integridade semântica sse $\exists\left(t_{i}, t_{j}\right) \in$ Rel, $\exists$ rule $_{h} \in R U^{R E L}$ tal que rule $_{h}\left(t_{i}, t_{j}\right)$ é false.

A integridade semântica compreende um conjunto de regras complexas de um UdD que garantem o estado de consistência dos dados, tais como restrições temporais ou baseadas em agregações. Uma violação ocorre se e somente se uma desses regras é desobedecida.

Exemplo: Uma regra da relação Cliente determina que somente as pessoas da faixa etária de 9 a 17 anos e moradoras da cidade de "SP" podem possuir um cartão de crédito no papel de co-titular. Para os demais estados esse relacionamento é proibido. Contudo, tal regra é desobedecida por um certo cliente (tupla $c 9$ ) do estado de "MG" que possui um cartão de crédito (tupla $c c 9$ ).

Definição 14 (Tupla Ausente): Seja mist $: D B \rightarrow\{$ true, false $\}$ uma função que retorna se uma relação de $D B$ representa todos os objetos requeridos do UdD. Uma tupla é ausente sse $\exists R_{i} \in D B$ tal que $\operatorname{mist}\left(R_{i}\right)$ é false.

Um esquema de banco de dados deve representar somente os objetos requeridos pelo UdD e seus respectivos fatos. A tupla ausente denota a falta de representação de certos objetos importantes do UdD.

Exemplo: Os co-titulares de certas contas de cartão de crédito (tuplas $c c 5$ a $c c 8$ ) não estão representados na relação Cliente.

Definição 15 (Tupla Falsa): Seja ftup $: r(R) \rightarrow\{$ true, false $\}$ uma função que retorna se uma tupla da relação $R$ obedece a certo conjunto de regras que determinam sua utilidade ao UdD. Uma tupla é falsa sse $\exists t_{i} \in r(R)$ tal que $f t u p\left(t_{i}\right)$ é false.

Um esquema de banco de dados deve somente representar os objetos requeridos do UdD e seus respectivos fatos. Uma tupla é denominada de falsa se e somente se representa um objeto que está além ou não é do interesse do UdD.

Exemplo: A tupla c7 da relação Cliente representa um consumidor que não possuiu um cartão de crédito ou débito.

Definição 16 (Tupla Sobrecarregada): Seja overt $: r(R) \rightarrow\{$ true, false $\}$ uma função que retorna se uma tupla da relação $R$ representa um único objeto do UdD. Uma tupla é sobrecarregada sse $\exists t_{i} \in r(R)$ tal que overt $\left(t_{i}\right)$ é false.

Uma tupla deve representar fatos sobre um único objeto do UdD. A sobrecarga denota a excessiva representação de objetos - dois ou mais - do UdD por uma única tupla.

Exemplo: "Dick Rhodes"e "Dick Rhodes" correspondem a duas pessoas para o UdD. Não obstante, a tupla c12 da relação Cliente representa ambas.

Definição 17 (Tuplas Duplicadas): Sejam $X_{1}$ e $X_{2}$ subconjuntos de atributos, $X_{1} \subset$ $R_{1}$ e $X_{2} \subset R_{2}$. Sejam $X_{1}$ e $X_{2}$ compatíveis em pares, na qual $\forall a_{1}^{i} \in X_{1}$ e $\forall a_{2}^{i} \in X_{2}$, $i \in[1, k], k \geq 1, \operatorname{dom}\left(a_{1}^{i}\right)$ e $\operatorname{dom}\left(a_{2}^{i}\right)$ são idênticos. Seja $\simeq_{i}$ o predicado de similaridade 
que determina que tuplas representam o mesmo objeto do UdD por meio dos atributos $a_{1}^{1} \simeq_{1} a_{2}^{1} \wedge \ldots \wedge a_{1}^{k} \simeq_{k} a_{2}^{k}$, denotado por $X_{1} \simeq X_{2}$. Existem tuplas duplicadas sse $\exists t_{1} \in$ $r\left(R_{1}\right), \exists t_{2} \in r\left(R_{2}\right)$ tal que $t_{1}\left[X_{1}\right] \simeq t_{2}\left[X_{2}\right]$

Esse defeito denota múltiplas tuplas de uma ou mais relações que referenciam o mesmo objeto do UdD. O conteúdo dessas tuplas podem apresentar valores idênticos, certo grau de similaridade ou mesmo majoritariamente divergentes, denotando as principais variantes.

Exemplo 1: A tuplas de clientes $c 4$ e $c 10$ representam o mesmo objeto do UdD com valores idênticos para a maioria dos atributos.

Exemplo 2: As tuplas de clientes $c 1$ e $c 3$ representam o mesmo objeto do UdD com alguma similaridade.

Exemplo 3: As tuplas de clientes $c 1$ e $c 9$ representam o mesmo objeto do UdD de forma contraditória.

Definição 18 (Referência Ausente): Seja Rel $: R_{1} \rightarrow R_{2}$ o conjunto de relacionamentos entre as relações $R_{1}, R_{2}$. Seja rrel : Rel $\rightarrow\{$ true, false $\}$ uma função que retorna se uma instância do relacionamento Rel ocorre no UdD. Uma referência é ausente sse $\exists t_{i} \in r\left(R_{1}\right), \exists t_{j} \in r\left(R_{2}\right)$ tal que $\left(t_{i}, t_{j}\right) \notin \operatorname{Rel}$ e $\operatorname{rrel}\left(t_{i}, t_{j}\right)$ é true.

Instâncias de um relacionamento representam fatos sobre objetos do UdD. O defeito de referência ausente ocorre se e somente se uma instância de relacionamento requerida não é representada.

Exemplo 1: Os clientes representados pelas tuplas $c 11$ and $c 12$ são casados. No entanto, o relacionamento correspondente não foi representado.

Exemplo 2: O cliente representado pela tupla $c 7$ é co-titular do cartão de crédito de número 201 - tupla cr5. Contudo, esse relacionamento inexiste na relação ContaCreditoCliente.

Definição 19 (Referência Incorreta): Seja $R e l: R_{1} \rightarrow R_{2}$ o conjunto de relacionamentos entre as relações $R_{1}, R_{2}$. Seja rrel : Rel $\rightarrow\{$ true, false $\}$ uma função que retorna se uma instância de relacionamento Rel ocorre no UdD. A referência incorreta existe sse $\exists\left(t_{i}, t_{j}\right) \in \operatorname{Rel}$ tal que $\operatorname{rrel}\left(t_{i}, t_{j}\right)$ é false.

Essa situação denota uma instância de relacionamento que não representa um fato sobre um objeto do UdD, muito embora a referida instância obedeça todas as regras de referência, razão de cardinalidade e de participação. As variantes de referência incorreta dependem do significado atribuído ao relacionamento.

Exemplo 1: A tupla c8 da relação Cliente é titular do cartão de crédito de número 199 (tupla $c c 6$ ). No entanto, esse cliente está relacionado ao cartão de crédito de número 200 (tupla $c c 7$ ).

Exemplo 2: Os clientes representados pelas tuplas $c 2$ e $c 4$ na relação Cliente são casa- 
dos. Porém, tais clientes aparecem relacionados a outros clientes por meio do relacionamento de papel "casado com" - atributo ConjugeCd.

Definição 20 (Tupla Atípica): Seja outl $: R(A) \rightarrow\{$ true, false $\}$ uma função que mapeia um atributo da relação $R$ para um resultado estatístico proveniente de métodos de detecção de atípicos. Uma tupla atípica ocorre sse $\exists t \in R, \exists a \in R(A)$ tal que outl(t[a]) é true.

Uma tupla atípica ou anômala diverge do comportamento comum observado nas demais tuplas de uma relação. Muito embora a tupla anômala não viole qualquer regra ou restrição, um avaliador da qualidade de dados pode determinar tal tupla como defeituosa. A composição não usual dos valores envolvendo vários atributos ou um atributo isolado são variantes de tupla atípica.

Exemplo 1: A tupla $c 2$ da relação Cliente revela uma situação incomum devido a composição dos valores dos atributos Salario, Cargo e Idade.

Exemplo 2: Os clientes que trabalham como "Bassist" apresentam salários similares. Contudo, a tupla $c 8$ da relação Cliente possui um salário muito menor do que os demais "Bassist".

Exemplo 3: O atributo Score da relação ContaClienteCredito possui uma restrição de domínio entre -2.99999 e 19.9999. A tupla cc10 apresenta um valor próximo ao limite superior do domínio, enquanto a faixa de pontuação das contas restantes oscilam entre 1 e 3.89099 .

Definição 21 (Valor Impreciso): Seja $\sigma$ o grau de imprecisão permitido para cada valor $v$ do atributo $a, a \in R(A)$, tal que $v-\sigma \leqslant v \leqslant v+\sigma$. Seja $r v: a \rightarrow \operatorname{dom}(a)$ uma função em $R$ que retorna o valor do atributo $a$ do UdD. O valor impreciso ocorre sse $\exists t \in r(R)$ tal que $|t[a]-r v(a)|>\sigma$.

O termo "impreciso" caracteriza um valor que está próximo do fato sobre um objeto do UdD. Essa proximidade denota um grau de imprecisão determinado por uma faixa de valores dentro do qual o valor acurado do fato deve estar.

Exemplo 1: O atributo Score da relação ContaDebitoCliente admite um grau de imprecisão representada pela faixa \pm 0.10000 . A tupla $d c 4$ possui o 1.60000 para o valor acurado de 1.50098 .

Exemplo 2: O atributo Score da relação ContaCreditoCliente admite um grau de imprecisão representada pela faixa \pm 0.00049 . A tupla $c c 3$ possui o valor 1.80500 para o valor acurado de 1.80523 .

Definição 22 (Valor Incorreto): Seja $r v: a \rightarrow \operatorname{dom}(a)$ uma função na relação $R$ que retorna o valor do atributo $a$ do UoD. Valores incorretos ocorrem sse $\exists t \in r(R)$ tal que $t[a] \neq r v(a)$. 
Um valor incorreto é uma representação infiel ou contraditória de um fato sobre um objeto no UdD. Em outras palavras, tal defeito denota uma grande discrepância entre o valor representado e o valor real do objeto.

Exemplo 1: O salário de um cliente é de $73.4 \mathrm{k}$, mas esse foi representado como $8 \mathrm{k}$ na tupla $c 5$.

Exemplo 2: O nome de um cliente é "Ridley Scott", mas esse foi representado como "Joan Ripley" na tupla $c 2$.

Definição 23 (Valores Homônimos): Seja $s p: r(R) \times r(R) \rightarrow\{$ true, false $\}$ uma função que retorna se a grafia e pronúncia dos valores dos atributos são iguais, de acordo com $L E X$. Seja me $: r(R) \times r(R) \rightarrow\{$ true, false $\}$ uma função que retorna se o significado dos valores dos atributos são iguais ou quase iguais, de acordo com $L E X$. Um atributo possui valores homônimos sse $\exists a \in R(A), \exists t_{i}, t_{j} \in r(R), i \neq j$, tal que $s p\left(t_{i}[a], t_{j}[a]\right)$ é true e $m e\left(t_{i}[a], t_{j}[a]\right)$ é false.

O conceito de homônimo denota termos cuja grafia e pronuncia são muito próximas, mas os significados são distintos [Houaiss, 2009]. Tal defeito surge se e somente se termos homônimos são aplicados de modo intercambiável para designar o mesmo fato sobre objetos do UdD.

Exemplo: As tuplas de clientes $c 9$ e $c 13$ possuem cargos distintos - respectivamente, "Main Manager" e "Principal" - representados por termos homônimos.

Definição 24 (Valores Sinônimos): Seja $s p: r(R) \times r(R) \rightarrow\{$ true, false $\}$ uma função que retorna se a grafia e pronúncia de valores de atributos são iguais, de acordo com $L E X$. Seja me $: r(R) \times r(R) \rightarrow\{$ true, false $\}$ uma função que retorna se o significado dos valores de atributos são iguais ou quase iguais, de acordo com $L E X$. Um atributo possui valores sinônimos sse $a \in R(A), \exists t_{i}, t_{j} \in r(R), i \neq j$, tal que $s p\left(t_{i}[a], t_{j}[a]\right)$ é false e $m e\left(t_{i}[a], t_{j}[a]\right)$ é true.

Sinônimos denotam termos com escrita distinta que compartilham significados iguais ou muito semelhantes [Houaiss, 2009]. Assim, qualquer um deles pode ser utilizado em uma sentença sem que ocorra a mudança do significado. Esses termos podem ser expressos em vernáculos, acrônimos, abreviações ou símbolos. Tal defeito surge se e somente se termos sinônimos são empregados de forma intercambiável para designar o mesmo fato sobre objetos do UdD.

Exemplo 1: As tuplas $c 1, c 4, c 5, c 8, c 10$ da relação Cliente representam o estado civil como "E" (espoused), "J" (joined), "U" (united) para designar casado ("M") em cada caso.

Exemplo 2: As tuplas $c 2$ e c4 da relação Cliente apresentam os cargos "Tapster" e "Barkeeper" cujo significado é o mesmo de "Bartender" em cada caso.

Definição 25 (Granularidade Heterogênea): Seja $G$ a granularidade definida para o atributo $a$ da relação $R, a \in R(A)$. Seja grain $: a \rightarrow\{$ true, false $\}$ uma função que 
retorna se um valor do atributo $a$ é compatível com a granularidade $G$. A granularidade heterogênea ocorre sse $\exists t_{i} \in r(R)$ tal que grain( $\left.t_{i}[a]\right)$ é false.

A granularidade denota o nível de abstração utilizado na representação de um valor. Um atributo possui granularidade heterogênea se e somente se alguns de seus valores representam fatos sobre objetos do UdD com diferentes níveis de abstração. Esses níveis de abstração podem possuir fatores distintos de disparidade e expor um padrão randômico ou dirigido a outros atributos.

Exemplo: O atributo Salario da relação Cliente deve representar a remuneração mensal. Porém, a tupla $c 4$ possui a remuneração anual.

Definição 26 (Unidade de Medida Heterogênea): Seja $\Omega$ uma relação de equivalência sobre os valores do atributo $a, a \in R(A)$, tal que $v_{i} \Omega v_{j}$ sse $v_{i}$ e $v_{j}$ possuem a mesma unidade de medida. Seja $M U_{\Omega}$ a classe de equivalência em $\Omega$ que contém todos os valores do atributo $a$ que possuem a unidade de medida requerida pelo UdD. A unidade de medida heterogênea ocorre sse $\exists t_{i} \in r(R)$ tal que $t_{i}[a] \notin M U_{\Omega}$.

Uma unidade de medida denota a magnitude de uma quantidade física necessária para prover uma base de comparação. Esse tipo de defeito ocorre se e somente se certos valores de um atributo representam fatos sobre objetos do UdD utilizando unidades de medida distintas. Essas unidades podem denotar magnitudes dissimilares e também expor um padrão randômico ou dirigido a outros atributos.

Exemplo: A relação Cliente deve representar salários em Dólares Norte-Americanos. Contudo, os clientes com o cargo de "Writer" - tuplas c10,c12 - possuem seus salários representados em Euro.

\subsection{Conclusão}

Aprimorar a qualidade dos dados requer alternativas que combinem procedimentos, métodos e técnicas. O pAQD provê informações práticas para selecionar a alternativa mais adequada por meio do mapeamento dos defeitos nos dados. Para proporcionar um mapeamento adequado, esse processo requer conhecimentos a respeito das estruturas dos defeitos nos dados de modo a determinar como esses defeitos deverão ser avaliados.

Este capítulo reportou uma taxonomia que apresenta descrições detalhadas sobre defeitos nos dados relativos aos critérios de qualidade da acurácia, completude e consistência. Para endereçar as questões e limitações debatidas na Seção 3.4, a taxonomia foi construída a partir de uma metodologia de três passos: o passo da revisão teórica proporcionou uma cobertura ampla e sistemática dos defeitos, bem como estabeleceu a terminologia e nomenclatura alinhadas ao jargão da área de banco de dados; os passos de classificação organizaram os defeitos nos dados segundo as respectivas granularidades de ocorrência e propriedades. 
A taxonomia contribui para várias necessidades do pAQD - Seção 4.1 - e das iniciativas de melhoria da qualidade de dados, incluindo o treinamento de agentes avaliadores da qualidade dos dados [George e Gao, 2011; Lee et al., 2007], estabelecimento de métricas de gerenciamento contínuo da qualidade dos dados [Lee et al., 2009; Redman e Blanton , 1997] e propiciar uma nomenclatura não ambígua e comum dos defeitos nos dados. No Capítulo 5, essa taxonomia representa um dos fundamentos para determinar um mapeamento entre defeitos nos dados e certas propriedades dos sistemas de visualização.

\subsubsection{Originalidade}

A taxonomia apresenta vários pontos de originalidade em relação ao estado-da-arte da literatura - Seção 3.4 -, sendo tais pontos discutidos a seguir. Como resultado direto dessa originalidade, foram publicados: um artigo com resultados parciais [Josko e Ferreira, 2014] e outro completo [Josko et al., 2016].

- Uso da revisão de tópicos da teoria de bancos de dados relacionais para determinar os defeitos nos dados. Os tópicos revelaram um conjunto de regras semânticas aplicáveis a um esquema de banco de dados para representar comportamentos de um UdD. Cada regra foi base para identificar uma ou mais violações - defeitos - que levam os dados a um estado defeituoso;

- Arranjo hierárquico dos defeitos nos dados de acordo com as propriedades herdadas das regras violadas correspondentes. Esse arranjo é adequado para identificar os defeitos, compreender suas propriedades e inter-relacionamentos, bem como estender a abrangência da taxonomia a defeitos em dados orientados a tempo - por exemplo;

- Uso de três elementos complementares para explicitar a estrutura dos defeitos nos dados e suas variantes, quais sejam o formal, o textual e os exemplos baseados em instâncias;

- Terminologia fundeada nos jargões da área de banco de dados, facilitando a interpretação e a comunicação entre os profissionais envolvidos no pAQD;

- Escopo objetivo em relação aos critérios de qualidade e características dos dados estruturado e atemporal - abordados. Tal abordagem situa precisamente a cobertura do presente trabalho;

- Defeitos consolidados e definidos segundo a estrutura comum, garantindo o mesmo nível de abstração. 


\section{Capítulo 5}

\section{Propriedades para Avaliação Visual da Qualidade dos Dados}

\subsection{Introdução}

Este capítulo detalha a segunda contribuição do presente trabalho: a caracterização dos limites dos sistemas de visualização como instrumento de apoio a avaliação visual de defeitos nos dados. Esse apoio denota que certas propriedades visuais-interativas podem organizar os dados de modo a beneficiar a extração de significados relevantes as atividades de avaliação da qualidade de dados [Tory e Moller, 2004; Ware, 2004].

Para alcançar essa caracterização, o estudo de caso múltiplo e exploratório - Seção 5.3 - é o método aplicado para compreender quais são as propriedades visuais-interativas mais promissoras na avaliação visual de defeitos nos dados que exijam alto grau de supervisão humana - Seção 2.2.3.3. A Seção 5.2 apresenta os conceitos relativos a avaliação visual da qualidade de dados. Por sua vez, a Seção 5.3 apresenta a configuração do estudo de caso conduzido pelo presente trabalho, enquanto as Seções 5.4 e 5.5 descrevem os resultados e as limitações do referido estudo de caso, respectivamente.

\subsection{Avaliação Visual da Qualidade dos Dados}

A literatura aborda vários aspectos que envolvem o pAQD, incluindo metodologias, técnicas de avaliação, certos aspectos culturais e políticos, e perspectivas curriculares [Batini et al., 2009; George e Gao, 2011; Kandel et al., 2012a; Klein, 2001; Klein et al., 1997; Lee et al., 2009]. Não obstante, são restritas as informações sobre o fluxo analítico e as práticas analíticas-colaborativas utilizadas na avaliação da qualidade dos dados mediadas por sistemas de visualização. Nesse contexto, certos trabalhos [Kandel et al., 2012a] permitem inferir uma visão acanhada e de alto nível do referido fluxo.

Este trabalho utiliza o termo análise visual da qualidade dos dados para denotar o 
processo analítico intenso de interpretar e compreender o estado atual dos dados mediado por sistemas de visualização. Esse processo apresenta um fluxo de três passos: a extração, a caracterização e o julgamento. Por meio de representações visuais interativas, um agente avaliador busca, extrai, correlaciona e compreende significados - padrões, relacionamentos e métricas - em diferentes granularidades de dados até reunir evidências semânticas que corroborem ou refutem a presença de um defeito nos dados. A natureza não linear desse fluxo denota que os aprendizados de um passo informam como refinar e reaplicar o próprio passo ou como proceder no passo seguinte.

A noção de sucessivas análises visuais até a síntese de evidências é expressa na área de visualização de dados por meio de diferentes perspectivas, tais como o Mantra de Busca de Informação - Information-Seeking-Mantra - [Shneiderman, 1996], o Mantra Visual Analítico - Visual Analytics Mantra - [Keim et al., 2010], a Criação de Significado - Sense Making - [Pirolli e Card, 2005] e o Processo de Inferência dos Dados [Friel et al., 2001].

\subsection{A Configuração do Estudo de Caso}

O método de estudo de casos apresenta crescente aplicação na área de visualização de dados para identificar, analisar e avaliar aspectos técnicos, sociais, perceptuais e cognitivos baseados em diferentes abordagens (estudos qualitativos observacionais, por exemplo) [Tory, 2014].

Esta seção caracteriza o estudo de caso conduzido por este trabalho no tocante ao objetivo, a organização, aos artefatos utilizados, aos procedimentos, as condições e aparatos e, as atividades analíticas aplicadas para reportar os resultados [Yin, 2009]. A seção subsequente - Seção 5.4 - descreve os resultados de cada uma das unidades de estudo que compõem o estudo de caso conduzido.

\subsubsection{O Escopo do Estudo de Caso}

Este trabalho utiliza o método de estudo de casos para responder: Quais e como as propriedades visuais-interativas dos sistemas de visualização podem facilitar a avaliação visual de defeitos que demandam alta supervisão humana? Essa pergunta é derivada do elo entre saliência visual e a necessidade da atividade de avaliação de dados - Seção 2.4.3. Cada representação visual possui uma convenção que determina suas características primitivas. Essas características facilitam descobrir certas informações relativas aos dados. Portanto, alinhar tais características as necessidades informacionais de uma atividade contribui para reduzir o esforço do agente humano. Isto posto, este estudo de caso pode ser desdobrado nas seguintes proposições de estudo:

- Como e quais propriedades visuais favorecem a detecção dos significados relativos a um defeito em resoluções crescentes de dados? 
- Como e quais propriedades visuais favorecem a quantificação de um defeito detectado em resoluções crescentes de dados?

- Como e quais propriedades interativas favorecem a detecção e quantificação dos defeitos?

A abordagem do estudo de caso é exploratória ${ }^{1}$ uma vez que a relevância das propriedades para a análise visual da qualidade dos dados é desconhecida de antemão [Tory , 2014; Yin, 2009]. Ainda, o estudo de caso é de natureza múltipla, isto é, possui várias unidades de estudo que correspondem a cada um dos defeitos nos dados que demandam maior supervisão humana. Os resultados desse estudo de caso devem expor afinidades entre certas propriedades e certos defeitos, bem como podem delinear dificuldades na detecção visual de um subconjunto de defeitos.

\subsubsection{Critérios de Seleção das Propriedades}

O escopo do estudo de caso abrange um subconjunto das propriedades visuais Seção 2.3.4.2.1 - e interativas - Seção 2.3.4.1 -, bem como dos defeitos nos dados - Seção 4.4.

Para as propriedades visuais, este trabalhou selecionou aquelas mais amplamente discutidas e presentes em diferentes técnicas de visualização, quais sejam tamanho, saturação/luminosidade, tonalidade, posição, forma e conexão. Adicionalmente, a técnica de interação treliça - trellis ou small multiples - também foi considerada por permitir a visão categorizada em painéis dos dados [Bertin, 1983].

No caso das propriedades interativas, o presente trabalho foi mais restritivo e observou aquelas que permitem a simplificação dos dados - filtro e aproximação geométrica - e o arranjo visual e espacial dos dados - ordenação, distorção espacial, mudança de opacidade. Essas propriedades interativas estão entre aquelas minimamente essenciais a um sistema de visualização que apoie uma análise nos moldes da avaliação visual da qualidade dos dados [Andrienko e Andrienko, 2006].

Por fim, este trabalho examinou os defeitos nos dados com alta supervisão humana. Tal escolha foi motivada pela forte dependência do conhecimento do contexto dos dados para determinar a presença desses defeitos. Um segundo motivo remete a pequena presença de abordagens computacionais que apoiem a avaliação da maioria dos referidos defeitos.

\subsubsection{O Arcabouço de Atividades}

O projeto de um sistema de visualização é um processo complexo que requer alinhar recursos de características variadas - incluindo técnicas de interação e capacidades computacionais - as exigências das atividades a serem apoiadas [Casner, 1991; Ware, 2004]. Dessa maneira, um arcabouço é utilizado para modelar as atividades de alto nível da

\footnotetext{
${ }^{1}$ Um estudo de caso exploratório investiga fenômenos que não possuem uma hipótese formulada ou o ambiente que envolve a pesquisa limita a escolha do método [Yin, 2009].
} 
avaliação dos defeitos e apoiar a condução do estudo de caso. O arcabouço é baseado na estrutura dos defeitos nos dados - Seção 4 -, certas características dos dados e na notação derivada de [Andrienko e Andrienko, 2006; Schulz et al., 2013].

\subsubsection{Definição de Atividade}

Uma atividade é uma abstração cuja natureza direciona a utilização dos sistemas de visualização [Andrienko e Andrienko, 2006; Yi et al., 2008]. Neste trabalho, essa abstração denota o esforço consciente de reconhecer e relacionar significados para determinar o nível de qualidade dos dados.

Atividades apresentam diferentes níveis de granularidade ou complexidade semântica. A hierarquia de atividades Analítica $\supseteq$ Sub - analítica Interativa $\supseteq$ Operacional utilizada nesse arcabouço é baseada na teoria de atividades [Gotz e Zhou, 2009] e nos níveis de interação [Sedig et al., 2014]. Tais teorias definem as representações visuais como mediadoras da cognição humana.

Uma atividade analítica representa os processos de análise de alto nível para um domínio em particular. Por sua vez, a atividade sub-analítica representa objetivos de investigação mais concretos para alcançar o objetivo da atividade analítica correspondente. O terceiro nível - atividade interativa - envolve passos atômicos desempenhados sobre uma representação visual, enquanto a atividade operacional denota ações de pouco valor semântico - seleção de um botão, por exemplo.

Isto posto, a avaliação de qualquer defeito nos dados é denotada pela atividade analítica $T_{\text {Nome_do_Defeito, }}$ composta por um fluxo dirigido de atividades sub-analíticas, tal que $T_{\text {Nome_do_Defeito }}=\left(T k_{1} \Rightarrow T k_{2} \Rightarrow \ldots \Rightarrow T k_{j}\right), j>1$. Cada atividade sub-analítica $T k_{e}$, $e=[1, j]$, possui um objetivo particular e seus resultados são insumos para a atividade sub-analítica subsequente, sendo expressa por $T k_{e}$ : Característica $\times$ Interação $\times$ Espaço.Dados $\rightarrow$ Resultado. Os tipos de atividades sub-analíticas e seus elementos são definidos a seguir.

- Atividades sub-analíticas apresentam dois tipos que denotam seus propósitos: a busca e a correlação. A primeira denota a intenção de explorar o espaço dos dados, identificar e fixar características próximas a estrutura do defeito avaliado. Já a correlação representa as técnicas analíticas aplicadas para comparar e estabelecer relacionamentos entre as referidas características para desenvolver novas ideias, questões ou hipóteses. Ambos os tipos podem manipular os dados em sua totalidade ou em regiões específicas.

- Característica especifica o conjunto de significados de interesse de uma atividade sub-analítica. Atividades do tipo busca observam padrões de dados ${ }^{2}$ - Tabela 5.1 -

\footnotetext{
${ }^{2}$ Padrão de dados é algo resultante de uma análise que denota um retrato do comportamento dos dados. Por sua vez, o comportamento dos dados representa um fenômeno inerente aos dados que pode
} 
em grandes resoluções de dados ou características específicas de objetos presentes em regiões reduzidas de dados. Em contraste, as atividades de correlação observam padrões, regiões de dados ou objetos específicos para derivar estruturas de relacionamento, tais como cíclico, discrepante, alterna diferenças, magnitude oposta, randômico, similar, mudança suave, dentre outras.

\begin{tabular}{lll}
\hline Classe de Padrão & Características da Classe de Padrão & Padrão \\
\hline Arranjo & Percepção de organização dos dados. Essa organização & Aumento \\
& denota a maneira na qual os atributos são posicionados & Circularidade \\
& para expor a ordem arbitrária introduzida aos dados. & Constância \\
& & Pico \\
& & Platô \\
& Percepção de estratos distintos de dados de acordo com & Vale \\
\hline Associação & a similaridade dos valores dos atributos envõo \\
& Naturalmente, essa classe requer diferenciação & Isolamento \\
& Percepção de diferenças entre dados com base & Similaridade \\
\hline Classificação & nos atributos representados visualmente. & Atípico \\
& Essa classe de padrão pode ser percebida sem & Desvio \\
& características de similaridade. & Exceção \\
& & Incoerência \\
& Percepção do modo geral na qual os valores do atributo & Parte-Todo \\
\hline alvico \\
& atributos de referência. & Densidade \\
& & Lacuna \\
& & Incoerência \\
& & Uniformidade \\
\hline
\end{tabular}

Tabela 5.1: Padrões agrupados por Classe

(Fontes: Adaptado de [Andrienko e Andrienko, 2006; Few, 2009])

- Interação representa os mecanismos que modificam dinamicamente uma representação visual para propiciar a interpretação de acordo com o objetivo uma atividade Seção 2.3.4.1. Embora existam várias classes de interação com diferentes nomenclaturas, este trabalho aborda aquelas ligadas a capacidade de especificação dos dados de interesse - simplificar -, especificação do arranjo espacial dos dados - arranjar.espaço -, de abstração ou realce dos dados - abstrair e destacar, respectivamente -, conforme observado na Tabela 2.3.

- Espaço.Dados denota os conjuntos de atributos $g$ e $b$ requeridos por uma atividade sub-analítica, representados por $g \sim b, g \cap b=\oslash, g, b \subseteq \bigcup_{i=1}^{n} R_{i}$ e $R_{i} \in B D$. O conjunto $g$ representa os atributos alvo da atividade de avaliação da qualidade, enquanto o $b$ denota os atributos de referência. Reunidos em uma visão global dos dados, esses atributos podem revelar certos padrões e outros significados necessários para detectar um defeito nos dados. Embora certos atributos de referência possam apresentar baixa qualidade, é improvável que todos estejam defeituosos.

- Resultado representa as entidades informacionais criadas pela atividade. O resultado

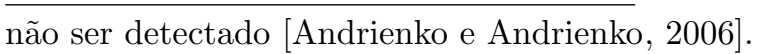


vazio de uma atividade determina a ausência ou a percepção visual inconclusiva de significados relativos a um defeito.

A Atividade 1 utiliza conceitos derivados de [Andrienko e Andrienko, 2006; Schulz et al. , 2013] e as definições supracitadas para ilustrar a composição de uma atividade analítica. Essa ilustração apresenta o relacionamento entre os elementos Caraterística, Interação e Espaço de Dados, o duto da atividade analítica e introduz os símbolos "” e “*”. O primeiro símbolo é um separador de múltiplos parâmetros para qualquer elemento da atividade, enquanto o segundo denota um atributo qualquer de referência - inclusive nenhum.

$$
\begin{aligned}
& T_{\text {Nome_do_Defeito }}= \\
& \left\{\text { Atividade }- \text { Sub-analítica }{ }_{1}\left(\text { Caracteristica }_{1} \text {, Interacão } o_{1} \mid \text { Interacãa }_{n}, \text { atributo }_{1} \mid \text { atributo }_{2} \sim *\right) \Rightarrow\right. \\
& \text { Atividade }- \text { Sub - analítica }{ }_{2}\left(\text { Caracteristica }_{1}, \text { Interacãa }_{1}, \text { atributo }_{1} \mid \text { atributo }_{2} \sim \text { atributo }_{4}\right) \Rightarrow \\
& \ldots \Rightarrow \\
& \text { Atividade - Sub - analítica } \left.\left(\text { Caracteristica }_{1} \mid \text { Caracteristica }_{j}, \text { Interacão }_{1}, \text { atributo }_{1} \mid \text { atributo }_{2} \sim *\right)\right\}
\end{aligned}
$$

Atividade 1: Notação das Atividades do Arcabouço

Baseado na notação anterior, a Atividade 2 exemplifica a atividade analítica para avaliar o defeito Violação de Dependência de Inclusão - Seção 4.4 - entre as relações $R_{1}$ e $R_{2}$. Esse defeito causa tuplas de $R_{1}$ não relacionadas a tuplas de $R_{2}$, denotando um padrão de isolamento.

De acordo com esse padrão, a atividade analítica é formada por quatro atividades sub-analíticas: a primeira inicia a busca pelo padrão (5.1) e prossegue no intuito de compreender (5.2) os padrões de defeitos na totalidade dos dados até concentrar a análise (5.3) em uma região específica dos dados com casos suspeitos e determinar a presença do defeito (5.4).

$T_{\text {ViolaGão_Dependência_Inclusão }}=$ $\left\{\right.$ Buscar(isolamento, arranjar.espaco, $R_{1}$. Key $\mid R_{2}$. Key $\left.\sim R_{1} \cdot * \mid R_{2} \cdot *\right) \Rightarrow$ Correlacionar(similaridade|isolamento, arranjar.espaco, $R_{1}$. Key $\mid R_{2}$. Key $\left.\sim R_{1} . * \mid R_{2} . *\right) \Rightarrow$ $\operatorname{Buscar}\left(n \tilde{a} o\right.$ - relacionados, simplificar|selecionar $\mid$ arranjar.espaco, $R_{1}$. Key $\mid R_{2}$. Key $\left.\sim R_{1} \cdot * \mid R_{2} . *\right) \Rightarrow$ Correlacionar(discrepância, arranjar.espaco, $R_{1}$. Key $\mid R_{2}$. Key $\left.\left.\sim R_{1} \cdot * \mid R_{2} \cdot *\right) \quad\right\}$

Atividade 2: Atividade de avaliação do defeito Violação de Dependência Inclusão

\subsubsection{O Participante}

Este estudo de caso contou com um participante experiente e motivado - Seção 2.2.3.1 - uma vez que os procedimentos desse estudo dependiam de bons conhecimentos rela- 
tivos a avaliação da qualidade de dados. Envolver participantes experientes impede observações discrepantes relativas a detecção e quantificação, e ainda proporciona resultados mais adequados para confirmar ou refutar o objetivo do estudo de caso [Bernard, 2011; Grinstein et al., 2002; Marghescu, 2008]. O participante deste estudo de caso possui experiência superior a seis anos e utiliza diferentes recursos nas análises diárias da qualidade de dados em ambientes de Data Warehouse, incluindo recursos programáveis - SQL -, multidimensionais - Cubos OLAP -, estatística descritiva e gráficos tradicionais como dispersão, histograma e linha.

No entanto, participantes experientes nem sempre estão acessíveis em número e disponibilidade de tempo razoáveis. Neste estudo de caso, embora o número de participantes possa parecer pequeno, suas descobertas foram baseadas em cerca de 400 ciclos de avaliação da qualidade de dados - Seção 5.3.7.

\subsubsection{As Condições}

O participante foi acomodado em uma sala reservada e equipada com uma estação de trabalho, um monitor de 21 polegadas com resolução de $1920 \times 1080$ pixels, os metadados dos artefatos de dados, as descrições das atividades analíticas, um caderno e algumas canetas. Um observador acompanhou todas as atividades executadas pelo participante junto ao $V i s 4 D D$, registrando notas e observações verbalizadas pelo participante com relação a detecção e quantificação dos defeitos.

\subsubsection{A Ferramenta de Apoio Vis4DD}

Este trabalho desenvolveu um sistema de visualização - denominado Visualization for Defect Detection ou Vis4DD - que reúne somente as propriedades alinhadas ao objetivo do presente estudo de caso - Seção 5.3.1.1. Conforme ilustra a Figura 5.1, o Vis4DD possui três espaços visuais principais: a parte superior oferece acesso as representações visuais agrupadas pela abordagem de reprodução gráfica dos dados - Seção 2.3.4.2 -, o painel esquerdo expõe as interações disponíveis e os respectivos parâmetros, enquanto o espaço restante é destinado a representação visual dos dados. Esse último espaço utiliza uma única técnica de visualização sem a difusão dos dados em múltiplas telas, evitando o efeito de rolagem - do inglês scrolling.

A disposição visual, a escala de cores e outros parâmetros - fontes, por exemplo - são mantidos iguais entre todas as representações visuais de modo a evitar o favorecimento a quaisquer propriedades observadas por este estudo de caso. Cada representação do Vis4DD contém interações de arranjo dos atributos, de filtro interativo, de marcação ${ }^{3}$ de um defeito e de persistência da representação visual corrente como um arquivo PNG.

\footnotetext{
${ }^{3}$ Essa operação de destaque não está disponível nas representações na qual o assinalamento do ponteiro é utilizado na operação de aproximação ou detalhes sobre demanda - configurações c3 e h1 da Tabela 5.2.
} 


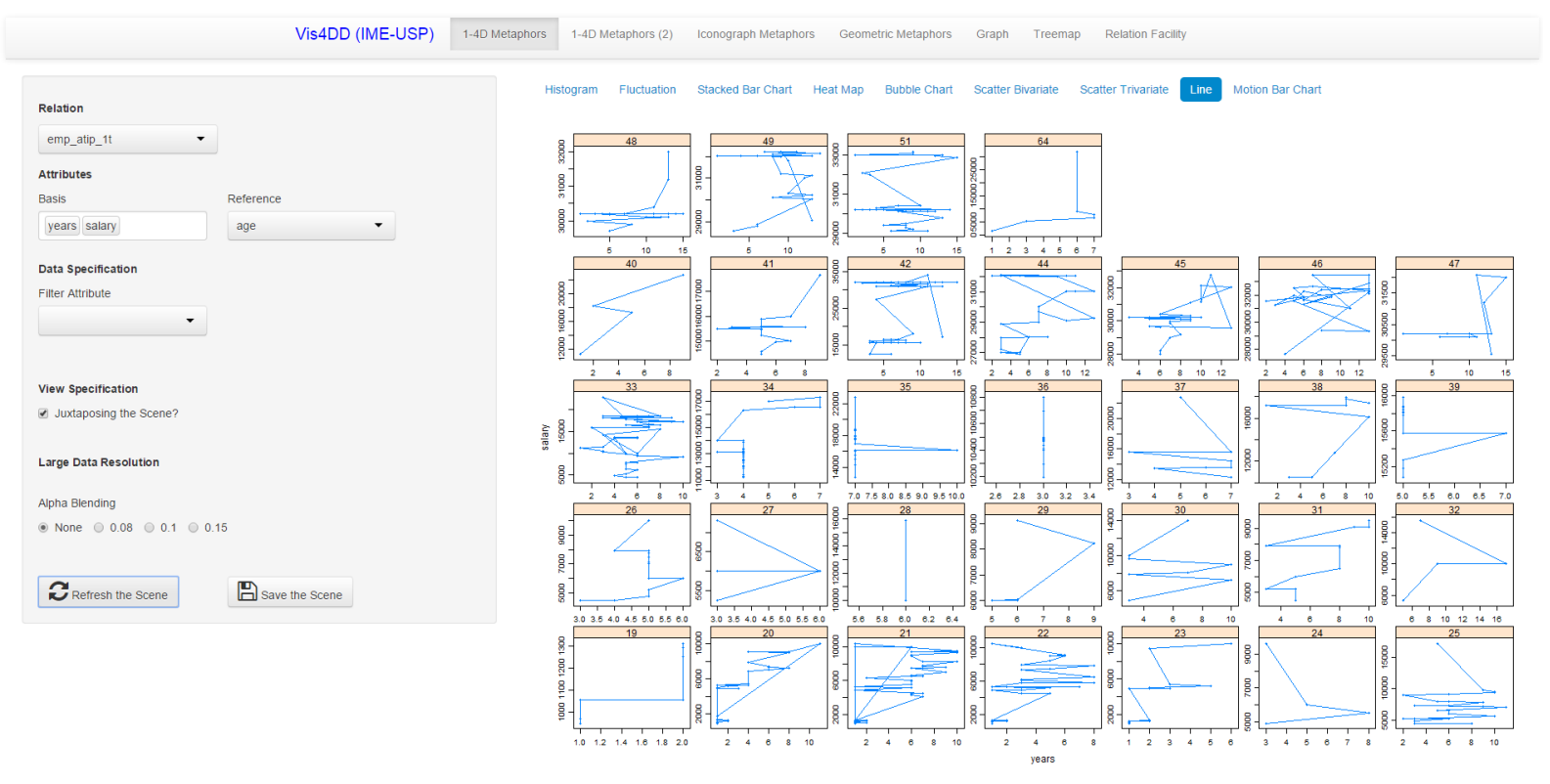

Figura 5.1: Espaços visuais do Vis4DD (Fonte: Elaborado pelo autor)

Todas as interações - e correspondentes parâmetros e tempos - desempenhadas sobre cada representação são registradas automaticamente - Anexo A.1.

A Figura 5.2 ilustra os componentes da arquitetura filtro-duto do $V i s 4 D D$ que são baseados no ambiente R-Project 3.1.2 em razão da sua portabilidade e a arquitetura dirigida a análise de dados [Chambers, 2008]. Sua interface é baseada nas capacidades do arcabouço Shiny para a criação de aplicações interativas no estilo web [Beeley, 2013]. O $V i s 4 D D$ adota a independência dos bancos de dados avaliados de modo a evitar interferências em suas transações, bem como propiciar um conjunto de dados estáticos para avaliação. Um servidor web pode ser utilizados para permitir a execução do $V i s 4 D D$ via internet.

O Filter and Zoom Engines permite a seleção das regiões de dados através de parâmetros relacionados ao tipo de dados do atributo escolhido ou por meio da seleção espacial dos dados, respectivamente. O Graphic Engine codifica os dados de acordo com a técnica de visualização escolhida, os parâmetros recebidos da interface e as características dos dados. Esse mecanismo pode manipular todos os dados ou regiões específicas determinadas pelo mecanismo de filtro e aproximação. O Register Engine registra todas as interações e seus respectivos parâmetros, bem como armazena a representação visual corrente quando determinado pelo agente avaliador da qualidade dos dados. Por fim, o Relation Facility permite carregar e descartar as relações conforme o interesse.

O Vis4DD seleciona uma dentre duas escalas de cores baseadas no modelo de eixos HSL - Hue, Saturation, Lightness - de acordo com as características da técnica de visualização [Silva et al., 2011]. A escala segmentada possui vinte e duas tonalidades de máximo contraste para favorecer a distinção dos valores em espaços de dados densos 


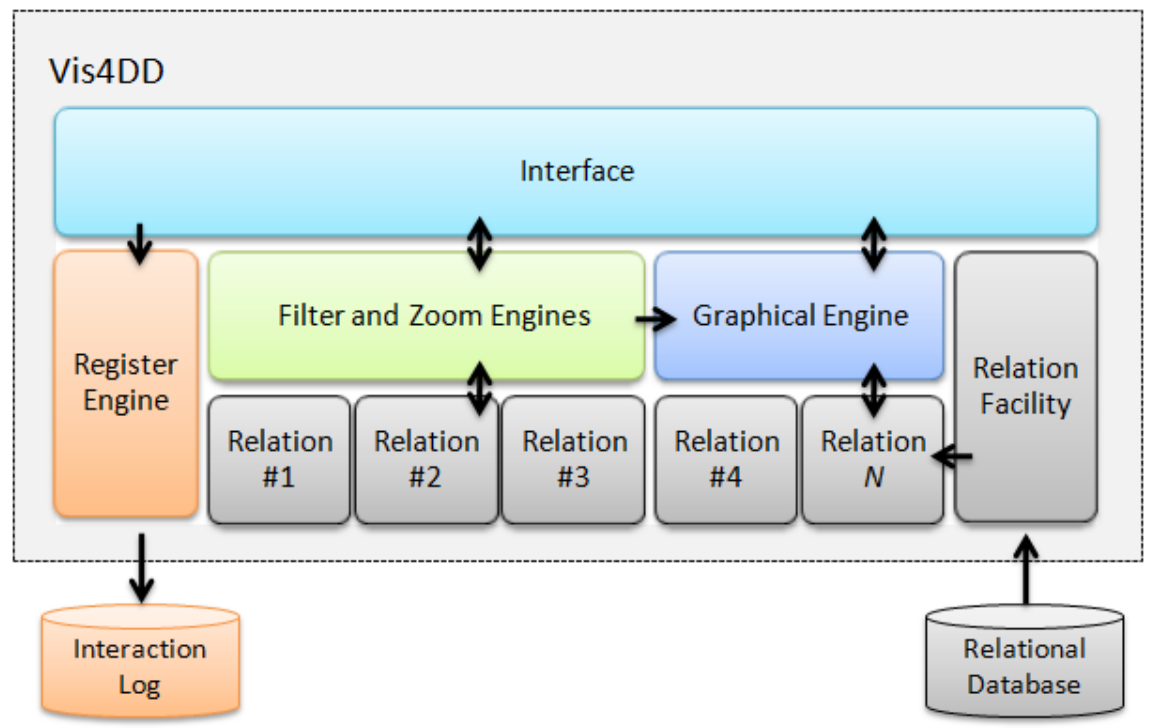

Figura 5.2: Os componentes do Vis4DD e suas interligações (Fonte: Elaborado pelo autor)

[Green-Armytage, 2010]. A rotação sobre o eixo $H$ - do vermelho ao azul - foi utilizada para gerar tonalidades, enquanto a saturação e a luminosidade permaneceram invariáveis.

Por sua vez, a escala de cores não segmentada utilizou duas estratégias para garantir o isomorfismo de dados quantitativos [Bergman et al., 1995]. A primeira estratégia utilizou duas tonalidades de famílias ${ }^{4}$ diferentes, luminosidade invariável e variação incremental de saturação para favorecer representações visuais com frequência espacial baixa ou pouco granular. Por sua vez, a segunda estratégia combinou luminosidade crescente, saturação decrescente e tonalidade única em representações visuais com maior granularidade espacial, isto é, que produziram mais de dez mil elementos visuais.

\subsubsection{Os Artefatos de Dados}

Cada defeito foi avaliado por meio de cinco relações com resoluções entre $10^{3}$ a $10^{7}$ tuplas. Algoritmos asseguraram a geração de até 1\% de dados defeituosos aderentes a estrutura do defeito em questão, bem como impuseram aos dados remanescentes regras de consistência, integridade e completude. O Quadro 5.1 apresenta o esquema das relações e respectivos metadados, enquanto os Quadros 5.2 a 5.4 descrevem os critérios de geração dos dados.

A geração dos dados defeituosos contou com o apoio da amostragem randômica sem reposição. Nesse método, cada amostra $s_{i}$ apresenta $n$ unidades distintas selecionadas randomicamente de uma população de $N$ unidades, de forma que $\bigcap_{i=1}^{k} s_{i}=\oslash$. A quantidade de amostras possíveis $k$ é determinada a partir do número de combinações entre $n$ unidades distintas tomadas da população $N$, denotada na equação combinatória

\footnotetext{
${ }^{4}$ Não foram combinadas cores associadas ao daltonismo parcial, tais como azul e amarelo ou vermelho e verde.
} 
$k=\left(\begin{array}{l}N \\ n\end{array}\right)=\frac{N !}{n !(N-n) !}$ [Thompson, 2012]. A propriedade de equânimidade probabilística da amostragem randômica garante a cada amostra $s_{i}$ a mesma chance de ser selecionada, denotada por $P\left(s_{i}\right)=\frac{1}{k}$.

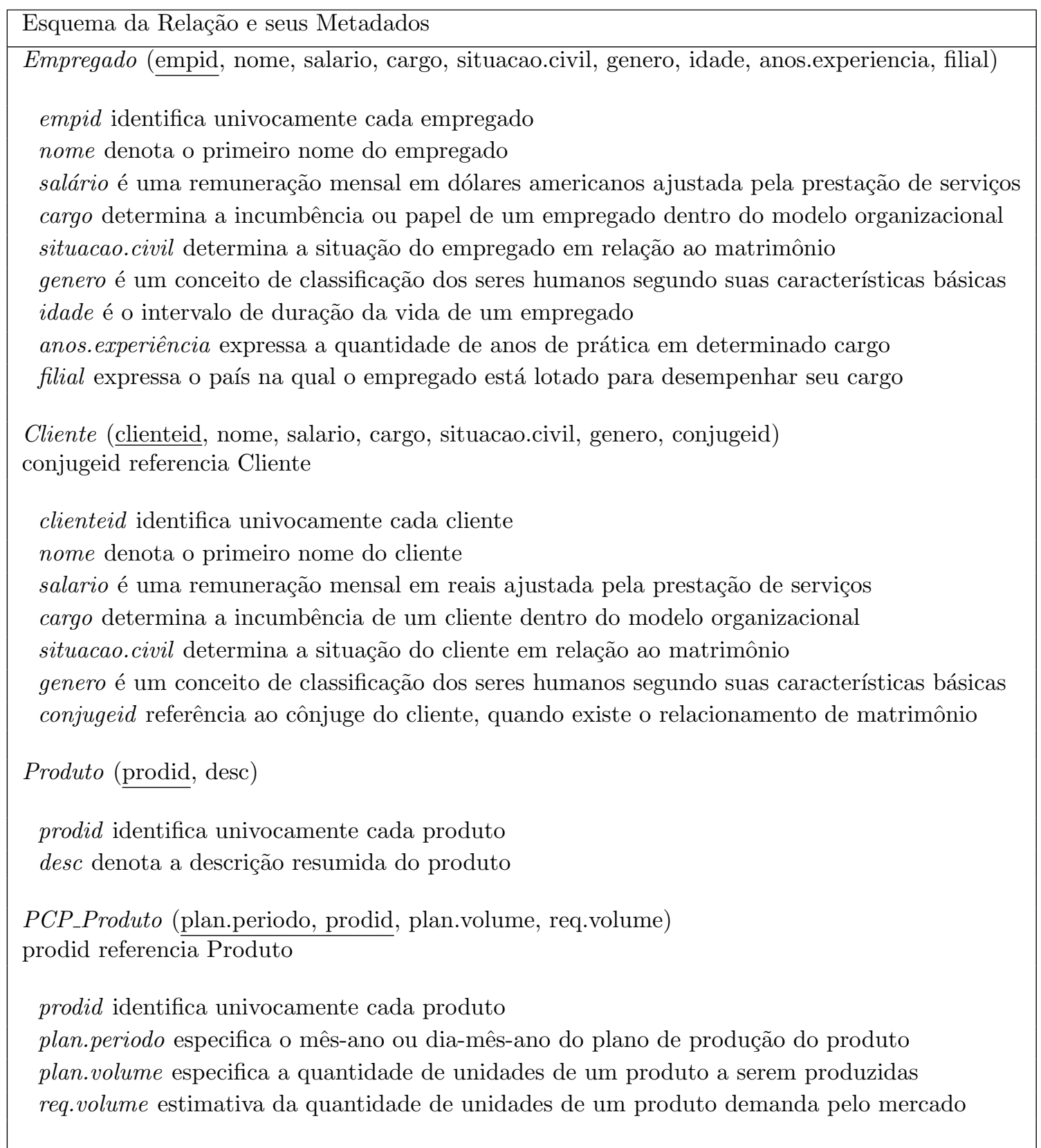

Quadro 5.1: Esquema e metadados das Relações utilizadas no Estudo de Caso (Fonte: Elaborado pelo autor)

\subsubsection{Os Procedimentos}

Este estudo de caso seguiu as etapas de arranjo do ambiente e dos artefatos, planejamento do procedimento de trabalho, preparação do participante, execução do estudo de caso para cada unidade de estudo e análise final. Concluída a etapa de arranjo, um estudo de caso piloto foi realizado para refinar e estabelecer o procedimento de trabalho observado 


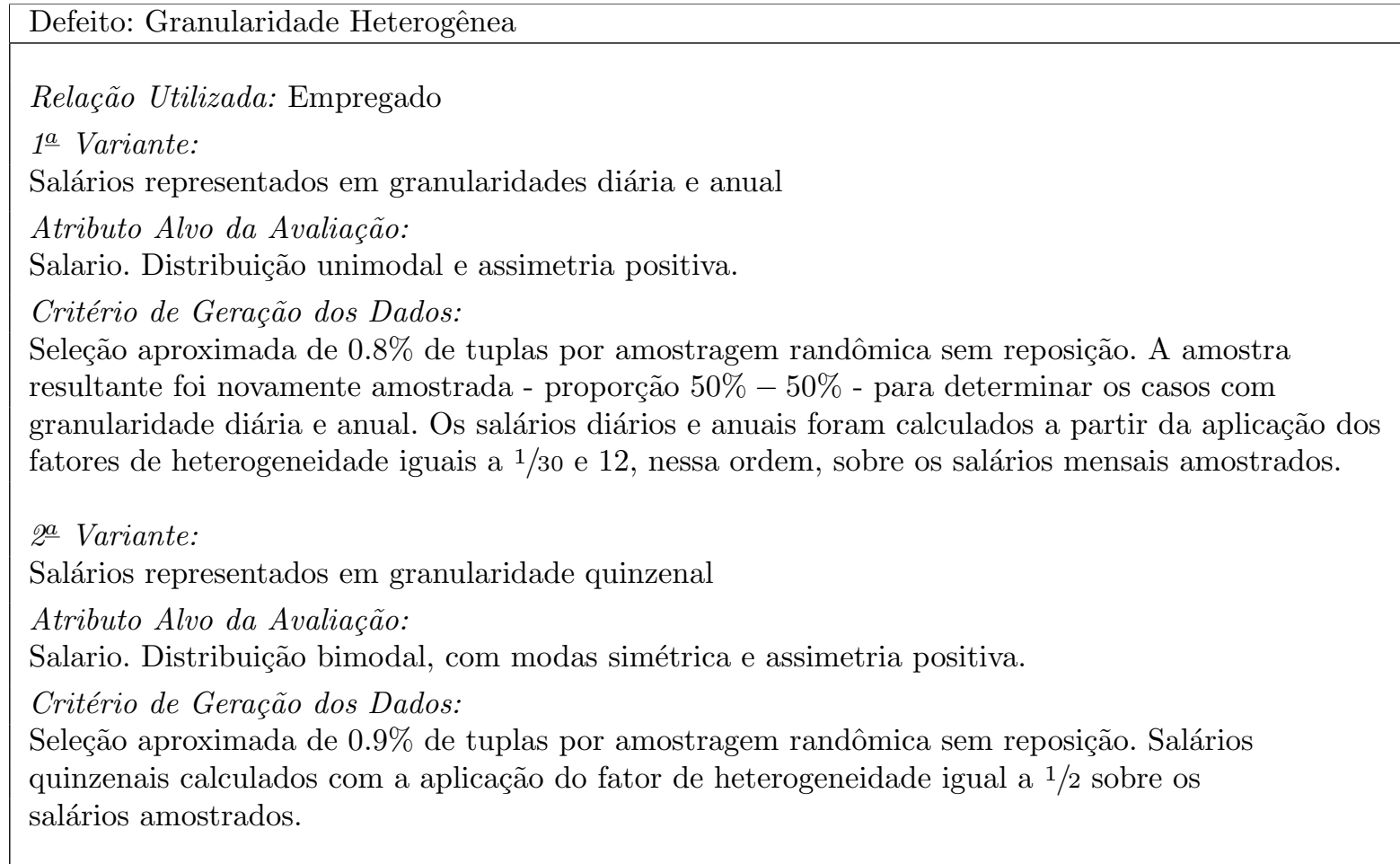

\begin{tabular}{l}
\hline Defeito: Referência Ausente \\
Relação Utilizada: Cliente \\
Variante Única: \\
Clientes casados, mas sem a representação dos respectivos relacionamentos. \\
Atributo Alvo da Avaliação: \\
Relacionamento denotado pelos identificadores de cliente e cônjuge. \\
Critério de Geração dos Dados: \\
Seleção aproximada de 0.8\% de tuplas por amostragem randômica sem reposição no estrato de \\
clientes com estado civil igual a "casado". As instâncias do relacionamento "cônjuge" foram \\
eliminadas para todas as tuplas amostras.
\end{tabular}

\section{Defeito: Referência Incorreta}

\section{Relação Utilizada: Cliente}

Variante Única :

Clientes não casados, mas com a representação dos respectivos relacionamentos.

Atributo Alvo da Avaliação:

Relacionamento denotado pelos identificadores de cliente e cônjuge.

Critério de Geração dos Dados:

Seleção aproximada de 1\% de tuplas por amostragem randômica sem reposição nos estratos de clientes com estado civil igual a "solteiro" ou "casado". A partir dessa amostra, novas amostragens permitiram produzir os relacionamentos uni $(\rightarrow)$ e bidirecionais $(\leftrightarrow)$ a seguir:

$$
\begin{aligned}
& \text { Cliente }_{\text {Solteiro }}^{X} \leftrightarrow \text { Cliente }_{\text {Solteiro }}^{Y}, \text { Cliente }_{\text {Solteiro }}^{X} \rightarrow \text { Cliente }_{\text {Solteiro }}^{Y} \rightarrow \text { Cliente }_{\text {Solteiro }}^{Z}, \\
& \text { Cliente }_{\text {Casado }}^{X} \rightarrow \text { Cliente }_{\text {Casado }}^{Y} \rightarrow \text { Cliente }_{\text {Casado }}^{Z}, \text { Cliente }_{\text {Casado }}^{X} \leftrightarrow \text { Cliente }_{\text {Casado }}^{X} \mathrm{e} \\
& \text { Cliente }_{\text {Casado }}^{X} \leftrightarrow \text { Cliente }_{\text {Casado }}^{Y} \text { marcados como sendo inexistentes no UdD. }
\end{aligned}
$$

Quadro 5.2: Características e critérios de geração dos dados defeituosos por Defeito e Variante - Parte I (Fonte: Elaborado pelo autor) 


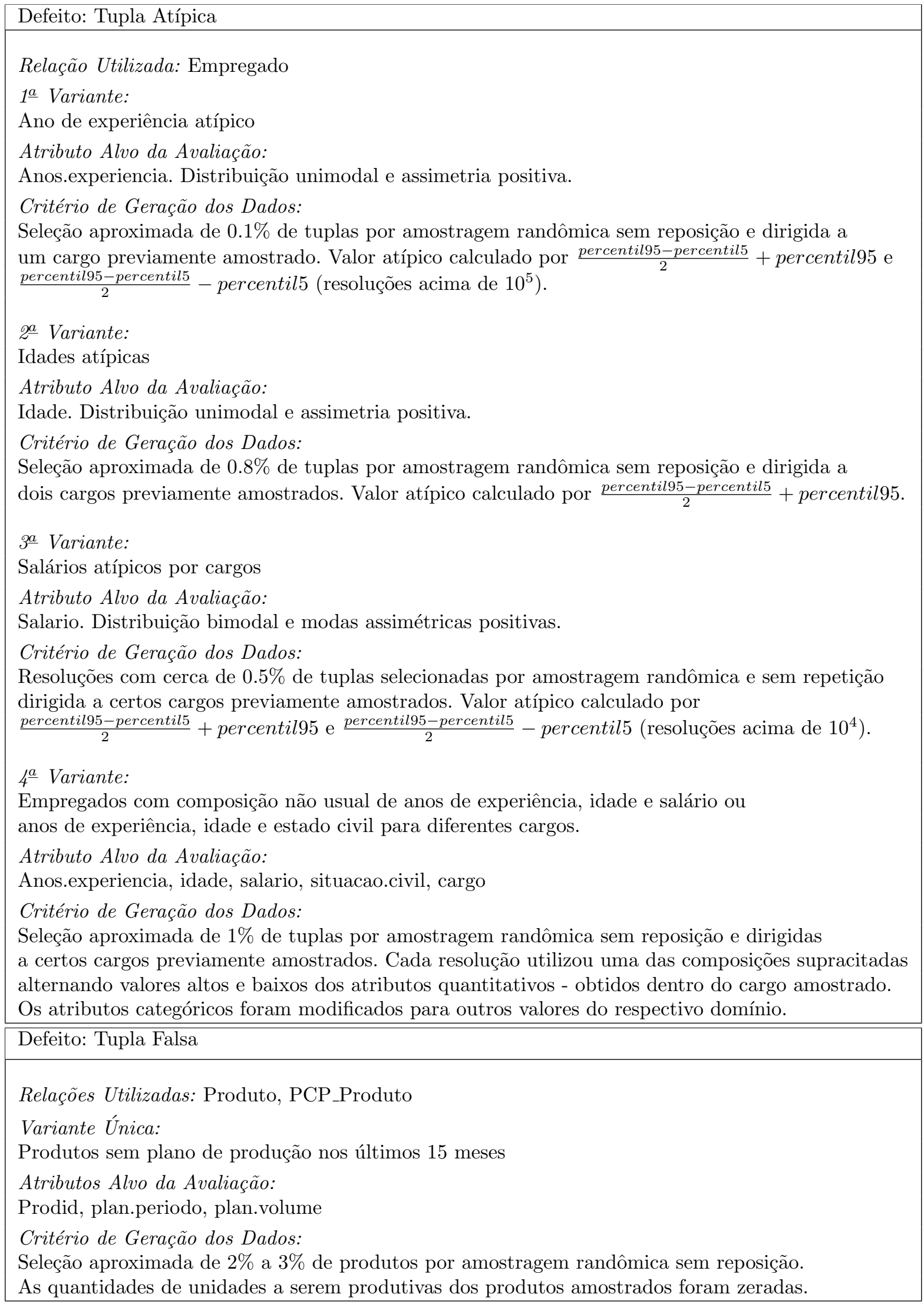

Quadro 5.3: Características e critérios de geração dos dados defeituosos por Defeito e Variante - Parte II (Fonte: Elaborado pelo autor) 


\begin{tabular}{|l|}
\hline Defeito: Unidade Medida Heterogênea \\
\hline Relação Utilizada: Empregado \\
Variante Única: \\
Salários representados em Dólar Canadense, Dólar Australiano e Euro \\
Atributo Alvo da Avaliação: \\
Salário. Distribuição bimodal e modas com assimetria positiva. \\
Critérios de Geração dos Dados: \\
Seleção aproximada de $0.8 \%$ de tuplas por amostragem randômica e sem reposição \\
dirigida a cargos e filiais previamente amostrados. Salários heterogêneos calculados a partir da \\
taxa de câmbio real - de certa data - entre o Dólar Americano e as moedas supracitadas. \\
Tais taxas produziram um fator de heterogeneidade aproximado de $1 / 5$ em média. \\
\hline
\end{tabular}

Quadro 5.4: Características e critérios de geração dos dados defeituosos por Defeito e Variante - Parte III (Fonte: Elaborado pelo autor)

na Figura 5.3. Na etapa de preparação, o participante recebeu as informações relativas ao estudo de caso e seus procedimentos, as estruturas dos defeitos, as atividades de avaliação e a semântica dos artefatos de dados. Ainda, houve um treinamento de trinta minutos para familiarizar o participante quanto as características do Vis4DD - Seção 5.3.4.

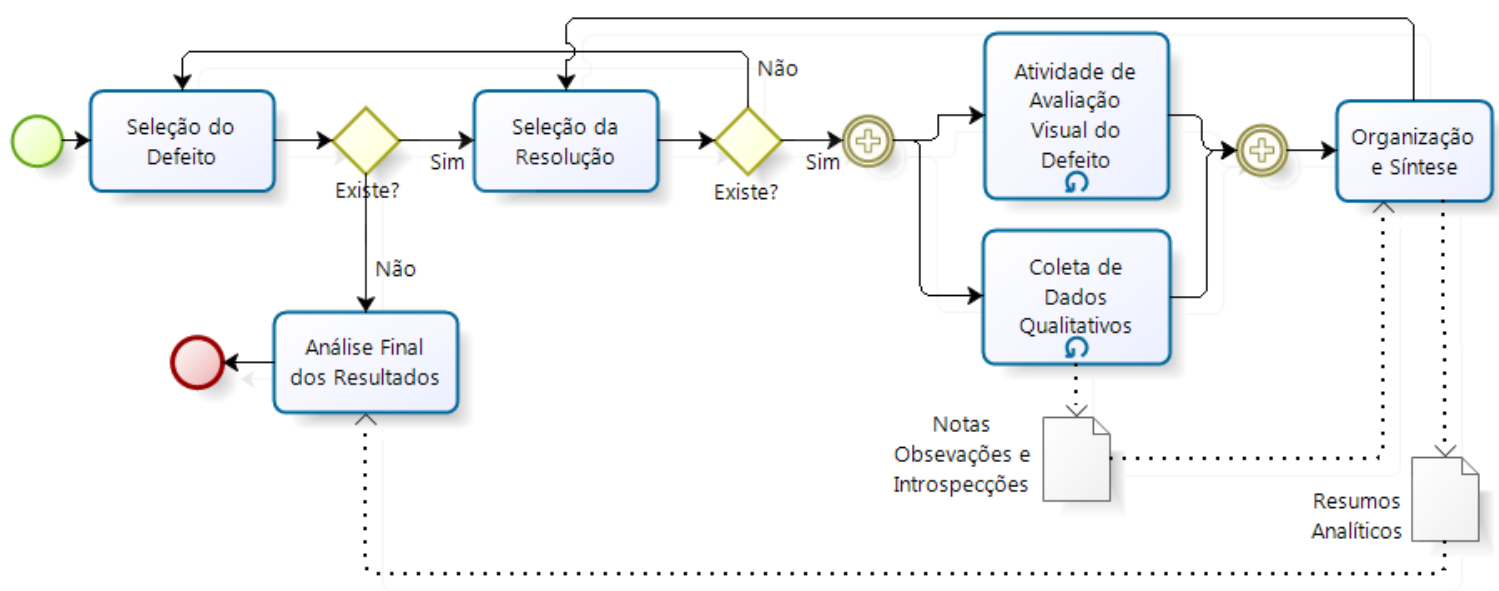

Figura 5.3: Esquema em BPMN do procedimento de trabalho do estudo de caso com múltiplas unidades de estudo (Fonte: Elaborado pelo autor)

Na etapa de execução de cada unidade de estudo - defeito -, a atividade de avaliação de cada defeito ocorreu em sessões de cerca de sessenta minutos. Contudo, certos defeitos como tupla atípica e granularidade heterogênea demandaram duas sessões. Em cada sessão, uma relação em particular era submetida a um conjunto de representações visuais previamente ordenadas pelo $V i s 4 D D$. Em cada representação visual isolada ${ }^{5}$, o participante desempenhou a análise dos dados balizado pela atividade de avaliação, assinalava o espaço - ou espaços - onde acredita existir a estrutura do defeito avaliado, determinava

\footnotetext{
${ }^{5} \mathrm{O}$ participante foi instruído a somente utilizar a representação visual corrente para avaliar a qualidade dos dados.
} 
o número de defeitos e persistia a representação visual corrente. Em contraste, aquelas representações visuais que não favoreceram a detecção dos defeitos foram marcadas como inadequadas. Não houve restrição de tempo para cada atividade. Ao término de todas as sessões, as notas e observações relativas a unidade de estudo foram reunidas, organizadas e sintetizadas - Seção A.2.

Com o término de todas as unidades de estudo, a etapa da análise final utilizou os ciclos de avaliação da qualidade dos dados como unidade de análise qualitativa. Um ciclo denota a ocasião durante a qual o participante organiza os atributos, detecta e quantifica cada variante de um defeito específico em dada resolução de dados. Esse ciclo também representa a ocasião na qual a representação visual não possibilita detectar certo defeito. Cada ciclo está associado a um conjunto de notas, observações e registros de interação utilizados na análise final. Este estudo de caso apresentou cerca de 400 ciclos.

Baseada nesses ciclos, a análise final realizou dois passos em sequência. O primeiro passo desenvolveu o conceito de configuração que reúne todas as propriedades do Vis4DD com participação causal na detecção ou quantificação dos defeitos nos dados. Essas configurações foram agrupadas pela propriedade visual base de codificação do atributo alvo da avaliação. Assim, certas representações visuais denotam mais do que uma configuração em acordância ao número de propriedades bases fornecidas. A Tabela 5.2 destaca as configurações e as respectivas propriedades visuais e interativas - Seções 2.3.4.2.1 e 2.3.4.1.

Neste estudo, o termo "detecção" denota a capacidade de revelar a estrutura do defeito e propiciar sua análise frente aos demais dados. O critério de capacidade considerou: i) a identificação completa ou parcial da estrutura de, ao menos, um caso defeituoso, ii) o custo computacional de renderização entre interações não superior a 60 segundos, iii) a viabilidade da análise visual em representações de dados de alta densidade. Por sua vez, o termo "quantificação" representa o grau de acuracidade na contagem do número de tuplas envolvidas no defeito identificado, sendo definido como: superior a $80 \%$, entre $30 \%$ e $80 \%$ inclusos, inferior a $30 \%$ ou não quantificável $0 \%$.

Por fim, o segundo passo analisou o relacionamento das diferentes propriedades e características dos dados que proporcionaram a detecção e quantificação observados na avaliação de todos os defeitos. Técnicas de estatística descritiva, de contraste e de construção de cadeia de evidências [Miles e Huberman, 1994] foram as principais técnicas utilizadas pelo procedimento analítico para descrever os resultados finais discutidos na seção a seguir.

\subsection{Resultados do Estudo de Caso}

Esta seção reporta as principais descobertas em relação a cada unidade de estudo, bem como relaciona as referidas descobertas aos resultados de trabalhos relacionados. 


\begin{tabular}{|c|c|c|c|c|c|c|c|c|c|c|c|c|c|c|}
\hline Prop. Base & Tipo de Descrição & 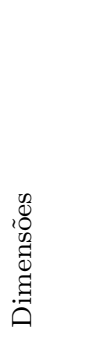 & 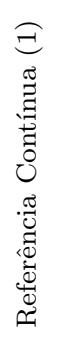 & 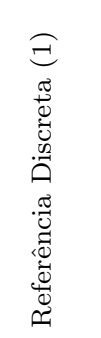 & 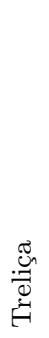 & 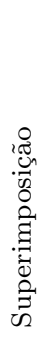 & 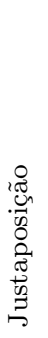 & 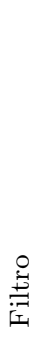 & 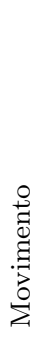 & 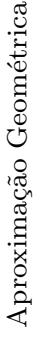 & 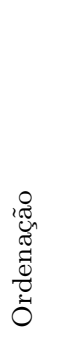 & 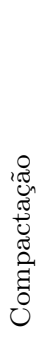 & 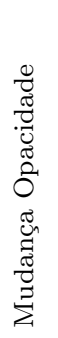 & 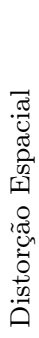 \\
\hline a1: Posição & Ponto por objeto & $2,3, \mathrm{~N}$ & $\mathrm{Q}, \mathrm{D}$ & $\mathrm{C}$ & - & $\bullet$ & - & $\bullet$ & - & - & - & - & - & $\bullet$ \\
\hline a2: & & 3 & $\mathrm{Q}, \mathrm{D}$ & $\mathrm{C}$ & $\bullet$ & $\bullet$ & - & $\bullet$ & - & - & - & - & - & $\bullet$ \\
\hline a3: & Frequência em Tamanho & 2 & - & $\mathrm{Q}, \mathrm{D}, \mathrm{C}$ & - & - & $\bullet$ & $\bullet$ & - & - & - & $\bullet$ & - & - \\
\hline a4: & Frequência em Tonalidade & 2 & Q & - & $\bullet$ & - & $\bullet$ & $\bullet$ & - & - & - & $\bullet$ & - & - \\
\hline a5: & Densidade em Saturação & 2 & $\mathrm{Q}$ & - & $\bullet$ & $\bullet$ & - & $\bullet$ & - & - & - & $\bullet$ & - & - \\
\hline a6: & Linha por objeto & $3, \mathrm{~N}$ & $\mathrm{Q}, \mathrm{D}$ & $\mathrm{C}$ & - & $\bullet$ & - & $\bullet$ & - & - & - & - & $\bullet$ & - \\
\hline a7: & & & & & $\bullet$ & $\bullet$ & - & $\bullet$ & - & - & - & - & $\bullet$ & - \\
\hline $\begin{array}{ll}\text { b1: } & \text { Saturação e } \\
& \text { Luminosidade }\end{array}$ & Cores por Valor Médio & 3 & Q,D & $\mathrm{C}$ & - & - & $\bullet$ & $\bullet$ & - & - & - & $\bullet$ & - & - \\
\hline c1: Tamanho & Proporção por Frequência & 1 & $\mathrm{Q}, \mathrm{D}$ & $\mathrm{C}$ & - & - & $\bullet$ & $\bullet$ & - & - & - & $\bullet$ & - & - \\
\hline $\mathrm{c} 2:$ & & 1 & $\mathrm{Q}, \mathrm{D}$ & $\mathrm{C}$ & $\bullet$ & - & $\bullet$ & $\bullet$ & - & - & - & $\bullet$ & - & - \\
\hline c3: & Proporção por Valor Absoluto & 4 & $\mathrm{Q}$ & $\mathrm{C}$ & - & $\bullet$ & - & $\bullet$ & - & - & - & - & - & - \\
\hline c4: & & 2 & $\mathrm{Q}$ & $\mathrm{C}$ & - & - & $\bullet$ & $\bullet$ & $\bullet$ & - & - & - & - & - \\
\hline c5: & Proporção por Valor Médio & $\mathrm{N}$ & $\mathrm{Q}, \mathrm{D}$ & $\mathrm{C}$ & - & - & $\bullet$ & $\bullet$ & - & $\bullet$ & $\bullet$ & $\bullet$ & - & - \\
\hline c6: & Proporção Parte-Todo & 3 & $\mathrm{Q}$ & $\mathrm{D}, \mathrm{C}$ & - & - & $\bullet$ & $\bullet$ & - & - & - & - & - & - \\
\hline d1: Tonalidade & Cores em Linhas & $3, \mathrm{~N}$ & Q,D & $\mathrm{C}$ & - & $\bullet$ & - & $\bullet$ & - & - & - & - & $\bullet$ & - \\
\hline d2: & Cores em Pontos & $3, \mathrm{~N}$ & $\mathrm{Q}, \mathrm{D}$ & $\mathrm{C}$ & - & $\bullet$ & - & $\bullet$ & - & - & - & - & - & $\bullet$ \\
\hline d3: & Cores em Tamanho & 4 & $\mathrm{Q}$ & $\mathrm{C}$ & - & $\bullet$ & - & $\bullet$ & - & - & - & - & - & - \\
\hline e1: Treliça & Rótulo & 3 & Q,D & $\mathrm{C}$ & - & $\bullet$ & - & $\bullet$ & - & - & - & - & - & $\bullet$ \\
\hline e2: & & $3, \mathrm{~N}$ & $\mathrm{Q}, \mathrm{D}$ & $\mathrm{C}$ & - & $\bullet$ & - & $\bullet$ & - & - & - & - & $\bullet$ & - \\
\hline e3: & & 1 & $\mathrm{Q}, \mathrm{D}$ & $\mathrm{C}$ & - & - & $\bullet$ & $\bullet$ & - & - & - & $\bullet$ & - & - \\
\hline f1: $\begin{array}{l}\text { Forma } \\
\text { (Ícone) }\end{array}$ & Proporção por Valor Absoluto & $\mathrm{N}$ & $\mathrm{Q}$ & - & - & - & $\bullet$ & $\bullet$ & - & - & - & - & - & - \\
\hline g1: Conexão & Grafo Dirigido Radial & 1 & - & $\mathrm{Q}, \mathrm{D}, \mathrm{C}$ & - & - & $\bullet$ & $\bullet$ & - & - & - & - & - & - \\
\hline g2: & & 0 & - & $\mathrm{Q}, \mathrm{D}, \mathrm{C}$ & - & - & $\bullet$ & $\bullet$ & - & - & - & - & - & - \\
\hline g3: & Grafo Não Dirigido Retilíneo & 1 & - & $\mathrm{Q}, \mathrm{D}, \mathrm{C}$ & - & - & $\bullet$ & $\bullet$ & - & - & - & - & - & - \\
\hline h1: $\begin{array}{l}\text { Hierarquia } \\
\text { Recursiva }\end{array}$ & Tamanho proporcional ao Valor & 5 & & $\mathrm{Q}, \mathrm{C}$ & - & - & $\bullet$ & - & - & $\bullet$ & - & $\bullet$ & - & - \\
\hline
\end{tabular}

Tabela 5.2: Matriz de configurações e respectivas propriedades

(Fonte: Elaborado pelo autor)

\subsubsection{Unidade de Estudo - Tupla Atípica}

Uma tupla atípica desvia do comportamento da maioria das tuplas de uma relação por diferentes razões - Seção 4.4. Este estudo observou as propriedades dos sistemas de visualização frente a quatro variantes relevantes do referido defeito.

A $1^{\underline{a}}$ variante denota a presença de pequena quantidade de valores atípicos em um atributo particular. A maioria das configurações favoreceram a atividade de avaliação Atividade 1 - dessa variante, mas com alternâncias de capacidade e de esforço requerido do participante que ocasionaram diferentes resultados - Figura 5.4b. 


\begin{abstract}
$T_{\text {Tupla_Atípica }=}$
( Buscar(atípico,arranjar.espaco, Empregado.anos.experiencia $\sim$ Empregado_atip.*) $\Rightarrow$ Correlacionar (parte - todo|atípico, arranjar.espaco|destacar, Empregado.anos.experiencia $\sim$ Empregado_atip.*) $\Rightarrow$ Buscar(atípico, simplificar|abstrair, Empregado.anos.experiencia $\sim$ Empregado_atip.*) $\Rightarrow$ Correlacionar (discrepância, arranjar.espaco|destacar, Empregado.anos.experiencia $\sim$ Empregado_atip.*) )
\end{abstract}

Atividade 1: Atividade de avaliação da primeira variante de Tupla Atípica

As configurações baseadas em posição foram superiores na detecção e quantificação por salientar os casos atípicos por meio do isolamento espacial. As configurações dotadas de compactação - a3, a4, a5 - proporcionaram resultados uniformes em todas as resoluções de dados e com baixo número de interações, como observado na Figura 5.5b. No entanto, aquelas configurações desprovidas de compactação - incluindo a1, a2, a6, a7 - apresentaram oclusão visual diretamente proporcional ao incremento das resoluções. Apesar do apoio das técnicas de interação - como distorção espacial e filtro - essas configurações ficaram limitadas a manipulação de relações não superiores a $10^{5}$ tuplas.

Os resultados da propriedade posição para a $1^{\underline{a}}$ variante complementam os trabalhos prévios de [Grinstein et al., 2002; Hoffman, 1999; Marghescu, 2007; Ward e Theroux, 1997] com respeito a deteç̧ão e quantificação em resoluções crescente de dados, bem como em relação ao uso da compactação.

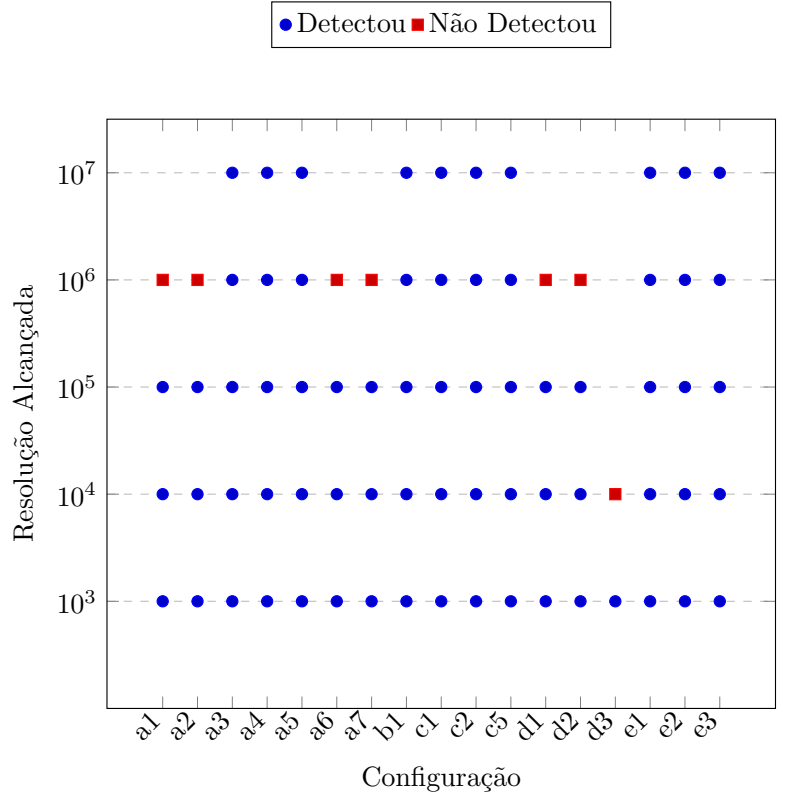

(a) Detecção por Resolução

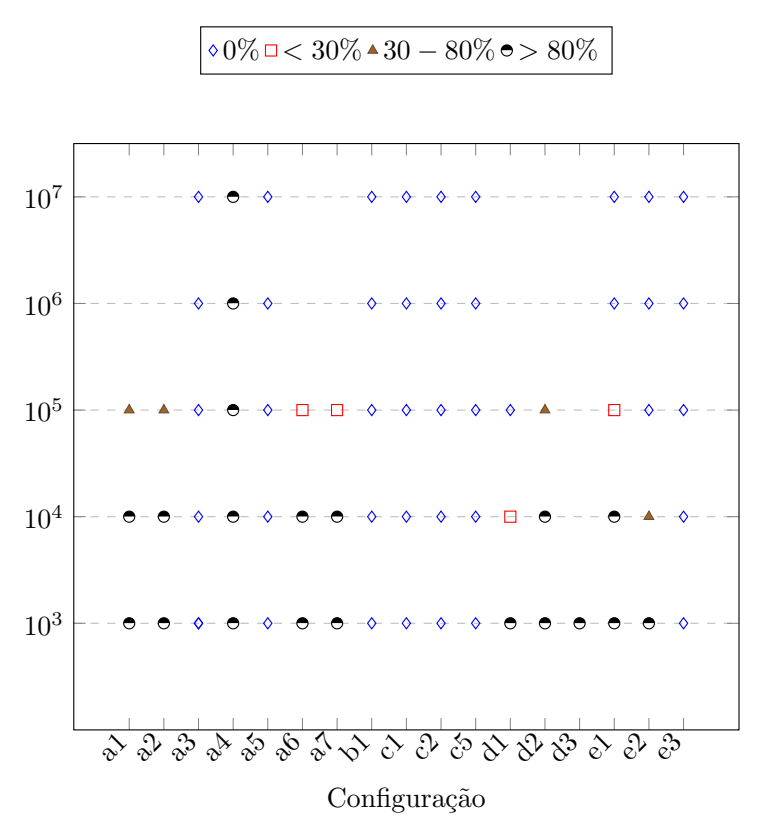

(b) Quantificação por Resolução

Figura 5.4: Resultados das configurações na avaliação da primeira variante de Tupla Atípica (Fonte: Elaborado pelo autor) 


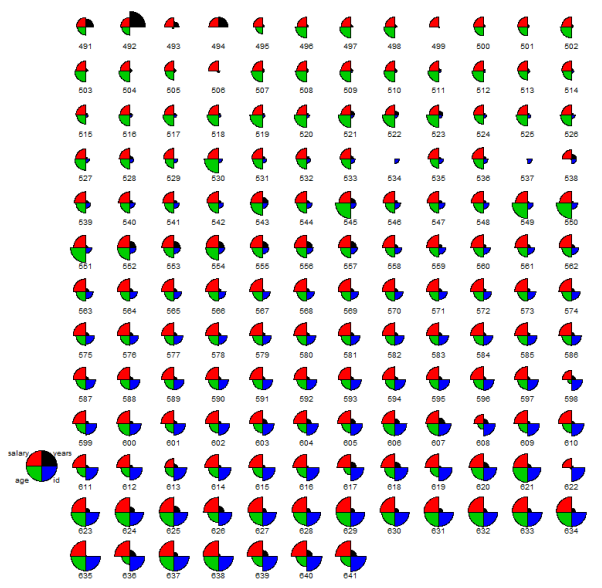

(a) Proporção das formas estabelecida somente para as tuplas expostas na cena em resolução de $10^{3}$ tuplas

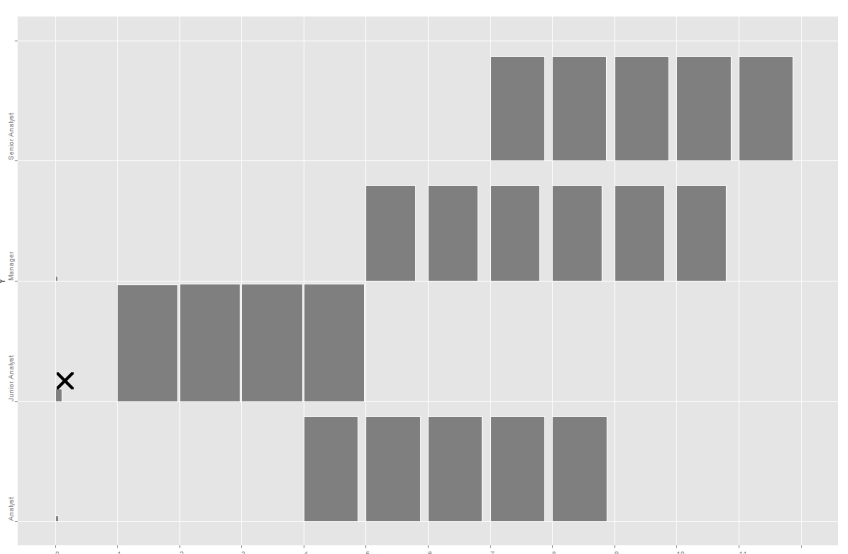

(b) Detecção sem quantificação por frequência em tamanho na resolução de $10^{7}$ tuplas

Figura 5.5: Fragmentos visuais da avaliação da primeira variante de Tupla Atípica

(Fonte: Elaborado pelo autor)

Em contraste, as configurações baseadas em tamanho e compactação inibiram a quantificação devido a diluição dos valores provocada pela concentração de tuplas. Para determinar a presença da maioria das tuplas atípicas, algumas dessas configurações - c1, c2 demandaram um aumento de $73 \%$ - de 15 para 26 - no número de agrupadores, enquanto outras - c5 - exigiram interações de ordenação e aproximação - cerca de duas em média. Os aspectos das cores apresentaram outros obstáculos que determinaram o diagnóstico parcial das tuplas defeituosas. A presença de elementos visuais - incluindo pontos e linhas - com tonalidades variadas exigiram do participante a utilização de uma interação de filtro e deslocamento espacial para isolar casos atípicos nas configurações $d 1$ a $d 3$. Apesar disso, seus resultados foram restritos as menores resoluções de dados - Figura 5.4b - devido a indissociação dos elementos visuais em espaços densamente populados.

Por sua vez, a configuração baseada em saturação/luminosidade - b1 - demandou duas interações de filtro em razão da diluição dos valores atípicos provocada pela média aritmética [Tukey, 1977]. Além disso, essa configuração criou obstáculos a derivação dos valores quantitativos a partir da referência tonalidade-magnitude, corroborando estudos prévios de [Bertin, 1983; Carpendale, 2003].

Em contraste aos casos acima, certas configurações não favoreceram a avaliação da $1^{\underline{a}}$ variante. As configurações baseadas em forma conduziram o participante a diagnósticos de falso-positivos em razão de suas proporções serem determinadas somente para as tuplas expostas - cento e cinquenta - e por provocar a importância relativa dos atributos características da face ou área -, conforme observado na Figura 5.5a. Em contraste, outras configurações impediram o julgamento da magnitude dos valores - incluindo $g 1$, g2 - ou promoveram a oclusão visual excessiva mesmo na menor resolução de dados - c3, c6.

A Figura 5.6 destaca os resultados relativos a $2^{a}$ variante de tupla atípica cuja estrutura 
denota a presença de vários valores atípicos em determinado atributo. Sua atividade de avaliação - Atividade 2 -, observações e resultados relativos a certas configurações são semelhantes àqueles discutidos na $1^{\underline{a}}$ variante, como no caso da configuração $a 4$ ilustrada na Figura 5.7b.

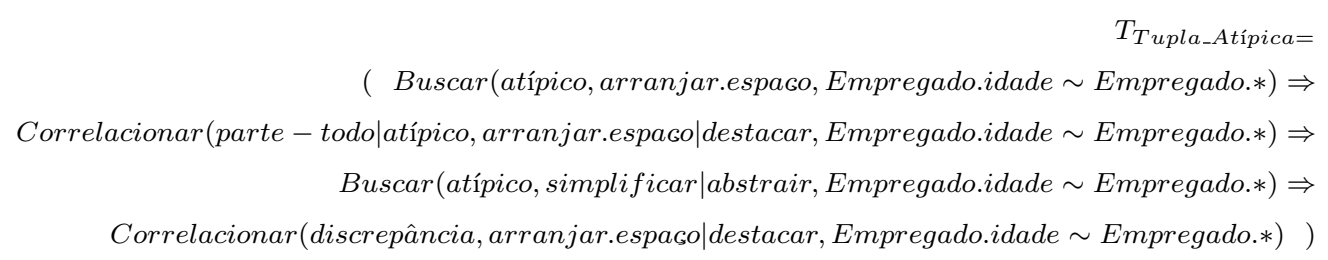

Atividade 2: Atividade de avaliação da segunda variante de Tupla Atípica

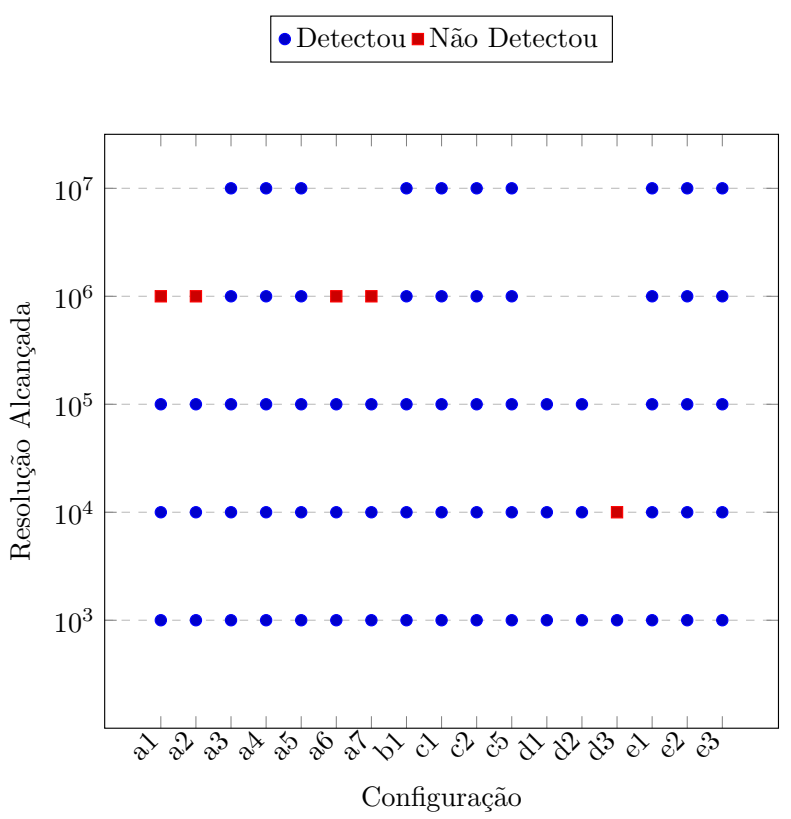

(a) Deteç̧ão por Resolução

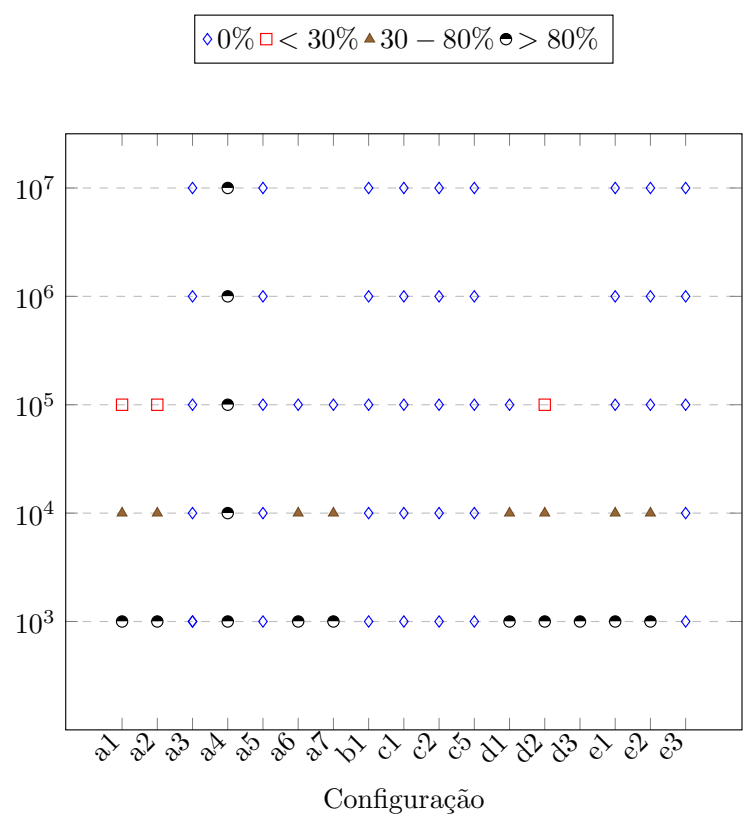

(b) Quantificação por Resolução

Figura 5.6: Resultados das configurações na avaliação da segunda variante de Tupla Atípica (Fonte: Elaborado pelo autor)

No entanto, a contraposição das Figuras $5.4 \mathrm{~b}$ e $5.6 \mathrm{~b}$ revela que certas configurações - a1, a2, a6, a7, d1, d2 - perderam a capacidade de quantificação na $2^{\underline{a}}$ variante devido ao incremento da oclusão visual. O número superior de tuplas defeituosas com sobreposição moderada determinou tal oclusão que não foi contornada pelo filtro, deslocamento espacial ou mudança de opacidade, esse último ilustrado na Figura 5.7a.

Valores não usuais interpostos entre categorias de dados com certa sobreposição é característica da $3^{\underline{a}}$ variante de Tupla Atípica. Sua estrutura - avaliada pela Atividade 3 - determinou as configurações mais apropriadas - Figura 5.8 - como aquelas capazes de 


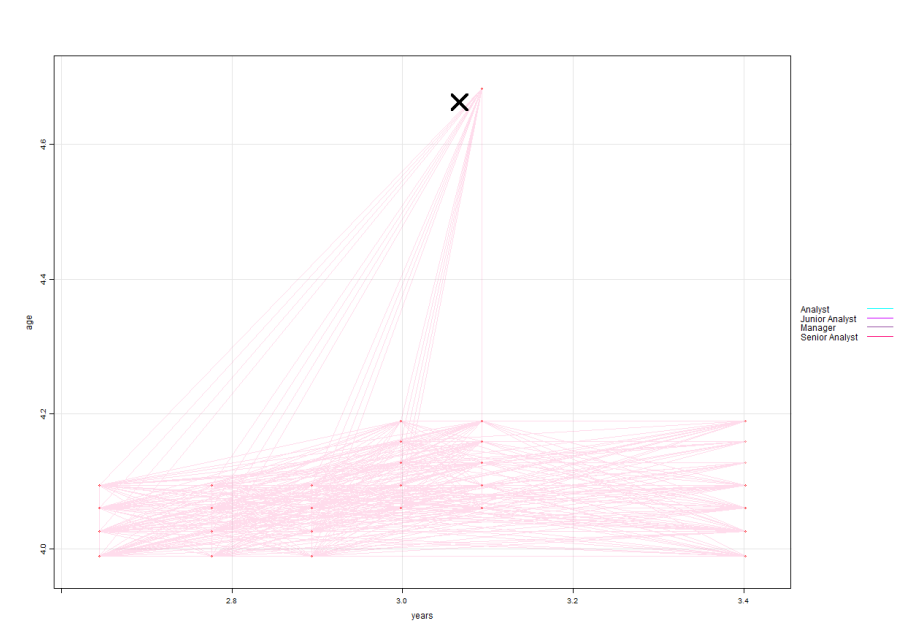

(a) Oclusão impede quantificação com Filtro e Mudança (b) de Opacidade em resolução $10^{5}$ tuplas

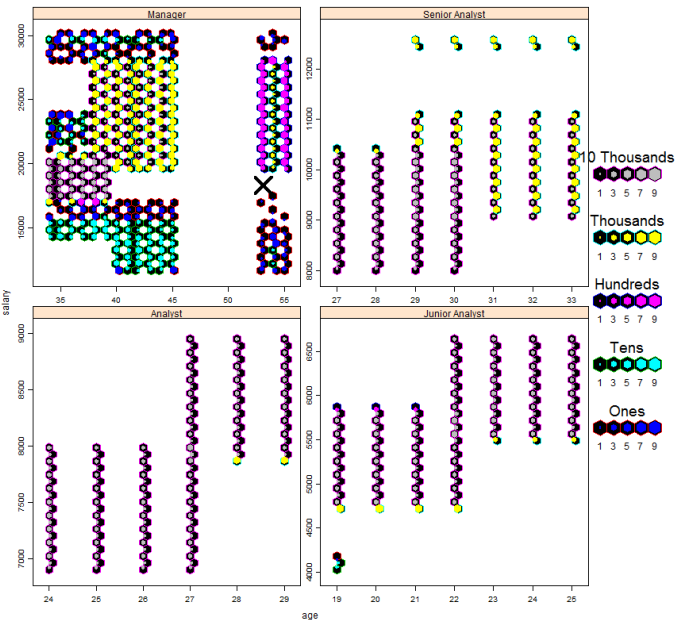

(b) Tuplas atípicas detectadas e quantificadas por Frequência em Tonalidade na resolução $10^{7}$

Figura 5.7: Fragmentos visuais da avaliação da segunda variante de Tupla Atípica (Fonte: Elaborado pelo autor)

correlacionar o atributo alvo a categoria, bem como representar atributos com domínios extensos. Essas condições desqualificaram as configurações c1 e a3, d1, e1, nessa ordem. A Figura 5.9a ilustra essa situação envolvendo a propriedade treliça.

$$
\begin{aligned}
& T_{\text {Tupla_Atípica }}= \\
& \text { ( Buscar (atípico, arranjar.espaco, Empregado.salario Empregado.cargo) } \Rightarrow \\
& \text { Correlacionar (parte - todo|atípico, arranjar.espaco|destacar, Empregado.salario } \sim \text { Empregado.cargo) } \Rightarrow \\
& \text { Buscar (atípico, simplificar|abstrair, Empregado.salario Empregado.cargo) } \Rightarrow \\
& \text { Correlacionar (discrepância, arranjar.espaco|destacar, Empregado.salario Empregado.cargo) ) }
\end{aligned}
$$

Atividade 3: Atividade de avaliação da terceira variante de Tupla Atípica

As configurações baseadas em posição mantiveram os melhores resultados de detecção e quantificação. O filtro, a treliça e o deslocamento espacial proporcionaram esses resultados de modo semelhante ao discutido nas duas primeiras variantes da Tupla Atípica. A mudança de opacidade ofereceu uma ligeira melhora na visão global dos dados, mas restrita as resoluções até $10^{4}$. Cumpre mencionar que a baixa sobreposição - cerca de $15 \%$ - dos salários entre diferentes cargos favoreceu o resultado das configurações baseadas em linha - a6, a\%. Como destaca certos trabalhos [Ward e Theroux, 1997], a detecção de atípicos por meio dessas configurações enfrenta dificuldades em categorias com moderada-alta sobreposição.

As demais configurações - incluindo c3, c5, c6, b1 - apresentaram efeitos similares aos descritos nas variantes anteriores. Como exemplo, a configuração baseada em saturação 


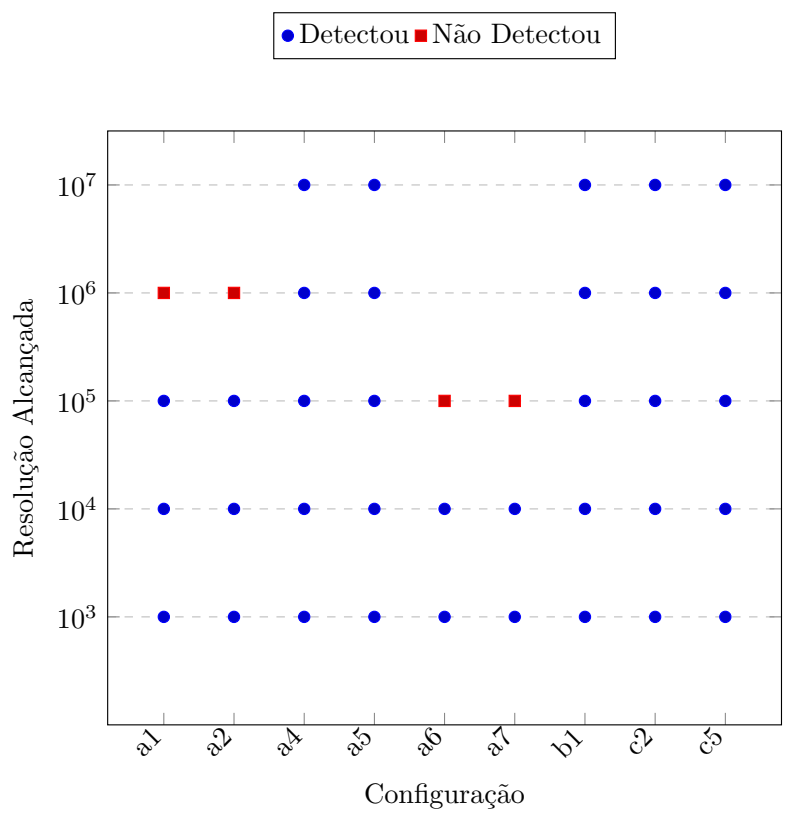

(a) Deteç̧ão por Resolução

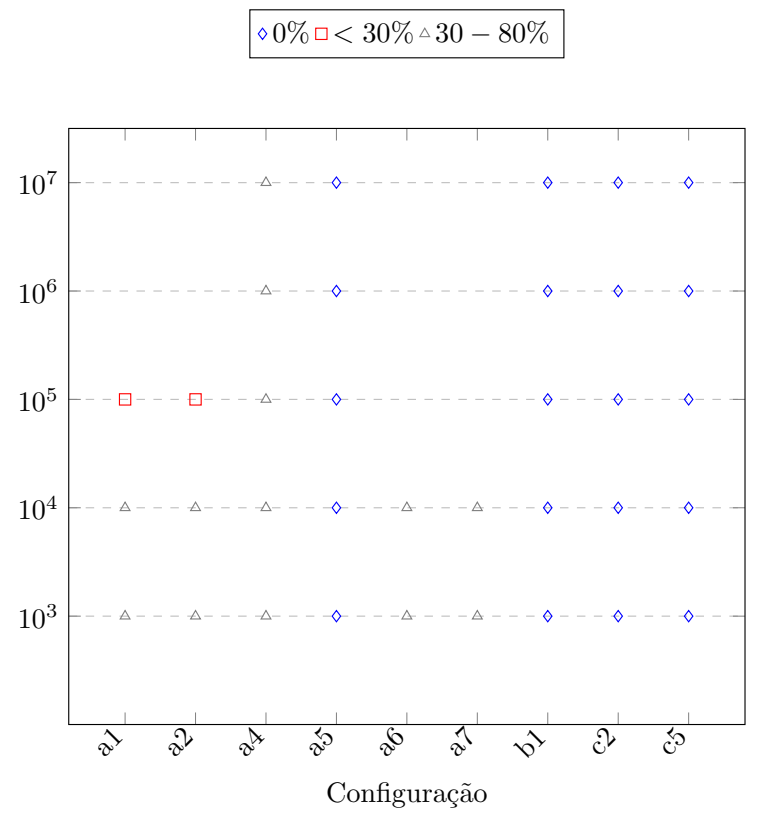

(b) Quantificação por Resolução

Figura 5.8: Resultados das configurações na avaliação da terceira variante de Tupla Atípica (Fonte: Elaborado pelo autor)

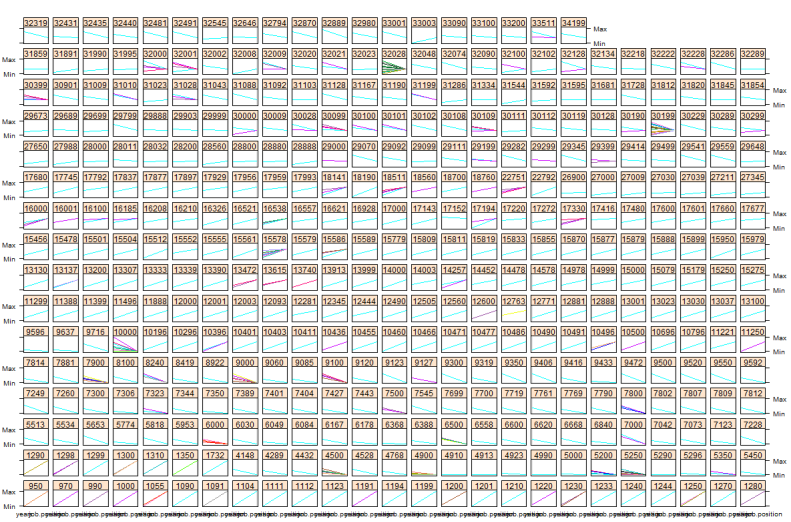

(a) Grande número de paíneis impediram a extração do padrão em resolução de $10^{3}$ tuplas

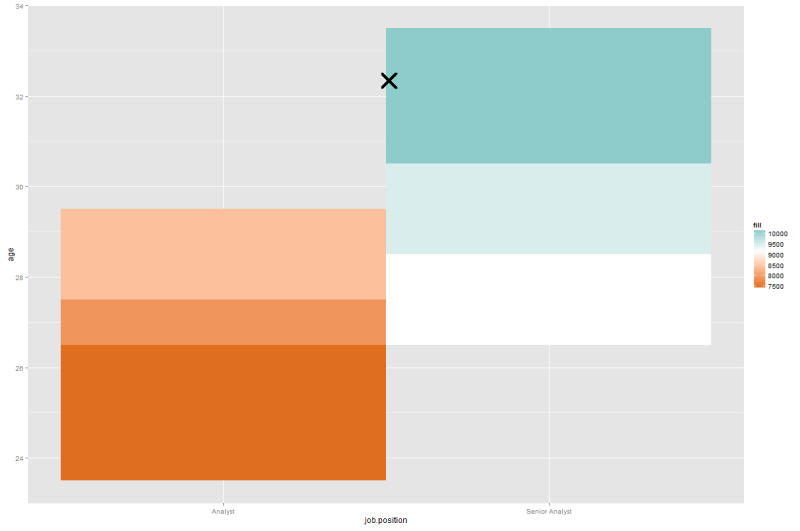

(b) Detecção por saturação após interações com filtro em resolução de $10^{7}$ tuplas

Figura 5.9: Fragmentos visuais da terceira variante de Tupla Atipica

(Fonte: Elaborado pelo autor)

demandou operações de filtragem - três em média - para revelar alguns casos relativos a $3^{\underline{a}}$ variante de Tupla Atípica, conforme observado na Figura 5.9b.

A mais complexa variante de Tupla Atípica - denominada de $4^{\underline{a}}$ variante - remete a combinação multifacetada de valores de um subconjunto de atributos de uma tupla. A necessidade de confrontar, no mínimo, quatro atributos quantitativos e qualitativos - Atividade 4 - determinou a relevância do número de dimensões e de tipos de dados heterogêneos. 


$$
\begin{aligned}
& \text { TTupla_Atípica }= \\
& \text { (Buscar(atípico, arranjar.espago, Empregado.anos.experiencia|idade|salario|estado.civil } \\
& \sim \text { Empregado.*) } \Rightarrow
\end{aligned}
$$

Atividade 4: Atividade de avaliação da quarta variante de Tupla Atípica

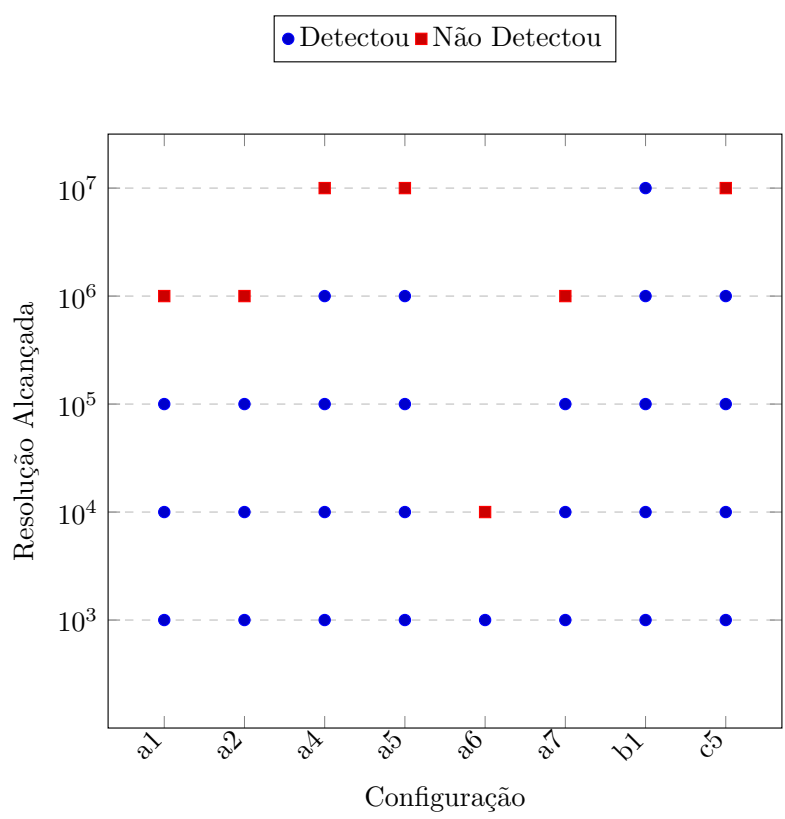

(a) Detecção por Resolução $\diamond 0 \% \square<30 \% \triangle 30-80 \%$

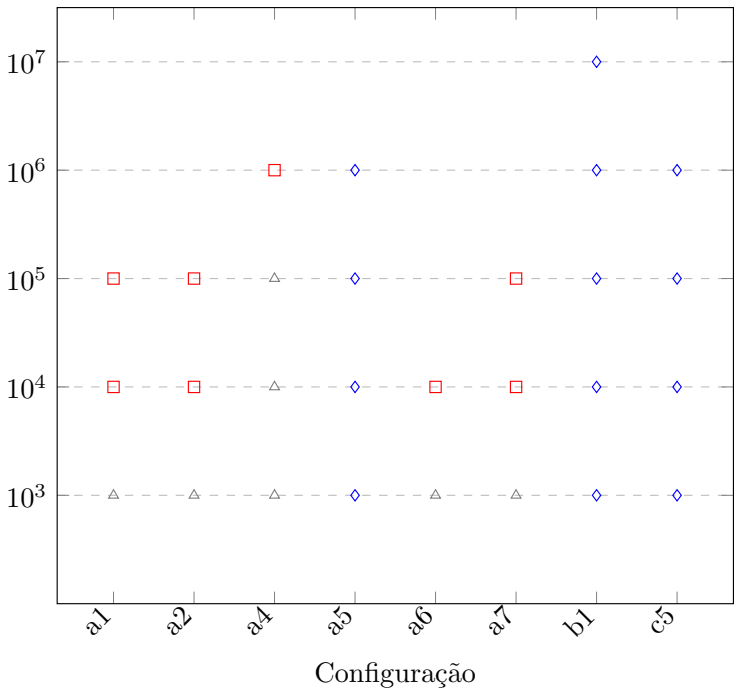

(b) Quantificação por Resolução

Figura 5.10: Resultados das configurações na avaliação da quarta variante de Tupla Atípica (Fonte: Elaborado pelo autor)

Por consequência, várias configurações com três dimensões ou menos - incluindo a treliça foram naturalmente inadequadas - Figura 5.10a. Embora o filtro e o arranjo dos atributos tenham possibilitado a detecção de uma combinação atípica por meio das configurações com três dimensões, as sucessivas transições visuais impuseram o esforço mental de manter e integrar fatos para completar a atividade de avaliação.

As configurações $a 7$ e $c 5$ melhor atenderam as necessidades da atividade de avaliação por meio de uma visão global dos dados com todos os atributos de interesse, mas com limites. A oclusão interna restringiu a primeira configuração as menores resoluções mesmo com o apoio da mudança de opacidade - Figura 5.11a. Já a segunda estabeleceu a utilização 
intensiva das aproximações - cerca de oito operações em média - para isolar os casos defeituosos, conforme ilustrado na Figura 5.11b.

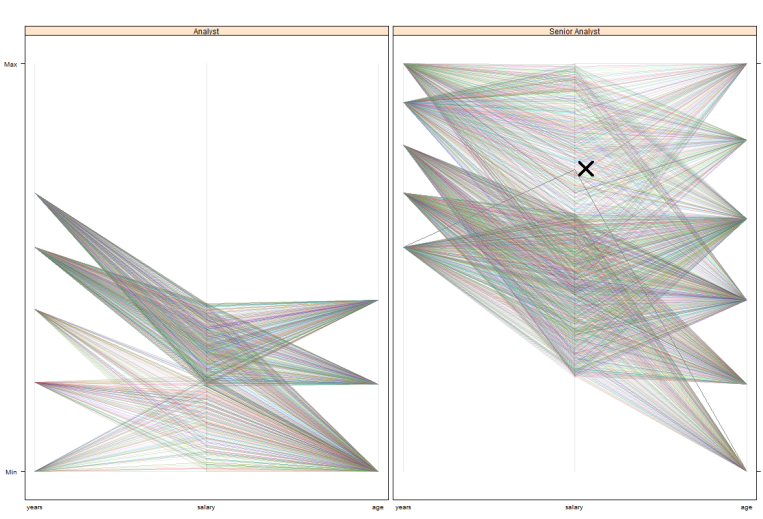

(a) Detecção por posição em linha com apoio de filtro, treliça e opacidade em resolução de $10^{4}$ tuplas

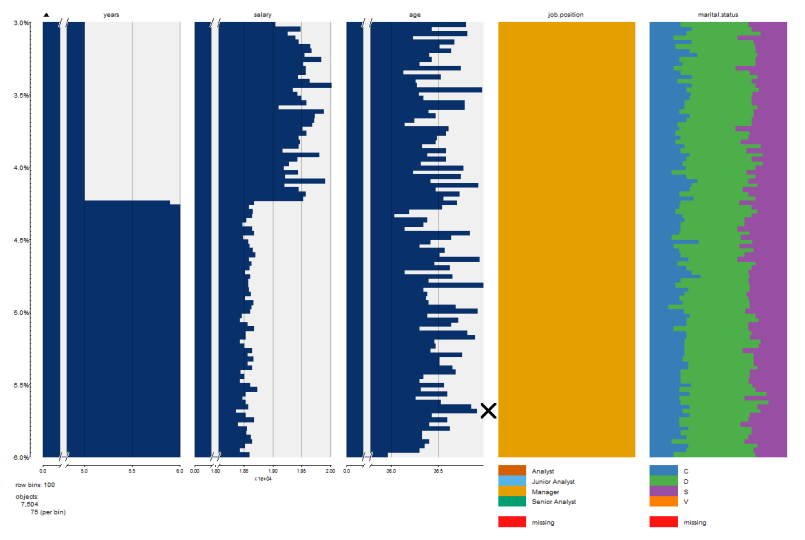

(b) Detecção por tamanho proporcional a média com apoio de aproximação em resolução de $10^{6}$ tuplas

Figura 5.11: Fragmentos visuais da avaliação da quarta variante de Tupla Atípica (Fonte: Elaborado pelo autor)

\subsubsection{Unidade de Estudo - Tupla Falsa}

Discutida na Seção 4.4, a tupla falsa é uma instância $t$ que atende a todas as restrições vigentes de uma dada relação $R, t \in r(R)$, mas que não possui representatividade ao UdD. Atributos de referência, o histórico sobre fatos do negócio ou transações realizadas sobre tuplas são recursos que promovem introspecções que, consideradas no contexto dos dados, podem determinar a presença desse defeito. Este estudo analisou as lacunas temporais no histórico de fatos do negócio empregando a Atividade 5, sendo os respectivos resultados sintetizados na Figura 5.12.

$$
\begin{aligned}
& T_{\text {Tupla_Falsa }}= \\
& \text { ( Buscar(constância|lacuna, simplificar|arranjar.espaco,PCP_Produto.prodid|plan.volume|plan.periodo } \\
& \sim \text { PCP_Produto.*) } \Rightarrow
\end{aligned}
$$

Atividade 5: Atividade de avaliação da Tupla Falsa 


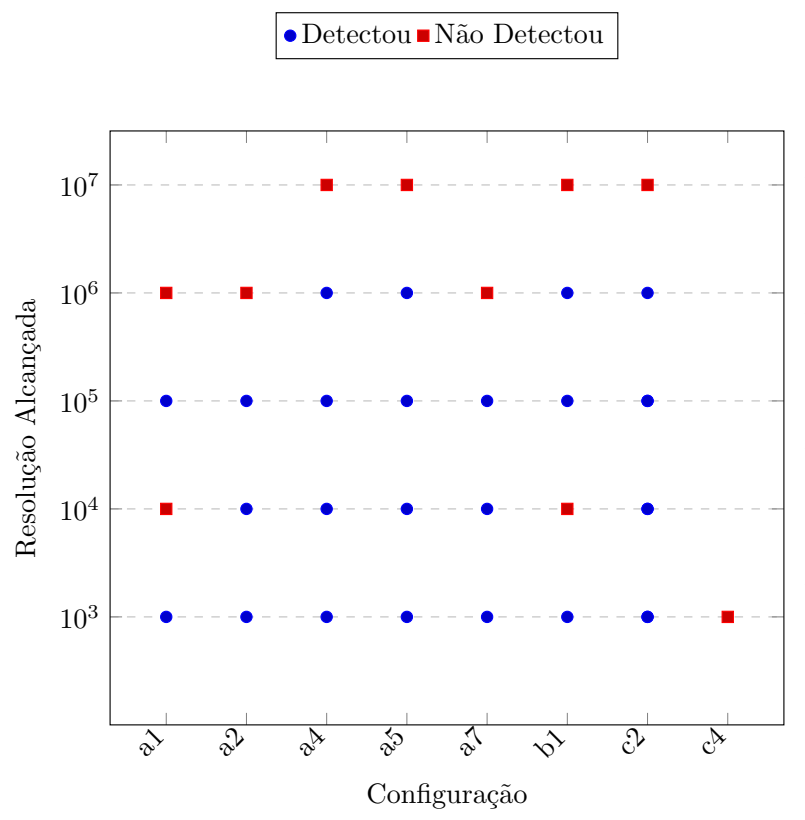

(a) Detecção por Resolução

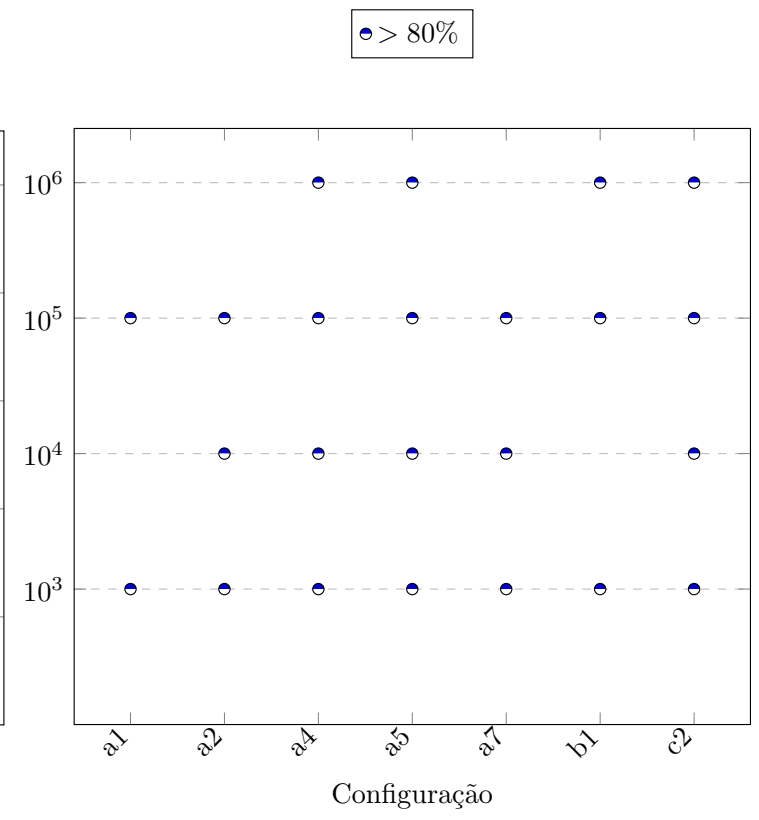

(b) Quantificação por Resolução

Figura 5.12: Resultados das configurações na avaliação da Tupla Falsa (Fonte: Elaborado pelo autor)

A técnica de filtro foi fundamental para favorecer a percepção visual do padrão relacionado a Tupla Falsa. Ao recortar os dados temporais, essa interação reduziu a oclusão interna dos painéis de treliça e complementou aquelas configurações com menos de três dimensões - a1, a2, c2, a4, a5 -, mas com limitações. Por exemplo, as configurações a4, a5 exigiram duas aplicações de filtros para isolar o padrão de tupla falsa na resolução de $10^{3}$ tuplas. A configuração baseada em saturação - b1 - permitiu a análise longitudinal dos dados temporais e facilitou a atividade de avaliação desse defeito, conforme observado na Figura 5.13b. Sua representação de dados em justaposição foi mais explícita em todas as resoluções frente as demais configurações que propiciaram a detecção. No entanto, tal configuração não obteve êxito nas resoluções na qual o atributo categórico avaliado apresentou um domínio superior a 80 elementos distintos - resoluções de $10^{4}$ e $10^{7}$ tuplas - em razão da sobreposição excessiva de elementos no eixo das ordenadas - Figura 5.12a.

A técnica de movimento - configuração $c 4$ - também beneficiou a análise longitudinal dos dados por meio do pulso ${ }^{6}$. Porém, essa técnica levou o participante a compreensão imprecisa das lacunas temporais e a fatiga devido a necessidade de conectar mentalmente fatos entre transições animadas - velocidade de 1,8 segundos. O extenso domínio dos atributos alvo - por exemplo, prodid variou de 28 a 450 produtos - pode ter bloqueado a percepção da natureza e a taxa de mudanças dos dados. Esses resultados complementam estudos em [Robertson et al., 2008; Ware, 2004].

\footnotetext{
${ }^{6} \mathrm{O}$ pulso representa um tipo de deslocamento baseado na repetida expansão e contração de um variável visual. Este estudo aplicou o pulso para a propriedade visual tamanho.
} 

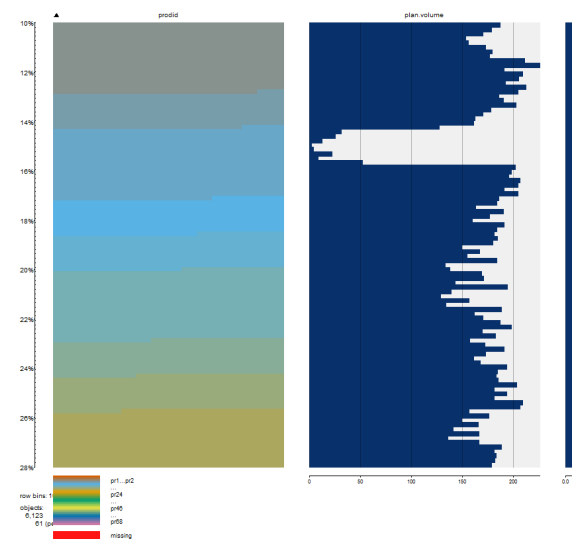

(a) Deteç̧ão inconclusiva de lacuna temporal em Proporção por Valor Médio em resolução de $10^{3}$ tuplas

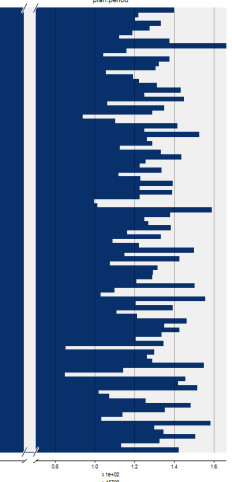
histórico com Saturação/Luminosidade em resolução de $10^{6}$ tuplas

Figura 5.13: Fragmentos visuais da avaliação de Tupla Falsa

(Fonte: Elaborado pelo autor)

Certas configurações impediram a avaliação da Tupla Falsa mesmo com o uso do filtro. O não atendimento da exigência por três atributos para viabilizar a análise - c1 -, a oclusão visual - a6 - e a incapacidade de representar domínios extensos - incluindo a3, d1, e1 - ou atributos do tipo data-hora - c3 - são as limitações de várias configurações. Além disso, a inexpressividade temporal desqualificou outras mais - incluindo $c 5, c 6, f 1, g 1, h 1$ - devido a obstrução na conclusão da atividade de avaliação, caso da configuração $c 5$ ilustrada na Figura 5.13a.

\subsubsection{Unidade de Estudo - Granularidade Heterogênea}

A granularidade heterogênea denota valores de um atributo representados em diferentes níveis de abstração - Seção 4.4. Essa heterogeneidade é representada por variantes com fatores de heterogeneidade diversos e comportamento randômico ou dirigido a certas categorias de dados. O fator de heterogeneidade expressa a distância entre o nível de abstração requerida e os heterogêneos. Este estudo examinou duas variantes de comportamento randômico e fatores de heterogeneidade distintos.

\footnotetext{
$T_{\text {Granularidade_Heterogênea }}=$

( Buscar(desvio, arranjar.espago, Empregado.salario Empregado.*) $\Rightarrow$ Correlacionar (parte - todo|desvio, arranjar.espaco|destacar, Empregado.salario $\sim$ Empregado.*) $\Rightarrow$ Buscar (incoerência, simplificar|abstrair, Empregado.salario Empregado.*) $\Rightarrow$ Correlacionar(alterna diferencas, arranjar.espaco|destacar, Empregado.salario Empregado.*) )
}

Atividade 6: Atividade de avaliação da primeira variante de Granularidade Heterogênea 


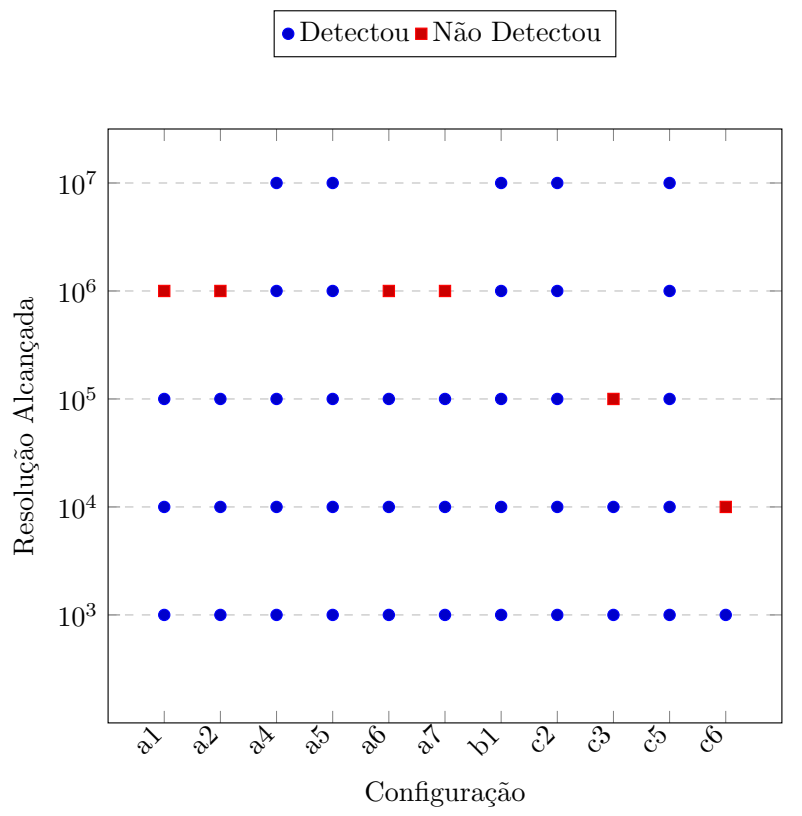

(a) Detecção por Resolução

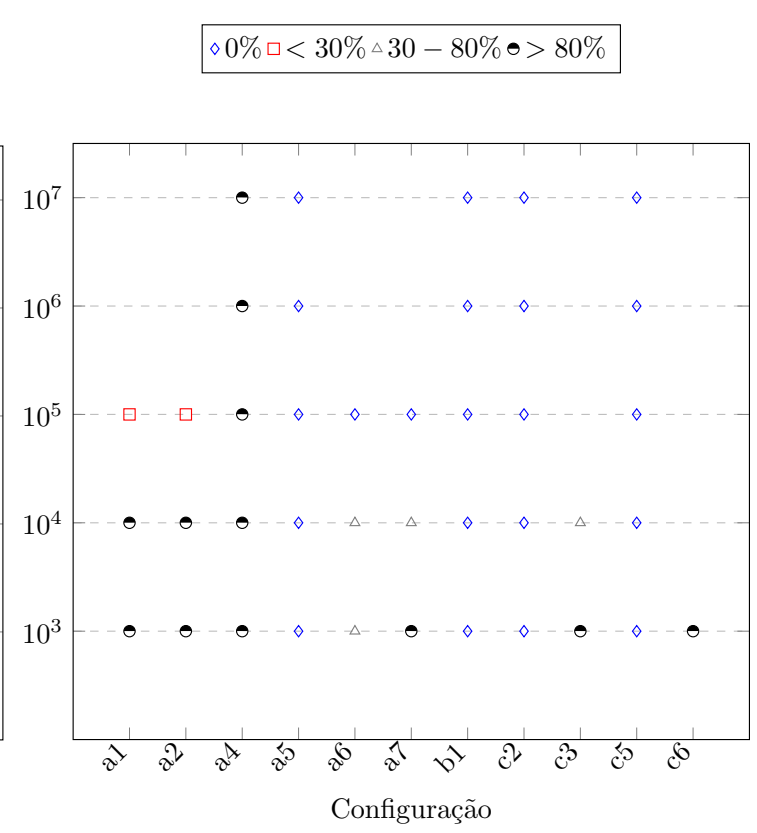

(b) Quantificação por Resolução

Figura 5.14: Resultados das configurações para a primeira variante de Granularidade Heterogênea (Fonte: Elaborado pelo autor)

A primeira variante apresentou alto fator de heterogeneidade, sendo avaliada pela Atividade 6 . O extenso domínio do atributo alvo e a exigência mínima de um atributo de referência desqualificaram aquelas configurações baseadas em representações discretas dos dados quantitativos - incluindo a3, e1, $d 1$ - ou com única dimensão disponível - $c 1$.

A propriedade posição novamente obteve os melhores resultados de detecção e quantificação, conforme destaca a Figura 5.14. Esses foram assegurados com o apoio da justaposição, do deslocamento espacial, do filtro e, principalmente, da compactação - ilustrada na Figura 5.15b.

$\mathrm{O}$ alto fator de heterogeneidade favoreceu os resultados das propriedades $s a$ turação/luminosidade e tamanho, embora ainda inferiores àqueles obtidos pela propriedade posição. A magnitude das instâncias heterogêneas e a baixa-moderada sobreposição entre dados homogêneos e heterogêneos permitiram ao participante observar - pela primeira vez - um defeito por meio das configurações $c 3$ e $c 6$, essa última observada na Figura 5.15a. Ainda, as referidas características dos dados reduziram o número de interações de aproximação na configuração $c 5$.

A representação de dados com heterogeneidade menos acentuada foi a característica da $2^{\underline{a}}$ variante. Apesar disso, certas configurações baseadas em posição apresentaram resultados aproximados àqueles discutidos na $1^{\underline{a}}$ variante, como revela a contraposição dos respectivos resultados nas Figuras 5.16 e 5.14. Essa proximidade é derivada do baixo número de regiões com tuplas homogêneas e heterogêneas sobrepostas, fato que salientou o padrão de heterogeneidade como observado na Figura 5.17b. 


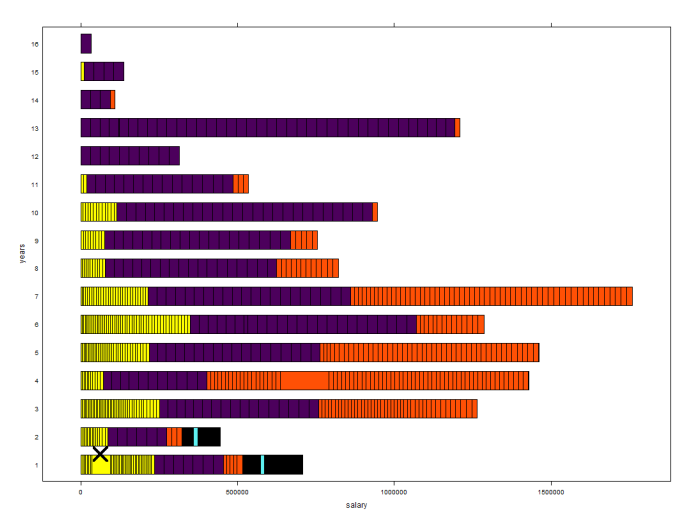

(a) Detecção por proporção parte-todo restrita a resolução de $10^{3}$ tuplas

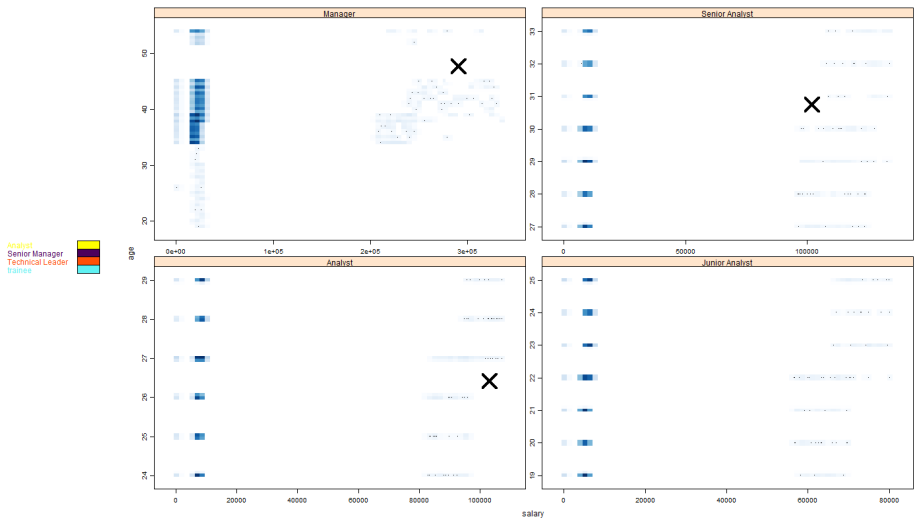

(b) Detecção com densidade em saturação e apoio da treliça em resolução de $10^{7}$ tuplas

Figura 5.15: Fragmentos visuais da avaliação da primeira variante de Granularidade Heterogênea (Fonte: Elaborado pelo autor)

A similaridade entre as variantes de granularidade heterogênea é presente na atividade de avaliação - Atividade 7. Tais atividades foram desiguais no grau de incoerência atribuído pelo participante na busca visual pelo padrão de heterogeneidade.

$$
\begin{aligned}
& T_{\text {Granularidade_Heterogênea }}= \\
&(\text { Buscar }(\text { desvio, arranjar.espaco, Empregado.salario } \sim \text { Empregado.*) } \Rightarrow \\
& \text { Correlacionar }(\text { parte }- \text { todo } \mid \text { desvio, arranjar.espaco|destacar, Empregado.salario } \sim \text { Empregado.* }) \Rightarrow \\
& \text { Buscar }(\text { incoerência, simplificar } \mid \text { abstrair, Empregado.salario } \sim \text { Empregado.* }) \Rightarrow \\
&\text { Correlacionar (alterna diferencas, arranjar.espaco|destacar, Empregado.salario } \sim \text { Empregado.*) })
\end{aligned}
$$

Atividade 7: Atividade de avaliação da segunda variante de Granularidade Heterogênea

Em contraste, a estrutura menos proeminente da heterogeneidade aumentou o esforço de análise realizada sobre as configurações baseadas em saturação/luminosidade e tamanho. A suavização do padrão do defeito em razão da média aritmética intensificou a exploração visual dos dados nas configurações $b 1$ e $c 5$, levando o participante assinalar um único caso defeituoso nas duas maiores resoluções. A questão da estrutura ainda provocou a perda da capacidade de detecção das configurações a6, a7, c3. Como exemplo, a superimposição dos dados da última configuração bloqueou a análise e a determinação dos parâmetros mais adequados para a filtragem, conforme observado na Figura 5.17a.

\subsubsection{Unidade de Estudo - Unidade de Medida Heterogênea}

Esse defeito denota valores de um atributo representados em quantidades físicas com diferentes magnitudes - Seção 4.4. Este estudo investigou uma variante de fator de heterogeneidade - distância entre a magnitude requerida e a defeituosa - inferior àquele 
- Detectou — Não Detectou

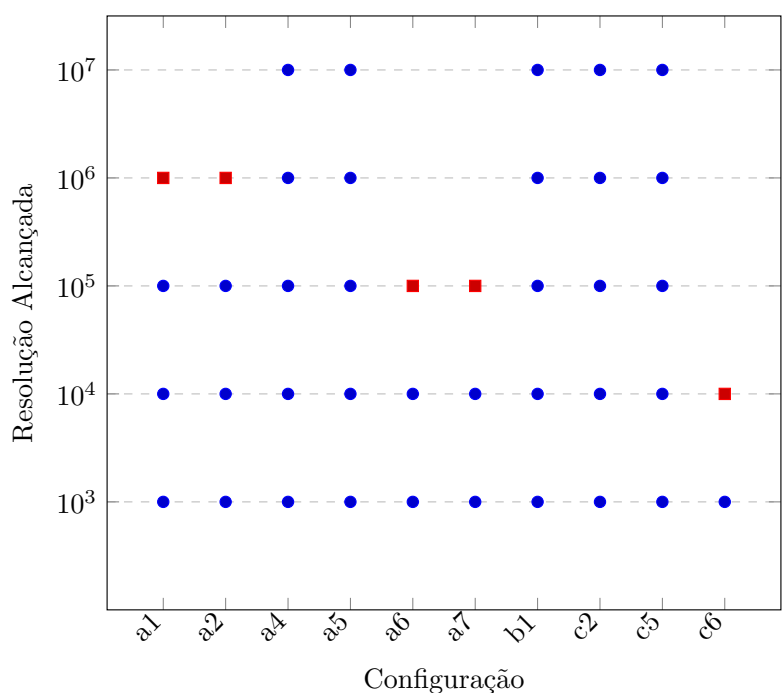

(a) Deteç̧ão por Resolução $\diamond 0 \% \square<30 \% \Delta 30-80 \% \bullet>80 \%$

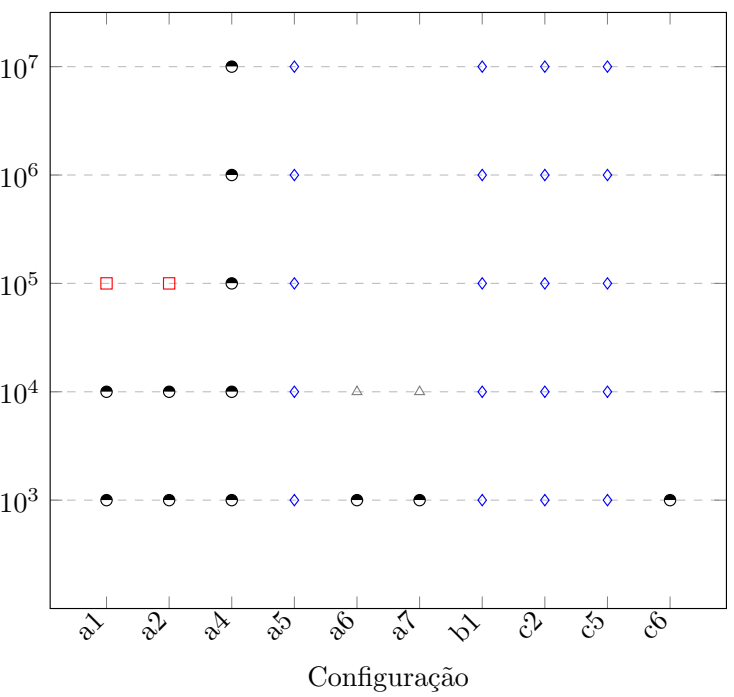

(b) Quantificação por Resolução

Figura 5.16: Resultados das configurações para a segunda variante de Granularidade Heterogênea (Fonte: Elaborado pelo autor)

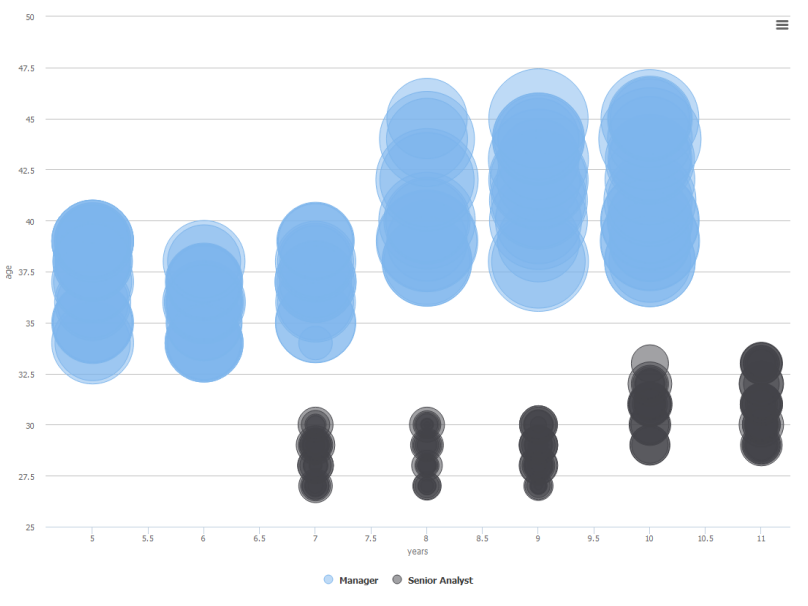

(a) Oclusão visual acentuada em tamanho proporcional ao valor em resolução de $10^{3}$ tuplas

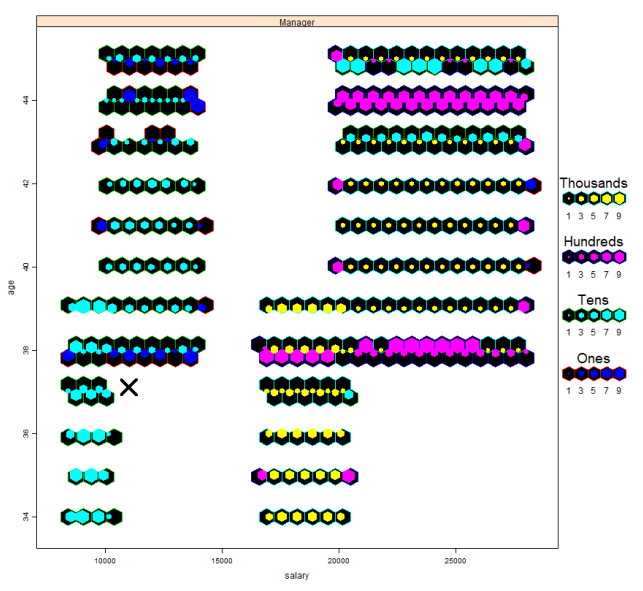

(b) Deteç̧ão e Quantificação com tamanho baseado em frequência e tonalidade em resolução de $10^{7}$ tuplas

Figura 5.17: Fragmentos visuais da avaliação da segunda variante de Granularidade Heterogênea (Fonte: Elaborado pelo autor)

adotado nos estudos envolvendo o defeito Granularidade Heterogênea - Quadros 5.2 e 5.4. Dessa forma, essa variante provocou regiões com sobreposição entre dados homogêneos e heterogêneos. 


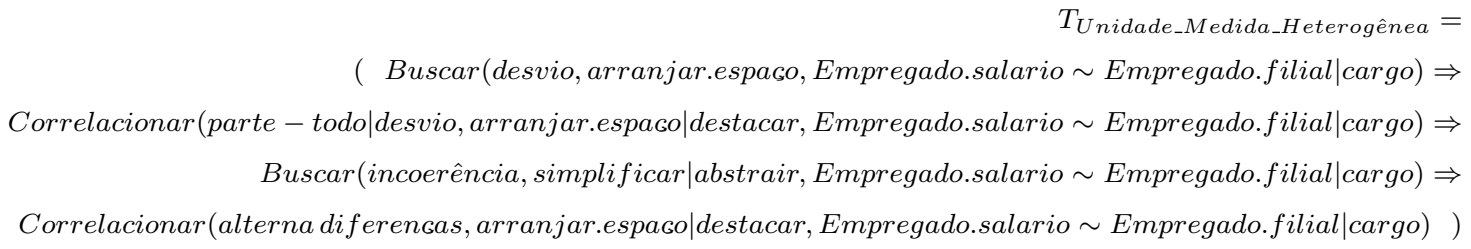

Atividade 8: Atividade de avaliação da Unidade de Medida Heterogênea

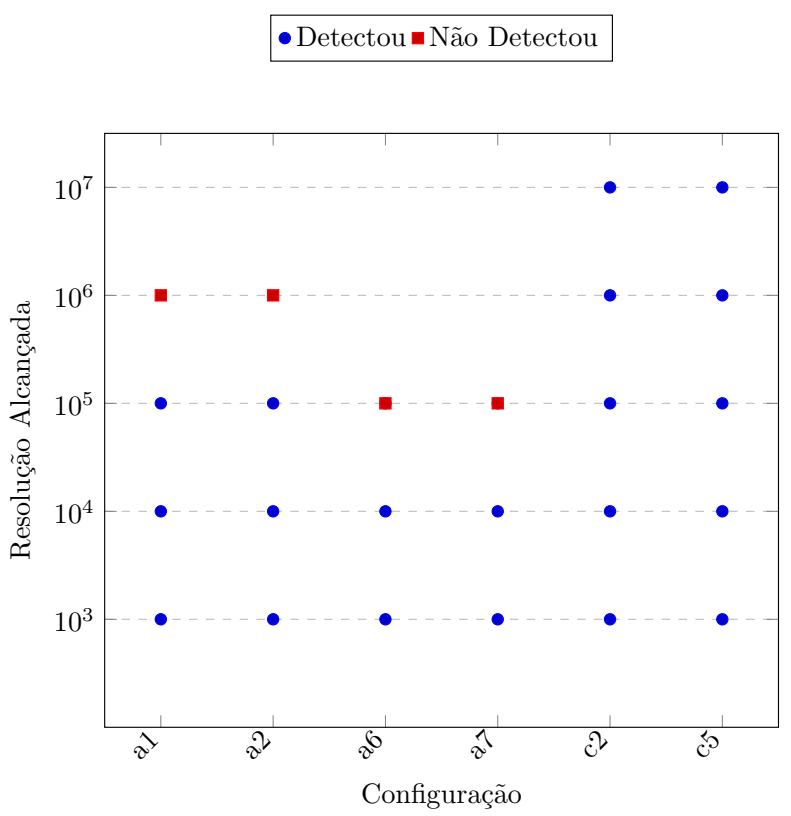

(a) Detecção por Resolução

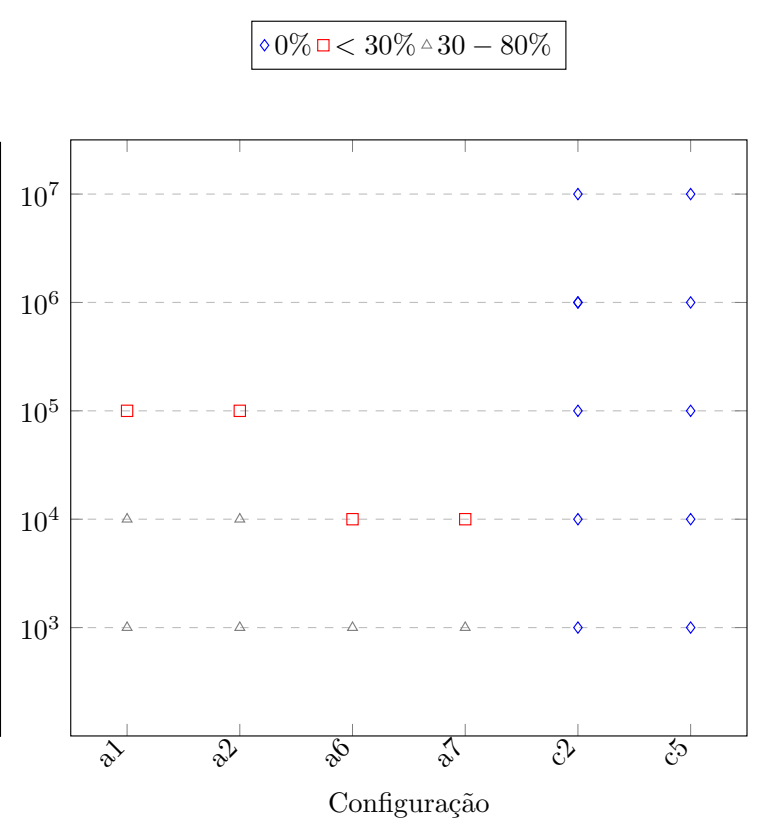

(b) Quantificação por Resolução

Figura 5.18: Resultados das configurações na avaliação da Unidade de Medida Heterogênea (Fonte: Elaborado pelo autor)

A análise do presente defeito - Atividade 8 - exigiu a manipulação de dois atributos categóricos e outro quantitativo de extenso domínio. Tais requisitos não foram satisfeitos por várias configurações, incluindo $a 3, a 4$, a5 e aquelas cuja propriedade base são baseadas em tonalidade e treliça.

Ademais, a ausência de elementos de referência - atributos ou relacionamentos - prejudicaram a percepção visual e a introspecção das instâncias heterogêneas entre as instâncias homogêneas. Logo, o resultado expresso na Figura 5.18a reflete a detecção majoritária das instâncias defeituosas nas regiões com reduzida ou nenhuma sobreposição.

Essas características dos dados impuseram a análise exploratória intensiva sobre as configurações baseadas em saturação/luminosidade e tamanho. A primeira não favoreceu o isolamento do padrão - mesmo com o uso do filtro - e levou ao assinalamento de falsos positivos em todas as resoluções. Na segunda, o participante realizou sucessivos recortes 


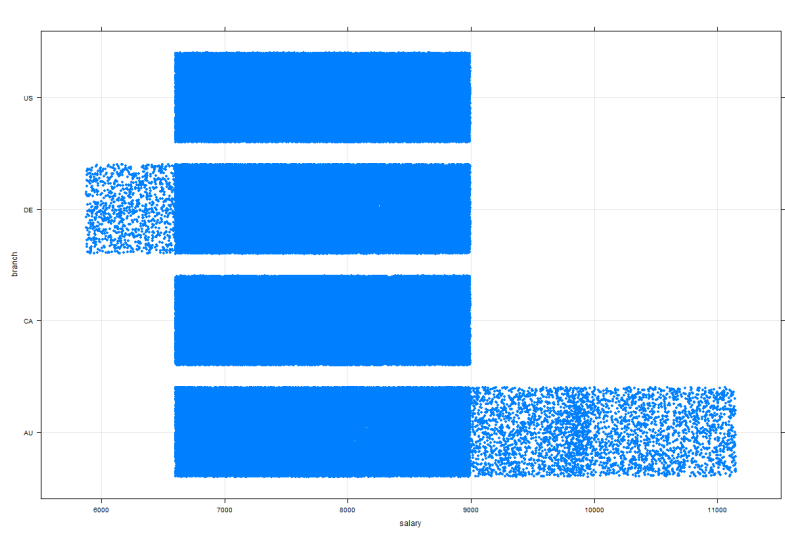

(a) Padrão é parcialmente revelado, mas análise é bloqueada por oclusão visual em resolução $10^{6}$

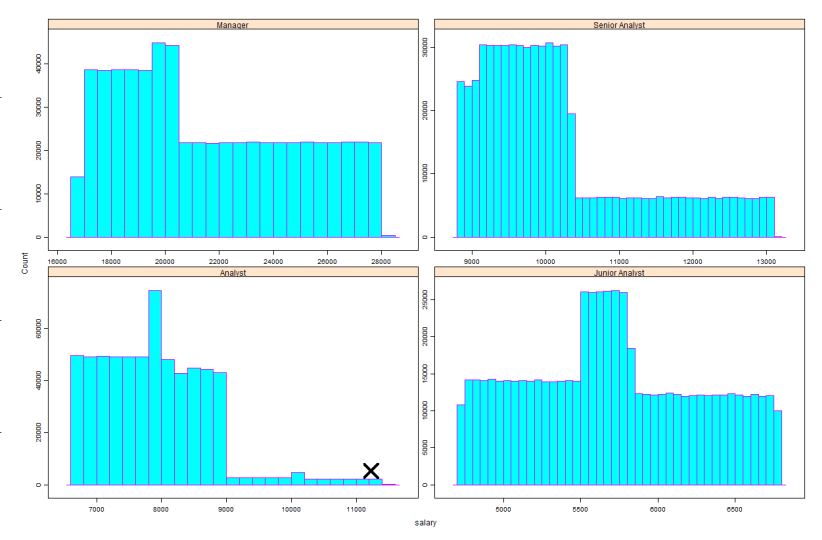

(b) Detecção com frequência apoiada por filtro $e$ treliça em resolução de $10^{7}$ tuplas

Figura 5.19: Fragmentos visuais da avaliação da Unidade de Medida Heterogênea (Fonte: Elaborado pelo autor)

nos dados por filial ou cargo até o isolamento de certos padrões de heterogeneidade, caso da configuração c2 ilustrada na Figura 5.19b. De modo semelhante, a configuração c5 exigiu sete operações de aproximações - em média - para revelar algumas das instâncias heterogêneas. Tais resultados corroboram as limitações da propriedade tamanho em prover a percepção acurada de flutuações suaves em dados quantitativos [Kosslyn, 2006; Yang et al., 2014].

Certas configurações baseadas em posição - a1, a2, a6, ał - proporcionaram um moderado apoio as avaliações de instâncias heterogêneas por meio da combinação do filtro e disposição espacial. Contudo, a oclusão visual com resoluções de dados mais expressivas - ilustrada na Figura 5.19a - limitou tais configurações as menores resoluções de dados, conforme abordado em unidades de estudo anteriores e observado na Figura 5.18a.

\subsubsection{Unidade de Estudo - Referência Ausente e Incorreta}

Relacionamentos inconsistentes constituem o objetivo de análise compartilhado pelos defeitos de Referência Incorreta e Ausente, conforme observado na Atividade 9. O primeiro denota a representação de relacionamentos inexistentes no UdD, enquanto o segundo expressa o caso oposto - Seção 4.4. Os resultados desses defeitos são reportados conjuntamente devido a proximidade. Especificidades serão destacadas, quando necessário. Somente certas configurações da classe grafos - Figura 5.20 - foram capazes de explicitar a estrutura de relacionamentos defeituosos por meio da imposição em rede, corroborando os estudos de [Bertin, 1983; Ware, 2004]. De fato, os grafos são fundamentais na representação de estruturas nos dados [Herman et al., 2000; Schulz et al., 2011]. 


$$
\begin{aligned}
& T_{\text {Referência }}= \\
& \text { ( Buscar(desvio, arranjar.espaco, Cliente.clienteid|conjugeid } \sim \text { Cliente. } *) \Rightarrow \\
& \text { Correlacionar (parte - todo|desvio, arranjar.espaco|destacar, Cliente.clienteid|conjugeid } \sim \text { Cliente.*) } \Rightarrow \\
& \text { Buscar (incoerência, simplificar|abstrair, Cliente.clienteid|conjugeid } \sim \text { Cliente. } *) \Rightarrow \\
& \text { Correlacionar (discrepante, arranjar.espaco|destacar, Cliente.clienteid|conjugeid } \sim \text { Cliente.*) ) }
\end{aligned}
$$

Atividade 9: Atividade de avaliação dos defeitos de referência ausente e incorreta

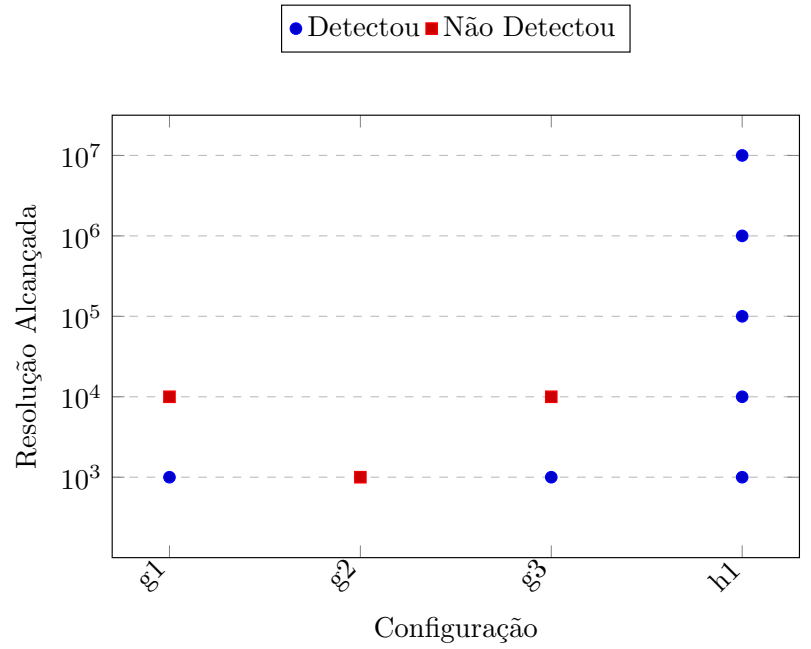

(a) Detecção por Resolução

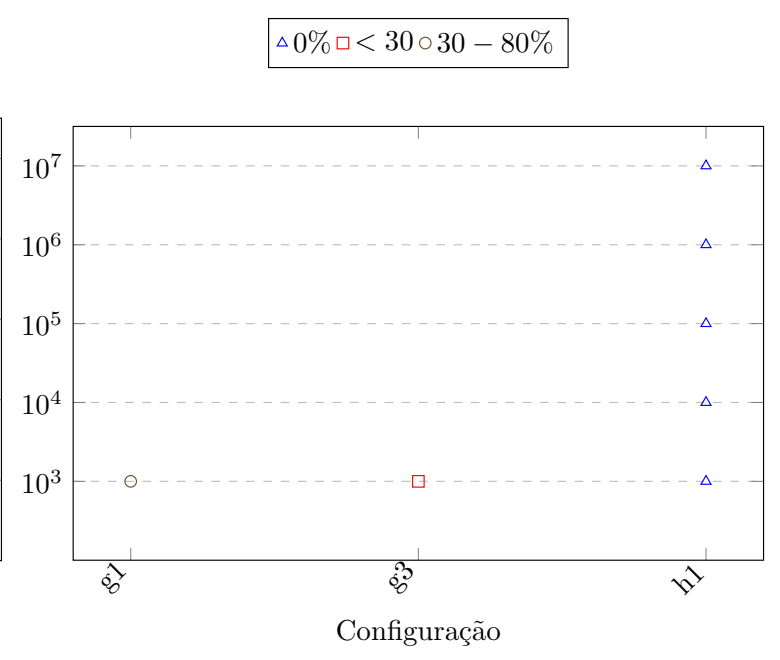

(b) Quantificação por Resolução

Figura 5.20: Resultados das configurações para referência ausente e incorreta (Fonte: Elaborado pelo autor)

A ausência de elementos de referências na configuração g2 - grafo não rotulado - inibiu a extração de significados capazes de determinar a presença dos defeitos de referência. Igualmente inadequado, o grafo não dirigido retilíneo - configuração g3 - obrigou o participante a realizar várias transições visuais devido ao limite de representação de 100 tuplas. Esse limite provocou os mesmos problemas da configuração $f 1$ discutida na Seção 5.4.1. Em contraste, a Figura 5.21a ilustra o grafo radial dirigido - configuração $g 1$ - que representa atributos de referência, a direção dos relacionamentos e o arranjo espacial aprimorado pela técnica Fruchterman-Reingold [Fruchterman e Reingold, 1991]. Essa composição facilitou a detecção e a quantificação majoritária dos relacionamentos defeituosos em virtude da impressão de fluidez e ausência de interrupções - princípio da continuidade ${ }^{7}$-, mas restrita a menor resolução de dados. A ausência de atributos de referência - ou outros recursos - impediu a exploração e detecção daqueles relacionamentos de casamentos que não existem no UdD.

\footnotetext{
${ }^{7} \mathrm{O}$ princípio da continuidade denota a tendência da visão humana em seguir uma direção determinada por um objeto até alcançar outro [Matlin, 2009]
} 


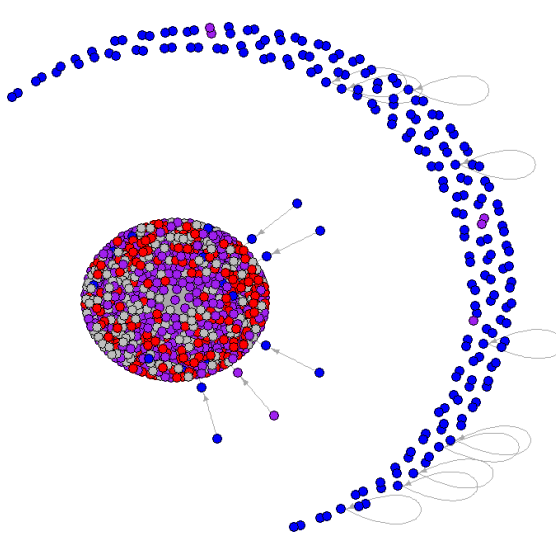

(a) Deteç̧ão e Quantificação com conexão radial dirigida em resolução $10^{3}$ tuplas

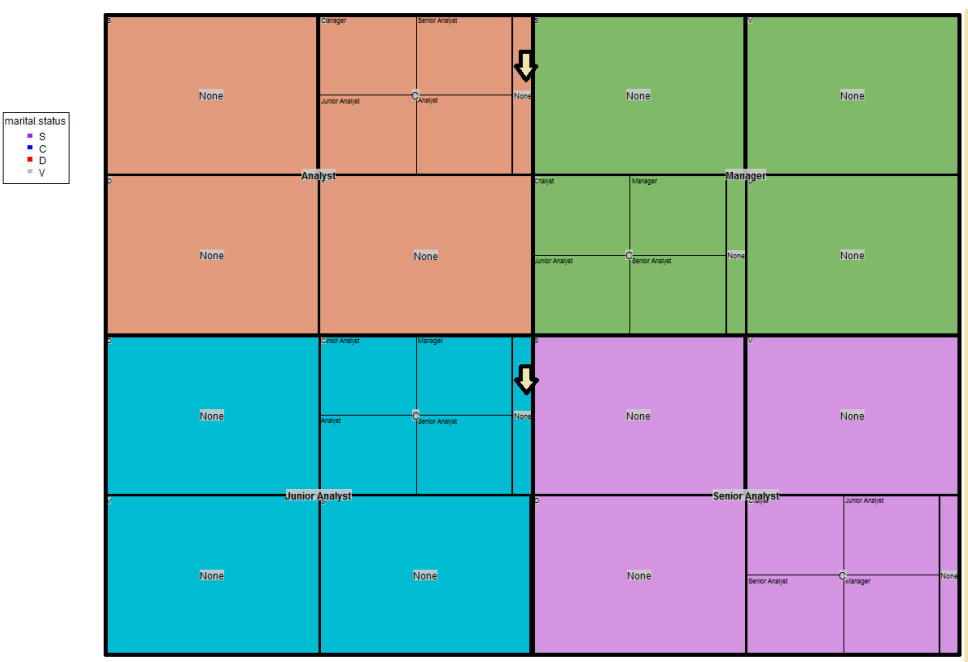

(b) Deteç̧ão de relacionamentos defeituosos em quatro niveis de hierarquização na resolução $10^{7}$ tuplas

Figura 5.21: Fragmentos visuais da avaliação de referência ausente e incorreta

(Fonte: Elaborado pelo autor)

A abordagem de divisão e preenchimento dos espaços da configuração h1 - Figura 5.21b proporcionou a visão global e uniforme dos dados em todas as resoluções, mas foi menos apropriada do que o grafo dirigido. O participante utilizou duas interações de aproximação em média para explorar a estrutura hierárquica - mesmo em baixa resolução de dados. No entanto, essas interações não foram suficientes para detectar as instâncias com autorelacionamentos ou com relacionamentos unidirecionais.

\subsubsection{Unidade de Estudo - Defeitos sem Evidência Visual}

Certos defeitos nos dados não foram relacionados a quaisquer propriedades visuais uma vez que suas estruturas não são visualmente perceptíveis. No caso dos defeitos Tupla Ausente e Tupla Sobrecarregada, a busca visual foi inócua uma vez que os fatos sobre os objetos do UdD alvos da avaliação sequer estavam representados na relação avaliada. Tuplas Duplicadas apresentam uma variedade intrincada de combinações que podem denotar uma duplicação em potencial cuja detecção é difícil mesmo para abordagens computacionais [Fan e Geerts, 2012; Ganti e Sarma, 2013].

Outros defeitos como Valor Incorreto, Valores Sinônimos e Valores Homônimos poderiam ser visualmente detectados em baixas resoluções e em atributos com domínio reduzido - menor do que $10^{3}$ tuplas e até 10 elementos distintos, respectivamente -, conforme observado na Figura 5.22. No entanto, essa avaliação baseada em esforço cognitivo é impraticável em cenários reais envolvendo maiores resoluções de dados. 


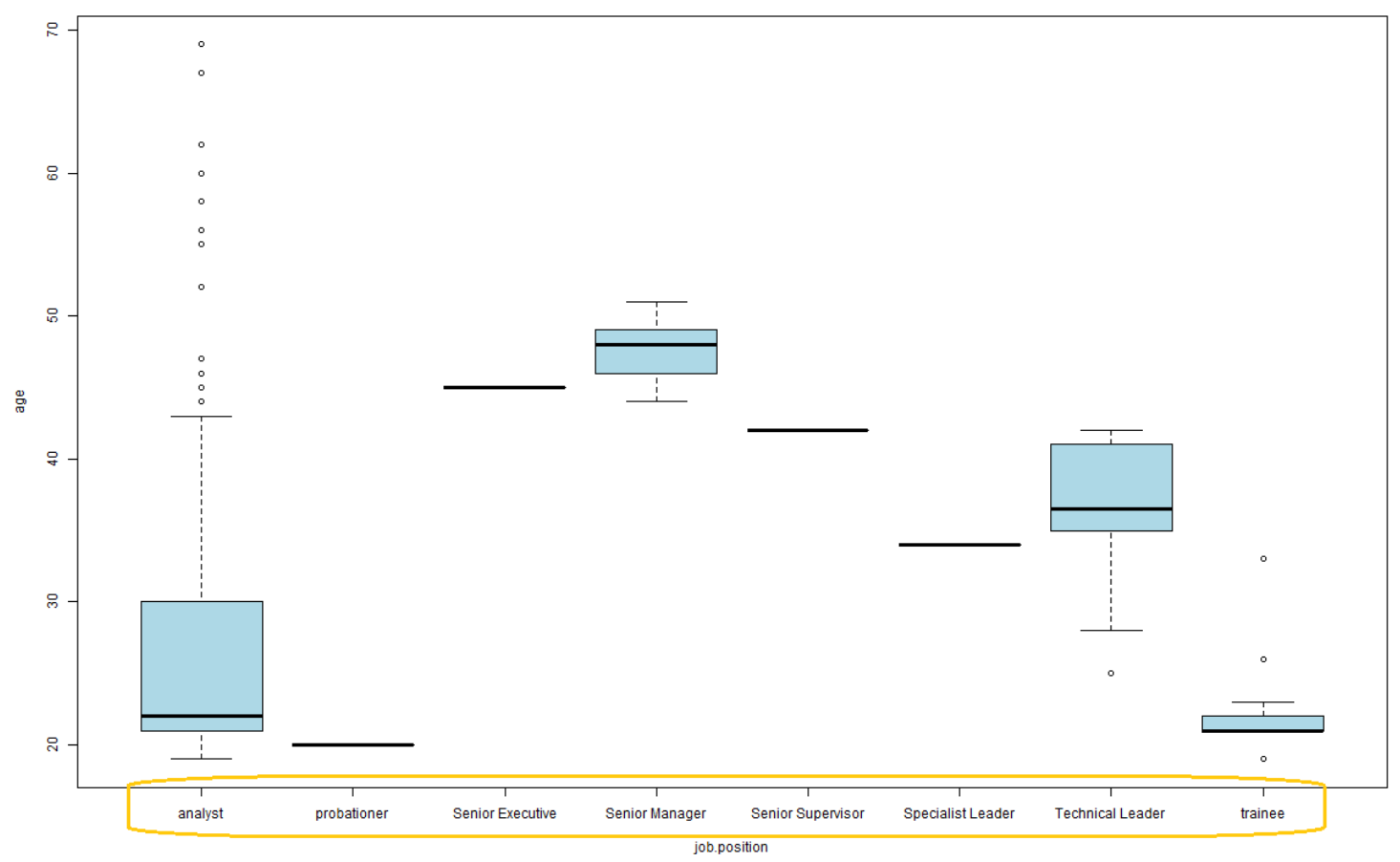

Figura 5.22: Valores sinônimos destacados em pequeno conjunto de vernáculos (Fonte: Elaborado pelo autor)

\subsection{Limitações do Estudo de Caso}

Essa seção descreve as principais limitações do presente estudo de caso. Uma delas remete ao conjunto de técnicas de visualização e interação utilizadas. Apesar de representativo, esse conjunto não observou a contribuição de certas propriedades visuais - textura, pixel e superfície -, visões concorrentes múltiplas, matrizes de telas ${ }^{8}$, visualizações embutidas ${ }^{9}$, mecanismos de normalização dos dados e derivação de dados determinadas por expressões ou modelos de relacionamento - por exemplo, modelos de regressão simples e linear. Ainda, não houve a possibilidade de selecionar tonalidades conforme a preferência, bem como o modelo de cor aplicado não é tão próximo a percepção humana quanto o modelo CIELab [Silva et al., 2011].

As influências do grau de familiaridade, da estética, da acuidade visual e do estilo cognitivo não foram mensuradas visto que excedem o escopo estabelecido. Contudo, as notas coletadas durante as sessões indicaram variações de esforço do participante com certas técnicas de visualização. Recursos adicionais como colaboração, utilização de bases de conhecimento e efeitos de aprendizagem representam temas de pesquisa futuros.

Relações com defeitos isolados e controlados são incomuns em cenários reais de diferentes organizações. Por isso, os resultados desse estudo de caso podem sofrer as influências

\footnotetext{
${ }^{8}$ Matriz de telas coordenadas escala a decodificação visual por meio da exposição dos dados em imagem do tamanho de uma parede arranjada em um conjunto coordenado de telas [Shneiderman, 2008].

${ }^{9}$ Uma visualização embutida é composta por uma técnica de visualização principal e uma ou mais técnicas secundárias distintas [Heer e Shneiderman, 2012].
} 
da complexa interdependência entre certos defeitos - Seção 2.2.3.3 e da variação das características dos dados defeituosos. Essas influências remetem a redução ou aumento nas capacidades de detecção e quantificação das propriedades.

No entanto, a estratégia de geração controlada dos dados foi muito relevante a consecução dos objetivos do presente estudo de caso por: i) garantir a atenção do participante a atividade de avaliação particular de um defeito, ii) permitir o controle das características e das semânticas dos dados, iii) favorecer a reunião de notas e observações qualitativas sobre a avaliação de cada defeito nas diferentes representações visuais.

\subsection{Conclusão}

Os resultados do presente estudo de caso revelaram relacionamentos entre certas propriedades dos sistemas de visualização e estruturas de defeitos nos dados que exigem alta supervisão humana, conforme descrito na Seção 5.6.1. Tais resultados permitiram a este trabalho prover as primeiras respostas as questões relativas a avaliação visual da qualidade dos dados não abordadas pelo estado-da-arte da literatura da área de visualização - Seção 3.5. A relevância dos relacionamentos propriedade-defeito para o diagnóstico da qualidade dos dados é discutida na Seção 5.6.2.

\subsubsection{O Relacionamento Propriedade-Defeito}

Os relacionamentos propriedade-defeito explicitam conjuntos de propriedades visuais e interativas que beneficiam a avaliação visual de diferentes defeitos em certas resoluções de dados, conforme observado na Tabela 5.3. Nessa tabela, a coluna "Nível de Resolução" denota a mais alta resolução de dados - em $10^{N}$ - na qual a detecção de um defeito foi possível. Cada coluna de defeito nos dados - e variantes correspondentes, quando aplicável - está relacionada a um fator de capacidade de quantificação. Tal fator é baseado na expressão $\left(\sum_{i=1}^{j}\right.$ valor $\left._{i} / \sum_{i=1}^{j} 4\right)$, onde $j$ é o número de resoluções de dados quantificadas e valor representa o peso - 1 para $0 \%$ até 4 para $>80 \%$ - de acordo com o grau de quantificação para cada defeito - Seção 5.3.7. Por exemplo, os fatores das configurações g1,g3 e $h 1$ para o defeito Referência Ausente foram $0.75(3 / 4), 0.5(2 / 4)$ e 0.25 (5/20), respectivamente.

Os relacionamentos discutidos a seguir não são prescritivos, mas proporcionam a primeira orientação para o projeto de sistemas de visualização mais aderentes as necessidades da avaliação visual da qualidade de dados. Cumpre ressaltar que as características dos dados avaliados - tipo, distribuição, extensão do domínio - devem ser considerados no projeto à medida que afetam as capacidades das propriedades, conforme discutidos em certas unidades de estudo. Além disso, certos relacionamentos dependem da disponibilidade de elementos de referência - atributos, relacionamentos, dentre outros - que favoreçam a 


\begin{tabular}{|c|c|c|c|c|c|c|c|c|c|c|c|c|}
\hline Propriedade Base & 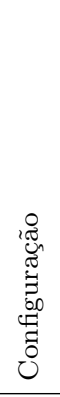 & 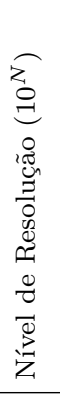 & 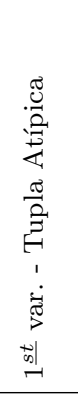 & 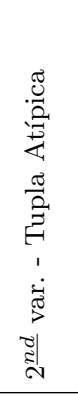 & 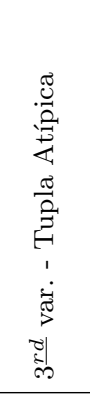 & 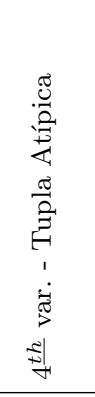 & 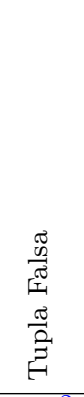 & 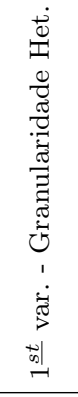 & 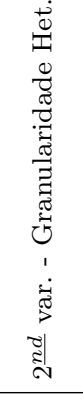 & 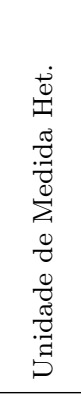 & 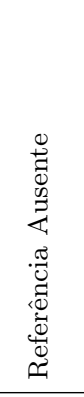 & 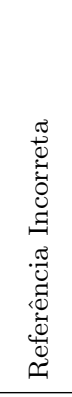 \\
\hline \multirow[t]{7}{*}{ Posição } & a1 & 5 & ++ & ++ & + & + & $++^{2}$ & ++ & ++ & + & $\cdot$ & $\cdot$ \\
\hline & $\mathrm{a} 2$ & 5 & ++ & ++ & + & + & ++ & ++ & ++ & + & . & $\cdot$ \\
\hline & a3 & 7 & -- & -- & $\cdot$ & $\cdot$ & $\cdot$ & $\cdot$ & $\cdot$ & $\cdot$ & · & $\cdot$ \\
\hline & $\mathrm{a} 4$ & 7 & ++ & ++ & ++ & + & ++ & ++ & ++ & . & $\cdot$ & $\cdot$ \\
\hline & a5 & 7 & -- & -- & -- & -- & ++ & -- & -- & $\cdot$ & . & . \\
\hline & a6 & 5 & ++ & + & $++^{1}$ & $+^{1}$ & $\cdot$ & + & $++^{1}$ & $+^{1}$ & . & . \\
\hline & a7 & 5 & ++ & + & $++^{1}$ & $++^{2}$ & $++^{2}$ & + & $++^{1}$ & $+^{1}$ & . & . \\
\hline $\begin{array}{l}\text { Saturação e } \\
\text { Luminosidade }\end{array}$ & b1 & 7 & -- & -- & -- & \multicolumn{6}{|c|}{ Luminosidade } & $\cdot$ \\
\hline \multirow[t]{6}{*}{ Tamanho } & $\mathrm{c} 1$ & 7 & -- & -- & $\cdot$ & $\cdot$ & $\cdot$ & $\cdot$ & $\cdot$ & $\cdot$ & $\cdot$ & $\cdot$ \\
\hline & $\mathrm{c} 2$ & 7 & -- & -- & -- & $\cdot$ & ++ & -- & -- & -- & $\cdot$ & $\cdot$ \\
\hline & c3 & 4 & $\cdot$ & $\cdot$ & $\cdot$ & $\cdot$ & $\cdot$ & ++ & $\cdot$ & $\cdot$ & . & $\cdot$ \\
\hline & $\mathrm{c} 4$ & $\oslash$ & & & & & . & & & & & \\
\hline & c5 & 7 & -- & -- & -- & -- & . & -- & -- & -- & · & $\cdot$ \\
\hline & c6 & 3 & $\cdot$ & $\cdot$ & $\cdot$ & $\cdot$ & . & ++ & ++ & $\cdot$ & $\cdot$ & $\cdot$ \\
\hline \multirow[t]{3}{*}{ Tonalidade } & $\mathrm{d} 1$ & 5 & + & + & $\cdot$ & $\cdot$ & $\cdot$ & $\cdot$ & $\cdot$ & $\cdot$ & $\cdot$ & $\cdot$ \\
\hline & $\mathrm{d} 2$ & 5 & ++ & ++ & . & $\cdot$ & . & $\cdot$ & $\cdot$ & $\cdot$ & $\cdot$ & $\cdot$ \\
\hline & d3 & 3 & ++ & ++ & $\cdot$ & $\cdot$ & $\cdot$ & . & $\cdot$ & $\cdot$ & $\cdot$ & $\cdot$ \\
\hline \multirow[t]{3}{*}{ Treliça } & e1 & 7 & ++ & + & $\cdot$ & $\cdot$ & $\cdot$ & $\cdot$ & $\cdot$ & $\cdot$ & $\cdot$ & $\cdot$ \\
\hline & $\mathrm{e} 2$ & 7 & + & + & . & . & . & . & . & $\cdot$ & . & $\cdot$ \\
\hline & e3 & 7 & -- & -- & $\cdot$ & . & . & . & $\cdot$ & . & . & $\cdot$ \\
\hline Forma (Ícone) & f1 & $\oslash$ & $\cdot$ & $\cdot$ & $\cdot$ & $\cdot$ & $\cdot$ & $\cdot$ & $\cdot$ & $\cdot$ & $\cdot$ & $\cdot$ \\
\hline \multirow[t]{3}{*}{ Conexão } & g1 & 3 & & & & & & & & & ++ & ++ \\
\hline & g2 & $\oslash$ & & & & & & & & & $\cdot$ & $\cdot$ \\
\hline & g3 & 2 & & & & & & & & & + & + \\
\hline Hieraquia Recursiva & h1 & 7 & & & & & & & & & -- & -- \\
\hline \multicolumn{13}{|c|}{$\begin{array}{l}\text { Fator de Capacidade de Quantificação }:++ \text { para }[0.75,1],+ \text { para }[0.5,0.75),- \text { para }[0.3,0.5),-- \text { para }[0,0.3) \text {, } \\
\text { (ponto) para não detectado, espaço em branco para não estudado }\end{array}$} \\
\hline 1: Restrito para resolu & ões d & dad & s de at & $10^{4} \mathrm{t}$ & & & & & & & & \\
\hline
\end{tabular}

Tabela 5.3: Resumo da relação propriedade-defeito baseados nas configurações (Fonte: Elaborado pelo autor)

introspecção relativa a estrutura de um defeito, caso contrário o defeito pode não ser revelado visualmente.

A propriedade posição proporcionou o apoio mais apropriado a avaliação visual da qualidade de dados por meio da preservação espacial dos padrões dos defeitos nos dados, particularmente nos casos envolvendo análises de dados quantitativos - corroborando [Bertin, 1983; Mackinlay, 1986]. Essa propriedade combinada a compactação possibilitou análises em resoluções de dados superiores ao limite de $10^{5}$ tuplas sustentado pela distorção espacial e mudança de opacidade - limites que corroboram [Hoffman, 1999; Unwin et al. , 2006]. Dentre as configurações baseadas em posição e desprovidas de compactação, a 
codificação da posição em pontos foi superior a codificação em linha. Essa última apresenta uma tendência para sobreposição de linhas que não foi contornada pela mudança de opacidade, fato que dificulta o julgamento de orientação e declive conforme destacado em [Grinstein et al., 2002; Unwin et al., 2006; Ward e Theroux, 1997].

As propriedades tonalidade e treliça obstruíram quase todas as atividades de avaliação cujos atributos alvos apresentavam domínios extensos. Tal efeito é devido a difusão dos valores em múltiplas cores e a alta densidade visual dos painéis de treliça, nessa ordem. Em contraste, tais propriedades foram adequadas para categorizar os dados por meio de atributos de referência - domínios de 10 e 70 elementos distintos, respectivamente - e favorecer as correlações e comparações. Esses resultados corroboram os pontos fortes e fracos revelados por trabalhos anteriores em relação a tonalidade [Silva et al., 2011] e a treliça [Kehrer et al., 2013; Unwin et al., 2006].

A propriedade saturação/luminosidade dificultou a interpretação de valores absolutos ou relações numéricas a partir do mapa de referência tonalidade-magnitude, corroborando [Bertin, 1983]. Como exemplo, essa propriedade levou o participante assinalar diferentes falsos-positivos nos casos envolvendo a análise de dados com pequena disparidade entre valores defeituosos e não defeituosos. No entanto, a saturação/luminosidade superou a propriedade posição nas análises longitudinais da flutuação da magnitude dos valores em razão da justaposição dos dados. Esse arranjo visual dos dados parece ter facilitado a detecção de significados do defeito Tupla Falsa, embora a preferência do participante não tenha sido coletada.

A interpretação quantitativa por meio da propriedade tamanho também foi difícil. Suas configurações baseadas em compactação impuseram a utilização intensiva da aproximação, do filtro ou do redimensionamento de intervalos, segundo a complexidade da atividade e a resolução dos dados. Essa situação foi parcialmente causada pela distorção da média aritmética - configuração c5 - e pelos intervalos de particionamento dos valores - configuração $c 1$. Por outro lado, as configurações baseadas em tamanho e desprovidas de compactação sofreram com a oclusão visual - configurações $c 3, c 4$ - ou dificultaram o julgamento e a comparação das magnitudes - especialmente para valores com pequena disparidade - devido a necessidade de julgar o comprimento sobre um eixo de valores acumulados - configuração c6. Esse último resultado corrobora estudos prévios em [Yang et al., 2014].

A configuração baseada em forma foi inadequada para avaliar todos os defeitos nos dados. Essa demandou uma intensiva transição entre representações visuais devido seu limite de representação de até 150 tuplas por vez. Tal situação foi agravada pelo fato das características das formas serem determinadas a partir dos dados exibidos, obstruindo a avaliação do participante. Esses resultados desviaram daqueles apresentados por [Rusu et al., 2009; Ward e Theroux, 1997] que apontaram os ícones como adequados a deteç̧ão da $1^{\underline{a}}$ variante de tuplas atípicas. 
As propriedades hierarquia recursiva e conexão presentes nos grafos foram adequadas na compreensão de instâncias de relacionamentos defeituosos, mas com diferentes capacidades. Dentre as configurações baseadas em conexão, o grafo dirigido radial com uma dimensão - configuração $g 1$ - proporcionou a avaliação mais intuitiva das referidas instâncias restrito a resolução de $10^{3}$ tuplas ao atender o princípio da continuidade - Seção 5.4.5. As demais configurações baseadas em conexão foram inadequadas devido a ausência de atributos de referência ou de arestas dirigidas.

De outro modo, a configuração baseada na hierarquia recursiva ofereceu uma visão uniforme em todas as resoluções de dados por meio da divisão recursiva do espaço visual baseada nos atributos analisados. Apesar disso, essa propriedade apresentou oclusão severa para atributos com extensos domínios, inibiu a detecção de relacionamentos unidirecionais e demandou um esforço maior de detecção comparado àquele do grafo dirigido radial. Embora este trabalho não tenha reunido dados relativos a efeitos de raciocínio - reasoning effects -, o resultado da propriedade hierarquia recursiva pode ter sido influenciado pela adoção de uma linha de pensamento baseado em fluxo por parte do participante.

Para todos os defeitos, o filtro e a aproximação geométrica foram indispensáveis para o refinamento fácil e contínuo dos dados às regiões de interesse da análise em questão. Observações registradas em diferentes unidades de estudo sugerem a necessidade de filtros com flexibilidade de especificar múltiplos predicados logicamente concatenados. Tal flexibilidade foi especialmente importante nas atividades de avaliação envolvendo análise visual intensiva ou atributos com domínios extensos. Esses resultados completam estudos anteriores [Grinstein et al., 2002; Marghescu, 2008; Ward e Theroux, 1997] que não avaliaram a contribuição das técnicas de interação. Cumpre também ressaltar a relevância do arranjo de atributos ao facilitar as atividades de avaliação por meio da disposição adjacente dos atributos de interesse, corroborando [Pirolli e Rao, 1996].

O alinhamento entre o número de atributos - ou dimensões - disponíveis em uma representação visual e o espaço de dados designado pela atividade de avaliação foi igualmente essencial para todos os defeitos. O desalinhamento - número de atributos das atividades de avaliação superior àqueles oferecidos pela técnica de visualização - afetou a efetividade da avaliação da qualidade uma vez que impôs ao participante a carga cognitiva de manter e integrar fatos entre as transições de rearranjo dos dados. Esses resultados corroboram trabalhos anteriores por [Card et al., 1999; Mackinlay, 1986; Ware, 2004].

\subsubsection{A Aplicação Prática da Relação Propriedade-Defeito}

Construir sistemas de visualização envolve a complexa combinação de propriedades selecionadas dentre várias possibilidades. Posto que a maneira como as pessoas utilizam tais sistemas afeta os resultados de processos analíticos, somente a combinação de certas propriedades provê o apoio apropriado a tais processos [Sedig et al., 2014; Tory e Moller 
, 2004; Ware, 2004]. Logo, fatores humanos representam elementos chave para o projeto de sistemas de visualização.

Uma das formas de considerar fatores humanos é selecionar as propriedades dos sistemas de visualização segundo as especificidades das atividades de um domínio, como aquelas da avaliação visual da qualidade de dados [Bertin, 1983; Tory e Moller, 2004; Ware, 2004]. A ausência da correspondência entre as representações visuais e o objetivo de uma atividade - conforme discutido nas Seções 2.4.3 e 5.3 - impede o agente avaliador da qualidade de responder a diferentes indagações por meio das referidas representações visuais [Mackinlay , 1986; Patterson et al., 2014; Thomas e Cook, 2005; Tory e Moller, 2004; Ware, 2010]. Tal fato denota a importância de toda visualização de dados favorecer a percepção dos significados requeridos ao desempenho de uma atividade.

Conforme detalhado na Seção 2.2.3, a atividade de avaliação da qualidade dos dados mapeia os defeitos nos dados por meio de três tarefas interdependentes. Para essa atividade, os sistemas de visualização apoiam as tarefas de busca e diagnóstico por meio de duas abordagens principais: Quality-Aware e Visual Diagnosis-Driven.

A abordagem Quality-Aware denota o uso de recursos computacionais semi ou não supervisionados baseados em asserções ou métodos quantitativos para extrair padrões de conformidade ou assinaturas matemáticas dos dados, respectivamente. Representações visuais comunicam essas informações de qualidade por meio de glifos, rótulos ou destaques visuais, evidenciando o controle exógeno discutido na Seção 2.4.3. Tais características são relevantes para defeitos que demandam baixa-moderada supervisão humana - Seção 2.2.3.3 - ou cujas estruturas não são visualmente perceptíveis - Seção 5.4.6.

A abordagem informacional do Quality-Aware requer conhecimentos técnicos e semânticos para selecionar e parametrizar os recursos apropriados a detecção de cada defeito [Dasu e Johnson, 2003; Rahm e Do, 2000]. Naturalmente, a apreciação humana dos potencias problemas de qualidade computados por tais recursos é necessária. À medida que esse procedimento pode envolver vários ajustes, a exposição dessas informações em qualquer visualização inibe a avaliação do recurso e, subsequentemente, da própria avaliação da qualidade dos dados.

A Figura 5.23 apresenta dois sistemas de visualização que exemplificam a circunstância supracitada. Aquele observado na Figura 5.23b facilitou a análise das tuplas potencialmente duplicadas - raias 2 e 4 - por meio do detalhamento dos respectivos relacionamentos a outras tuplas. Conforme discutido na Seção 5.6.1, defeitos que remetem a relacionamentos entre tuplas são melhores avaliados por grafos.

Em contraste, o sistema da Figura 5.23a representou os potencias duplicados de modo inconclusivo. Note que não é claro se todas as tuplas destacadas representam a mesma duplicação, bem como o espaçamento utilizado obstruí a correlação entre as tuplas ao violar ao princípio da proximidade - Seção 3.3.4.3.2.

Visto que as propriedades das visualizações determinam quais significados podem ser de- 


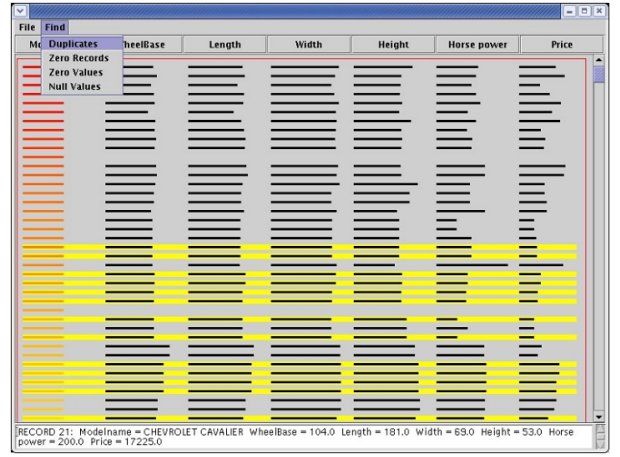

(a) DaVis (Fonte: [Sulo et al., 2005])

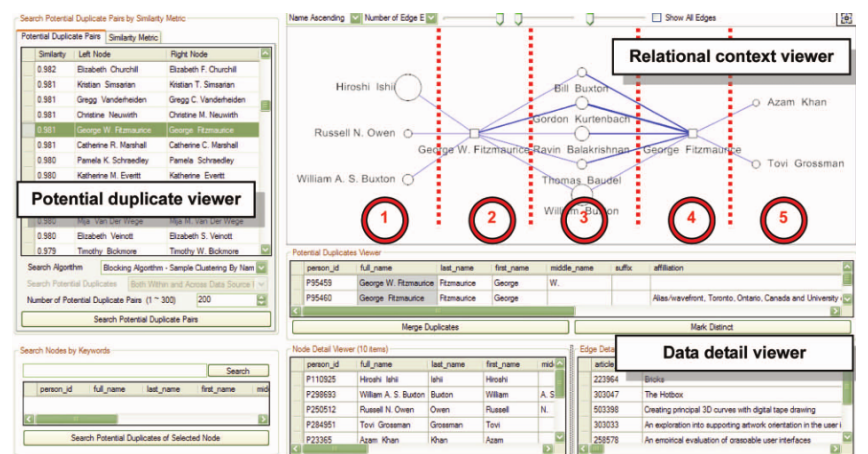

(b) D-DUPE (Fonte: [Kang et al., 2008])

Figura 5.23: Tuplas potencialmente duplicadas comunicadas por abordagens computacionais

las extraídos [Bertin, 1983; Card et al., 1999], o exemplo acima corrobora a relevância do relacionamento propriedade-defeito para a abordagem Quality-Aware. De fato, o alinhamento entre as propriedades que favorecem a percepção da estrutura do defeito e as informações de qualidade computadas podem alavancar a avaliação da qualidade dos dados.

De outro modo, a abordagem Visual Diagnosis-Driven denota o uso intensivo da análise visual de significados para determinar dados defeituosos. Essa abordagem permite moldar, explorar, criticar e confirmar hipóteses de modo direto e interativo. Para tanto, essa abordagem depende da experiência, do conhecimento do contexto dos dados e do esforço atentivo de um agente avaliador da qualidade apoiado por um sistema de visualização adequado. Por esse motivo, o conhecimento do relacionamento propriedade-defeito é naturalmente indispensável para a seleção das técnicas de visualização e de interação.

A natureza supervisionada dessa abordagem visual é relevante para aqueles defeitos cuja determinação depende fortemente da supervisão humana e a contribuição das abordagens computacionais - quando disponíveis - é restrita.

A discussão acima demonstra que os relacionamentos propriedade-defeito - Seção 5.6.1 constituem insumos relevantes ao projeto de sistemas de visualização para a avaliação da qualidade dos dados, independentemente da abordagem. Esses relacionamentos provêem um mapeamento base que reduz a subjetividade e informa se certas propriedades visuais ou interativas são adequadas a avaliação de um defeito em dada resolução de dados. Adicionalmente, esse mapeamento é o ponto de início para estudos de avaliação sobre fatores mais específicos - incluindo estilo cognitivo, preferências pessoais, nível de experiência, efeitos de aprendizagem, colaboração - relativos a avaliação visual da qualidade dos dados. O conhecimento dos relacionamentos propriedade-defeito é coberto de maneira restrita no estado-da-arte da literatura de visualização de dados, conforme discutido na Seção 3.5. O principal limite do relacionamento propriedade-defeito remete a manipulação de enormes resoluções de dados, questão intrínseca do pAQD - Seção 2.2.3.1. Poucas técnicas de 
visualização sustentam resoluções significativas de dados - superior ou igual a $10^{8}$ - e que facilitem a avaliação dos defeitos cobertos pelo presente trabalho. Uma vez que determinar a qualidade não requer todo o universo dos dados, a segmentação desses em subconjuntos representativos pode ser uma solução factível. Neste trabalho, o termo "representativo" denota aqui a noção de subconjuntos de dados que necessariamente carreguem instâncias dos defeitos de interesse.

\subsubsection{Originalidade}

A configuração e os resultados do estudo de caso do presente trabalho revelam vários pontos de originalidade em relação aos trabalhos relacionados - Seção 3.5 -, resultando na publicação de um artigo com resultados completos [Josko e Ferreira, 2016]. Os principais pontos de originalidade são discutidos a seguir.

- Uso de um arcabouço para descrever as atividades de avaliação da qualidade de dados. Essas atividades foram relevantes como apoio ao trabalho de análise desempenhado pelo participante, bem como na determinação das técnicas de interação incorporadas a ferramenta de apoio;

- Uso de participante experiente no processo de avaliação da qualidade de dados, fato que proporcionou uma contribuição direta nos resultados finais da análise qualitativa;

- Desenvolvimento de uma ferramenta de apoio - Vis4DD - específica as necessidades do estudo de caso e desprovidas de elementos de dispersão da atenção do participante;

- Análise das propriedades visuais que compõem as técnicas de visualização, fato que torna os resultados deste trabalho mais abrangentes, isto é, independente da técnica de visualização. Tal abordagem diferente drasticamente dos trabalhos relacionados - Seções 5.4 e 3.5 - que analisam técnicas de visualização específicas;

- Cobertura de diferentes defeitos nos dados - e variantes correspondentes - em resoluções crescentes de dados. Essa abordagem permitiu claramente delinear os limites e as contribuições de cada uma das propriedades visuais-interativas pertencentes ao escopo do presente estudo de caso;

- Análise das propriedades quanto as ações de detecção e a quantificação dos defeitos nos dados. A segunda representa um enfoque inédito em relação aos trabalhos relacionados. 
162 PROPRIEDADES PARA AVALIAÇÃO VISUAL DA QUALIDADE DOS DADOS 


\section{Capítulo 6}

\section{Conclusão}

\subsection{Síntese do Trabalho}

Os efeitos da baixa qualidade dos dados sobre a confiabilidade dos resultados dos processos analíticos são notórios. Garantir dados nos patamares de qualidade requeridos por tais processos exige iniciativas de manutenção e melhoria contínua dos dados.

O presente trabalho caracterizou o processo de Avaliação da Qualidade de Dados ou pAQD - Capítulo 2 -, relevante instrumento de apoio as referidas iniciativas por meio do mapeamento dos defeitos nos dados. Esse processo é cercado por desafios organizacionais, culturais e técnicos que determinam sua complexidade e custo de realização. A automação representa o meio de viabilizar a realização eficiente do pAQD, especialmente no cenário de grandes resoluções de dados. Este trabalho caracterizou as duas principais abordagens de automação de avaliação da qualidade dos dados, quais sejam a computacional e a mediada pela visualização de dados - respectivamente, Seções 3.2 e 3.3 .

Independentemente da abordagem, determinar a qualidade dos dados exige a compreensão segura sobre a estrutura dos defeitos alvos da avaliação. Devido essa importância, o presente trabalho apresentou no Capítulo 4 uma taxonomia de defeitos em dados estruturados e atemporais relativos a acuracidade, a completude e a consistência de modo a suplantar as limitações averiguadas nos vários trabalhos relacionados, conforme discutido na Seção 3.4 .

Além disso, confirmar ou refutar um defeito depende do conhecimento do contexto dos dados avaliados. Por isso, a supervisão humana é requerida ao longo da avaliação da qualidade. A visualização de dados representa uma área de pesquisa que reúne conhecimentos de diferentes disciplinas na produção de representações visuais capazes de facilitar a compreensão de fenômenos presentes nos dados de modo supervisionado. Este trabalho conceituou tal área e descreveu os elementos que compõem os sistemas de visualização - Seção 2.3 -, bem como apresentou os tópicos centrais que norteiam a visualização de dados: a percepção e cognição humana - Seção 2.4 . 
O projeto de sistemas de visualização de dados conta com uma ampla literatura de perspectiva e propósito distintos. Conforme analisado pelo presente trabalho - Seção 3.5 -, essa literatura não apresenta indicações específicas para o desenvolvimento de sistemas de visualização que atendam a avaliação visual da qualidade dos dados. Em outras palavras, não existe um relacionamento explícito entre as estruturas dos defeitos avaliados em resoluções de dados expressivas e as propriedades visuais-interativas dos sistemas de visualização.

Em vista disso, este trabalho aplicou um estudo de caso múltiplo com o objetivo de determinar um primeiro conjunto de relacionamentos e limites entre propriedades visuaisinterativas relevantes dos sistemas de visualização e as estruturas dos defeitos nos dados. Os resultados do referido estudo de caso - Capítulo 5 - ampliam e complementam trabalhos relacionados que avaliaram a capacidade de pequeno conjunto de propriedades visuais na detecção de um defeito específico - variantes de tupla atípica -, majoritariamente. Ademais, esses resultados também corroboram trabalhos que organizam o espaço visual de acordo com as propriedades que favorecem a realização de certas atividades de propósito geral derivação de valor absoluto, dentre outros.

\subsection{Principais Contribuições}

O presente trabalho descreveu duas contribuições com implicações teóricas e práticas ao pAQD, quais sejam a taxomia de defeitos nos dados e o relacionamento entre as propriedades visuais-interativas dos sistemas de visualização e as estruturas dos defeitos nos dados. Tais contribuições contemplaram a questão da avaliação visual de defeitos nos dados, com especial atenção àqueles cujas regras são de difícil especificação.

O desenvolvimento da taxonomia de defeitos nos dados ocorreu a partir da análise do estado-da-arte da literatura correspondente. Essa análise destacou diferentes limites que precisavam ser contornados para proporcionar melhor apoio a avaliação da qualidade dos dados e aos objetivos deste trabalho. Dentre os limites identificados, citam-se:

- Terminologia com grande variabilidade e distante daquela utilizada na área de banco de dados;

- Linguagem informal e ambígua na descrição dos defeitos nos dados;

- Ausência de critérios de seleção dos defeitos abordados, provocando a mescla entre defeitos relativos a diferentes critérios e aspectos da qualidade, como conteúdo, estrutura e contexto - Quadro 2.1;

- Defeitos nos dados com níveis de abstração diferentes;

- Ausência de atenção com a evolução e a cobertura de defeitos relativos a acuracidade, completude e inconsistência. 
Os limites da literatura balizaram o estabelecimento de uma abordagem metodológica de três etapas. A primeira etapa determinou uma extensa análise de tópicos da teoria relacional para identificar violações as regras que descrevem o UdD - os defeitos -, definir a linguagem e a terminologia de descrição mais apropriadas e organizar os defeitos segundo um nível de abstração coerente com base nas respectivas características estruturais. As etapas subsequentes descreveram os defeitos por meio da combinação de recursos formais, textuais e exemplos, bem como classificou os defeitos segundo os critérios de propriedades compartilhas e granularidades de ocorrência.

Discutida no Capítulo 4, a taxonomia resultante [Josko e Ferreira, 2014; Josko et al. , 2016] descreve as características estruturais de 26 defeitos nos dados, dos quais 9 não foram tratados pelo estado-da-arte das taxonomias. Tais estruturas revelam o problema relacionado aos dados e servem como fundamento para questões relacionadas ao pAQD, tais como: selecionar as abordagens de detecção mais adequadas; projetar abordagens de detecção de defeitos - como o Vis4DD desenvolvido por este trabalho na Seção 5.3.4 -; treinar avaliadores de qualidade; estabelecer prioridades de avaliação da qualidade; estabelecer uma terminologia de defeitos organizacional; estabelecer mapas de métricas de qualidade dos dados.

A necessidade do relacionamento propriedades-defeitos decorreu das constatações provenientes do levantamento bibliográfico rigoroso - Seção 3.3 - e da análise da literatura relativa ao projeto de sistemas de visualização - Seção 3.5. O primeiro contribuiu com um conjunto de observações sobre sistemas de visualização projetados para a avaliação da qualidade de dados propostos em diferentes áreas de conhecimento. Dentre as várias observações, citam-se:

- Não foram apresentadas se e como as estruturas dos defeitos, as características dos dados, as necessidades das atividades de avaliação de qualidade ou qualquer outro aspecto determinaram as propriedades dos respectivos sistemas;

- Tendência de especialização das técnicas de visualização a comunicação de informações de qualidade computacionalmente identificadas - abordagem Quality-Aware;

- Ausência de estudos relativos a capacidade de detectar defeitos e inferir as respectivas quantidades em dados visualmente representados.

Por sua vez, a análise da literatura contribuiu para revelar a carência de conhecimentos para o projeto de sistemas de visualização capazes de apoiar a avaliação visual da qualidade dos dados. Embora relevantes trabalhos classifiquem propriedades visuais de acordo com a facilidade de percepção humana, essa classificação não garante a detecção de defeitos com diferentes estruturas.

A partir dessas observações, este trabalho conduziu um estudo de caso com o objetivo de mapear as propriedades dos sistemas de visualização mais adequadas a avaliação de 
defeitos de acordo com suas estruturas. De natureza exploratória e observacional, o estudo de caso foi organizado - Seção 5.3 - de modo a reunir observações e notas relativas as atividades de detecção e quantificação de defeitos apoiadas por um conjunto de propriedades dos sistemas de visualização. A ferramenta $V i s 4 D D$ foi construída para apoiar esse procedimento e capturar informações adicionais sobre as interações realizadas.

Os resultados do estudo de caso [Josko e Ferreira, 2016] evidenciam que as estruturas dos defeitos e o tamanho das resoluções de dados determinaram a contribuição das propriedades visuais-interativas na avaliação visual da qualidade. Essas evidências contribuíram no estabelecimento dos relacionamentos propriedades-defeitos e no complemento do estadoda-arte da literatura de visualização de dados - Seções 5.4 e 5.6.

Os relacionamentos propriedades-defeitos provêem um mapeamento base que reduz a subjetividade na escolha das propriedades, pois permite identificar se certa propriedade é adequada para avaliar um defeito em dada resolução de dados. Adicionalmente, o mapeamento é base para estudos futuros relacionados a aspectos mais específicos - incluindo estilo cognitivo, nível de experiência, efeitos de aprendizagem, colaboração - relativos a avaliação da qualidade dos dados mediada por sistemas de visualização.

\subsection{Limites}

Apesar dos promissores resultados do presente trabalho em relação a avaliação visual da qualidade de dados, certas limitações devem ser observadas em adição àquelas apresentadas na Seção 5.5.

Uma das limitações remete ao tamanho das resoluções de dados visualmente manipuladas. As técnicas de visualização baseadas na decodificação individual dos dados e equipadas com recursos de distorção espacial e mudança de opacidade não proporcionaram escalabilidade visual, conforme observado em outros trabalhos [Liu et al., 2013; Unwin et al. ,2006].

Em contraste, as técnicas com compactação foram mais invariantes a flutuação da resolução dos dados [Liu et al., 2013; Mayorga e Gleicher, 2013]. Associadas a interatividade, tais técnicas possibilitaram a representação das maiores resoluções de dados utilizadas neste trabalho - $10^{6}$ e $10^{7}$ tuplas. No entanto, a compactação demandou um maior número de interações e elevou o esforço ao longo das análises visuais. Por isso, a manipulação de resoluções crescentes de dados constitui um desafio real a avaliação visual da qualidade dos dados.

Outra limitação do presente trabalho está relacionada a ausência de recursos de apoio semântico. A avaliação visual da qualidade de dados depende do conhecimento do contexto dos dados e da capacidade de distinção semântica dos agentes avaliadores de qualidade. Desse modo, sistemas de visualizações que representem os dados e as respectivas informações semânticas podem contribuir na aferição da qualidade. 


\subsection{Oportunidades de Pesquisa}

A natureza multidisciplinar do presente trabalho favoreceu a identificação de diferentes ideias para avançar o conhecimento relativo a avaliação visual da qualidade dos dados. Algumas dessas ideias apresentam relação direta às limitações deste trabalho, enquanto outras denotam oportunidades verificadas no decurso desta pesquisa.

A organização taxonômica de defeitos nos dados referenciados pelo tempo representa uma das oportunidades devido a forte presença de bancos de dados temporais em diferentes contextos organizacionais. Essa referência expande a perspectiva da qualidade dos dados ao considerar a representação de fatos sobre objetos de um UdD dentro de uma janela temporal. Em outras palavras, a temporalidade estabelece um novo conjunto de restrições, dependências e propriedades nos dados que, consequentemente, implicam em novos defeitos. Tais defeitos foram parcialmente cobertos pelo trabalho de [Gschwandtner et al., 2012] à medida que aspectos relevantes dos bancos de dados temporais - incluindo restrições de chaves primárias, integridade referencial temporais e bitemporalidade ${ }^{1}$ das relações - não foram endereçados. Na linha de taxonomia, outra oportunidade é demonstrar a cobertura da taxonomia apresentada por este trabalho.

Outra oportunidade remete a condução da avaliação da qualidade de enormes resoluções de dados - $10^{15}$ tuplas, por exemplo - geograficamente distribuídos que são relevantes fatores de influência do pAQD - Seção 2.2.3.1. O grande desafio nesse contexto é promover uma avaliação balizada pela participação humana, com uma abrangência representativa dos dados e consumo de tempo praticável. A representatividade é necessária à medida que certos defeitos somente são revelados quando certos dados - que podem estar presentes em diferentes unidades de distribuição - estão reunidos. Assim, essa oportunidade de pesquisa envolve analisar a combinação de abordagens computacionais semi-supervisionadas, técnicas estatísticas, técnicas de processamento massivo e visualizações de dados de modo a favorecer avaliações cruzadas de dados distribuídos. Esses recursos poderiam promover um fluxo de avaliação sobre regiões representativas de dados distribuídos que compartilham certa assinatura matemática ou padrão definido pelo agente humano. Em outras palavras, a oportunidade é propiciar a análise visual sobre dados em resolução menor e altamente representativa, conforme desafio apontado em [Wong et al., 2012].

Por fim, considerando as propriedades dos sistemas de visualização, quatro oportunidades de continuidade podem ser definidas. A primeira remete a análise das propriedades não cobertas pelo presente trabalho em relação a avaliação visual da qualidade, incluindo as visões múltiplas concorrentes - Seção 2.3.4.1 -, as visualizações orientadas a pixel Seção 2.3.4.2 -, as visualizações embutidas - Seção 5.5 - e as visualizações baseadas em

\footnotetext{
${ }^{1}$ Relações bitemporais representam dois períodos de tempo, quais sejam valid time e transaction time. O primeiro denota quando um fato foi válido para o UdD em questão, enquanto o segundo representa o histórico de mudanças de estado de uma relação [Snodgrass, 1999].
} 
grafo com capacidade de manipular maiores resoluções de dados e preservar a direção das arestas.

Por sua vez, a segunda oportunidade remete a análise das propriedades visuais-interativas para o subconjunto de defeitos não cobertos pelo presente trabalho, quais sejam aqueles que demandam baixa ou moderada supervisão humana.

A terceira endereça a análise de aspectos cognitivos aplicados ao projeto de sistemas de visualização. Em uma perspectiva ampla, a preocupação dessa análise é organizar visualmente os dados de modo a favorecer a recuperação de estruturas de conhecimento e facilitar o raciocínio ao longo da avaliação da qualidade de dados. Isto posto, essa oportunidade naturalmente envolve a participação direta - e antes do desenvolvimento do sistema - de agentes avaliadores da qualidade em um estudo de caso de longo prazo. Esse tipo de estudo propicia uma melhor compreensão sobre os princípios aplicados ao projeto de sistemas de visualização [Shneiderman e Plaisant, 2006].

A quarta oportunidade denota a oferta de recursos de acesso as semânticas relativas aos dados avaliados visualmente, incluindo Ontologias e Bases de Conhecimento. Tais recursos podem contribuir na avaliação da qualidade dos dados à medida que reduzem a dependência da memória do agente avaliador da qualidade. 


\section{Apêndice A}

\section{Anexo}

\section{A.1 Registro das Interações}

O Vis4DD realizou o registro automático das interações - e respectivos parâmetros - ao longo das sessões componentes do estudo de caso. Conforme observado na Figura A.1, esse registro contempla os atributos alvo da avaliação e de referência - BasisAttr e ReferenceAttr -, o atributo e parâmetro utilizado para filtrar dados - FilterAttr e FilterParms -, a indicação de uso de mudança de opacidade ou distorção espacial - AlphaBlend - e a indicação da compactação por suavização ou recipiente - Smooth_Binned - para avaliar uma relação - Relation - por meio de uma técnica de visualização - Scene - em determinada data e hora - TimeOFInteraction. Os parâmetros não utilizados em uma interação são assinalados com "None".

\footnotetext{
TimeOFInteraction; Relation;Scene;BasisAttr;ReferenceAttr;FilterAttr;FilterParms;nBins;AlphaBlend;Smooth_Binned 2015-01-24 15:00:32; emp_atip_1t;SPlot Matrix;years-salary; fname; None; None; None; None; None; None; None; None 2015-01-24 15:01:08;emp_atip_1t;SPlot Matrix;years-salary;fname;None;None;None;None; Jitter;None; None;None 2015-01-24 15:02:21;emp atip 1t;SPlot Matrix;years-salary;job.position;None;None;None;None; None; None; None; None 2015-01-24 15:02:58;emp_atip_1t;SPlot Matrix;years-salary;job.position;None;None;None;None; Jitter;None; None;None 2015-01-24 15:03:44;emp_atip_1t;SPlot Matrix;years-salary;job.position;None;None; None; None; None; None; None; None 2015-01-24 15:05:02;emp_atip_1t;PCoordinate;years-salary-age;job.position;None;None; None; 1; None; None; None; None 2015-01-24 15:05:55;emp_atip_1t;PCoordinate;years-salary-age;job.position;None;None;None;1;None; None;None;None 2015-01-24 15:07:02;emp_atip_1t;PCoordinate;years-salary-age;job.position;None;None;None; 1;None; None; None; None 2015-01-24 15:07:51;emp_atip_100t;SPlot Matrix;years-salary;fname; None;None;None; None; None; None; None; None 2015-01-24 15:08:22;emp_atip_100t;SPlot Matrix;years-salary;fname;None; None; None; None; Jitter; None; None; None 2015-01-24 15:09:12;emp_atip_100t;SPlot Matrix;years-salary;fname;years;13-9-10-11;None; None; Jitter; None; None; None 2015-01-24 15:10:02;emp_atip_10t;PCoordinate;years-salary-age;job.position;None;None;None; 1; None; None; None; None 2015-01-24 15:10:02; emp atip_10t;PCoordinate;years-salary-age;job.position;None;None; None;1;None; None; None; None 2015-01-24 15:11:02;emp_atip_100t;PCoordinate;years-salary-age;job.position;None; None; None;1; None; None; None; None 2015-01-24 15:11:02;emp_atip_100t;PCoordinate;years-salary-age;job.position;None; None; None;1;None; None; None; None 2015-01-24 15:12:02;emp_atip_100t;PCoordinate;years-salary-age;job.position;years;10-11-13-9; None;1;None; None; None; None 2015-01-24 15:12:02;emp atip_100t;PCoordinate;years-salary-age;job.position;years;10-11-13-9;None;1;None;None;None;None 2015-01-24 15:15:02; emp_atip_100t;PCoordinate;years-age;job.position;years;10-11-13-9; None;1;None; None; None; None 2015-01-24 15:15:02; emp_atip_100t;PCoordinate;years-age-salary;job.position;years;10-11-13-9; None;1; None; None; None; None 2015-01-24 15:18:02;emp_atip_100t;PCoordinate;years-age-salary;job.position;years;10-11-13-9;None;1;None;None; None; None 2015-01-24 15:20:02; emp_atip_100t;PCoordinate;years-age-salary;job.position;years;10-11-13-9;None;1;None; None; None;None
}

Figura A.1: Fragmento do registro de interações realizado pelo Vis4DD (Fonte: Elaborado pelo autor) 


\section{A.2 Resumos Analíticos}

Conforme mencionado na Seção 5.3.7, o resumo analítico representa o artefato produzido ao final de cada unidade de estudo. As informações qualitativas desse artefato evoluíram à medida que as diferentes configurações e resoluções de dados eram utilizadas dentro da unidade de estudo em questão.

A Figura A.2 apresenta um fragmento do resumo analítico relativo a unidade de estudo da $1^{\underline{a}}$ variante de Tupla Atípica para um subconjunto de configurações. Essa figura permite observar na coluna "Notes/Observations" as palavras chaves utilizadas como agrupadoras das observações relativas as interações, as propriedades visuais, aos atributos de referência e a análise contextual dos dados. Cumpre mencionar que a indicação das configurações - coluna "Config." - ocorreu na etapa de Análise Final dos Resultados para facilitar a apuração dos resultados.

\begin{tabular}{|c|c|c|c|c|c|c|c|}
\hline Visualization Technique & Config. & $10^{3}$ Relation & $10^{4}$ Relation & $10^{5}$ Relation & $10^{6}$ Relation & $10^{7}$ Relation & Notes/Observations \\
\hline \multirow[t]{2}{*}{ Histogram } & c1 & 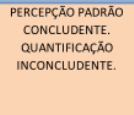 & $\begin{array}{l}\text { PERCEPCĀO PADRĀO } \\
\text { CONCLUDENTE. } \\
\text { QUANATIICACÁO } \\
\text { INCONCLUENTE. }\end{array}$ & $\begin{array}{l}\text { PERCEPCĀAO PADRĀO } \\
\text { CONCLUDENTE. } \\
\text { QUANTFICACĀO } \\
\text { INCONCLUDENTE. }\end{array}$ & $\begin{array}{c}\text { PERCEPC̄ĀO } \\
\text { PADRÃO } \\
\text { CONCLUDENTE. } \\
\text { QUANTIFCACĀO } \\
\text { INCONCLUDENTE. }\end{array}$ & $\begin{array}{l}\text { PERCEPC̄ĀO } \\
\text { PADRÃO } \\
\text { CONCLUDENTE. } \\
\text { QUANTIFCACÁA } \\
\text { INCONCLUDENTE. }\end{array}$ & 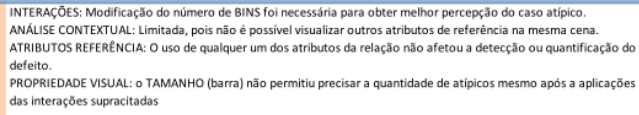 \\
\hline & $\mathrm{c2}^{2}$ & $\begin{array}{l}\text { PERCEPCĀO PADRĀO } \\
\text { CONCLUDENTE. } \\
\text { OUANTIFCAÇO } \\
\text { INCONCLUDENTE. }\end{array}$ & 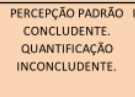 & $\begin{array}{l}\text { PERCEPCĀO PADRĀO } \\
\text { CONCLDENTE. } \\
\text { QUANTFFICACĂO } \\
\text { INCONCLUDENTE. }\end{array}$ & $\begin{array}{l}\text { PERCEPCĀ̄O } \\
\text { PADRĀO } \\
\text { CONCLUDENTE. } \\
\text { QUUATTFICACĀO } \\
\text { INCONCLUDENTE. }\end{array}$ & $\begin{array}{l}\text { PERCEPÇĀO } \\
\text { PADRĀO } \\
\text { CONCLUDENTE. } \\
\text { QUANTIFCACĀO } \\
\text { INCONCLUDENTE. }\end{array}$ & 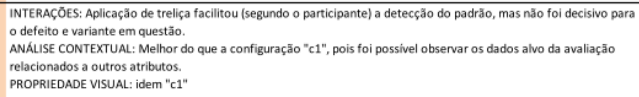 \\
\hline Chernoff Faces & f1 & 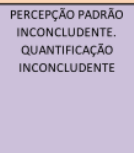 & Nẵo escalável & & & & 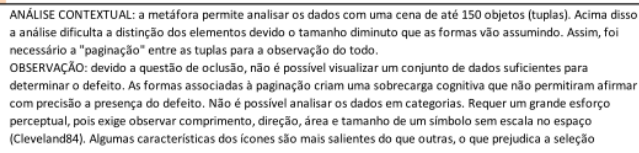 \\
\hline \multirow[t]{2}{*}{ Buble Chart } & c3 & $\begin{array}{l}\text { PERCEPCĀO PADRR̃o } \\
\text { CONCLUDENTE. } \\
\text { OQANATIFACACOO } \\
\text { INCONCLUDENTE. }\end{array}$ & \begin{tabular}{|l} 
Năo escalível \\
\end{tabular} & & & & 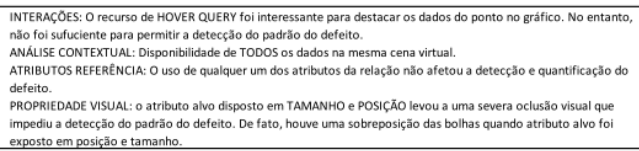 \\
\hline & $\mathrm{d} 3$ & $\begin{array}{l}\text { PERCEPCĀO PADRĀO } \\
\text { CONCLUDENTE. } \\
\text { QUANTIFCACAO } \\
\text { CONCLUDENTE. }\end{array}$ & Nåo escal'svel & & & & 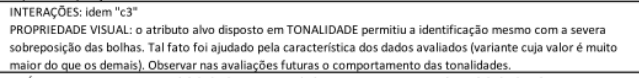 \\
\hline $\begin{array}{l}\text { Parallel Coordinates } \\
\end{array}$ & 96,27 & 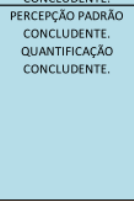 & $\begin{array}{l}\text { PERCEPCAOA PADRŔO } \\
\text { CONCLUDENTE. } \\
\text { QUANTIIICACAOO } \\
\text { CONCLUDENTE. }\end{array}$ & $\begin{array}{l}\text { PERCEPÇÃO PADRÃO } \\
\text { CONCLUDENTE. } \\
\text { QUANTIIICACAOA } \\
\text { CONCLUDENTE. }\end{array}$ & Nāo escalâvel & & 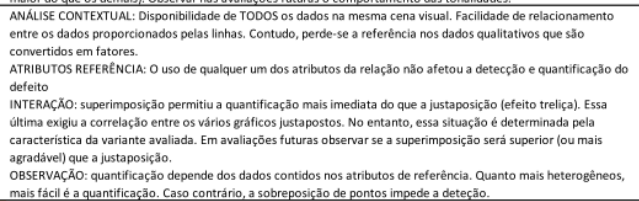 \\
\hline HeatMap & b1 & $\begin{array}{l}\text { PERCEPCĀO PADRĀO } \\
\text { CONCLUDENTE. } \\
\text { QUANFIFCAÇO } \\
\text { INCONCLUDENTE. }\end{array}$ & $\begin{array}{l}\text { PERREPCĀO PADRÁO } \\
\text { CONCLUDENTE. } \\
\text { QUANITICACÁO } \\
\text { INCONCLUDENTE. }\end{array}$ & $\begin{array}{l}\text { PERCEPCĀO PADRĀO } \\
\text { CONCLUDENTE. } \\
\text { QUANTFICACAOA } \\
\text { INCONCLUDENTE. }\end{array}$ & $\begin{array}{l}\text { PERCEPCĀOA } \\
\text { PADRÁO } \\
\text { CONCLUDENTE. } \\
\text { QUANTIFICACĀO } \\
\text { INCONCLUDENTE. }\end{array}$ & 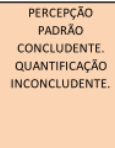 & 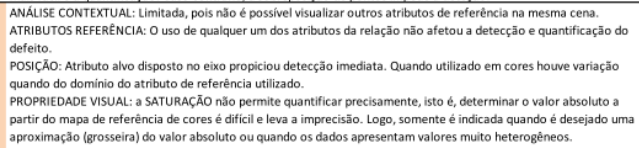 \\
\hline
\end{tabular}

Figura A.2: Fragmento de resumo analítico - Tupla Atípica (Fonte: Elaborado pelo autor) 


\section{Referências Bibliográficas}

Abiteboul et al. (1995) Serge Abiteboul, Richard Hull e Victor Vianu. Foundations of databases, volume 8, chapter A Larger Perspective, páginas 216-235. Addison-Wesley Reading. 106, 108

Adler et al. (2013) Daniel Adler, Christian Gläser, Oleg Nenadic, Jens Oehlschlägel e Walter Zucchini. ff: Memory-efficient Storage of Large Data on Disk and Fast Access functions. The R-Project for Statistical Computing, 2013. URL http://cran.r-project. org/web/packages/ff. Acessado em JUN/2013. 83

Ahlberg e Shneiderman (1994) Christopher Ahlberg e Ben Shneiderman. Visual information seeking: tight coupling of dynamic query filters with starfield displays. Em Proceedings of the SIGCHI Conference on Human Factors in Computing Systems, CHI '94, páginas 313-317, New York, NY, USA. ACM. ISBN 0-89791-650-6. doi: 10.1145/191666.191775. 48

Almutiry et al. (2016) Omar Almutiry, Gary Wills e Richard Crowder. A dimensionoriented taxonomy of data quality problems in electronic health records. IADIS International Journal on WWW/Internet, 13(2):98-114. URL http://eprints.soton.ac.uk/ $384258 / .98$

Alves e Menezes (2007) André Alexandre Alves e Octaviano M de S Menezes. Cartão de Crédito Private Label. Novatec. 110

Ambler e Sadalage (2006) Scott W Ambler e Pramod J Sadalage. Refactoring databases: Evolutionary database design. Pearson Education. 97

Anderson (2005) John R Anderson. Cognitive psychology and its implications . WH Freeman/Times Books/Henry Holt \& Co. 60, 62, 63

Andrienko e Andrienko (2006) Natalia Andrienko e Gennady Andrienko. Exploratory analysis of spatial and temporal data. Springer. xx, 43, 63, 125, 126, 127, 128

Angiulli e Fassetti (2014) Fabrizio Angiulli e Fabio Fassetti. Exploiting domain knowledge to detect outliers. Data Mining and Knowledge Discovery, 28(2):519-568. 102

Baldonado et al. (2000) Michelle Q Wang Baldonado, Allison Woodruff e Allan Kuchinsky. Guidelines for using multiple views in information visualization. Em Proceedings of the working conference on Advanced visual interfaces, páginas 110-119. ACM. 88,100

Barateiro e Galhardas (2005) José Barateiro e Helena Galhardas. A Survey of Data Quality Tools. Datenbank-Spektrum, 14(15-21):48. 98 
Batini et al. (2009) Carlo Batini, Cinzia Cappiello, Chiara Francalanci e Andrea Maurino. Methodologies for data quality assessment and improvement. ACM Comput. Surv., 41(3):16:1-16:52. ISSN 0360-0300. doi: 10.1145/1541880.1541883. 33, 38, 123

Beeley (2013) Chris Beeley. Web application development with $R$ using Shiny. Packt Publishing Ltd. 130

Bennett et al. (2006) Kevin B. Bennett, Allen L. Nagy e John M. Flach. Handbook of Human Factors and Ergonomics, chapter Visual Displays, páginas 1189-1221. John Wiley \& Sons, Inc., 3rd. ed. ISBN 9780470048207. doi: 10.1002/0470048204.ch45. URL http://dx.doi.org/10.1002/0470048204.ch45. 77

Bergman et al. (1995) Lawrence D Bergman, Bernice E Rogowitz e Lloyd A Treinish. A rule-based tool for assisting colormap selection. Em Proceedings of the 6th conference on Visualization'95, página 118. IEEE Computer Society. 131

Bernard (2011) H Russell Bernard. Research methods in anthropology: Qualitative and quantitative approaches. Rowman Altamira. 129

Berti-Equille et al. (2015) Laure Berti-Equille, Ji Meng Loh e Tamraparni Dasu. A masking index for quantifying hidden glitches. Knowledge and Information Systems, $44(2): 253-277.39$

Bertin (1983) Jacques Bertin. Semiology of graphics: diagrams, networks, maps. University of Wisconsin press. 58, 59, 101, 125, 139, 151, 156, 157, 159, 160

Bertossi et al. (2011) Leopoldo Bertossi, Flavio Rizzolo e Lei Jiang. Data quality is context dependent. Em Enabling Real-Time Business Intelligence, páginas 52-67. Springer. 24, 34, 35, 102

Borek et al. (2011) A Borek, P Woodall, M Oberhofer e AK Parlikad. A classification of data quality assessment methods. Em ICIQ 2011-Proceedings of the 16th International Conference on Information Quality, páginas 189-203. 97, 105

Bovee et al. (2003) Matthew Bovee, Rajendra P. Srivastava e Brenda Mak. A conceptual framework and belief-function approach to assessing overall information quality. International Journal of Intelligent Systems, 18(1):51-74. ISSN 1098-111X. doi: 10.1002/int.10074. 36, 37, 39

Campello et al. (2015) Ricardo JGB Campello, Davoud Moulavi, Arthur Zimek e Jörg Sander. Hierarchical density estimates for data clustering, visualization, and outlier detection. ACM Transactions on Knowledge Discovery from Data (TKDD), 10(1):5. 70

Card et al. (1999) Stuart K Card, Jock D Mackinlay e Ben Shneiderman. Readings in information visualization: using vision to think, chapter Information Visualization, páginas 1-34. Morgan Kaufmann Publishers Inc. 27, 40, 41, 42, 53, 158, 160

Carpendale (2003) MST Carpendale. Considering visual variables as a basis for information visualisation. Computer Science TR\# 2001-693, 16. 139 
Casner (1991) Stephen M Casner. Task-analytic approach to the automated design of graphic presentations. ACM Transactions on Graphics (TOG), 10(2):111-151. 24, 101, 125

Castro (2013) Aldemar A. Castro. Curso de revisão sistemática e metanálise., 2013. URL http://www.virtual.epm.br/cursos/metanalise. Acessado em JUN/2013. 69, 73

Chambers (1983) Cleveland W. S. Keiner B. Tukey P. A. Chambers, John M. Graphical methods for data analysis. Duxbury Press. 48, 56, 57, 58

Chambers (2008) John M Chambers. Software for data analysis: programming with $R$. Springer. 130

Chan (2006) W.W.Y. Chan. A survey on Multivariate Data visualization. Relatório técnico, Hong Kong University of Science and Technology. xv, xix, 54, 55

Chandola et al. (2009) Varun Chandola, Arindam Banerjee e Vipin Kumar. Anomaly detection: A survey. ACM Comput. Surv., 41(3):15:1-15:58. ISSN 0360-0300. doi: 10.1145/1541880.1541882. 24, 67, 68

Chaudhuri et al. (2003) Surajit Chaudhuri, Kris Ganjam, Venkatesh Ganti e Rajeev Motwani. Robust and efficient fuzzy match for online data cleaning. Em Proceedings of the 2003 ACM SIGMOD international conference on Management of data, páginas 313-324. ACM. 97

Chen (2015) Cheng Chen. A system to support clerical review, correction and confirmation assertions in entity identity information management. Em International Conference on Information Quality, Cambridge, MA, USA. xvi, 90, 91

Chernoff (1973) Herman Chernoff. The use of faces to represent points in k-dimensional space graphically. Journal of the American Statistical Association, 68(342):361-368. 56

Chu et al. (2013) Xu Chu, Ihab F Ilyas e Paolo Papotti. Holistic data cleaning: Putting violations into context. Em Data Engineering (ICDE), 2013 IEEE 29th International Conference on, páginas 458-469. IEEE. 97

Convertino et al. (2003) Gregorio Convertino, Jian Chen, Beth Yost, Y-S Ryu e Chris North. Exploring context switching and cognition in dual-view coordinated visualizations. Em Coordinated and Multiple Views in Exploratory Visualization, 2003. Proceedings. International Conference on, páginas 55-62. IEEE. 88

Cook e Swayne (2007) Dianne Cook e Deborah F Swayne. Interactive and dynamic graphics for data analysis: with $R$ and GGobi, chapter Missing Data, páginas 47-62. Springer. xv, xvi, 51, 74, 75

Correa et al. (2009) C.D. Correa, Yu-Hsuan Chan e Kwan-Liu Ma. A framework for uncertainty-aware visual analytics. Em Visual Analytics Science and Technology, 2009. VAST 2009. IEEE Symposium on, páginas 51 -58. doi: 10.1109/VAST.2009.5332611. 41

Council (2012) The Australian Research Council. ERA Journal List, 2012. 69 
Craft e Cairns (2008) Brock Craft e Paul Cairns. Directions for Methodological Research in Information Visualization. Em Proceedings of the 2008 12th International Conference Information Visualisation, IV '08, páginas 44-50, Washington, DC, USA. IEEE Computer Society. ISBN 978-0-7695-3268-4. doi: 10.1109/IV.2008.88. URL http://dx.doi.org/10.1109/IV.2008.88. 24

Csinger (1992) Andrew Csinger. The psychology of visualization. Relatório Técnico TR-92-28. 100

Cui et al. (2006) Qingguang Cui, Matthew Ward, Elke Rundensteiner e Jing Yang. Measuring data abstraction quality in multiresolution visualizations. Visualization and Computer Graphics, IEEE Transactions on, 12(5):709-716. 77, 79

Dasu (2013) Tamraparni Dasu. Data Glitches: Monsters in Your Data. Em Handbook of Data Quality, páginas 163-178. Springer. 23, 24, 35, 63, 68, 102

Dasu e Johnson (2003) Tamraparni Dasu e Theodore Johnson. Exploratory Data Mining and Data Cleaning, chapter Data Quality, páginas 99-138. John Wiley \& Sons, Inc., New York, NY, USA, 1 ed. ISBN 0471268518. 34, 68, 102, 104, 159

de Almeida et al. (2013) Wesley Gongora de Almeida, Rafael Timoteo de Sousa, Flavio Elias de Deus, Georges Daniel Amvame Nze e Fabio Lucio Lopes de Mendonca. Taxonomy of data quality problems in multidimensional Data Warehouse models. Em Information Systems and Technologies (CISTI), 2013 8th Iberian Conference on, páginas 1-7. IEEE. 98

De Veaux e Hand (2005) Richard D. De Veaux e David J. Hand. How to Lie with Bad Data. Statistical Science, 20(3):231-238. 24

Dix e Ellis (1998) Alan Dix e Geoffrey Ellis. Starting simple: adding value to static visualisation through simple interaction. Em Proceedings of the working conference on Advanced visual interfaces, AVI '98, páginas 124-134, New York, NY, USA. ACM. doi: 10.1145/948496.948514. 44, 45

Do (2009) Hong-Hai Do. Encyclopedia of database systems, chapter Data Conflicts, páginas 634-638. Springer Berlin, Heidelberg, Germany. 66, 67, 98

Doshi et al. (2003) P.R. Doshi, Geraldine E, G.E. Rosario, E.A. Rundensteiner e M.A. Ward. A strategy selection framework for adaptive prefetching in data visualization. Em Scientific and Statistical Database Management. 15th International Conference on, páginas 107-116. doi: 10.1109/SSDM.2003.1214972. 79

Ellis e Dix (2007) Geoffrey Ellis e Alan Dix. A taxonomy of clutter reduction for information visualisation. Visualization and Computer Graphics, IEEE Transactions on, 13(6):1216-1223. 45

Elsmari e Navathe (2010) Ramez Elsmari e Sham Navathe. Fundamentals of database systems. Addison-Wesley, 6th. ed. 106, 107

English (2009) Larry P English. Information quality applied: Best practices for improving business information, processes and systems, chapter Process and Business Failure: the high costs of low quality information, páginas 3-25. Wiley Publishing. 23, 24 
English (1999) Larry P. English. Improving data warehouse and business information quality: methods for reducing costs and increasing profits. John Wiley \& Sons, Inc., New York, NY, USA. ISBN 0-471-25383-9. 31, 32, 34, 36, 37, 97, 99

Eppler (2003) Martin J. Eppler. Managing Information Quality: Increasing the value of information in Knowledge-intensive products and processes. Springer-Verlag New York, Inc., Secaucus, NJ, USA. ISBN 3540003983. 31, 32, 36, 37, 38, 99

Fan e Geerts (2012) Wenfei Fan e Floris Geerts. Foundations of data quality management. Synthesis Lectures on Data Management, 4(5):1-217. 97, 98, 102, 106, 108, 153

Feofiloff et al. (2011) Paulo Feofiloff, Yoshiharu Kohayakawa e Yoshiko Wakabayashi. Uma introdução sucinta à teoria dos grafos. Disponıvel em http://www. ime. usp. br/ pf/teoriadosgrafos. 57,59

Fernstad e Glen (2014) Sara Johansson Fernstad e Robert C Glen. Visual analysis of missing dataTo see what isn't there. Em Visual Analytics Science and Technology (VAST), 2014 IEEE Conference on, páginas 249-250. IEEE. 70

Few (2009) Stephen Few. Now You See It: Simple Visualization Techniques for Quantitative Analysis. Analytics Press, USA, 1st ed. ISBN 0970601980, 9780970601988. xv, $\mathrm{xx}, 47,51,53,127$

Fox et al. (1994) Christopher Fox, Anany Levitin e Thomas Redman. The notion of data and its quality dimensions. Inf. Process. Manage., 30(1):9-19. ISSN 0306-4573. doi: 10.1016/0306-4573(94)90020-5. 32, 38

Friel et al. (2001) Susan N Friel, Frances R Curcio e George W Bright. Making sense of graphs: Critical factors influencing comprehension and instructional implications. Journal for Research in mathematics Education, páginas 124-158. 124

Fruchterman e Reingold (1991) Thomas MJ Fruchterman e Edward M Reingold. Graph drawing by force-directed placement. Software: Practice and experience, 21(11): 1129-1164. 152

Fua et al. (1999) Ying-Huey Fua, M.O. Ward e E.A. Rundensteiner. Navigating hierarchies with structure-based brushes. Em Information Visualization, 1999. (Info Vis '99) Proceedings. 1999 IEEE Symposium on, páginas 58-64, 146. xvi, 77, 79

Führing e Naumann (2007) P. Führing e F. Naumann. Emergent data quality annotation and visualization. Em Proceedings of the International Conference on Information Quality (IQ07), Cambridge, MA, USA. xvi, 81, 82

Gahegan (1999) Mark Gahegan. Four barriers to the development of effective exploratory visualisation tools for the geosciences. International Journal of Geographical Information Science, 13(4):289-309. 41

Gahegan e Ehlers (2000) Mark Gahegan e Manfred Ehlers. A framework for the modelling of uncertainty between remote sensing and geographic information systems. ISPRS Journal of Photogrammetry and Remote Sensing, 55(3):176-188. 41 
Ganti e Sarma (2013) Venkatesh Ganti e Anish Das Sarma. Data cleaning: A practical perspective. Synthesis Lectures on Data Management, 5(3):1-85. 97, 153

George e Gao (2011) Elaine George e Jing Gao. Relevance of Information Quality Studies in Information Systems Education in Australia. Em 16th International Conference on Information Quality, páginas 1-15. MIT Information Quality Program. 122, 123

Gorton e Gracio (2012) Ian Gorton e Deborah K Gracio. Data-Intensive Computing: A Challenge for the 21st Century, chapter Data-Intensive Computing: A Challenge for the 21st Century, páginas 1-11. Cambridge University Press. 23

Gotz e Zhou (2009) David Gotz e Michelle X Zhou. Characterizing users' visual analytic activity for insight provenance. Information Visualization, 8(1):42-55. 126

Green-Armytage (2010) Paul Green-Armytage. A colour alphabet and the limits of colour coding. JAIC-Journal of the International Colour Association, 5. 131

Grefen (1993) Paul WPJ Grefen. Combining Theory and Practice in Integrity Control: A Declarative Approach to the Specification of a Transaction Modification Subsystem. Em Proceedings of the 19th International Conference on Very Large Data Bases, páginas 581-591. Morgan Kaufmann Publishers Inc. 106, 108

Grinstein et al. (2002) Georges G Grinstein, Patrick Hoffman, Ronald M Pickett e SHARON J Laskowski. Benchmark development for the evaluation of visualization for data mining. Information visualization in data mining and knowledge discovery, páginas 129-176. 27, 100, 129, 138, 157, 158

Gschwandtner et al. (2012) Theresia Gschwandtner, Johannes Gärtner, Wolfgang Aigner e Silvia Miksch. A taxonomy of dirty time-oriented data. Em Multidisciplinary Research and Practice for Information Systems, páginas 58-72. Springer. 98, 167

Heer e Shneiderman (2012) Jeffrey Heer e Ben Shneiderman. Interactive Dynamics for Visual Analysis. Queue, 10(2):30:30-30:55. ISSN 1542-7730. doi: 10.1145/2133416. 2146416. xv, 27, 45, 46, 47, 48, 49, 50, 100, 104, 154

Heer et al. (2009) Jeffrey Heer, Fernanda B. Viégas e Martin Wattenberg. Voyagers and voyeurs: Supporting asynchronous collaborative visualization. Commun. ACM, 52 (1):87-97. ISSN 0001-0782. doi: 10.1145/1435417.1435439. xv, 46

Hegarty (2011) Mary Hegarty. The Cognitive Science of Visual-Spatial Displays: Implications for Design. Topics in Cognitive Science, 3(3):446-474. ISSN 1756-8765. doi: 10.1111/j.1756-8765.2011.01150.x. 24, 40, 41, 63

Helfert e Ge (2006) M Helfert e M Ge. A Review of Information Quality Research. Em 11th International Conference on Information Quality. 97, 98

Herman et al. (2000) Ivan Herman, Guy Melançon e M Scott Marshall. Graph visualization and navigation in information visualization: A survey. Visualization and Computer Graphics, IEEE Transactions on, 6(1):24-43. xix, 55, 151

Hoffman (1999) Patrick E Hoffman. Table visualizations: a formal model and its applications. Tese de Doutorado, University of Massachusetts Lowell. 27, 100, 138, 156 
Houaiss (2009) Antonio Houaiss. Dicionário Houaiss de Língua Portuguesa. Objetiva. 120

Hu e Feng (2005) W. Hu e J. Feng. Data and information quality: an informationtheoretic perspective. Computing and Information Systems, 9(3):32. 32

Hur et al. (2012) Inkyoung Hur, S Kim, Anya Savikhin e Ji Soo Yi. A Comparative Study of Three Sorting Techniques in Performing Cognitive Tasks on a Tabular Representation. International Journal of Human-Computer Interaction. doi: doi:10.1080/10447318.2012.713802. 83

Inselberg e Dimsdale (1990) Alfred Inselberg e Bernard Dimsdale. Parallel coordinates: a tool for visualizing multi-dimensional geometry. Em Visualization, 1990. Visualization'90., Proceedings of the First IEEE Conference on, páginas 361-378. IEEE. 58

Jankun-Kelly et al. (2002) T. J. Jankun-Kelly, Kwan Liu Ma e Michael Gertz. A model for the visualization exploration process. Em Proceedings of the conference on Visualization '02, VIS '02, páginas 323-330, Washington, DC, USA. IEEE Computer Society. ISBN 0-7803-7498-3. xv, 44, 49

Januzaj e Januzaj (2009) Eshref Januzaj e Visar Januzaj. An Application of Data Mining to Identify Data Quality Problems. Em Proceedings of the 2009 Third International Conference on Advanced Engineering Computing and Applications in Sciences, ADVCOMP '09, páginas 17-22, Washington, DC, USA. IEEE Computer Society. ISBN 978-0-7695-3829-7. doi: 10.1109/ADVCOMP.2009.11. 68

Jarke et al. (1999) Matthias Jarke, Manfred A. Jeusfeld, Christoph Quix e Panos Vassiliadis. Architecture and quality in data warehouses: An extended repository approach. Information Systems, 24(3):229 - 253. ISSN 0306-4379. doi: 10.1016/S0306-4379(99)00017-4. 10th International Conference on Advanced Information Systems Engineering. 36, 37, 38

Jiang et al. (2008) Lei Jiang, Alex Borgida e John Mylopoulos. Towards a compositional semantic account of data quality attributes. Em Conceptual Modeling-ER 2008, páginas 55-68. Springer. 34, 35

Josko e Ferreira (2014) João Marcelo Borovina Josko e João Eduardo Ferreira. Data quality assessment of very large database through visualization system. Em 29th Brazilian Symposium on Database, páginas 295-303, Curitiba, Brazil. SBC. 28, 122, 165

Josko e Ferreira (2016) João Marcelo Borovina Josko e João Eduardo Ferreira. Visualization properties for Data Quality Visual Assessment: An exploratory Case Study. Information Visualization. doi: 10.1177/1473871616629516. 28, 161, 166

Josko et al. (2016) João Marcelo Borovina Josko, Marcio Katsumi Oikawa e João Eduardo Ferreira. A Formal Taxonomy to Improve Data Defect Description. Em Hong Gao, Jinho Kim e Yasushi Sakurai, editors, Database Systems for Advanced Applications: DASFAA 2016 International Workshops: BDMS, BDQM, MoI, and SeCoP, Dallas, TX, USA, April 16-19, 2016, Proceedings, páginas 307-320, Cham. Springer International Publishing. ISBN 978-3-319-32055-7. doi: 10.1007/978-3-319-32055-7_25. URL http://dx.doi.org/10.1007/978-3-319-32055-7_25. xvi, xxi, 28, 108, 109, 122, 165 
Jun et al. (2011) Esther Jun, Steven Landry e Gavriel Salvendy. A visual information processing model to characterize interactive visualization environments. Intl. Journal of Human-Computer Interaction, 27(4):348-363. 27, 44, 63

Kachkaev e Wood (2012) Alexander Kachkaev e Jo Wood. Using visual analytics to detect problems in datasets collected from photo-sharing services. Em Visual Analytics Science and Technology (VAST), 2012 IEEE Conference on, páginas 231-232. IEEE. 71

Kandel et al. (2011) Sean Kandel, Jeffrey Heer, Catherine Plaisant, Jessie Kennedy, Frank van Ham, Nathalie Henry Riche, Chris Weaver, Bongshin Lee, Dominique Brodbeck e Paolo Buono. Research directions in data wrangling: visuatizations and transformations for usable and credible data. Information Visualization, 10(4):271-288. ISSN 1473-8716. doi: 10.1177/1473871611415994. 47

Kandel et al. (2012a) Sean Kandel, Andreas Paepcke, Joseph M Hellerstein e Jeffrey Heer. Enterprise data analysis and visualization: An interview study. Visualization and Computer Graphics, IEEE Transactions on, 18(12):2917-2926. 63, 123

Kandel et al. (2012b) Sean Kandel, Ravi Parikh, Andreas Paepcke, Joseph M. Hellerstein e Jeffrey Heer. Profiler: integrated statistical analysis and visualization for data quality assessment. Em Proceedings of the International Working Conference on Advanced Visual Interfaces, AVI '12, páginas 547-554, New York, NY, USA. ACM. ISBN 978-1-4503-1287-5. doi: 10.1145/2254556.2254659. URL http://doi.acm.org/10.1145/ 2254556.2254659. xv, xvi, xix, 35, 53, 86, 87, 100

Kandogan (2001) Eser Kandogan. Visualizing Multi-dimensional Clusters, Trends, and Outliers using Star Coordinates. KDD. 70

Kang et al. (2008) Hyunmo Kang, Lise Getoor, Ben Shneiderman, Mustafa Bilgic e Louis Licamele. Interactive Entity Resolution in Relational Data: A Visual Analytic Tool and Its Evaluation. IEEE Transactions on Visualization and Computer Graphics, 14(5):999-1014. ISSN 1077-2626. doi: 10.1109/TVCG.2008.55. xvi, 27, 80, 100, 160

Karr et al. (2006) Alan F. Karr, Ashish P. Sanil e David L. Banks. Data quality: A statistical perspective. Statistical Methodology, 3(2):137 - 173. ISSN 1572-3127. doi: 10.1016/j.stamet.2005.08.005. 104

Kehrer et al. (2013) Johannes Kehrer, Harald Piringer, Wolfgang Berger e M Eduard Groller. A model for structure-based comparison of many categories in small-multiple displays. Visualization and Computer Graphics, IEEE Transactions on, 19(12):22872296. 100,157

Keim e Kriegel (1996) D.A. Keim e H.-P. Kriegel. Visualization techniques for mining large databases: a comparison. Knowledge and Data Engineering, IEEE Transactions on, 8(6):923 -938. ISSN 1041-4347. doi: 10.1109/69.553159. 54, 55

Keim et al. (2010) Daniel Keim, Jörn Kohlhammer, Geoffrey Ellis e Florian Mansmann. Mastering the Information Age: Solving Problems with Visual Analytics. Eurographics Association - Germany. 24, 44, 72, 124 
Keim (2002) Daniel A. Keim. Information Visualization and Visual Data Mining. IEEE Transactions on Visualization and Computer Graphics, 8(1):1-8. ISSN 1077-2626. doi: 10.1109/2945.981847. URL http://dx.doi.org/10.1109/2945.981847. xix, 44, 45, 46, 53, $55,68,100$

Keim e Krigel (1994) Daniel A. Keim e Hans-Peter Krigel. VisDB: Database Exploration Using Multidimensional Visualization. IEEE Comput. Graph. Appl., 14(5):40-49. ISSN 0272-1716. doi: 10.1109/38.310723. xv, 52

Khosravani (2012) Hamid Reza Khosravani. Proposing an Improved Semantic and Syntactic Data Quality Mining Method using Clustering and Fuzzy Techniques. International Journal of Applied Information Systems, 3(3):8-12. Published by Foundation of Computer Science, New York, USA. 68

Kim et al. (2003) Won Kim, Byoung-Ju Choi, Eui-Kyeong Hong, Soo-Kyung Kim e Doheon Lee. A Taxonomy of Dirty Data. Data Min. Knowl. Discov., 7(1):81-99. ISSN 1384-5810. doi: 10.1023/A:1021564703268. 35, 98, 99, 100

Klein (2001) Barbara D Klein. Detecting errors in data: clarification of the impact of base rate expectations and incentives. Omega, 29(5):391-404. 35, 123

Klein et al. (1997) Barbara D Klein, Dale L Goodhue e Gordon B Davis. Can humans detect errors in data? Impact of base rates, incentives, and goals. Management Information Systems Quarterly, 21:169-194. 33, 34, 35, 123

Kosslyn (2006) Stephen M Kosslyn. Graph design for the eye and mind. Oxford University Press. 63, 74, 151

Lam et al. (2012) Heidi Lam, Enrico Bertini, Petra Isenberg, Catherine Plaisant e Sheelagh Carpendale. Empirical studies in information visualization: Seven scenarios. Visualization and Computer Graphics, IEEE Transactions on, 18(9):1520-1536. 72

Laranjeiro et al. (2015) Nuno Laranjeiro, Seyma Nur Soydemir e Jorge Bernardino. A Survey on Data Quality: Classifying Poor Data. Em Dependable Computing (PRDC), 2015 IEEE 21st Pacific Rim International Symposium on, páginas 179-188. IEEE. 99, 104

Lee (2003) Yang W. Lee. Crafting Rules: Context-Reflective Data Quality Problem Solving. Journal of Management Information Systems, 20(3):93-119. ISSN 0742-1222. $24,33,34$

Lee et al. (2007) Yang W Lee, Elizabeth Pierce, John Talburt, Richard Y Wang e Hongwei Zhu. A curriculum for a master of science in information quality. Journal of Information Systems Education, 18(2):233. 122

Lee et al. (2009) Yang W. Lee, Leo L. Pipino, James D. Funk e Richard Y. Wang. Journey to Data Quality. The MIT Press. ISBN 0262513358, 9780262513357. 24, 32, $33,34,35,102,122,123$

Li et al. (2011) Lin Li, Taoxin Peng e Jessie Kennedy. A rule based taxonomy of dirty data. GSTF International Journal on Computing, 1(2):140-148. 98, 99, 100 
Liiv (2010) Innar Liiv. Seriation and matrix reordering methods: An historical overview. Statistical Analysis and Data Mining, 3(2):70-91. ISSN 1932-1872. doi: 10.1002/sam. 10071. 50

Liu et al. (2013) Zhicheng Liu, Biye Jiang e Jeffrey Heer. immens: Real-time visual querying of big data. Em Eurographics Conference on Visualization, volume 32. 166

Loshin (2010) D. Loshin. The Practitioner's Guide to Data Quality Improvement. Morgan Kaufmann. xix, 24, 32, 33, 34, 35, 36, 63, 65, 66, 67, 102, 105

MacEachren et al. (2005) Alan M. MacEachren, Anthony Robinson, Susan Hopper, Steven Gardner, Robert Murray, Mark Gahegan e Elisabeth Hetzler. Visualizing Geospatial Information Uncertainty: What We Know and What We Need to Know. Cartography and Geographic Information Science, 32(3):139-160. doi: doi:10.1559/1523040054738936. 41

Maciel et al. (2008) M Maciel, Bianchi Serique Meiguins, R Loureno, A Meiguins e $\mathrm{P}$ Godinho. The Impact of Multiple Coordinated Views on the Visual Data Exploration and Analysis. Em Information Visualisation, 2008. IV'08. 12th International Conference, páginas 113-119. IEEE. 76

Mackinlay (1986) Jock Mackinlay. Automating the design of graphical presentations of relational information. ACM Transactions on Graphics (TOG), 5(2):110-141. 59, 101, $156,158,159$

Maier (1983) David Maier. The theory of relational databases, volume 11. Computer science press Rockville. 106, 108, 115

Malik e Unwin (2012) W.A. Malik e A. Unwin. Interactive Graphics for Analysing Quality of Survey Data. Journal of Data Science, 10(3):385-402. xvi, 40, 85

Malik et al. (2010) Waqas Ahmed Malik, Antony Unwin e Alexander Gribov. An Interactive Graphical System for Visualizing Data Quality-Tableplot Graphics. Em Classification as a Tool for Research, páginas 331-339. Springer. 24, 26, 58, 65, 82

Marghescu (2007) Dorina Marghescu. User evaluation of multidimensional data visualization techniques for financial benchmarking. Em Proceedings of the European Conference on Information Management and Evaluation, página 341. Academic Conferences Limited. 26, 27, 138

Marghescu (2008) Dorina Marghescu. Evaluating multidimensional visualization techniques in data mining tasks. Tese de Doutorado, Turku Centre Computer Science. 100, 129,158

Marr (1982) David Marr. Vision - A computational investigation into the human representation and processing. Freeman \& Co., San Francisco. xvi, 60, 61

Matlin (2009) Margaret W. Matlin. Cognition. John Wiley \& Sons, Inc. 40, 60, 61, 62, 77,152

Mayorga e Gleicher (2013) Adrian Mayorga e Michael Gleicher. Splatterplots: Overcoming Overdraw in Scatter Plots. Visualization and Computer Graphics, IEEE Transactions on, 19(9):1526-1538. ISSN 1077-2626. doi: 10.1109/TVCG.2013.65. 166 
Miles e Huberman (1994) Matthew B Miles e A Michael Huberman. Qualitative data analysis: An expanded sourcebook. Sage. 136

Mosley et al. (2010) Mark Mosley, Michael H Brackett, Susan Earley e Deborah Henderson. DAMA guide to the data management body of knowledge, chapter Data Quality Management, páginas 291 - 316. Technics Publications. 36, 37, 38, 39

Mueller e Coppoolse (2013) Roland M Mueller e Dalco Coppoolse. Using Incentive Systems to Increase Information Quality in Business Intelligence: A Quasi-Experiment in the Financial Services Industry. Em System Sciences (HICSS), 2013 46th Hawaii International Conference on, páginas 3827-3836. IEEE. 35

Müller e Freytag (2005) H. Müller e J.C. Freytag. Problems, methods, and challenges in comprehensive data cleansing. Relatório Técnico HUB-IB-164, Humboldt University Berlin. 98, 99

Naumann (2002) F. Naumann. Quality-Driven Query Answering for Integrated Information Systems, volume 2261. Springer. 24, 34, 36, 37, 38, 39, 63, 65, 102

Naumann (2014) Felix Naumann. Data profiling revisited. ACM SIGMOD Record, 42 (4):40-49. 24, 67, 97, 102, 105

Oliveira et al. (2005) P. Oliveira, F. Rodrigues e P. Henriques. A formal definition of data quality problems. Em International Conference on Information Quality. 98, 99

Olson (2003) Jack Olson. Data Quality: The Accuracy Dimension. Morgan Kaufmann Publishers Inc., San Francisco, CA, USA. ISBN 1558608915. 23, 32, 35, 66, 104

Palmer (1999) Stephen E Palmer. Vision science: Photons to phenomenology, volume 1. MIT press Cambridge, MA. xvi, 60, 61, 62

Patterson et al. (2014) Robert E Patterson, Leslie M Blaha, Georges G Grinstein, Kristen K Liggett, David E Kaveney, Kathleen C Sheldon, Paul R Havig e Jason A Moore. A human cognition framework for information visualization. Computers \& Graphics, 42:42-58. 40, 60, 62, 63, 101, 102, 159

Pirolli e Card (2005) Peter Pirolli e Stuart Card. The sensemaking process and leverage points for analyst technology as identified through cognitive task analysis. Em Proceedings of International Conference on Intelligence Analysis, volume 5, páginas 2-4. 124

Pirolli e Rao (1996) Peter Pirolli e Ramana Rao. Table lens as a tool for making sense of data. Em Proceedings of the workshop on Advanced visual interfaces, AVI '96, páginas 67-80, New York, NY, USA. ACM. ISBN 0-89791-834-7. doi: 10.1145/948449.948460. 83,158

Porter e Duff (1984) Thomas Porter e Tom Duff. Compositing digital images. Em ACM Siggraph Computer Graphics, volume 18, páginas 253-259. ACM. 49

Potter et al. (2012) Kristin Potter, Paul Rosen e ChrisR. Johnson. From Quantification to Visualization: A Taxonomy of Uncertainty Visualization Approaches. Em AndrewM. Dienstfrey e RonaldF. Boisvert, editors, Uncertainty Quantification in Scientific Computing, volume 377 of IFIP Advances in Information and Communication 
Technology, páginas 226-249. Springer Berlin Heidelberg. ISBN 978-3-642-32676-9. doi: 10.1007/978-3-642-32677-6_15. 27, 41, 71, 101

Rahm e Do (2000) E. Rahm e H.H. Do. Data Cleaning: Problems and Current Approaches. IEEE Bulletin of the Technical Committee on Data Engineering, 24:11. 65, 68, 98, 99, 102, 105, 159

Ramaswamy et al. (2000) Sridhar Ramaswamy, Rajeev Rastogi e Kyuseok Shim. Efficient algorithms for mining outliers from large data sets. Em ACM SIGMOD Record, volume 29, páginas 427-438. ACM. 108

Redman e Blanton (1997) T.C. Redman e A. Blanton. Data quality for the information age. Artech House, Inc. 32, 35, 36, 37, 38, 39, 122

Redman et al. (2011) T.C. Redman, C. Fox e A. Levitin. Understanding Information Retrieval Systems: Management, Types, and Standards, chapter Data and Data Quality, páginas 269-284. Auerbach Publications. 23, 24, 32, 33

Redman (1998) Thomas C Redman. The impact of poor data quality on the typical enterprise. Communications of the ACM, 41(2):79-82. 24

Research e of Australasia (2010) Computing Research e Education Association of Australasia. The ERA Conference Ranking Exercise, 2010. 69

Reuters (2011) Thomson Reuters. Journal Citation Reports. http://wokinfo.com, 2011. 69

Robertson et al. (2008) George Robertson, Roland Fernandez, Danyel Fisher, Bongshin Lee e John Stasko. Effectiveness of animation in trend visualization. Visualization and Computer Graphics, IEEE Transactions on, 14(6):1325-1332. 100, 145

Robertson et al. (2005) George G. Robertson, Mary P. Czerwinski e John E. Churchill. Visualization of mappings between schemas. Em Proceedings of the SIGCHI Conference on Human Factors in Computing Systems, CHI '05, páginas 431-439, New York, NY, USA. ACM. ISBN 1-58113-998-5. doi: 10.1145/1054972.1055032. URL http://doi.acm. org/10.1145/1054972.1055032. 71

Rodrigues et al. (2007) José Fernando Rodrigues, Agma JM Traina, Maria Cristina F de Oliveira e Caetano Traina. The Spatial-Perceptual Design Space: A New Comprehension for Data Visualization. Information Visualization, 6(4):261-279. 53

Rundensteiner et al. (2007) E.A. Rundensteiner, M.O. Ward, Z. Xie, Q. Cui, C.V. Wad, D. Yang e S. Huang. Xmdvtool Q: quality-aware interactive data exploration. Em Proceedings of the 2007 ACM SIGMOD international conference on Management of data, páginas 1109-1112. ACM. 77

Rusu et al. (2009) Adrian Rusu, Confesor Santiago, Andrew Crowell e Eric Thomas. Enhanced star glyphs for multiple-source data analysis. Em Information Visualisation, 2009 13th International Conference, páginas 183-190. IEEE. 157

Sadiq et al. (2011) Shazia Sadiq, Naiem Khodabandehloo Yeganeh e Marta Indulska. 20 years of data quality research: Themes, trends and synergies. Em The 22nd Australasian Database Conference., Sidney, Australia. 69 
Scannapieco e Catarci (2002) M. Scannapieco e T. Catarci. Data quality under a computer science perspective. Archivi \& Computer, 2:1-15. 35, 36, 38

Schmid (2005) Joachim Schmid. The main steps to data quality. Em Advances in Data Mining, páginas 69-77. Springer. 39, 97, 99

Schulmeyer e McManus (1999) G. Gordon Schulmeyer e James I. McManus. Handbook of software quality assurance, chapter Software Quality Assurance - Coming to Terms, páginas 1 - 25. Prentice-Hall PRT. 31, 32

Schulz et al. (2011) H Schulz, Steffen Hadlak e Heidrun Schumann. The design space of implicit hierarchy visualization: A survey. Visualization and Computer Graphics, IEEE Transactions on, 17(4):393-411. xix, 55, 151

Schulz et al. (2013) Hans-Jorg Schulz, Thomas Nocke, Magnus Heitzler e Heidrun Schumann. A design space of visualization tasks. Visualization and Computer Graphics, IEEE Transactions on, 19(12):2366-2375. 101, 126, 128

Sedig et al. (2014) Kamran Sedig, Paul Parsons, Mark Dittmer e Robert Haworth. Human-centered interactivity of visualization tools: Micro-and macro-level considerations. Em Handbook of Human Centric Visualization, páginas 717-743. Springer. 44, 126,158

Shneiderman (2008) Ben Shneiderman. Extreme visualization: squeezing a billion records into a million pixels. Em Proceedings of the 2008 ACM SIGMOD international conference on Management of data, páginas 3-12. ACM. 154

Shneiderman (1992) Ben Shneiderman. Tree visualization with tree-maps: 2-d spacefilling approach. ACM Transactions on graphics (TOG), 11(1):92-99. 59

Shneiderman (1996) Ben Shneiderman. The Eyes Have It: A Task by Data Type Taxonomy for Information Visualizations. Em Proceedings of the 1996 IEEE Symposium on Visual Languages, VL '96, páginas 336-, Washington, DC, USA. IEEE Computer Society. ISBN 0-8186-7508-X. URL http://dl.acm.org/citation.cfm?id=832277.834354. $45,48,53,54,100,124$

Shneiderman e Plaisant (2006) Ben Shneiderman e Catherine Plaisant. Strategies for evaluating information visualization tools: multi-dimensional in-depth long-term case studies. Em Proceedings of the 2006 AVI workshop on BEyond time and errors: novel evaluation methods for information visualization, BELIV '06, páginas 1-7, New York, NY, USA. ACM. ISBN 1-59593-562-2. doi: 10.1145/1168149.1168158. URL http://doi.acm.org/10.1145/1168149.1168158. 72, 168

Silva et al. (2007) Claudio T. Silva, Juliana Freire e Steven P. Callahan. Provenance for Visualizations: Reproducibility and Beyond. IEEE Computing in Science \& Engineering, 9(5):82-89. ISSN 1521-9615. doi: 10.1109/MCSE.2007.106. URL http://dx.doi.org/10.1109/MCSE.2007.106. 45, 46, 104

Silva et al. (2011) Samuel Silva, Beatriz Sousa Santos e Joaquim Madeira. Using color in visualization: A survey. Computers \& Graphics, 35(2):320-333. 130, 154, 157 
Singh e Singh (2010) Ranjit Singh e Kawaljeet Singh. A descriptive classification of causes of data quality problems in data warehousing. International Journal of Computer Science Issues, 7(3):41-50. 98

Skeels et al. (2010) Meredith Skeels, Bongshin Lee, Greg Smith e George Robertson. Revealing uncertainty for information visualization. Em Proceedings of the working conference on Advanced visual interfaces, AVI '08, páginas 376-379, New York, NY, USA. ACM. ISBN 978-1-60558-141-5. doi: 10.1145/1385569.1385637. URL http://doi. acm.org/10.1145/1385569.1385637. 41

Sluban et al. (2014) Borut Sluban, Dragan Gamberger e Nada Lavrač. Ensemble-based noise detection: noise ranking and visual performance evaluation. Data Mining and Knowledge Discovery, 28(2):265-303. 102

Smith (1998) Gerald F Smith. Quality problem solving, chapter Problem-Solving Fundamentals, páginas 14-44. American Society for Quality. 33, 35, 40, 62

Snodgrass (1999) Richard Thomas Snodgrass. Developing time-oriented database applications in $S Q L$, chapter Fundamental Concepts, páginas 1-24. Morgan Kaufmann Publishers Inc. 167

Stvilia et al. (2007) Besiki Stvilia, Les Gasser, Michael B. Twidale e Linda C. Smith. A framework for information quality assessment. Journal of the American Society for Information Science and Technology, 58(12):1720-1733. ISSN 1532-2882. doi: 10.1002/ asi.v58:12. 32

Sulo et al. (2005) Rajmonda Sulo, Stephen Eick e Robert Grossman. DaVis: a tool for visualizing data quality. Posters Compendium of InfoVis, 2005:45-46. xvi, 76, 77, 160

Swayne et al. (2003) Deborah F Swayne, Duncan Temple Lang, Andreas Buja e Dianne Cook. GGobi: evolving from XGobi into an extensible framework for interactive data visualization. Computational Statistics Eamp; Data Analysis, 43(4):423 - 444. ISSN 0167-9473. doi: 10.1016/S0167-9473(02)00286-4. 74

Swayne e Buja (1998) D.F. Swayne e A. Buja. Missing Data in Interactive HighDimensional Data Visualization. Computational statistics, 13:15-26. 74, 75

Swayne et al. (1998) D.F. Swayne, D. Cook e A. Buja. XGobi: Interactive Dynamic Data Visualization in the X Window System. Journal of Computational and Graphical Statistics, páginas 113-130. 74

Tan et al. (2006) Pang-Ning Tan, Michael Steinbach e Vipin Kumar. Introduction to Data Mining, chapter Anomaly Detection, páginas 651-684. Addison-Wesley Longman Publishing Co., Inc., Boston, MA, USA. ISBN 0321321367. 68

Tang et al. (2004) Diane Tang, Chris Stolte e Robert Bosch. Design choices when architecting visualizations. Information Visualization, 3(2):65-79. 100

Tavanti e Lind (2001) Monica Tavanti e Mats Lind. 2D vs 3D, implications on spatial memory. Em Information Visualization, 2001. INFOVIS 2001. IEEE Symposium on, páginas 139-145. IEEE. 88 
Telea (2008) A.C. Telea. Data visualization: principles and practice. AK Peters. xv, 42, $43,81,91$

Templ et al. (2012) Matthias Templ, Andreas Alfons e Peter Filzmoser. Exploring incomplete data using visualization techniques. Advances in Data Analysis and Classification, 6:29-47. ISSN 1862-5347. 10.1007/s11634-011-0102-y. xvi, 27, 84

Teng et al. (2012) Dongxing Teng, Haiyan Yang, Cuixia Ma e Hongan Wang. VDQAM: A toolkit for database quality evaluation based on visual morphology. Em IEEE Conference on Visual Analytics Science and Technology (VAST), páginas 245-246. IEEE. xvi, 88,89

Tennekes et al. (2011) M. Tennekes, E. de Jonge e PJH Daas. Visual profiling of large statistical datasets. Em European New Techniques and Technology for Statistics, Brussels, Belgium. xvi, 82, 83

Tennekes et al. (2013) Martijn Tennekes, Edwin de Jonge, Piet JH Daas e Statistics Netherlands. Visualizing and Inspecting Large Datasets with Tableplots. Journal of Data Science, 11:43-58. 26, 27, 82, 100

Theus et al. (1997) M. Theus, H. Hofmann, B. Siegl e A. Unwin. MANET: Extensions to Interactive Statistical Graphics for Missing Values. Em New Techniques and Technologies for Statistics II, páginas 247-259. IOS Press Amsterdam. xvi, 73, 74

Theus (2003) Martin Theus. Interactive data visualization using mondrian. Journal of Statistical Software, 7(11):1-9. 85, 86

Thomas e Cook (2005) James J Thomas e Kristin A Cook. Illuminating the path: The research and development agenda for visual analytics. IEEE Computer Society Press. $24,40,44,72,77,159$

Thompson (2012) Steven K. Thompson. Simple Random Sampling, páginas 9-37. John Wiley \& Sons, Inc. ISBN 9781118162934. doi: 10.1002/9781118162934.ch2. URL http://dx.doi.org/10.1002/9781118162934.ch2. 132

Thomson et al. (2005) J. Thomson, E. Hetzler, A. MacEachren, M. Gahegan e M. Pavel. A typology for visualizing uncertainty. Em Proc. SPIE, volume 5669, páginas 146-157. $27,42,101$

Tory (2014) Melanie Tory. User Studies in Visualization: A Reflection on Methods. Em Handbook of Human Centric Visualization, páginas 411-426. Springer. 124, 125

Tory e Moller (2004) Melanie Tory e Torsten Moller. Human factors in visualization research. Visualization and Computer Graphics, IEEE Transactions on, 10(1):72-84. 24, 63, 102, 123, 158, 159

Treisman (1985) Anne Treisman. Preattentive processing in vision. Computer vision, graphics, and image processing, 31(2):156-177. 61

Tufte e Graves-Morris (1983) Edward R Tufte e PR Graves-Morris. The visual display of quantitative information, volume 2. Graphics press Cheshire, CT. 57

Tukey (1977) John Wilder Tukey. Exploratory Data Analysis. Addison-Wesley. 84, 139 
Unwin et al. (1996) Antony Unwin, George Hawkins, Heike Hofmann e Bernd Siegl. Interactive graphics for data sets with missing valuesMANET. Journal of Computational and Graphical Statistics, 5(2):113-122. 73

Unwin et al. (2006) Antony Unwin, Martin Theus e Heike Hofmann. Graphics of large datasets: visualizing a million. Springer. 56, 57, 73, 74, 76, 81, 91, 156, 157, 166

Upson et al. (1989) Craig Upson, Thomas Faulhaber, Jr., David Kamins, David H. Laidlaw, David Schlegel, Jefrey Vroom, Robert Gurwitz e Andries van Dam. The Application Visualization System: A Computational Environment for Scientific Visualization. IEEE Comput. Graph. Appl., 9(4):30-42. ISSN 0272-1716. doi: 10.1109/38.31462. 42

Valiati et al. (2006) Eliane R. A. Valiati, Marcelo S. Pimenta e Carla M. D. S. Freitas. A taxonomy of tasks for guiding the evaluation of multidimensional visualizations. Em Proceedings of the 2006 AVI workshop on BEyond time and errors: novel evaluation methods for information visualization, BELIV '06, páginas 1-6, New York, NY, USA. ACM. ISBN 1-59593-562-2. doi: 10.1145/1168149.1168169. 100

Wand e Wang (1996) Yair Wand e Richard Y. Wang. Anchoring data quality dimensions in ontological foundations. Commun. ACM, 39(11):86-95. ISSN 0001-0782. doi: 10.1145/240455.240479. 36, 37, 38, 39

Wang et al. (2013) Kun Wang, Dongxing Teng Haiyan Yang Cuixia Ma e Hongan Wang. DQvis: A Toolkit for Visual Quality Analysis for Relational Database. Em 17th International Conference on Information Visualisation. xvi, 89, 90

Wang e Strong (1996) Richard Y. Wang e Diane M. Strong. Beyond accuracy: what data quality means to data consumers. J. Manage. Inf. Syst., 12(4):5-33. ISSN 07421222. URL http://dl.acm.org/citation.cfm?id=1189570.1189572. 36, 37, 38, 39

Ward e Theroux (1997) Matthew O Ward e Kevin J Theroux. Perceptual benchmarking for multivariate data visualization. Em Scientific Visualization Conference, 1997, páginas 314-321. IEEE. 26, 27, 70, 74, 100, 138, 141, 157, 158

Ware (2004) Colin Ware. Information Visualization: Perception for Design. Morgan Kaufmann Publishers Inc., San Francisco, CA, USA. ISBN 1558608192. xix, 24, 26, $27,40,44,45,48,59,61,62,63,100,102,123,125,145,151,158,159$

Ware (2010) Colin Ware. Visual thinking for design. Morgan Kaufmann. 41, 159

Wilkinson et al. (2006) Leland Wilkinson, D Wills, D Rope, A Norton e R Dubbs. The grammar of graphics. Springer. 101

Winkler (2004) William E Winkler. Methods for evaluating and creating data quality. Information Systems, 29(7):531-550. 97

Wong et al. (2012) Pak Chung Wong, Han-Wei Shen e Chaomei Chen. Top Ten Interaction Challenges in Extreme-Scale Visual Analytics. Em Expanding the Frontiers of Visual Analytics and Visualization, páginas 197-207. Springer. 167

Xie et al. (2006) Zaixian Xie, Shiping Huang, M.O. Ward e E.A. Rundensteiner. Exploratory Visualization of Multivariate Data with Variable Quality. Em Visual Analytics Science And Technology, 2006 IEEE Symposium On, páginas 183 -190. doi: 10.1109/VAST.2006.261424. xvi, 77, 78 
Yang et al. (2014) Huahai Yang, Yunyao Li e Michelle X Zhou. Understand users comprehension and preferences for composing information visualizations. ACM Transactions on Computer-Human Interaction (TOCHI), 21(1):6. 100, 151, 157

Yi et al. (2007) Ji Soo Yi, Youn ah Kang, John T Stasko e Julie A Jacko. Toward a deeper understanding of the role of interaction in information visualization. Visualization and Computer Graphics, IEEE Transactions on, 13(6):1224-1231. 44, 45

Yi et al. (2008) Ji Soo Yi, Youn-ah Kang, John T Stasko e Julie A Jacko. Understanding and characterizing insights: how do people gain insights using information visualization? Em Proceedings of the 2008 Workshop on BEyond time and errors: novel evaLuation methods for Information Visualization, página 4. ACM. 44, 126

Yin (2009) Robert K Yin. Case study research: Design and methods. Sage publications. 124,125

Zaixian et al. (2007) Xie Zaixian, Matthew O Ward, Elke A Rundensteiner e Huang Shiping. Integrating data and quality space interactions in exploratory visualizations. Em Coordinated and Multiple Views in Exploratory Visualization, 200\%. CMV'07. Fifth International Conference on, páginas 47-60. IEEE. 100

Zeng et al. (2012) Li Zeng, Ling Li, Lian Duan, Kevin Lu, Zhongzhi Shi, Maoguang Wang, Wenjuan Wu e Ping Luo. Distributed data mining: a survey. Information Technology and Management, 13(4):403-409. 69

Zhang et al. (1996) Tian Zhang, Raghu Ramakrishnan e Miron Livny. BIRCH: an efficient data clustering method for very large databases. Em ACM SIGMOD Record, volume 25, páginas 103-114. ACM. 80

Zhang e Wu (2010) Yan Zhang e Xindong Wu. Integrating induction and deduction for noisy data mining. Information Sciences, 180(14):2663-2673. 105

Zhou e Talburt (2012) Y Zhou e RJ Talburt. OYSTER: An Open Source Entity Resolution System Supporting Identity Information Management. Em ID360-The Global Forum on Identity, Austin. 90

Zhu et al. (2009) Ying Zhu, Xiaoyuan Suo e G Scott Owen. A Visual Data Exploration Framework for Complex Problem Solving Based on Extended Cognitive Fit Theory. Em Advances in Visual Computing, páginas 869-878. Springer. 101 


\section{Índice Remissivo}

Avaliação da Qualidade dos Dados

Abordagens de Avaliação

Data Profiling, 66

Mineração de Dados, 67

Visual e Visual Analítica, 69

Critérios de Qualidade, 35

Fatores de Influência, 33

Qualidade, 31

Qualidade de Dados e Informação, 32

Cognição Humana

Sistema Dual, 60

Interferência do Conhecimento, 62

Primitivas Visuais Otimizadas, 61

Defeitos nos Dados

Abordagens de Descrição, 97

Complementar, 97

Limpeza de Dados, 97

Taxonomias, 98

Propriedades, 39

Taxonomia Formal

Classificação por Granularidade, 107

Classificação por Natureza, 107

Linguagem de Formalização, 108

Revisão Teórica, 105

Estudo de Caso

Metodologia

Artefatos de Dados, 131

Atividades de Avaliação, 125

Critérios - Propriedades, 125

Etapas do Procedimento, 132

Proposições de Estudo, 124

Registro Interações, 169

Resumos Analíticos, 170

Vis4DD, 129

Relacionamento Propriedade-Defeito

Aplicação, 158

Delineamento, 155
Limites, 154

Visualização de Dados

Abordagens de Projeto, 100

Conceitos

Benefícios a cognição, 40

Ramificações, 41

Transformações nos Dados, 42

Qualidade de Dados

Avaliação Visual, 123

Incerteza e Qualidade de Dados, 41 